University of New Hampshire

University of New Hampshire Scholars' Repository

Doctoral Dissertations

Student Scholarship

Spring 2006

\title{
Red ink: Native Americans picking up the pen in the colonial period
}

Drew Lopenzina

University of New Hampshire, Durham

Follow this and additional works at: https://scholars.unh.edu/dissertation

\section{Recommended Citation}

Lopenzina, Drew, "Red ink: Native Americans picking up the pen in the colonial period" (2006). Doctoral Dissertations. 323.

https://scholars.unh.edu/dissertation/323

This Dissertation is brought to you for free and open access by the Student Scholarship at University of New Hampshire Scholars' Repository. It has been accepted for inclusion in Doctoral Dissertations by an authorized administrator of University of New Hampshire Scholars' Repository. For more information, please contact Scholarly.Communication@unh.edu. 
Red Ink: Native Americans Picking Up The Pen In The Colonial Period

BY

DREW LOPENZINA

Bachelor's Degree, University of Massachusetts, Amberst, 1999

Master's Degree, University of New Hampshire, Durham, 2001

DISSERTATION

Submitted to the University of New Hampshire

In Partial Fulfillment of

The Requirements for the Degree of

Doctor of Philosophy

In

English Literature

May, 2006 
UMI Number: 3217431

Copyright 2006 by

Lopenzina, Drew

All rights reserved.

\section{INFORMATION TO USERS}

The quality of this reproduction is dependent upon the quality of the copy submitted. Broken or indistinct print, colored or poor quality illustrations and photographs, print bleed-through, substandard margins, and improper alignment can adversely affect reproduction.

In the unlikely event that the author did not send a complete manuscript and there are missing pages, these will be noted. Also, if unauthorized copyright material had to be removed, a note will indicate the deletion.

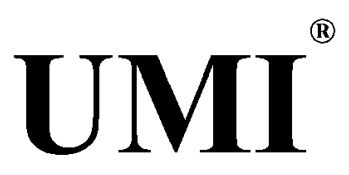

UMI Microform 3217431

Copyright 2006 by ProQuest Information and Learning Company.

All rights reserved. This microform edition is protected against unauthorized copying under Title 17, United States Code.

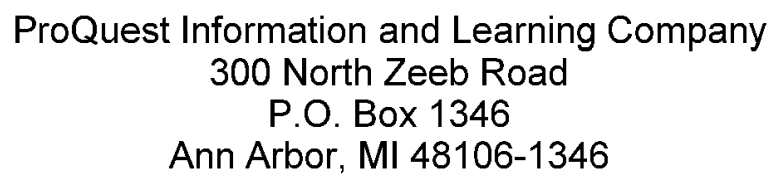




\section{ALL RIGHTS RESERVED}

c 2006

Drew Lopenzina 
This dissertation has been examined and approved.

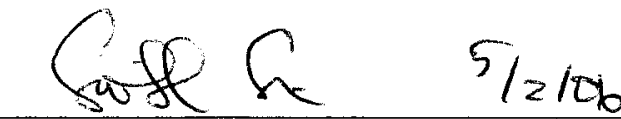

Dissertation Director, Siobhan Senier, Associate Professor of English

$$
\text { Brigetti Baifey 5-2-ib }
$$

Brigitte Bailey, Associate Professor of English

Dan wather

David Watters, Professor of English

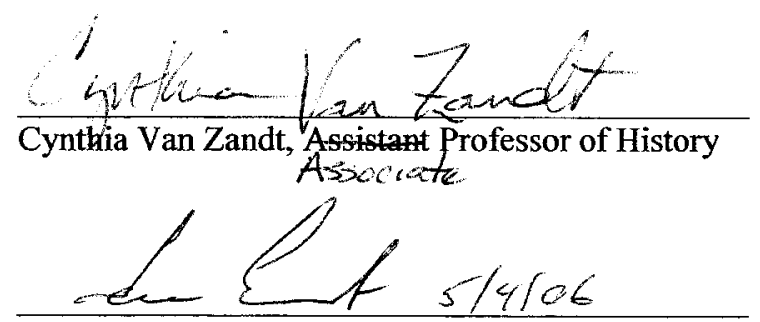

John Ernest, Eberly Family Distinguished Professor at West Virginia University, Morgantown, WV

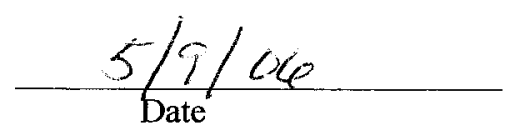




\section{ACKNOWLEDGEMENTS}

I would like to thank my family, friends and the members of my dissertation committee for their help, understanding, guidance and patience throughout this project. Special mention must go out to Barbara Morrison who has stood alongside through all the difficult hours, to Dylan and Amelia whose time with their father was forever compromised, though they never complained, to Siobhan Senier for her careful readings, insight and patient advice over occasional pints, to John Ernest for the long conversations, unusually wise counsel and the generous offering of his time over many years, to Keith Botelho who kept pace and drove me to reach the finish line in the spirit of friendship, to Greg Brennan who remained endlessly interested even when my own interest was failing, to Greg Guthrie for the last minute copy-editing and more, to my students who kept me grounded in the understanding of what this is all really about, and to Briggs Bailey for always having answers from the corner office. Special thanks also to my mother and father for all they do, to Pete for occasionally coming up to the Press Room even when time was short, to Jimmy for the canoe trips, Betty for the cookies, and my dog for giving me an excuse to leave the computer and get outside at three to four hour intervals each day. Much thanks also to David Watters, Cynthia Van Zandt, Monica Chiu, Sue Schibanoff and 999ers, and a tip of the hat to Emily Hinnov, Scott Rudd, Lisa Feldman, Kuhio Walters, David Edwards, Scott Massey and others who contributed to keeping me sane during an incredibly difficult process. May all favors be reciprocated some day in a like spirit of giving and support. 


\section{TABLE OF CONTENTS}

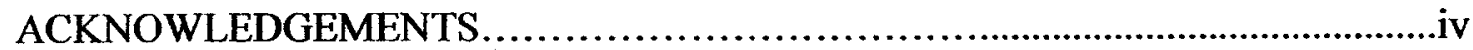

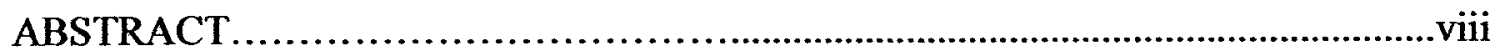

CHAPTER

PAGE

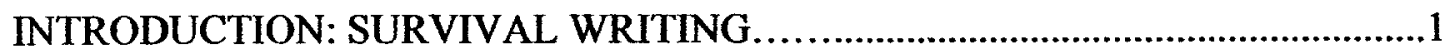

I. WUSSUCKWHEKE OR THE PAINTED LETTER: GLIMPSES OF NATIVE SIGNIFICATION ACKNOWLEDGED AND UNWITNESSED $\ldots \ldots \ldots \ldots \ldots \ldots \ldots \ldots . \ldots 4$

A. While You Were Sleeping: Colonialism's Unrecorded Dialogues..........45

B. Pharmakon or Key?: Opening up an Idea of Writing in Native Space

C. First Glimpses: Witnessing and Unwitnessing the Materials of Civilization in New Spain.

D. Black Robes and Birch Bark: Jesuits Encountering Native Writing in New France.

E. From Wussuckwhommin to Wussuckwheke: The Transformative Nature of Writing and the Word.

II. AMALECK (WRITTEN IN STONE): ELIDING INDIGENOUS PRESENCE THROUGH WRITING IN COLONIAL NEW ENGLAND.

A. Eden as Ground Zero: Locating Western Epistemologies of Containment...111

B. Moses in America: Lost Civilizations and the Intelligibility of Rock Carvings

C. Captive Audiences: New England's Early Native Students or "First Fruits."

D. Paradise Lost Again: Unwitnessing the Pequot Massacre in Puritan Accounts of the Pequot War. 
III. PRAYING INDIANS, PRINTING DEVILS: CENTERS OF INDEGENIETY WITHIN COLONIAL CONTAINMENTS

A. Setting up Shop: Harvard's Indian College and the Mission of John Eliot Amongst the Natives of New England.

B. A Town Called "Rejoycing": Establishing the Praying Town on Native Space.

C. Shadow Printer: The invisible Native hand on the Lever of the Press

D. Tears and Testimonies: "Tears of Repentance" and Eliot's Indian Dialogues

E. Thresholds of Change: Caleb Cheeshateaumauk's "Honoratissimi Benefactores".

IV. BENEATH THE WAVE: THE MAINTENANCE OF NATIVE TRADITION IN HIDDEN TRANSCRIPTS, 1700-1768.

A. Diving into the Wreck: Locating the Hidden Transcripts of Resistance in Native Writings of the Eighteenth Century.

B. "This Indian Land": Writings in the Massachusett Language and Sustaining Native Space.

C. Evangelism and Eye-strain: Samson Occom's Native-Centered Vision of Evangelism.

D. “An Undoubted Call”: A Native Agency for Occom's Tour of England......285

E. "The Doctor is Turn'd Heretical": The Declaration of Independence in Occom's "A Short Narrative of My Life".

V. 0' BROTHERTON WHERE ART THOU: COOPERSTOWN, BROTHERTON AND THE PERSISTENCE OF PLACE IN THE AMERICAN WILDERNESS

A. A Tale of Two Settlements: Forging "A Body Politick" in the American Wilderness.

B. Mount Vision: Selectively Surveying the Terrain in Cooper's The Pioneers

C. "Natural Rights": The Mohegan and the Mason Land Case. 330 
D. O Mohegan: Joseph Johnson and the Writing of Brotherton into Being......336

E. "The Best Land I Ever Did See": The Brotherton Exodus....................347

CONCLUSION: CONDOLING METAMORA.........................................363

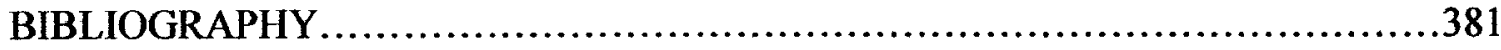




\title{
ABSTRACT \\ RED INK: NATIVE AMERICANS PICKING UP THE PEN IN THE COLONIAL PERIOD
}

By

\author{
Drew Lopenzina \\ University of New Hampshire, May, 2006 \\ Dissertation Director: Associate Professor Siobhan Senier
}

This dissertation looks at the ways that Native Americans appropriated alphabetic literacy for their own purposes in the colonial period. Studies of Native writing tend to begin with the Mohegan preacher Samson Occom whose A Sermon Preached by Samson Occom (1772) is the first known publication by a Native author on the North American continent. This work, however, locates Occom near the end of a series of earlier Native contacts with the written word, the fragments of which are scattered throughout the archive of the colonizer. While scholars have become largely familiarized with the representational modes in American literature that force the Native figure into patterns of either assimilation or extinction, I complicate this paradigm by exploring the interventions of seventeenth and eighteenth-century Natives whose writings reflect active attempts at community building within traditional Native frameworks. I argue that once Native writings are removed from their colonized contexts and recentered in Native space, we begin to see how such notes, letters, fragments, written testimonies, and eventually, publications were composed in the service of survivance and continuance rather than as capitulations to the dominant culture. Too often the Native acquisition of literacy has been equated with being fitting into a cultural straight-jacket, as though once the rhetorics of print discourse have been adopted, one can speak only through the colonizer's voice. Not until recently have some critics, 
particularly Native American scholars, come to question the interpretive utility of such convictions, and begun to think instead upon the contiguous line of Native tradition that runs from the era prior to colonization into the present day. I draw from the archival resources of both American and Native American Literature in an attempt to review the phenomena of colonization as a series of negotiations and survival strategies that can be more fully comprehended through a focused recognition of indigenous rhetorical and intellectual traditions. Rather than regarding the moment (or moments) of cultural contact as one in which European culture violently and tragically dismantles Native culture, I suggest how an understanding of this period must be complicated by a deeper recognition of the communitarian responses Native Americans were forging to European presence on indigenous soil. 


\section{INTRODUCTION}

\section{SURVIVAL WRITING}

The United States insulates itself within an amnesia that doesn 't acknowledge that kind of history. The victors (discoverers, settlers, real estate developers, government leaders, etc.) can afford that, it seems, as long as they maintain control and feel they don't have to face the truth. But Indians? What choice do we have?

Simon Ortiz

Thus it was that Hiowatha,

In his wisdom, taught the people

All the mysteries of painting,

All the art of Picture-Writing,

On the smooth bark of the birch-tree,

On the white skin of the reindeer,

On the graveposts of the village

Henry Wadsworth Longfellow

But spring is floating / to the canyon rim; / needles burst yellow /

And the stories have built a new house.

Wendy Rose

Amidst the many press releases and images documenting the devastating tsunami that swept over the islands and coastal regions of India, Africa and South Asia on 26 December 2004, one story in particular struck me as eerily anachronistic, like something pilfered from a trove of much earlier documents, belonging to a different era, a different people, an entirely separate textual encounter. The story from the Associated Press wire service told how "members of the ancient Jarawa tribe emerged from their forest habitat yesterday ... seven men-wearing underwear, amulets, and colored headbands with leaves, and carrying bows and arrows."1 These 
natives were met by two reporters, a photographer, and a group of relief workers who had come to check on the status of the Jarawa following the natural disaster, bringing food, water and other supplies. What struck me, however, was how the specifics of this modern day encounter with the ostensible other might not have been out of place in the journals of Columbus, the relations of the French Jesuits, or the personal accounts and historical narratives of the first settlers of New England ("come over and help us," the Puritans imagined the indigenous peoples of America calling out to them). ${ }^{2}$ In fact, what makes the account so utterly familiar and yet so strange is that, however out of place (or time) the encounter might appear, the text of the encounter is thoroughly informed by the previous writings of the aforementioned commentators. The circumstances are irrevocably locked within the steady gaze of the western reporters who, although barred from taking photographs ("we fall sick if we are photographed," one of the Jarawa is said to explain), still manage to shine a directed beam of light through the canopy of this jungle scene to imprint an image of two alien cultures, one presumably civilized and the other savage, coming face to face over a wide crevasse of technological and cognitive difference. $^{3}$

Contact. It is here we encounter one another, again perhaps, with uncertain footing on this contested, subjected plain-a meeting at once strange and all too familiar, new and ancient, textual and experiential, filled with expectations and anxieties, governed by signs of questionable interpretation, validity, and origin. If the hermeneutics of such an encounter are decidedly internalized for those of us dwelling on this western rim of the twenty-first century, yet there persists the lingering threat of an alternate reading, the remote possibility of displacement, and an awareness that any contact with an other has the dual capacity for challenging sacred notions while simultaneously hardening oneself into prior (or a priori) stances. The greatest threat inherent in contact is that for individuals as well as entire cultures it is as, or more, likely to prompt an attempted retreat into the safely established confines of an imagined, pristine, identity 
as to engender a shift in one's perception of world order. The result is never precisely a reified sameness, but rather an entry point into what Homi Bhabha has referred to as the cultural "interstices," or in-between spaces "that initiate new signs of identity, and innovative signs of collaboration, and contestation, in the act of defining the idea of society itself." of the encounter engender uncertainty, they can nevertheless be forced into the service of preexisting narrative tropes, cognitive patterns, "discourse," in an effort to retain a sense of narrative cohesion. As I will argue in this dissertation, that sense of cohesion, which is vital to a vibrant, self-assured cultural identity, is too often achieved through a monologic manipulation of events and memory that have the effect of taking us further away from an accurate engagement with ourselves and our pasts. Through what I refer to as the act of unwitnessing, cultures become like trauma patients who have "blocked out" certain memories of the past in order to cope in the present.

Unwitnessing is not simply the inability to see things that should be apparent to all. Nor is it the result, necessarily, of ignorance or an utter failure of imagination. Unwitnessing is the largely passive decision to maintain a particular narrative structure by keeping undesirable aspects of cultural memory repressed or inactive. For European explorers and settlers of the colonial period the undesirable aspects of memory consisted of repeated acts of denigration and violence toward Native peoples, which stood in sharp relief to the rhetoric of uplift driving so much of the colonial endeavor. The rift between rhetoric and deed was not simply an embarrassing contradiction. It was, in my estimation, a trauma operating on a cultural level, driving colonists to spontaneously distort and amend their collective memory. This distortion inevitably manifests itself in the archival representation of the acts in question, in which undesirable knowledge is at once noted and then immediately stricken out, or unwitnessed. As I will demonstrate, this process can be seen in effect almost every time a European observer commented upon Native culture. Colonial reporters would offer detailed observations about 
Native customs, traditions, and spiritual practices before concluding that these very same qualities were, in fact, nonexistent in indigenous life. In every case what was physically observed gave way to a more persuasive ideological noesis in which the colonists might see themselves as bringing Christian religion and civilization to a people who suffered for the want of these constructs. In other words, to maintain the ideological framework of the colonial endeavor the evidence of the senses had to be rhetorically undone. Once having denied the existence of Native culture it was a small step to deny or suppress the presence of the Indian himself, leading to the unwitnessing of entire Native communities referred to in modern parlance as the trope of the vanishing Indian.

When Greek/Cherokee novelist and essayist Thomas King writes "the truth about stories is that that's all we are," he is acknowledging the important, even indispensable, role narrative plays in the formation of cultural identity. ${ }^{5}$ If that narrative is disrupted by violent events or policies, the core of selfhood is disrupted as well. Psychologist and trauma scholar Judith Herman writes about the manner in which trauma, as clinically understood, is also in essence the disruption of narrative. She notes that traumatic memories "are not encoded like the ordinary memories of adults in a verbal, linear narrative that is assimilated into an ongoing life story," but rather it is as if "time stops at the moment of trauma." The person or group of people who suffer from this effect have lost the ability to enfold the moment of rupture at the heart of the trauma into a linear narrative structure. Their narrative becomes static. Therefore, according to Herman, in order to hold "traumatic reality in consciousness requires a social context that affirms and protects the victim and that joins the victim and witness in a common alliance. For the individual victim, this social context is created by relationships with friends, lovers, and family. For the larger society, the social context is created by political movements that give voice to the disempowered."?

In Native American studies the concept of "continuance" offers the rhetorical materials 
of healing. Continuance is the political and cultural consciousness that attempts to restore Native traditions and histories to a linear narrative structure after centuries of colonial disruption. Rather than regarding the moment of contact with Europeans as the locus of an irrevocable epistemological departure, Native scholars have tried in recent years to focus instead on the unbroken materials of culture and tradition that can be made a part of a continuing narrative of Native presence on the North American continent. As much as this is a process of cultural affirmation in the current moment, it is also necessarily an historical process and one that more often than not finds itself in contention with the institutional memory of the dominant culture. For instance, the United States habitually refuses to officially remember the particulars of treaties or to even recognize the existence of entire indigenous nations, despite the unambiguous manner in which these entities appear in archival sources. From the perspective of the dominant culture, a political consciousness receptive to the legitimacy of Native claims to sovereignty stands as an open threat to the narrative structure upon which the United States rests as a nation. The stories that both Native peoples and the settler culture tell themselves to bestow legitimacy upon their historical presence are, in effect, utterly incompatible with one another. For Native American communities, acts of witnessing are essential to the maintenance of a vital cultural narrative. The dominant culture, however, finds itself perpetually invested in acts of unwitnessing in order to perpetuate its own sense of historical integrity.

One might conclude that the process I describe here is an inevitable power dynamic, and that the victors of a particular encounter have always retained the privilege of writing and defining history. As I hope to demonstrate however, the process at work is more complicated than this. In fact, those who return to the written archives to construct historical narratives are often tarred with the dubious label of "revisionist" as though they are the ones in fact altering the historical record. This is a consequence of the manner in which the settler culture has so meticulously forgotten the materials uncovered. The inherent violence of unwitnessing 
destabilizes the historical process, legitimating violence and oppression by relying on ahistorical narrative frameworks. The maintenance of such frameworks is ultimately detrimental to the psychic and material life of a community, locking it into cycles of irreparable violence to itself and others. As Judith Herman makes clear, it takes more than the recovery of a particular historical narrative to heal this affliction. She observes that advances only occur when they are supported by political movements powerful enough to legitimate alliances between groups, and "to counteract the ordinary social processes of silencing and denial. In the absence of strong political movements for human rights, the active process of bearing witness inevitably gives way to the active process of forgetting. Repression, dissociation, and denial are phenomena of social as well as individual consciousness." ${ }^{\circ}$ Violent historical events, policies, and decisions may acquire an archival presence, but even when such occurrences are repeatedly addressed and articulated by those who feel afflicted by them, they have a tendency to recede back into the peripheries, unable to find a permanent home in the general consciousness. This speaks to the political resiliency of the narrative that has been used to paper over traumatic knowledge. Nevertheless, the traumatic knowledge does not go away. It surfaces and resurfaces throughout time, bleeding through the protective layers of coating like thick red ink.

To return to the example of the Jarawa for a moment, it seems likely that the basic narrative materials of the aforementioned encounter have already fixed themselves in the imagination without further help from any textual description: light and dark skins stumbling across one another in a wilderness, the fully clothed confronting the scantily clad, the gleaming accessories of twenty first century technology pitted against the organic weaponry of a remote and "ancient" people; all of this tightly stationed in a small, shadowed clearing closely penned by the broad-leafed understory of thick forest primeval. The scene is already impressed in our minds like a block print from some early American textbook, for we have encountered these "simulations" many times before, in both history and narrative. In the journals of Columbus we 
read, "many people came who were ... all naked and painted white, red, black and in many different ways. They carried spears and some of them brought balls of cotton to barter ... They still consider our coming a great marvel. I think they believe we have come from the sky."9 Alongside the startling revelation of sheer difference one senses the assumption of cultural advantage in the telling, one group descending from the sky (the reporters in our present day encounter arrive by helicopter, in fact, despite the unwelcoming warning arrows fired at earlier aircraft entering Jarawa space) whereas the naked tribesmen seem to sprout from the heart of the jungle itself. The article posits the Jarawa not as an organized social body belonging to structured communities with villages, towns, laws and rituals, but as creatures of the "forest habitat," almost as though they reside in the leafy canopy itself. While the reporters and relief workers have purposefully come for humanitarian reasons, the natives simply "emerge" from the woods, like a capricious, unexpected force or presence, disassociated from deliberate thought and action. Even scientific cause and effect breaks down in radical fashion, so that something as innocuous as the taking of a photograph provokes illness (do the Jarawa really maintain that photographs make them ill or have they simply learned to be protective of how they are represented by western media?).

As is typical in such accounts, the language is subconsciously geared toward strengthening perceptions of western normalcy by projecting strangeness upon its counterpart. The reporters and relief workers remain invisible because they are already inscribed as the standard by which difference is measured. As Edward Said asserts in his seminal work on the cultural representation of others, Orientalism, the West casts itself as "spectator, judge and jury, [over] every facet of Oriental behavior."10 There is no need for the West to describe itself, for it already regards itself as the accepted norm. But, in a sense, there is little need to describe the Jarawa either, unless it is to reaffirm what are also the accepted norms in encountering the other. The framework for the encounter is always fixed. What is difficult to perceive, however, is what 
has been blocked out, or unwitnessed, in order to create this scene. How does the framing of this encounter shield us from the history and complexity of Jarawa life, their previous encounters with Europeans that resulted in near devastation and the reasoned determination of the Jarawa to remain isolated? The AP article, rather than addressing such concerns, leaves us with stock images only of the wild savage who momentarily enters into the clearing so that the light of modern day civilization might briefly illuminate his presence and fix him in time.

The initial assumption of the relief workers was that the Jarawa, a tribe of about 1,000 people, had been entirely wiped out by the powerful tsunami. This assumption is cemented in the cold hard fact that some 150,000 human lives were lost in the more modernized (post-colonized) societies that lay in the path of the tidal wave, entire communities devastated and in need of international assistance. But the Jarawa, far from requiring aid from their more technologically advanced neighbors, amazingly claim not to have lost a single life in the catastrophe. It is this fact of their survival that codifies Jarawa difference. Had they been wiped out by the tsunami, as was first assumed, they would have finally been brought into the fold of the twenty first century; a people made containable by their disappearance, their tragic susceptibility to disaster. In the words of Jace Weaver, "extinction is a superior means of creating indigeneity."11 But their continued survival insures a certain alterity, testifies to a world, a ready supply, of natural indicators that signify differently for them than for western civilization. According to the newspaper article, the islanders surprisingly but politely refuse assistance, closing off the interview and consigning modern civilization to outer darkness by insisting, "my world is in the forest . . Y Your world is outside. We don't like people from outside." ${ }^{12}$ In all likelihood, the indigenous peoples who met Columbus some five hundred years earlier were not long in reaching a similar conclusion, despite their initial hospitality.

The truth of the matter is that the Jarawa vigorously maintain their isolation from the rest of the world, not out of some parochial primitive impulse, but as a result of hard won 
experience. The Andaman Islands have been in the path of European colonial ventures for the last four hundred or so years. Like Native populations elsewhere in the world, they were subject to enslavement and virulent diseases as a result of contacts. Further engagement with western adventurers led to epidemic alcoholism and a reliance on European trade goods that resulted in economic dependency and an erosion of traditional practices. The clear cutting of forests to build colonial settlements on the Andaman Islands left the Native inhabitants exposed to the violence of seasonal storms. The Jarawa were not in need of European intervention. They were, in fact, spared by their determined resistance to European interference. But the newspaper story is presented to us in a manner that omits such pertinent information. The violence of colonialism is either forgotten or ignored. By such means does the West continue to insist upon its superior civilization, its pure, altruistic intentions, and continue to apply pressure on the Jarawa to finally "enter into the twenty first century" as though somehow they weren't already there. ${ }^{13}$

I do not conclude from this that such isolation is good, noble, or even desirable. But the story of the Jararwa is, on some level, startling and a wake up call to those who are convinced of the superiority of Western technology. The recent leveling of the city of New Orleans by Hurricane Katrina's storm surge, a tragedy exacerbated by the drainage of silt from the Mississippi River Delta and the clear cutting of coastal forest and vegetation (both a result of under-regulated coastal development), is yet another wake up call. Modern civilization, as represented by the technologically centered epistemologies of the west, is in dire need of reestablishing a dialogue with the local environments it colonizes, as well as with the peoples who have traditionally populated these environments. The west treats the Earth much in the same way it has treated those cultures it has come into contact with and historically dominated-as though neither had anything much of relevance to say. This is not simply the result of a profound and destructive arrogance, although that is part of it. Anyone who thinks for any length upon these matters must at some point conclude that there is something we are not seeing. That, 
whatever its strengths, this entity we have been pleased to call western civilization is functionally blind to the ramifications of its actions on both an environmental and a human scale, and must place itself in the service of elaborate historical fantasies in order to maintain its forward momentum.

This work concerns itself with how the ruptured ligaments of discourse I describe, the processes of unwitnessing, are both maintained and contested within the periods of engagement we call "contact." I will largely focus on the ways in which the indigenous peoples of the American northeast labored to rhetorically assert their own discursive practices and concerns in the emerging narrative of a colonized America. The reasons for their doing so were complex and varied, but predominately centered around combating the effects of colonialism by improving negotiating positions in land transactions and treaties. My contention is that Natives were quick to intuit the utility of what I call "alphabetic writing," and rather than resisting its presence, actively sought it out, just as they sought out and incorporated a host of other European trade goods and practices into their traditional routines. Through an engagement with European literary practices, many Native communities, and particularly the Algonquian communities I focus on, were able to sustain a period of stability and keep alive traditional modes of existence that were otherwise threatened by the forced fragmentation and transformed physical reality of the colonized world. What begins as a series of pragmatic engagements to achieve quite local ends becomes an increasingly more innovative and energetic process by which embattled, decimated communities seize the opportunity to come together in a revitalized Native space. This process also becomes the means of challenging the dominant culture's ability to construct and control Native identity from both within and without the very site of power, the house of the archive, from which such a construction is generated. In effect, Native communities in the Northeast sought out and utilized alphabetic writing to preserve tradition and community in the colonial period. These efforts, alongside the colonial attempt to write over and rhetorically elide 
Native presence on the American continent, comprise the "red ink" of my title.

The ways that Natives engaged with Western literacy cannot, in the end, be read as an unqualified success story, nor is it my objective to make it one. The price Native communities have been forced to pay so that Europeans could transplant themselves on this soil is by every measure too high. By investigating the textual endeavors of Natives in this period, however, and the underlying motives for such endeavors, we might harvest the narrative materials that lead to a more cohesive understanding of both Native and colonial life in this period. As Native communities became increasingly more disenfranchised, marginalized, and therefore "invisible" in the seventeenth and eighteenth centuries, it became imperative to further engage with the dominant culture and insist upon a political presence within this nation's borders. On some occasions such an insistence was pursued through retaliation and open warfare. But a battle was also being waged on the textual front, an effort to either secure the rights of Native communities or to influence the overall conversation concerning indigenous rights and historical grievances. Whatever the effectiveness of such endeavors at the time, these writings retain a resonance that is still capable of speaking to us in the present and contributing to a narrative of Native resistance that stands in opposition to the discourse of the "vanished Indian" so vigorously pursued by the colonist. But a contextual shift is required to allow these texts, which are often sites of colonial containment themselves, to speak from a space of Native authority.

The first steps that Natives took toward reading and writing are often thought of as the first steps taken away from traditional Native culture and Native community. This probably has more to do with the discursive strategies of the dominant culture of the nineteenth and twentieth centuries than any fidelity to the lived experiences of Native communities. In well-meaning high school and college curricula it is taught that Native Americans first encountered the letter through nineteenth-century institutionalized boarding schools. Native children were brought far from their homes to reside in these schools and were forced to cut their hair, abandon their 
traditional dress and forbidden to speak their own languages. Carlisle School founder Richard Henry Pratt's often invoked dictum, "kill the Indian and save the man," offers a helpful summation of the cultural violence done by these institutions, whatever the intentions of some of the well-meaning people who signed onto this endeavor. Countless children died of disease in these germ factories. Many others came home and faced difficulties reintegrating themselves into their own families and communities after having been so forcefully purged of their cultural underpinnings. But these schools also became a launching pad for the careers of prominent nineteenth-century Indian intellectuals like Charles Eastman, Zitkala-Sa, Charles Montezuma and Luther Standing Bear, all of whom had ultimately conflicted feelings about these institutions and wrote eloquently about their experiences. ${ }^{14}$

These are all important remembrances, and they have been brought into our educational discourse, in part, to repair a historical trauma. But they also help to reinforce the impression that Native Americans were ultimately resistant to the technology of writing or that writing was a tool that did more harm than good for a people grounded in oral traditions. As Peter Nabokov notes in his investigation of oral noetics, $A$ Forest of Time, the "symbols of writing and the Book became such diagnostics for the invasive society, and of its ominous, depersonalized efficiency, as to insinuate themselves into their [indigenous peoples'] most ahistorical genres." ${ }^{\prime 5}$ Writing and the Book are repeatedly held up as the distinctive markers of the civilization being imposed by EuroAmericans and vehemently rejected by Natives. And, as Nabokov suggests, even attempts to recuperate "ahistorical," or oral, traditions are considered to be contaminated by their emergence into the realm of written records and accounts. In effect, once a discursive tradition is communicated in writing, it is thought to have entered into what French theorist Jacques Derrida refers to as the "archive," or "the residence of the superior magistrates, the archons, those who commanded."16 I will refer to this throughout as "the house of the archive," which is the house of hegemonic control and containment. Having entered into such a space, narrative then falls under 
the interpretive jurisdiction of those who control it. I remain somewhat skeptical of the totalizing nature of this paradigm, however, and tend to view this as yet one more gesture toward colonial appropriation. As I will elaborate more fully in chapter four, there remain bodies of thought and knowledge that, even as they interact with the archival house of power, draw their narrative cohesion from beyond its purview and are a part of what anthropologist James C. Scott refers to as the "hidden transcript," archons. Can there not stand alongside the house of the archive interpretive frameworks that do not fall under its domain? Perhaps a longhouse of the archive, with roots in Native epistemologies?

Even granting this, however, we must remain keenly aware of just how much historical interpretation is driven by European standards of perception and European agendas. Luther Standing Bear, who was among the first class of Native Americans to attend the Indian Boarding School at Carlisle, Pennsylvania in 1879 , wryly noted of the "white man,"

his law was a written law; his divine Decalogue reposed in a book. And what better proof that his advent into this country and his subsequent acts were the result of divine will! He brought the Word! There ensued a blind worship of written history, of books, of the written word, that has denuded the spoken word of its power and sacredness [my text reads "scaredness," but I trust that this, too, might be thought of as a culturally driven editorial slippage]. The written word became established as a criterion of the superior man a symbol of emotional fineness. The man who could write his name on a piece of paper, whether or not he possessed the spiritual fineness to honor those words in speech, was by some miraculous formula a more highly developed and sensitized person than the one who had never had a pen in hand, but whose spoken word was inviolable and whose sense of honor and truth was paramount. ${ }^{18}$

We should not regard it as ironic that Standing Bear himself was leveling this indictment in writing. He is not against writing as a technology. He is merely cognizant of the bogus hierarchy that has been established and maintained - the fact that "with false reasoning was the quality of human character measured by man's ability to make with an implement a mark upon paper."19

Part of my project then is to demonstrate the ways that Natives actively sought out the technology of alphabetic writing for their own purposes, within their own traditional framework 
of needs and responses. Helpful to my thinking through these issues has been Abenaki historian Lisa Brooks, who writes in her 2004 doctoral dissertation The Common Pot, that "the most common forms that Native writing took in the eighteenth and nineteenth centuries reflect ... earlier Native traditions." She refers here to awikhigans, or hieroglyphic symbols written on birch bark, and wampum, or small shells strung together in patterns, which according to Iroquois tradition bound "words to deeds." Brooks notes that "transformations occurred in Native writings when the European system of recording and sending words entered Native space. Birchbark messages became letters and petitions, wampum council records became treaties, journey pictographs became written communal narratives." Brooks maintains that the "texts that emerged from within the Native space of the northeast represent a uniquely indigenous literary tradition."20

I think this tradition needs to be comprehended more fully before one can enter into a useful discussion on how Natives appropriate the skills of alphabetic literacy, and in my first and second chapters I spend some time thinking about how Native writing operates within oral culture. I have seen belts of wampum, looked at Sioux Winter Counts, even walked through Petroglyph National Forest in Albuquerque, New Mexico, and yet it still came as news to me (and maybe I was behind the eight ball on this) that American Indians had their own systems of transmitting information independent of mnemonic devices prior to European colonization. Perhaps I had been told at some point that the Mayans had developed systems of writing, and kept libraries full of books, before Cortez appeared and tore it all to the ground. I had heard, vaguely, of the Quiche Mayan Popol-Vuh and the Walam Olum of the Lenape. But even this information somehow evaded my overall sense of Native civilization or remained stubbornly apart from a more persistent cultural narrative that I was familiar with inhabiting, in which Native culture was an oral culture and therefore didn't have, or even understand, the concept of writing. Useful for me, then, is not only the manner in which Brooks introduces a counter 
narrative about Native writing, but also how she sees this narrative originating from what she calls "Native space." Native space, as Brooks conceives it, is a site both conceptual and geographical. It consists of the cognitive space that arises from "a network of relations: the marriages and relationships that connected people and the places they inhabited," but it is also the physical space of villages and "waterways containing many different groups of people as well as animal, plant, and rock beings which was sustained through the constant transformative 'being' of its inhabitants." 21 Ultimately I feel it is a narrative space that exists within a chain of stories and traditions that are passed from generation to generation and remain deeply rooted to a relationship with a particular geographical environment.

When Europeans arrived on these shores, they too entered into this Native space, which Brooks metaphorically equates with "the Common Pot," where "shared space means shared consequences and shared pain" and where the actions of all its inhabitants "would affect the whole." ${ }^{.22}$ Part of the colonial project of acquisition and containment, however, was to transform Native space into colonial space, and this too occurs, in many ways, on a textual or conceptual plane. As Mary Louise Pratt points out in her influential treatise on colonial travel narratives, Imperial Eyes, from the very first moments of encounter the colonist regarded both land and inhabitants as resources, to be contained, collected, and sold on the open market. Much of how we understand these contacts is defined by the textual productions that flow from colonized space and the appropriations of the "seeing man," or "he whose imperial eyes passively look out and possess. ${ }^{.23}$ This space was in some cases regarded as an uncultivated paradise, a virgin land "longing to be sped" in the words of the English trader Thomas Morton ${ }^{24}$ In other instances it was the "howling wilderness" so often invoked by Puritan recorders who, as Sacvan Bercovitch has noted, were bent on inscribing their experience within a typological framework, equating their presence in North America with the exodus of the Jews through the deserts of Sinai and Palestine. ${ }^{25}$ In this account, it is the Puritans who "redeem" a barren and forsaken landscape and 
restore it to God's good grace by domesticating its wild inhabitants and "improving" the uncultivated land. In either case it is the colonists who are the actors, the redeemers and the definers of space. But we should labor to give equal credence to Brooks' interpretation, wherein it is the colonists entering upon Native space-not a desert wilderness, but a space of cooperation and interdependence, a sustaining space of villages and larger kinship networks that has become the most agriculturally productive in the history of the world. And it is a narrative space, too, whose stories can still be told and heard and enfolded into codes of conduct and belief.

Native scholars Vine Deloria, Jr., and Daniel R. Wildcat, articulating a system of indigenous metaphysics in their collaborative Power and Place, define the category of being "indigenous" as nothing more than "to be of a place" and to have one's culture grounded in the experiential relationship that develops from the encounter with that place over a period of centuries, or perhaps even millennia. ${ }^{26}$ Deloria and Wildcat maintain that,

when we hear the elders tell about things we must remember that they are basically reporting on their experiences or the experiences of their elders. Indians as a rule do not try to bring existing bits of knowledge into categories and rubrics that can be used to do further investigation and experimentation with nature. The Indian system requires a prodigious memory and a willingness to remain humble in spite of one's great knowledge. $^{27}$

The authors describe an epistemological tradition that is rooted in experience and observation of relationships and interactions in a particular geographic location, and they compare this with what they consider to be the more intrusive epistemologies of "the Western scientific method of investigation," which is "controlled by doctrine [and] often denies experiences that could provide important data for consideration." 28 Wildcat and Deloria describe what I think of as a Native philosophy of engagement. One must enter into a relationship with the world as one finds it and endeavor to comprehend how such relationships operate and maintain balance within a particular environment. This should not be understood as an essential trait, a type of alterity, or something 
we might think of as genetically transmitted, carried in the blood. There is no reason to assume that all indigenous people adhere to such beliefs or maintain some sort of ethnic connection to them. But it is what Osage scholar Robert Warrior refers to as a "Native intellectual tradition" that has arisen from a long period of intimacy with particular locales of Native space and stands in sharp contrast to Pratt's observation of the classificatory systems of European explorers for whom the natural world, as encountered, was a site of utter disorder and chaos in need of containment. ${ }^{29}$ According to Pratt, European adventurers, following the example of the biblical Adam, took on the task of "locating every species on the planet, extracting it from its particular, arbitrary surroundings (the chaos), and placing it in its appropriate spot in the system (the order-book, collection, or garden) with its new written, secular European name. ${ }^{.30}$ Whereas Native culture had embraced an overall philosophy of engagement, the European encounter with the world was driven by acts of containment. I do not intend these to be coinages of any sort, but rather ready and useful terms for interpreting the responses of these separate cultures in moments of contact. If the traditional cultures and practices of Native America have historically been viewed by westerners as either primitive or lacking a sound scientific foundation, this perhaps has more to do with the constrictions of being perceived through a narrative framework of containment or a different experiential series of historical encounters, than with any universal parameter by which we might measure such concepts as "modern," "technologically advanced," or "civilized."

Europeans classified the indigenous people of this continent as savages. This classification had more to do with doctrine than direct observation. Only on rare occasions might an observer emerge from this fog of doctrine to note the bonds of community, art, culture, and spirituality that were as central to the lives of Natives as they were to Europeans. The sixteenthcentury Spanish monk Bartolome de Las Casas, who was a firsthand witness to the wholesale slaughter of Mayan and Aztecan culture, observed that "they are so skilled in every mechanical 
art that with every right they should be set ahead of all the nations of the known world on this score, so very beautiful in their skill and artistry are the things this people produces in the grace of its architecture, its painting, and its needlework."31 Fray Bernadino de Sahagun, the sixteenthcentury Spanish friar who compiled the materials of the Florentine Codex, a book of Nahautl history and folklore, wrote of the indigenous people of New Spain,

they communicated with one another by means of representation and paintings. And all the ancient customs and books they had about them were painted with figures and representations in such a way that they knew and had records of the things their ancestors had done and had left in their annals more than a thousand years ago, before the Spaniards had come to this land. Most of these books and writings were burned when the other idolatrous things were destroyed. But many remained hidden, for we have seen them. And even now they are kept. ${ }^{32}$

In spite of such rare postings, however, a much larger body of literature surrounding the coming together of western and Native cultures remains wrapped up in the negative terms and epistemological perceptions that European explorers used to describe and contain the colonial encounter. It served the military and economic objectives of these adventurers to categorize the peoples of the western hemisphere as "other," as less than human, as "barbarian." And these perceptions became encoded in countless tracts and publications over a period of centuries, until even today, a large segment of the American public remains convinced of the absolute veracity of these representations. It is hardly recognized that Native communities were also inscribing these encounters in their cultural memories and placing them within traditional frameworks consistent with their own views of the world. Natives are not supposed to have recorded these events because they lacked art, culture, and history. They were presumably unable to write, and therefore their ability to retain centuries-old news was prone to fallacy and corruption. And, in any event, who was left to tell the tale? The colonizer has historically assumed the role of remembering this event for all parties concerned.

Columbus, upon reaching the West Indies in his first voyage, persistently remarked how the islanders he met "would easily be made Christians, for they appeared to me to have no 
religion." ${ }^{33}$ Amerigo Vespucci wrote back from his travels in 1498 that "amongst those people we did not learn that they had any law, nor can they be called Moors nor Jews, and they are worse than pagans, because we never saw them offer any sacrifice. ${ }^{.34}$ In the earliest document brought back from New England's first settlement in Plymouth, Massachussets, one commentator (probably Edward Winslow) notes how the Natives are "few and doe but run over the grasse, as doe also the Foxes and wildebeests: they are not industrious, neither have art, science, skill or faculties to use either the land or the commodities of it." ${ }^{35}$ From the very first recorded meetings, therefore, Europeans saw Native culture as a blank slate upon which they could (and must) superimpose their own belief systems. As Roy Harvey Pearce observed as early as 1953 (we are still, culturally, in the process of trying to absorb this information), colonists came to define civilization itself as the counterpart to savagism, which was the term most often used to evoke (or revoke) Native civilization. In other words, as European culture violently planted itself on American shores, it suffered an anxiety of identity that could only fully define itself in contrast to what it supposed it was not. The way to maintain such a dichotomy was by categorically refusing to acknowledge the cultural validity, even the essential humanity, of that which was being transplanted. For, if indigenous culture proved all too human, the violence of removing it from view would provoke an axial shift, all at once illegitimating European culture. ${ }^{36}$

Native American criticism has most recently labored to reverse the lens through which we view the production of literature and culture, locating strands of continuity that stretch beyond the encoded parameters of contact with Europeans and emphasizing the vitality and validity of indigenous world views instead. Craig Womack's articulation of this idea in his groundbreaking book Red on Red is worth quoting at length. He writes,

I am more interested in what can be innovated and initiated by Native people in analyzing their own cultures rather than deconstructing Native viewpoints and arguing for their European underpinnings or even concentrating on white atrocities and Indian victims. When cultural contact between Native Americans and Europeans has occurred throughout history, I am assuming that it is just as likely that things European are Indianized rather than the anthropological assumption that things Indian are 
always swallowed up by European culture. I reject, in other words, the supremacist notion that assimilation can only go in one direction, that white culture always overpowers Indian culture, that white is inherently more powerful than red, that Indian resistance has never occurred in such a fashion that things European have been radically subverted by Indians. ${ }^{37}$

The project of the last decade or so on Native American issues, then, has been to shift the focus of the gaze, or as Pratt suggests, to "decolonize knowledge," not only so that white-European culture might begin to acknowledge its complicity in establishing a destructive, contradictory, and self-serving imperialist legacy, but to discover how Native Americans might view their own largely ignored historical contributions and literary productions as part of a continuous legacy rather than a divided and fragmented one. ${ }^{38}$ By shifting the dynamics of contact and uncovering a vital middle ground wherein Native traditions, influences, and political legacies are allowed to assert themselves, we bring into relief a more complex and comprehensive network of relationships, legalities, and possibilities. White hegemony no longer shines with the armor of inevitability. The advancing frontier of Euro-American containment becomes dissipated and problematized within the more culturally porous, deconcretized space of the "contact zone."

As early American literary criticism seeks to grapple with these issues, however, the tendency has been to not engage directly with any body of Native American work, but to tread along more familiar cultural pathways. Certainly a large body of work has been critical of the violence of colonialism in perceptive and inventive ways, but in important works by Pearce, Richard Slotkin, Leslie Fiedler, Michelle Burnham, Lucy Maddox, and even Pratt (my focus here resting on works that concern themselves with literary productions, as opposed to historical criticism), the critical gaze remained largely fixed on the European account of colonization and the discursive strategies of the fledgling Union, as though American Indians posted no observations of their own in all this flurry of contact. Often, when white critics do cross over into the interpretive contact zones, drawing on Native source materials as their subject (as Arnold Krupat and David Brumble have done, to name only two), the reception amongst Native critics 
has been lukewarm. Cherokee literary critic Jace Weaver writes that "for too many non-Native scholars like Arnold Krupat and John Bierhorst, the only 'genuine' Indian literature consists of oral myths. It ceases to be Indian when it employs Western forms such as the short story or the novel." ${ }^{39}$ I agree with Weaver's impulse to "define literature broadly as the total written output of a people" (to which I would probably include the oral output as well), without being too concerned about how medium and genre subsume cultural agency. But I am not certain that there are any grounds to dispute Krupat on this matter, as his work The Voice in the Margin contemplates both oral (as told to) and written Native productions, as well as the interesting areas of merger. Yes, both Krupat and Brumble seek to identify certain narrative traditions that might be considered more or less "indigenous," but rather than maintain that Native writers abandon this tradition when they employ European narrative forms, Krupat underscores the heterodoxical nature of narrative itself. His notion of "cosmopolitanism" is an embracing of the dialogic, an acceptance of many voices and cultural concerns without reifying parochialism or calling out for a universal voice. ${ }^{40}$

Krupat ultimately thinks in terms of an "Indigenous Literature" that effectively merges the values and forms of traditional culture with those of the hegemonic culture, forming what he refers to as an "international canon." And it is here, I think, that Krupat's vision rests uncomfortably with a number of contemporary Native critics, as it disallows the political importance of maintaining discrete literary traditions. The gesture strikes one as too universal or as yet another inevitable form of appropriation into western normative values, however wellintentioned or cosmopolitan in its objectives (aren't colonial objectives always dressed up as well-intentioned and cosmopolitan?). The point must not be in learning how to distinguish between traditional and western modes or in considering how to merge them together, but in recognizing two separate political entities. There is always a danger that the idea of a Native literature becomes as quickly subsumed by American literature as Native presence is subsumed 
and problematized by colonial presence. The canon itself, naturally, is a site of containment. Out of this problematic, generated at least in part by Krupat's cosmopolitan ethos, emerges the discourse of "intellectual sovereignty." Weaver notes of Native literature and Native criticism, "we must drink from our own wells and, in the case of religious studies and literary criticism, indeed, first sink wells from which to drink. ${ }^{942}$ These watering holes have been staked off most recently by terms like Craig Womack's "literary separatism," Scott Lyons' "rhetorical sovereignty," Robert Warrior's “tribal secrets," and Elizabeth Cooke-Lynn's critique of cosmopolitanism, with Native authors and critics understandably invested in securing control of their own discursive practices and intellectual traditions after centuries of being defined and categorized by outsiders. Nevertheless the result on either end can appear as a series of endlessly one-sided accounts in which two peoples in historical and geographical proximity to one another must continue to assert that they cannot see or comment upon the other. ${ }^{43}$ This might be appropriate, if not for the fact that a great portion of Native literature, both written and oral, has been produced in direct conversation with American literature, and a great portion of American literature (while needing to be in greater dialogue with Native literature) imagines itself to be in conversation with an indigenous presence or specter that has become a quintessential feature of its cultural output. It may be necessary to maintain these literatures as wholly discrete entities, but we are in need of a paradigm by which they might nonetheless remain in conversation with one another.

For those who would like to engage in a discourse that takes into account Native American viewpoints, the project becomes one of locating Native texts and traditions and placing them within a context that is neither entirely separate from, nor beholden to, western literary traditions. Native American literacy has a life and mind all its own and its roots sink deeper than even our latest forays into gaze-shifting, or a more inclusive canonical framework, might suggest. As Womack has asserted, a Native American literary criticism should "emphasize unique Native 
worldviews and political realities, search for differences as often as similarities, and attempt to find Native literature's place in Indian country, rather than Native literature's place in the canon. ${ }^{, 44}$ Tapping into these worldviews, however, requires that one remain open to interpretive frameworks that often stray from, or run counter to, some of the more well-trod paths of EuroAmerican literary and critical traditions. Robert Warrior refers to such interpretive frameworks as a Native American "intellectual sovereignty" or the advancement of critical processes that privilege Native worldviews and political exigencies. Contrary to a recent survey of critical approaches to Native literature advanced by Elvira Pulitano, Warrior does not deny or contest that American Indian literatures can be influenced by white European culture. Nor does he seek an all-encompassing paradigm for what a Native American worldview might be. ${ }^{45}$ Nevertheless he suggests that the study and cultivation of Native critical traditions become "a way of life." Like Deloria and Wildcat, he makes an interesting case for a certain localized land aesthetic in which "children and adults learned how to behave through the example of those who had piled up enough life experience to know something about how to relate to the world. ${ }^{, 47} \mathrm{He}$ goes on to state that "western Christian culture and society is built upon the delusion that human beings as individuals and in social groupings can somehow overcome the influence of the non-human world. ${ }^{\circledR 48}$ Warrior feels that an earth-centered aesthetic arises from long proximity with a geographical location, so that one's culture, one's literature, one's very means of survival is inseparable from the environment from which it is sprung. This is what makes a particular literary tradition "indigenous." One reconnects with this way of life through the selfdetermination to build communities, through political organization, and by reasserting proprietorship over land and one's own cultural narratives, thus forging a body of critical indigenous responses to those narratives. According to Warrior, a sovereign identity need not be legally recognized to imagine itself a cohesive community. It is equally important for Native groups to recognize themselves and negotiate their own values, finding validation through self- 
expression and self-recognition as a cultural entity.

Following up on this notion, Weaver writes that "language and narrative have tremendous power to create community. Indeed, it may be that the People cannot have life outside of stories, their existence contingent upon the telling and hearing of communal stories." 49 Expressing this concept as "communitism," Weaver traces Native intellectual sovereignty to the maintenance of a communal identity, transferred through the incorporation of traditional narratives and the creation of new narratives. He suggests that, for communities that have "too often been fractured and rendered dysfunctional by the effects of more than 500 years of colonization," it becomes imperative to promote communitist values as a "means to participate in the healing of the grief and sense of exile." ${ }^{50} \mathrm{He}$ asserts it is writing that "prepares the ground for recovery, and even re-creation, of Indian identity and culture." ${ }^{\text {51 }}$ For Weaver there are no stories carried in the blood. To be Indian is to identify oneself as Indian through lineage and culture. "Communitism" is the combination of a sense of community with deliberate activism to maintain and perpetuate identity. While much of contemporary criticism has been premised upon notions of problematizing identity and representation, Native American criticism seems to be seeking a vital reaffirmation of identity through its literary productions.

Representation does not have the power to create for us a material reality. Our impressions of the past must remain impressions only, just as our impressions of the present must negotiate the presumably endless channel locks between perception, reality, and representation. But the material world beats daily at the door of our perception all the same, and our worlds are formed, however imprecisely, by how we collectively answer the call, drawing from the materials at hand. The Iroquois have a ritual called the condolence ceremony, which was traditionally put into motion whenever the various nations, whether "white" or "red," came together in council or mourning. The ceremony codified the assumption that two parties would 
have contesting versions of reality, differing accounts of significant events, and personal grievances that might bar the way to reconciliation or constructive deliberation. As Lisa Brooks states, "they knew that before peacemaking could begin, nations had to acknowledge and clear each other's grief." 52 The condolence ritual (reductively referred to in white parlance as "passing around the peace-pipe") failed to signify for European adventurers who recognized the gravity of the event but merely went through the motions it demanded of them in order to humor their "red brethren." The ceremony asked that when two parties come together they engage in a mutual process of wiping the smoke from the eyes, the sand from the ears and the obstructions from the throat. These rituals, if followed precisely, would lead to a requickening, or revitalization. Drawn from the foundational Deganawidah myth, the process was central to the success of Hiawatha in bringing peace to the warring clans and establishing the Long House of the five nations of the Iroquois in the time before Europeans arrived on the continent.

The condolence ritual marks a deliberate and psychologically complex attempt to distill order from the chaos of war and to alleviate the endless cycles of violence and grief by establishing Gaiwiio, or the "Good Mind." ${ }^{53}$ Anthony Wallace, in his classic examination of Iroquois revitalization, The Death and Rebirth of the Seneca, describes Gaiwiio as a kind of gospel "transmitted by word of mouth from preacher to preacher" so that it might be chanted in the Longhouse ceremonies at midwinter and again at the green corn ceremony in fall. ${ }^{54}$ This ritual, historically, was also the source of wampum exchange, which started not as a bartering system or currency as Europeans interpreted it, but as a symbolic representation that gave force and presence to the spoken words of the ceremony. Hiawatha created the wampum, stringing shells onto braided lengths of lake rushes and repeating the words, "this I would do if I found anyone burdened with grief even as I am. I would take these shell strings in my hand and console them. The strings would become words and lift away the darkness with which they are covered. Holding these in my hand, my words would be true." 55 The exchange of wampum was then used 
in the ceremony by which the warring tribes of the Northeast became reconciled, creating a ritualized space for aggrieved parties to tell their tales. In a sense, wampum, which has taken on a very different meaning in the cultural relationship European adventurers have had with it, was the original trauma literature of the Haudenosaunee, or Longhouse People. A literature meant to both express and displace grief. The condolence ceremony, acknowledging that "all around you are hostile agencies which are each thinking, 'I will frustrate their purpose," was an attempt at healing cultural discord, lifting the veil of traumatic grief that cultures experience, particularly in time of war, establishing consensual agreements, and restoring the "good mind."

Contemporary theorists seem enamored with the metaphysics of trauma because of the implied fragmentation of memory and presence that is sometimes associated with it, and which plays well in the deconstructionist's paradigm of differance. These critics have tended to focus on the phenomena of psychogenic amnesia, the unknowability of the traumatic moment, and experience itself, which bears an intriguing relationship with Heidegger's notions of being and Derrida's nostalgia for origins. According to Cathy Caruth, the "accident . . . does not simply represent the violence of a collision but also conveys the impact of its very incomprehensibility. $" 57$ Trauma, engendered and sustained by cognitive dislocation, is a complex relation between knowing and not knowing, built around a rupture that can only be apprehended through a priori repetitions-involuntary reconstructions of an event that one failed to comprehend or adequately process when it occurred. For some theorists the very condition of existence is trauma, and literature is its repetition. ${ }^{58}$

For Jonathan Shay, however, whose work with traumatized war veterans has led to his book Achilles in Vietnam, the important considerations when dealing with trauma are social and political. He asks how we might attempt to heal trauma by restoring the integrity of cultural narratives. For even though an instance of unanticipated violence may disrupt an illusion of narrative continuity for one (a disruption that leads to feelings of rage, helplessness, severe 
depression, and at times amnesia), that illusion is more often than not still studiously maintained by the larger culture. When the trauma sufferer attempts to make his or her own story known, it is roundly dismissed by those who apprehend the maintenance of themis (a Homeric term that, roughly translated by Shay, means "what's right") to be threatened by that particular narrative. In other words, it is the trauma narrative that threatens the sense of "what's right" for the rest of society, as it intimates what is, in fact, so terribly wrong. The effects of all this have psychohistoric ramifications that Shay senses in operation in Homeric times, manifested most explicitly in the rage of Achilles in The Iliad, and that can certainly be applied to the situation of colonial representations of Native identity. The master narrative of the colonizers is one that strategically represses the awful outrages (cultural slippages perhaps) that were committed against the indigenous peoples of this country. In a sense, culture itself is a construction that attempts to contain traumatic knowledge through coercive, hegemonic power, or what anthropologist James C. Scott refers to as "the public transcript." If, as Shay asserts, the trauma narrative "is a challenge to the rightness of the social order, to the trustworthiness of themis," then the ideal response (in the perfect world that Shay is positing) would be that we all "strive to be a trustworthy audience for victims of abuse of power." To do this, Shay says, "we must overcome all the good reasons why normal adults do not want to hear trauma narratives. If forced to hear them, normal people deny their truth. If forced to accept them as true, they often forget them. ${ }^{60}$ The true restoration of themis must involve an accommodation of the trauma sufferer's narrative. As long as such narratives are tamped down, the symptomatic social ills of rage, denial, depression, etc., will continue on both ends.

Abenaki ethnographer Fred Wiseman notes that "condolence is based on the theory that the emotions must be addressed before politics. ${ }^{.61}$ To create a community of listeners is the goal of the condolence ceremony-to restore a new sense of what's right, or Gaiwiio, through the ritualized clearing of grief and the airing out of grievances. When Hiawatha displaces his grief 
onto the wampum, the wampum "become words" that lift away the cover of darkness. In a sense he is performing the literary repetition that at once reenacts the rupture and yet creates a space for it to heal itself through narrative. In my mind, this is something that all responsible literature and all responsible criticism might reasonably aspire toward-to create a space where grief may be cleared and competing narratives lifted up from the fog of discursive containments. Continuance is the act of restoring cultural integrity by filling in the narrative gaps and asking others, inviting others, to acknowledge the emergent historical offering.

My own concern here, then, is not with victimization, so much as with how cultures experience a psychogenic amnesia of their own in their attempts to block out the disturbing, threatening, and undesirable narratives of others. I call this effect "cultural amnesia" and the act of addressing it, healing its ruptures, is always a sociopolitical as well as historical/literary one. Psychologist Judith Herman maintains that

denial, repression, and dissociation operate on a social as well as an individual level ... like traumatized people, we have been cut off from the knowledge of our past.

Like traumatized people, we need to understand the past in order to reclaim the present and the future. Therefore, an understanding of psychological trauma begins with rediscovering history. ${ }^{62}$

This act of rediscovery must, by necessity, involve making a space for the narrative that has been elided, must make a space for the narrator of alterity, the voice that threatens, challenges, recovers. For Native American communities, having survived centuries of war, poverty, and pestilence as a direct result of colonization, it is not simply a matter of discovering their own histories (which are, in fact, fairly well realized in certain settings), so much as realizing strategies to make such histories available to a settler culture that has conveniently forgotten its own complicity in the ongoing betrayal of themis. Sometimes it is a matter of taking the narratives that exist and freeing them from their sites of archival containment, allowing them to speak in a new contextualized setting. 
Stephen Greenblatt writes about the sense of wonder Europeans experienced (whether genuinely or manufactured for their own purposes) in coming to the American continents in his book Marvelous Possessions. But he cautions, "I have been very wary of taking anything Europeans wrote or drew as an accurate and reliable account of the nature of the New World lands and its peoples. ${ }^{" 63}$ In this he is in agreement with Gerald Vizenor who has termed the archival productions of the colonist "manifest manners," or "the absence of the real in the ruins of tribal representations. ${ }^{.64}$ His is, in part, a move toward exposing the ruptures inherent in representation, but infusing such ruptures with a political force, the intentionality of which is never in question. Representation, as it displaces or simulates the real, is often an act of annihilation - a means by which what is not included in the representation becomes unreal. Most Euro-American representations of Natives or Native culture deploy manifest manners to remove the "real" Indian and replace her/him with the ideologically motivated alternative, or what Vizenor calls "the simulations of dominance." Vizenor, too, posits that new simulations of survivance are being constructed to "undermine the simulations of the unreal in the literature of dominance." ${ }^{.65}$ He views this as a "trickster hermeneutics" that offers access to the "shimmer of a tribal presence in simulations. ${ }^{.66}$

Literary discussions of an earlier period placed a great deal of historical and ethnographic value upon the written impressions of European observers or "the simulations of dominance." Greenblatt however feels he must categorically deny any validity to the representations of peoples and sights that generated the wonder at the center of his argument even while admitting to the near impossibility of his task. And, in fact, so much of what we claim to know about this time and the horrific acts that accompanied it are contingent upon the accounts left behind by explorers, adventurers, proselytizers, and random witnesses. While remaining respectful of Vizenor's skepticism and Greenblatt's cautiousness, it must be noted that we can hardly dispense with these texts as valuable lenses through which to view and 
comprehend a shared past. Rather than regard them as purely a vehicle through which we might narcissistically navel gaze at our own monologic responses as a culture, we might work at drawing together the materials at hand in the hope of creating something more of a historical tapestry or bricolage that is not exclusively reliant on the colonizer's voice.

Witnessing, which is a form of contact, is still the only means available to achieve consensus concerning events that cannot be reconstructed by any means other than testimony. Thomas King, meditating upon Columbus' account of his first meeting with indigenous people in America concludes,

Columbus didn't know where he was. He didn't know who the people were. So he guessed. Since he was looking for India, these must be Indians. Not his fault he was lost. And for all the erroneous assumptions that this first description contains, it's a reasonably honest report of what the good admiral saw. Tall, good-looking, naked people who were unfamiliar with steel weapons. ${ }^{67}$

King says, "we can forgive and forget the nonsense about being 'good servants' and the 'easily made into Christians' part, can't we ${ }^{368}$ King is being partly facetious. And yet, I believe the question, and the statement proceeding it, are partly in earnest as well. This is the Longhouse method of relating history. King has his own story to tell, much like Columbus, and he offers it in carefully measured words. He knows that stories are "like medicine, that a story told one way could cure, that the same story told another way could injure. ${ }^{.69}$ So it isn't that he suggests we should take narrative at face value. But we must create a space for narrative to emerge, to credit narrative rather than exploit its weaknesses, to seek understanding rather than insist upon incomprehensibility, to engage rather than contain, and, through a process of engagement, to restore the good mind.

In Marvelous Possessions, Greenblatt presents us with the extraordinary account of French pastor Jean de Lery who traveled to Brazil in 1557 and lived with the Tupinamba, assembling his observations in his History of a Voyage to the Land of Brazil. Lery experiences a certain rapture after witnessing a Native ceremony that he initially had characterized as a 
"witches Sabbath." But after prolonged exposure, he reaches a different understanding of how the ritual actually built layers of "measured harmonies" that had the effect of lifting his heart and transporting him into a liminal state-liminal because the aesthetic wonder (sublimity) of this experience transcends cultural judgment or bias, at least for the duration of the ceremony. ${ }^{70} \mathrm{As}$ Lery understood it, the narrative elements of the Tupinamba ceremony recount, "a tale of a flood in ancient times that had covered the world and drowned everyone except their ancestors who climbed to safety in the highest trees." Lery ultimately comprehends this experience by framing it within a ready-made paradigm that views it as a "corrupt oral version of the biblical flood"-_corrupt," of course, because Lery's system of interpretation insists upon the absolute integrity of its own narratives to the exclusion of all others. ${ }^{71}$ As Greenblatt notes, however, the sense of wonder Lery exhibits seems to push him beyond the internalized processes of "aesthetic recoding" by which he seeks to contain the experience. The very slippage engendered by the events in question allows for something to pass through the discursive seams. While "witches sabbath" and "corrupt oral narrative" may be the two poles by which Lery might seek to contain the experience, what goes unarticulated is how he has moved toward an understanding of the Tupinamba as a people with literature. He even goes so far as to record a musical notation of the ceremony. And if we can strip away layers of subjectified window dressing and acknowledge that Lery, like Columbus, like the rest of us, is an imperfect reporter, we can still believe that a valuable fragment of Tupinamba culture imposes itself through this narrative. A sort of text within a text. A shimmer of a tribal presence.

And one is tempted to suggest that perhaps Lery has given us an important clue for comprehending contemporary events in this account as well. Is it possible that the Jarawa survived the tsunami of December 2004 by climbing to the tops of the tallest trees, as did the Tupinamba ancestors in the ceremony he recounts? As reductive as such a move may appear-equating the practices of two different cultures separated by vast time and distance- it 
remains as likely an explanation as any of how the Jarawa weathered the storm. The newspaper article with which I began this lengthy discussion asserts that Ashu, "an arrow wielding Jarawa . . . did not want to give details of how his people survived the tsunami, which killed 901 people and left 5,914 missing on the other Andaman and Nicobar islands." ${ }^{22}$ But it stands to reason that they saved themselves by having developed an intimate knowledge, an indigenous knowledge, of their environment and by having remembered the stories of their fathers, and their father's fathers, on how to recognize certain signs and respond to certain events. They did not question these memories, but acted upon them. This is what makes them indigenous. The Jarawa are protective of their culture. And although we may regard them as hopelessly locked in the past, they remain very much a part of the present and have, in fact, managed to avert two catastrophes thus far: the natural disaster in question and the more recurrent, insistent and insidious cultural tsunami of westernization.

My work focuses on the spaces where the oral and written traditions of Native cultures begin to merge together, quite often within those colonized locations that have been regarded as subjugated or silenced margins. As. we come to grips with the fact that nearly every effort at reaffirming the continuance of traditional literatures takes us back in some way, shape, or form through the colonial archive, however, we might take hope in the prospect that the simulations of survivance can operate retroactively, through a kind of cross-cultural analysis, to remove the smoke, unplug the ears, and open the throat for others to speak. My goal is to establish how, even through the textual containments by which we encounter Native presence in the colonial period, one can sense the threads of continuity and begin to heal the narrative ligaments that connect Native writings to the maintenance of Native culture and traditions. I hope that by establishing these contexts, one can begin to open a space to lift the cover of darkness and create and sustain a community of listeners. It has historically been easy to dismiss the Christian tracts of writers like Samson Occom, William Apess, and Charles Eastman as so thoroughly assimilated that they 
could not possibly register a relevant act of resistance. These forced dichotomies are part and parcel of the effects of colonization, an effect of double consciousness that plays out in the overall cultural literature where the oral tradition lurks behind the veil, while the written presents its assimilated facade. As long as the dichotomy is enforced under the gaze of white hegemonic culture there remain what W.E.B. Du Bois referred to as "two unreconciled strivings; two warring ideals in one dark body."73

My project then is to locate a body of work by Native American writers that has been largely overlooked and to attempt to view it from within the traditions of Native discourse communities. I argue that when Native Americans took up the technology of alphabetic writing it was not so much a concession to the dominant culture as an attempt to preserve land, traditions, and culture. Alphabetic texts are admittedly complex, highly specialized sites of engagement and containment. Nevertheless they are also highly efficient carriers of culture. It is difficult to attribute to oral culture, whatever its strengths, that same tensile valence that adheres to the textual operation. Certainly there is an eminent cultural and political presence that manifests itself outside the text, for it is safe to say that European societies would not have armed themselves and engaged in costly negotiations, treaties, and bloody conflicts with mere silenced margin dwellers. Whatever is excluded should not be consigned to the blank waste, the nonentity, of the margin. I prefer to call the site of silence "ground zero" - a space that has been isolated and contained, presumably by the inevitable ebb and flow of history, but in actuality by the construction of a privileged cultural narrative that is quite deliberate in the materials it gathers for consumption and perusal. The site of silence, this ground zero, while always in full view, remains cognitively displaced by the imposition of rigid cultural barriers. As such, we, Americans, apprehend the hand of violent oppression and abuse that sweeps through this space, but perform an elaborate unwitnessing to displace it from its source. We see but do not see, know but do not know. The result is that the psychic world of the dominant culture is severely, 
perversely, altered by that to which it cannot admit. It is forced into repetitions that seek to repair the unanticipated violence through a reordering of narrative and agency. A constructed notion of Native American identity becomes the most useful set of materials for these foundational narratives, but such simulations of nativity are always in the process of ordering their own removals, imposing their own exile. They become, like Longfellow's Hiawatha, the prophets of their own doom. Like the Jarawa, they are more comprehensible as flood victims than as survivors.

Studies of Native American writing tend to begin with the Mohegan preacher Samson Occom whose 1772 A Sermon Preached by Samson Occom is the first known publication by a Native author in North America. My dissertation, however, locates Occom near the end of a series of earlier Native contacts with the written word, the traces of which are scattered throughout the texts of the colonizer. While scholars have become largely familiarized with the representational modes in American literature that force the Native figure into what Lucy Maddox categorizes as patterns of either assimilation or extinction, I complicate this paradigm by exploring the interventions of seventeenth and eighteenth-century Natives whose writings challenge and upset this notion. I maintain that once Native writings are removed from their colonized contexts and recentered in Native space, we begin to see how such notes, letters, fragments, written testimonies and, eventually, publications were composed in the service of survivance and continuance rather than as full capitulations to a dominant culture. Too often the Native acquisition of literacy has been equated with fitting oneself into a cultural straightjacket, as though once the rhetorics of print discourse have been adopted, one can speak only through the colonizer's voice. Not until recently have critics, particularly Native American scholars such as Brooks, Womack, Warrior, King, and Weaver, come to question the interpretive utility of such convictions and begun to think instead upon the contiguous line of Native tradition that runs from the era prior to colonization into the present day. 
Chapter one looks at the phenomenon of "Contact," the early meetings of Natives with Spanish, French, and English colonizers, focusing on the scene of writing itself. European observers were invested in declaiming the validity of Native civilization, their narratives tending to obfuscate or dislocate evidence of the complexity and richness of indigenous traditions. Through colonial commentaries by Columbus, the French Jesuit Paul le Jeune, and Puritan outcast Roger Williams, as well as through anonymous writings of indigenous commentators of the time, one begins to see how the colonizers engaged in a deliberate act of unwitnessing in order to justify their violent excesses. Writing becomes the definitive marker of how western civilization separates itself from a presumably inferior culture. Therefore, as I argue, all evidence of an indigenous writing must be denigrated or contained. But the indigenous peoples of America did write and leave records, from the Popul Vuh of Quiche Mayan culture to the awhikigans used by woodland Natives of the Northeast. An examination of these modes of writing and the cultural contexts that produced them casts new interpretive light upon the ubiquitous colonial construction of the awe-struck "savage" confronting "paper that could speak."

Chapter two explores how a philosophy of containment, the act of unwitnessing, has cultural and political ramifications in New England and for American culture in general. The tendency of the first Puritan settlers to view the American landscape in typological arrangements had a dislocating effect. America appears in its textual representations as both desert and paradise, and the indigenous inhabitants are regarded as members of a lost civilization that had, through the absence of texts and writing-their untypological engagement with the land-descended into a state of barbarism and forgotten their compact with the one true God. An examination of the earliest colonial texts to emerge out of New England, like Roger Williams' $A$ Key Into the Language of America, the colonial Puritan propaganda tract New England's First Fruits, and various contemporary accounts of the 1636-37 Pequot War, suggest an emerging rhetorical battlefield in which the Indian becomes a central figure. The most contested figure in 
this period is a Pequot named Wequash, who is offered up as either an early missionary success or a conflicted and traumatized survivor of colonial massacre. I demonstrate how efforts to contain and control the events of the Pequot War become inseparable from the program of spreading the gospel to the Natives.

Chapter three follows the curious progress of the first printing press through colonial New England in the 1600s as it becomes not only the voice of Puritan hegemony, but the premier tool in the endeavor to assimilate the local Natives. In fact, the printing press becomes so entangled in the cultural encounter between Europeans and Natives that it spends its formative years housed in the building of the Indian College at Harvard, where it is maintained by a Nipmuck "printer's devil" named James Printer and a large portion of its output, including the first "Eliot Bible," is written in the Massachusett language. Harvard itself is founded with the understanding that one of its major functions will be to educate the "poor Indians." In this chapter I follow the lives of three writing Natives, Thomas Waban, James Printer, and Caleb Cheeshateaumauk, whose fates become closely entwined with Native education and the press. Following their engagements through The Eliot Tracts, Daniel Gookin's Historical Collections, and other texts and fragments of the period, I locate their contributions and their influences, noticing how, in significant ways, the first printed matter in colonial New England was printed in red ink.

Chapter four shifts the focus to Samson Occom, an eighteenth-century Mohegan, and the first American Indian to leave behind an extensive legacy of publications, journals, sermons, and letters. While it may be tempting to view Occom, an ordained and deeply committed Presbyterian minister, as one who has fully assimilated himself into a system of European thought and traditions, I will demonstrate the many ways in which Occom's commitment to his own traditions, his own people, are expressed and kept alive, not only within his published writings, but through his private life and actions. Paying particular attention to his journals and his 1768 
"A Short Narrative of My Life," I demonstrate how Occom, and others associated with his movement, carries on the struggle for tribal autonomy, following in the tradition of Pocahontas, Waban, Printer, and Cheeshateaumauk, by becoming a cultural intermediary looking for inventive ways to keep his community of Mohegans intact.

Chapter five shifts attention from Occom to the life of his son-in-law, Joseph Johnson. In Johnson's journals and letters we discover the voice of an often conflicted Mohegan youth whose personal crisis of identity is, in many ways, the crisis of his people. Johnson is caught up in a cultural moment that will soon become defined by the likes of James Fenimore Cooper, Lydia Maria Child, and other nineteenth-century American writers. But Johnson emerges as a charismatic and influential force in the lives of New England Natives, clearing the path for the unforced removal of his people to the newly conceived town of Brotherton, on Oneida territory in upstate New York. While Johnson's personal writings exhibit a youth caught in the bind of clashing cultures and conflicting discourses, his public writings demonstrate a growing mastery of European forms that enables him to lobby for what he hopes might be a more advantageous future for New England Natives. He virtually writes Brotherton into being in a tireless string of letters to government agents, fellow Mohegans, patrons, preachers, teachers, and missionaries. He must negotiate with other Indian nations and master the customs of oratory as well as print discourse in his dizzying campaign to create a new homeland for his people.

I conclude with a glance ahead at William Apess and a reading of his 1836 Eulogy on King Philip. Apess' attempt to relocate Native history, while pulling back into focus colonial atrocities, is informed by a sophisticated awareness of how print discourse has served to distort colonial memory and how Native American presence is undermined by a systematic rhetorical framing of Native identity. I see Apess' Eulogy unfolding in a dramatic space that places itself in direct conversation with John Augustus Stones' popular 1829 play, Metamora or The Last of the Wampanoags. I recontextualize the setting, however, offering the ceremonial dynamic of the 
condolence ritual as a stage upon which to open the elided aspects of these historical narratives. Ultimately Native writers engaged with literacy in the colonial period in an effort to enter into conversation with the colonizing agent and to address the ongoing traumatic elisions of white history-making. Expressing the nature of this intervention, Apess informs us that his reason for bringing such Native "beings" before the public is so that they "shall live forever in the memory of the world" and if possible "melt the prejudice that exists in the hearts of those who are in the possession of his soil." Some 170 years later, this remains a worthy endeavor.

In the writings of Caleb Cheeshateaumauk, Thomas Waban, James Printer, Samson Occom, Joseph Johnson, William Apess, and others we can locate very deliberate responses to the pressing exigencies of their respective communities. Rather than view the entry into print discourse as antithetical to authentic Native culture, I see it as the appropriation of a tool that allowed Native leaders to assert their continued presence into the interstices of a western discourse that labored daily to deny their existence. In short, Native Americans picking up the pen in colonial America was an act that drew as much from the reservoirs of Native resistance and continuance as from the dynamic changes set in motion by contact with a different culture. It was the equivalent of knowing just when to climb the tall trees to weather the storm. 
${ }^{1}$ Neelesh Misra and Rupak Sanyal, "In Rare Meeting; tribesmen tell officials of survival," The Boston Globe, 7 Jan. 2005, sec. A 18.

${ }^{2}$ In the official seal to the Massachusetts Bay Colony.

${ }^{3}$ It is of interest to note that the Jarawas themselves were described by Marco Polo as a "people without a king, and are idolaters, and are no better than wild beasts. And I assure you all the men of Angamanain have heads like dogs, and teeth and eyes likewise; in fact, in the face they are all just like big mastiff dogs! They have a quantity of spices; but they are a most cruel generation, and eat everybody that they catch, if not of their own race." Madhusree Mukerjee, The Land of Naked People: Encounters with Stone Age Islanders (New York: Houghton Mifflin Co., 2003), xi.

${ }^{4}$ Homi Bhabha, The Location of Culture (New York: Routledge, 1994) 1-2.

${ }^{5}$ Thomas King, The Truth About Stories: A Native Narrative (Minneapolis: University of Minnesota Press, 2003), 2.

${ }^{6}$ Judith Herman, Trauma and Recovery: The Aftermath of Violence-from Domestic Abuse to Political Terror (New York: Basic Books, 1992), 37.

${ }^{7}$ Tbid., 9.

${ }^{8}$ Herman, Trauma and Recovery, 9.

${ }^{9}$ Christopher Columbus, The Four Voyages, ed. and trans. J. M. Cohen (New York: Penguin Books, 1969), 72 .

${ }^{10}$ Edward Said. Orientalism (New York: Vintage Books, 1978), 109.

${ }^{11}$ Jace Weaver, That the People Might Live: Native Literatures and Native American Community (New York: Oxford University Press, 1997), 17.

${ }^{12}$ Misra, Sanyal, "In rare meeting," 18.

${ }^{13}$ See Mukerjee, The Land of the Naked People.

${ }^{14}$ Some of the more famous primary texts from the nineteenth and early twentieth-century boarding school era were Charles Eastman, From the Deep Woods to Civilization (Boston: Little Brown, 1916), Zitkala-Sa, American Indian Stories (Lincoln: University of Nebraska Press, 1985), Luther Standing Bear, My People the Sioux (Lincoln: University of Nebraska Press, 1928). Wynema, the first novel known to be written by a Native American woman also concerned the Boarding School experience. See S. Alice Callahan, Wynema: A Child of the Forest, ed. A LaVonne Brown Ruoff (Lincoln: University of Nebraska Press, 1997). The 
boarding school experience continues to be a topic of contemporary Native novels as well.

${ }^{15}$ Peter Nabokov, A Forest of Time: American Indian Ways of History (Cambridge, UK: Cambridge University Press, 2002), 249.

${ }^{16}$ Jacques Derrida, Archive Fever: A Freudian Impression, trans. Eric Prenowitz (Chicago: University of Chicago Press, 1996), 2.

${ }^{17}$ James C. Scott, Domination and the Arts of Resistance: Hidden Transcripts (New Haven: Yale university Press, 1990).

${ }^{18}$ Luther Standing Bear, Land of the Spotted Eagle (Lincoln, NE: University of Nebraska Press, (1933) 1978), 249.

${ }^{19}$ Ibid., 249.

${ }^{20}$ Lisa Tanya Brooks, The Common Pot: Indigenous Writing and the reconstruction of Native Space in the Northeast, A Dissertation Presented to the Faculty of the Graduate School of Cornell University (Ann Arbor, MI: UMI and Proquest Information and Learning, 2004), 11-12.

${ }^{21}$ Ibid., 1-3.

${ }^{22}$ Ibid., 5.

${ }^{23}$ Mary Louise Pratt, Imperial Eyes: Travel Writing and Transculturation (New York: Routledge Press, 1992), 7.

${ }^{24}$ Thomas Morton, New English Canaan (New York: De Capo Press, 1969, 1637), 10.

${ }^{25}$ See Sacvan Bercovitch, The American Puritan Imagination: Essays in Revaluation (New York: Cambridge University Press, 1974), 11. Bercovitch notes how the Puritan settlers cast their experience within a framework that equates their experience with the Jews who journeyed through a desert wilderness, purged themselves in the Red Sea, and then entered the holy land which they then redeemed from a state of captivity, or "her long slothful sleep" into state of grace.

${ }^{26}$ Vine Deloria Jr. and Daniel R. Wildcat, Power and Place: Indian Education in America (Golden, CO: Fulcrum Resources, 2001), 31.

${ }^{27}$ Ibid., 22.

${ }^{28}$ Ibid., 27-28. 
${ }^{29}$ Robert Warrior, Tribal Secrets: Recovering American Indian Intellectual Traditions (Minneapolis: University of Minnesota Press, 1995), 104-1 15. Warrior places himself in direct conversation with Deloria when he notes that the world has "a moral being" $(110)$, and that Native culture was authenticated not through principles or doctrine, but through the establishing of an intimate relationship with place, based on observation and experience rather than some vague romantic link to the land (111).

${ }^{30}$ Pratt, Imperial Eyes, 31.

${ }^{31}$ Bartolome de Las Casas, In Defense of the Indians, trans. Stafford Poole (DeKalb: Northern Illinois University Press, 1992), 44.

${ }^{32}$ Fray Bernardino De Sahagun, Florentine Codex: General History of the Things of New Spain, Introductory Volume, eds Arthur J. O. Anderson and Charles Dibble (Salt Lake City: The School of American Research and the University of Utah, 1982), 82.

${ }^{33}$ Columbus, The Four Voyages, 56.

${ }^{34}$ Amerigo Vespucci, "Letter to Pier Soerini, Confalonier of the Republic of Florence," The English Literatures of America 1500-1800, ed. Myra Jehlen and Michael Warner (New York: Routledge, 1997), 22.

${ }^{35}$ Edward Winslow, A Relation or Journall of the Beginning and Proceeding of the English Plantation Setled at Plimoth (London: John Bellamie, 1622), 68.

${ }^{36}$ As Winslow notes in $A$ Relation, the presumed failure of Natives to improve upon the land made it not only imperative, but legal, for Europeans to take ownership. He writes "As the ancient Patriarkes therefore removed from straiter places into more roomthy, where the Land lay idle and waste, and none used it, though there dwelt inhabitants by them ... So it is lawful now to take a land which none useth, and make use of it" (Ibid.,68).

37 Craig Womack. Red on Red: Native American Literary Separatism (Minneapolis: University of Minnesota Press, 1999), 12.

${ }^{38}$ Pratt, Imperial Eyes, 2.

${ }^{39}$ Weaver, That the People Might Live, $\mathrm{x}$.

${ }^{40}$ Arnold Krupat, The Voice in the Margin: Native American Literature and Canon (Berkeley: University of California Press, 1989), 198.

${ }^{41}$ Ibid., 214. 
${ }^{42}$ Weaver, That the People Might Live, xii.

${ }^{43}$ This is not to say that Krupat and Brumble have been categorically ignored. And there are remarkable exceptions. Peter Nabokov, David Murray, and Bernd Peyer come immediately to mind.

${ }^{44}$ Womack, Red on Red, 11.

${ }^{45}$ Pulitano comes back repeatedly to the notion that, when focusing on Native intellectual traditions, recent Native critics are ignoring how the intellectuals in question were already deeply immersed in and affected by white culture and norms. Warrior, for instance, draws inspiration from Vine Deloria Jr. and John Joseph Mathews, both of whom he regards as Native writers who have relied upon Native epistemologies to inform their life and work. Pulitano points out however that both Mathews and Deloria possessed a kind of "international and global experience" or "cultural hybridization" that made them unlikely candidates for representing traditions thought to be purely Native. (63-64). Pulitano is accusing Warrior of attempting to forge an essentialist thetoric - the very thing Warrior claims he is laboring to avoid. Pulitano's stance, however, demonstrates how the rhetorical deck is stacked against Native intellectuals of both yesterday and today. Simply because cultures come into contact with one another, it does not dictate that tradition cannot be traced back to a particular heritage, or that people cannot find strength, comfort, and intellectual solace in such tradition. Warrior points to traditions that arise from a particular knowledge base, experience, and intimacy with a geographical area. That intimacy, over a period of centuries, is threaded into the lifeways, language and practice of a people. Regardless of other cultural influences which are always present, one can still lay claim to customs and traditions that can be traced back to their people's engagement with the land. To call this essentialist is to misunderstand the word. It is rather an acknowledgement of the manner in which culture is constructed and the ways in which environment plays a role in that construction. See Elvira Pulitano, Toward a Native American Critical Theory (Lincoln: University of Nebraska Press, 2003).

${ }^{46}$ Warrior, Tribal Secrets, 123.

${ }^{47}$ Ibid., 110.

${ }^{48}$ Ibid., 114.

${ }^{49}$ Weaver, That the People Might Live, 40.

${ }^{50}$ Ibid., 43.

${ }^{51}$ Ibid., 44.

${ }^{52}$ Brooks, The Common Pot, 161.

${ }^{53}$ Anthony F. C. Wallace, The Death and Rebirth of the Seneca (New York: Knopf, 1970), 95.

${ }^{54}$ Anthony Wallace, Death and Rebirth, 7-8. 
${ }^{55}$ Paul A. W. Wallace, White Roots of Peace: The Iroquois Book of Life (Sante Fe: Clear Light Publishers, 1994), 52.

${ }^{36}$ Horatio Hale, ed. The Iroquois Book of Rites (Toronto: University of Toronto Press, 1963), 117.

${ }^{57}$ Cathy Caruth, Unclaimed Experience: Trauma, Narrative, and History (Baltimore: The Johns Hopkins University Press, 1996), 6.

${ }^{58}$ Caruth, who is reinterpreting notions of trauma first articulated by Freud in Beyond the Pleasure Principle, states that "trauma [is] the very origin of consciousness and all of life itself" (Ibid., 104). Her point is that the awakening of consciousness from a previous state of cognitive inertia was itself a moment of violent awakening that could not be apprehended and engendered consciousness as a series of repetitions unable to perceive its own origins.

${ }^{59}$ Scott, The Hidden Transcript, $\mathrm{x}$

${ }^{60}$ Jonathan Shay, Achilles In Vietnam: Combat Trauma and the Undoing of Character (New York: Maxwell Macmillan, 1994), 193.

${ }^{61}$ Frederick Matthew Wiseman. Voice of the Dawn: An Autohistory of the Abenaki Nation (Hanover, NH: University Press of New England, 2001), 81.

${ }^{62}$ Herman, Trauma and Recovery, 2.

${ }^{63}$ Stephen Greenblatt, Marvelous Possessions: The Wonder of the New World (Chicago: The University of Chicago Press, 1991), 7.

${ }^{64}$ Gerald Vizenor, Manifest Manners: Postindian Warriors of Survivance (Hanover, NH: University Press of New England, 1994), 8.

${ }^{65}$ Ibid., 12

${ }^{66}$ Ibid., 15.

${ }^{67}$ King, The Truth About Stories, 70.

${ }^{68}$ Ibid., 70.

${ }^{69}$ Ibid., 92. 
${ }^{70}$ Greenblatt, Marvelous Possessions, 16.

${ }^{71}$ Ibid., 17.

${ }^{72}$ On the radio program National Geographic World Talk, Madhusree Mukerjee, who has lived with and written on the Jarawa, claims that the Jarawa, unlike their Nicobar neighbors, ran to high ground when they sensed the flood was coming and took to the tallest trees.

${ }^{73}$ W.E.B. Du Bois, The Souls of Black Folk (New York: Random House, 2003), 5. 


\section{CHAPTER 1}

\section{WUSSUCKWHEKE OR THE PAINTED LETTER: GLIMPSES OF NATIVE SIGNIFICATION ACKNOWLEDGED AND UNWITNESSED}

The advent of Native written literature did not, in any way, mark the passing of native oral literature. In fact, they occupy the same space, the same time. And, if you know where to stand, you can hear the two of them talking to each other. Thomas King

Writing is unfortunately like painting; for the creations of the painter have the attitude of life, and yet if you ask them a question they preserve a solemn silence.

Plato

\section{While You Were Sleeping: Colonialism's Unrecorded Dialogues}

Shhh. Roger Williams pretends to be sleeping. But in fact he is listening in on a conversation between the Narragansett sachem Miantonomo and another of the "Quinnihticut" Natives with whom he has sheltered and who continue their talk long after Williams has retired for the night. ${ }^{1}$ The conversation concerns Manittoo wussuckwheke, which, according to Williams, is the Narragansett word for "Writing" or "God's Booke." Throughout the evening Williams has extolled the virtuous wonders of this product to the gathered community, but he is a stranger in a strange land and his singular ideas about salvation and the afterlife are not accepted without debate. The "Quinnihticut" man begins the dialogue which Williams has transcribed in such a manner:

Our fathers have told us, that our soules goe to the Southwest.

The Sachim answered, But how doe you know your selfe, that your soules go to the Southwest; did you ever see a soule goe thither?

The Native replyed; when did he [Williams] see a soule goe to Heaven or Hell?

The Sachim againe replied: He hath books and writings, and one which God himselfe made, concerning mens soules, and therefore may well know more than wee 
that have none, but take all upon trust from our forefathers. ${ }^{2}$

This stolen exchange, an interesting moment of what might be thought of as cultural eavesdropping, would find its way into Williams' A Key into the Language of America, written in 1643 as Williams sailed toward England in an effort to win a charter for his new settlement. The Key, virtually unique in the enormous catalogue of documents to emerge from the colonial endeavor, was (for its time) a surprisingly attentive accumulation of words and phrases roughly translated from the Algonquian that attempted to not only bridge the language barrier between settler and native, but to relate the customs and temperament of New England's indigenous peoples. As Williams said of this project “a little Key may open a Box, where lies a bunch of Keyes," and he expressed that his acquisition of this tool had allowed him to "unlocke some rarities concerning the Natives" and enter "into the secrets of those Countries" where they dwelled between the English, French, and Dutch settlements. ${ }^{3}$

Perhaps this language sounds penetrative and intrusive. Richard Cogley, who has written definitively on the missionary work of John Eliot, the so-called "apostle to the Indians," considered Williams' little book something of a "primer for aspiring missionaries."4 And in fact Williams quickly brings the Key to its central question which is "to that great Point of their Conversion so much to bee longed for, and by all New English so much pretended." Williams forwards the idea that, for any sort of Christian "progress" to take place amongst the natives, moves had to be made toward acquiring the native language, understanding indigenous customs, and even respecting their title to the land. His views struck his Christian neighbors as extreme, even in a colony of extremists. He was reviled by the histories of his day, called "unsettled in judgment" by Plymouth governor William Bradford, full of "error and presumption" by Massachusetts Bay Colony governor John Winthrop, and mocked as a chaser of windmills by Cotton Mather. John Cotton angrily contested Williams' views in a series of published letters, and Nathaniel Morton wrote of Williams' "great and lamentable apostasy," which lay in his 
expressed belief that the King's patent in the colonies was invalid. ${ }^{6}$ The treatise Williams wrote concerning native title to the land was ordered burned by the Massachusetts General Court, and his positions were considered enough of a threat to result in his being banished from the colonies.

Mid-twentieth-century critics like Ola Winslow and Perry Miller argue that, whatever the merits of Williams' legacy, his rhetoric was ill-advised for the times. Miller, in a sense, aligns himself with the early settlers, agreeing with their view of Williams as a threat to colonial stability or the stability of any era, arguing that "he became, as indeed he remains, a menace to society." Miller is skeptical of attempts to associate Williams with our current legacy of church and state separation, because he regards Williams as an impractical religious purist of the highest degree. But Williams' extremism was of an interesting brand, its channels of rhetoric generally leaning more toward notions of tolerance than exclusion. The Puritan congregationalism that sprung from Calvinist doctrine saw itself as a return to a scriptural engagement with Christianity. European Catholicism had organized itself, over the course of a millennium, around traditions and rituals that sprang up organically around the worship of Jesus Christ. The Anglican church, although it split from the Catholic church, still carried the residue of these traditions. By returning to the text, the Puritans sought to circumvent many of these traditions and practices that had no original articulation in scripture or the ministry of Christ. If the word of God was directly given in the Bible, than anything not in the Bible was superfluous to Christian worship. But if the Puritans were invested in this textual engagement, Williams is the high theorist of scriptural doctrine, recognizing its many slippages and contradictions, which he reconciles as "mysteries." He didn't feel as though Scripture could be read as a legal document or that any one interpretation could withstand scrutiny. ${ }^{8}$ This results in a distrust of orthodoxy itself and a tendency, in Williams, to favor tolerance, believing that a perfect interpretation of God's word awaited the return of Christ. This philosophy of tolerance leads Williams into a cultural and philosophical relationship with the Natives of New England. 
This encounter has, historically, been romanticized, but given little critical attention. Only recently have critics like Jennifer Reid and Patricia Rubertone begun to focus more exclusively on Williams' encounter with Narragansett culture. Both of these critics, however, are dismissive of Williams' claims in the Key. Rubertone, who integrates an analysis of Williams' text with an archeological investigation of Narragansett culture, cautions that colonial authors "invented the voices of Native peoples, rendering their statements in halting, ambiguous, and often muffled tones." Point by point, Rubertone focuses on the particulars of Narragansett culture that seem to elude Williams' vision. She correctly apprehends how the Key has evolved in many ways, as the authoritative text on Narragansett culture, and she seeks to correct this tradition. In some ways, however, Rubertone misses what I find to be one of the most compelling aspects of Williams' Key, which is the lens it opens into his partial assimilation into Narraganset culture and his internalization of Narragansett epistemologies. In this vein, Neal Salisbury argues that Williams experienced a complete "immersion in Indian culture," and notes that Williams, in the end, objected to the project of forcing Christianity upon Native populations. Williams entered instead into a relationship of exchange and engagement with the Narragansett, mirroring native practices of "reciprocity."10

For our purposes the Key is the most comprehensive artifact of an important cultural engagement, a rough sketch of Williams' time spent amongst the Narragansett after being banished from the New England settlements. It afforded Williams a certain amount of authority concerning Indian issues amongst his English patrons and had a significant effect on the course of Indian re-education in the colonies. ${ }^{11}$ Williams questioned the efficacy of colonial attempts at converting the Native population and effectively accused his Puritan neighbors of failing to fulfill the claims of their charter. Perhaps he felt the claims themselves were erroneous. Nevertheless he was influential in instrumenting a shift toward colonial appropriation of native language in order to spread the gospel, rather than forcing natives to learn English. The Key 
opens a fascinating, though not quite unproblematic, lens upon the ideological exchanges that occur alongside language exchange, a bartering in words, texts, and ideas that developed between the Narragansett and at least one European settler of the New England colonies who, optimistically, suggested that by paying attention to one another's languages and customs one might "spread civilitie." I2 I use it here as a launching pad of sorts to think about such encounters.

While Williams, in accordance with his own lights, was a diligent recorder of Narragansett language and customs, we might question whether the dialogue transcribed at the start of this chapter ever took place or if it was in fact an instance of cultural wish fulfillment, what Gerald Vizenor regards as "manifest manners," in which Native presence is strategically displaced by white representation. ${ }^{13}$ A Key appropriates Native figures to represent Williams' own personal agenda. One senses the voice of Williams speaking through Miantonomo when he records, "how do you know yourself that your soules go to the southwest" [italics mine]. Clearly the "your" should read as "our" in this sentence, as Miantonomo is referring to long held beliefs and practices shared in common by he and the Quinnihticut man. As the dialogue is offered, however, Miantonomo seems to fill in for the absent voice of Williams while the Quinnihticut Native plays the role of skeptic or foil. Tellingly, Miantonomo gets the last word, dispelling the objections of his companion. ${ }^{14}$ We might accept that the conversation simply ended where Williams leaves it, all other concerns being swept aside by the inescapable authority of the book and writing. More likely, however, is that Williams drifts off into a kind of sleep at this precise moment, leaving any significant articulation of resistance to his worldview to pass unnoticed, unrecorded, as though it had never been. And in a sense it is Williams' sleeping that concerns us more than his waking. For it was generally the case that any reasoned Native resistance to colonial hegemony in seventeenth-century New England was to remain veiled in archival slumber or, to put it more bluntly, was purposefully contained by scripting it out of the colonial experience. When the so-called Indians of America spoke of their own lives and loves, their 
traditions, their legitimacy as a people and a culture, the colonial scribe lay sleeping, or pretending to sleep. Even Williams - so attentive to Native language and practices that his partial assimilation into their customs should be considered yet another slumbering giant buried deep within the lines of his Key-was only able to hear partial conversations, snippets of newes, and only seemed able to relate in writing what his ever awake English audience needed, or was able, to hear in regards to the Native population of America. ${ }^{15}$

The presumption of Miantonomo's discourse, as Williams offers it, is clear. European religious belief has the greater claim to authenticity by virtue of its being written down. The word it carries is more durable than the orally transmitted beliefs of America's indigenous peoples because alphabetic literacy has seared its content like God's very own brand upon the raw flesh of the page. The text of the Christian Bible is said to have spilled from the mind (if not the mouth) of God directly to the pens of prophets, thereby preserving its message unerringly from one generation to the next. It was a narrative, a tradition, not susceptible to human error. Williams writes of the Narragansett that "they have no Clothes, Bookes, nor Letters, and conceive their Fathers never had; and therefore they are easily perswaded that the God that made English men is a greater God." 16 We are asked to believe that even Miantonomo, who would later be executed by colonial fiat, is persuaded by this most convincing, yet most confounding, of European trade goods, the book.

If the dialogue Williams offers is either imagined or adumbrated, however, the criticism offered by the nameless Quinnihticut man seems perfectly accurate and a natural extension of the matter at hand. Williams has not actually witnessed the marvels that he and his manittoo wussuckwheke advertise ("when did he see a soule goe to Heaven or Hell?"). The printed word truly has no more claim to authenticity than the spoken one, and perhaps even less of a claim, as those who participated in the moment of its inscription, those who might bear witness for its veracity, are long gone from the scene. As the Quinnihticut man (whose very namelessness is a 
kind of erasure) aptly intuits, there is no contiguous human connection between the author of such sentiments and the evangelist who promotes them. In fact, there is not even a shared geographical, familial, or cultural relationship between the two. The defense offered is, therefore, strictly tautological. When the Quinnihticut man wonders if Williams has actually seen the things of which he has spoken, the written text is offered as its own proof. But what if Roger Williams hadn't drifted off into sleep at just this moment? What if all the colonial pens did not habitually succumb to exhaustion at the instant a Native consciousness, comprised of a political and cultural "indigenous" awareness contrary to colonial objectives, was poised to assert itself? What might have been recorded then? Or what might have been penned in red ink, while the pen of the colonist slept?

As Williams himself notes, the manner of the Narragansett was

upon any tidings to sit round double or treble or more, as their numbers be; I have seen neer a thousand in a round, where English could not well neere halfe so many have sitten: Every man hath his pipe of their Tobacco, and a deepe silence they make, and attention give to him that Speaketh; and many of them will deliver themselves, either in a relation of news, or in a consultation, with very emphaticall speech and great action, commonly an houre, and sometimes two hours together. ${ }^{17}$

We might well imagine that on the night in question, had they considered the matter weighty enough, the Narragansett community assembled around Miantonomo's lodge would have discussed Williams' notions well into the night, hearing out the opinion of all who wished to speak, measuring each argument carefully before reaching any conclusions as a group. Beyond that, while Williams slept, they might have broached the larger problem of what to make of the Europeans in general, who by this point were arriving in ever larger numbers and causing great disruptions, not only through geographical expansion and violent conflict, but also through the introduction of devastating diseases that had spread like wildfire since their arrival. They might have wondered at the savage nature of the white men who, despite their desirable trade goods, seemed to lack a capacity for comprehending any system of values other than their own, who were in general rude, intolerant, sore losers when it came to striking a deal and accustomed to 
making statements that did not fall into line with their actions. As Williams duly noted, it was not unusual for an Indian to ask, somewhat sardonically, "You know God, Will you lie Englishman?"18

The Narragansett, of course, also "knew God," and they may have spoken of their own Manito of the southwest, Cautantowwit, who first created man and woman out of stone, but disliking that model, broke the stone into many pieces and formed man and women again from a tree, this first couple becoming the progenitors of their nation. ${ }^{19}$ And at some point in the evening, while Williams lay sleeping, someone was likely to have brought up the issue of the white man's military might. They may have invoked the fate of the neighboring Pequot nation, the rush to war by the English colonists, and the terrible efficiency with which Pequot men, women and children had been cut down during the fort fight at Mystic. They may have recalled their own participation in that battle, and their subsequent horror at its "too furious" nature. Indeed, some around the fire may have been Pequot themselves, adopted into the Narragansett tribe or held captive, and if they had a place and a voice at that counsel they may have been insistent upon revenge for their mothers, their daughters, their sons, and their fathers killed in the massacre. Might not the various nations gather together and force the English back into the sea? Miantonomo himself was said to have forwarded such a pan-Indian strategy in years to come, declaring it in the best interests of the various indigenous nations to "be one as they [the English] are, otherwise we shall be all gone shortly."21

And after all this, they may have indeed come back around to the notion of manittoo wussuckwheke. God's Booke. For in some ways this remained at the center of the problem. What could this book, that seemed to mean everything to the English, possibly signify to the Narragansett and to the other Native populations of the northeast? What did it portend? What use could they make of it? Colonial recorders offer a large number of accounts in which the indigenous man first encounters the book. These accounts were of special interest to the colonist, 
because they presented an opportunity to display what they felt to be the superior quality of their culture. It was the book, more than guns and steel and other trade goods, that best represented the civilization they were exporting to the new world. Thomas Hariot, who joined the Roanoke colony in Virginia during the years $1585-86$, noted "the booke materially and of it selfe was not of any such vertue, as I thought they did conceive, but onely the doctrine there-in contained: yet would many be glad to touch it, to embrace it, to kisse it, to holde it to their breastes and heads, and stroke all over their body with it." ${ }^{\text {,2 }}$ The French Jesuit, father Paul Le Jeune, would claim of the Huron in his 1635 Relation that "above all," they admired European "writing, for they could not conceive how, what one of us, being in the village, had said to them, and put down at the same time in writing, another, who meanwhile was in a house far away, could say readily on seeing the writing. I believe they have made a hundred trials of it." ${ }^{23}$ And according to Roger Williams, there was really only one appropriate response to the introduction of this product, the European material trade good par excellence. He writes that when Natives were confronted with any "apprehension of excellency in Men, Women, Birds, Beasts, Fish, \&c." they would give it the label of "Manittoo, that is, it is a God." But especially, Williams notes, of books and letters "they will end thus: Manittowock They are Gods."24

There is no reason to think that the Narragansett were unable to appreciate the splendor of books, both as material objects and as tools. Ethnohistorian James Axtell posits that "the Indians' 'admiration' of the Europeans' printed books was simply an appreciation of the sheer technological novelty of thinner-than-birch bark paper, uniform typefaces, gold-stamped bindings, and illustrations of strange faces and unfamiliar places. ${ }^{25}$ But the Narragansett also would have been cognizant of the uses that letters and writing could be put toward and how such a technology might assist them in their own purposes. We might imagine that Natives were resistant to this technology, but in fact, both Miantonomo and his uncle, the sachem Canonicus, had frequently employed Williams' services as scribe. In order to correspond with the other New 
England colonies, they would ask "Wussuckwheke, yimmi, Make me a Letter," and Williams notes that this was something "they have often desired of me upon many occasions; for their good and peace. ${ }^{26}$ Like some other European products such as guns, blankets, and cookware, writing had a durability and a transportability that made it desirable, a force that lent credence regardless of what use was made of it. While a frequent trope in European travel writing would, as Hariot and Le Jeune's accounts suggest, have Native peoples stand in puerile awe of written communication, regarding it as a kind of totemic magic, Williams makes clear that his Native acquaintances, at least, were comfortable enough with the form to put it to their own uses. Therefore it remains a distinct possibility that, as they discussed the problem of "God's Booke," the Narragansett would have seen the utility in appropriating this tool, harnessing its powers for their own purposes, just as they had come to employ many other European trade goods to seeming advantage in their daily lives.

But writing could also be regarded as problematic. As a skill it was difficult to acquire, the time and solitary effort needed to master it did not readily conform with the seasonal relocations and shared responsibilities of Native communities, and perhaps most significantly, the entire bulk of this product, whatever its uses, appeared to be inextricably bound to European narratives, European values, European beliefs and modes of thought. The danger of being indoctrinated into European literacy was that one would also be implicated into European culture and lured away from one's own traditions. The dialogue Williams offers typifies a certain understanding of this dynamic between two cultures - one oral, one literate - and the anxieties attendant upon such an intersection of discourses. Embedded somewhere within this understanding is an apprehension of how the written word, perhaps even more than the doctrines that it furthered, might quickly begin to operate, to borrow Jacques Derrida's term, as a pharmakon, both remedy and poison, insinuating itself into the fabric of long held belief systems, provoking amnesia, unraveling even as it stitched something new together, sowing germs of 
doubt and discord under the guise of rock-hard truths. ${ }^{27}$ Thomas Mayhew, who "labored" amongst the Martha's Vineyard Indians in the seventeenth century, claimed of the Natives that "having many calamities among, they laid the cause of all their wants, sicknesses, and death, upon their departing from their old heathenish ways." He notes that only one named Hiacoomes "held out," and "being desirous to read, the English gave him a primer, which he still carries about with him." 28 This, of course, is likely to speak more toward ingrained English assumptions than any genuine indigenous response to the trials this particular community was undergoing at the time. But there is reason enough to apprehend that those trials were genuine, tragic, transformative, and their effects rippled through both culture and community. As these trials ensued, the English were standing by, ever ready with their books and doctrine, "as one that stands by a running river filling many vessels . . . with everlasting knowledge."29 Such knowledge was meant to displace, not fortify, evict, not nurture the store of knowledge and tradition already possessed by Native cultures. As most students of philosophy and literature realize, even Socrates struggled with such tensions and noted the ways in which the "discovery" of writing would "create forgetfulness in the learner's soul.,30 The Sioux writer, Luther Standing Bear, observed a similar effect when he commented, "countless leaves on countless books have robbed a people of both history and memory."31

Williams' snippet of dialogue between Miantonomo and the Quinnihticut man, like so many other similarly designed passages in the colonial archive, is somewhat smugly designed to exploit the assumption commonly held as true by his European audience: that literacy, and particularly print discourse, supersedes the more porous nature of oral tradition. As Walter Ong has noted, "print encourages a sense of closure, a sense that what has been found in a text is finalized, has reached a state of completion." 32 Once it reaches this stage it will not be changed, it adheres to a specific order, a contained signification. ${ }^{33}$ This often contributes to the illusion that writing concretizes truths. But even Williams' culture was not completely comfortable with 
this notion, and so an extra layer of foundation was added by attributing the indisputable source of all their thinking not to human writers, but to God. Walter Mignolo observes that in the period of Spanish colonization the human book had "two functions: to know the creator of the universe by reading His Book and, at the same time, to censure every human expression in which the Devil manifests itself by dictating false books." ${ }^{34}$ Such a philosophy could tolerate only one version of events, one cosmology, one set of spiritual beliefs and was in absolute antipathy to oral belief systems, which often did not depend upon a closed reading of a particular narrative. Peter Nabokov describes the multiple versions of experience and belief accommodated by oral tradition as its "defining benefit and unending pleasure." He feels that it is precisely "the incessant wrangling over truth, and the sense of endless rehearsal, that are the yeasty essence of cultural reproduction and that provide one of humankind's most creative alternatives to totalitarianism. "35 If Christian explorers were wedded to their totalizing ideology of one God, one religion, Native epistemologies seem not to have demanded such uniformity of belief, did not demand the illusion of closure that print discourse imposes on perception. Although I will show that Native peoples had their own systems of signifiers, or hieroglyphs, prior to European contact, the purpose of these symbols was not to cordon off spiritual or intellectual enquiry. They served instead to offer interpretations of events that could be told in a different manner by different readers and were not in need of fixed versions to retain cultural validity. I would like to explore further the implied view of the Quinnihticut man in Roger Williams' dialogue, for whom alphabetic writing held no mesmerizing charm, but was simply another product of the colonist.

\section{Pharmakon or Key?: Opening Up an Idea of Writing in Native Space}

George Tinker in his treatise on Native spirituality entitled Spirit and Resistance, notes that the imposition of the "Hebrew Bible" on Native American cultures "has two primary effects that are dysfunctional for Native American communities. First it abrogates (explicitly or 
implicitly) the validity of Native American traditions. Second, it inherently prescribes replacing one's own history with someone else's history as an ineluctable prerequisite for conversion." 36 The imposition of Christian norms on Native communities was regarded as a benevolent act by the colonists, even when it required the utmost violence to effect. It was the rhetorical lock, stock, and barrel of colonial conquest, the altruistic impulse by which cultures perceived to have been seated in darkness were given the once-in-a-lifetime opportunity of embracing Christian light and community. As the Royal Patent of the first settlers in Virginia affirmed, the chief end of the colony was the "propagating of Christian religion to such people as yet live in darkness and miserable ignorance of the true knowledge and worship of God, and may in time bring the infidels and savages living in those parts to human civility and to a settled and quiet government." ${ }^{37}$ The justification for this altruistic interference relied heavily on the oft-repeated assumption that Natives had no culture of their own, no law, no religion, in effect, none of the cultural artifacts presumed to be a result of writing. For the settler culture this meant that there were only two possible avenues for indigenous culture to pursue, which Lucy Maddox, in her book Removals, breaks down as either assimilation or extinction. ${ }^{38}$

While, in nearly every case, it is the settler who forces these terms upon the Natives, the literary productions of the settler cast Natives in the role of adopting such choices for themselves. In other words, the Native is seen as either freely accepting the superiority of western civilization (as we see Miantonomo doing in Williams' dialogue), or recognizing his/her own incompatibility with a superior culture, which results in the sort of lamentable but necessary departure that one sees in productions like Longfellow's "Song of Hiawatha." When the black robes first arrive upon the shores of lake Gitche Gumee in Longfellow's poem, Hiawatha, who might be understood not only as culture-giver to the Natives, but as a stand-in for Native culture itself, orders his own departure. He announces,

"I am going, O my people, On a long and distant journey; 
Many moons and many winters

Will have come, and will have vanished,

Ere I come again to see you.

But my guests I leave behind me;

Listen to their words of wisdom,

Listen to the truth they tell you,

For the Master of Life has sent them

From the land of light and morning!"

It is the black robes, or French Jesuits, sent by the "Master of Life," arriving with the "truth" in the form of God's written word that has signaled the end of Hiawatha's usefulness. And in full recognition of this, he paddles off gently into the good night of history's outer darkness. Rather than being represented as a principal figure in the development of Iroquois culture, Hiawatha is regarded as a cultural placeholder, put in charge of the children of the forest until the proper spiritual authorities can finally arrive on the scene. Maddox notes how influential nineteenthcentury writers, such as James Fenimore Cooper, Catherine Sedgwick, Lydia Maria Child, Henry David Thoreau, and others, were inclined to romanticize Native presence and disappearance in a like manner. They had achieved a comfortable geographical and political distance from the ongoing policies of confrontation and forced removal that were driving Natives from their lands in other parts of the nation and had imbibed the lesson, repeated from the earliest days of colonization, of their vanishing. Although their works may appear sympathetic to Native concerns in some respects, they are gathering together the loose materials of cultural annihilation. Native civilization is driven underground by European representation.

The emergent proposition was that if Natives were to survive at all, they would have to sacrifice their own cultures and adopt the ways of European civilization. What this meant in particular was giving up traditional hunting and agricultural practices to farm individually owned lots of land; forsaking customs of communally held properties; sacrificing spiritual ceremonies, dress, and habits for Christian forms of worship and attire, abandoning systems of reciprocity for capitalist exchange, and replacing one's own language with that of the dominant regional power. As mentioned earlier, Richard Henry Pratt best articulated this for Americans with his dictum to 
"kill the Indian and save the man." Pratt, however, was not the progenitor of this doctrine, but rather the child of it. The distinction of the famous Carlisle School is that it was the first federally funded Native boarding school. It launched a perhaps more systematic or official effort on the part of the US government to turn Natives into US citizens, though of a lesser sort, by eradicating their cultures and then leaving them to fend for themselves with their new industrial and agricultural educations on the diminished dust-choked tracts of land that had been left them. Implicit in the Boarding School arrangement was not only the erasure of Native lifeways, but the idea that Native leaders were unlikely to rebel if their own children were in the custody of EuroAmerican educators.

If the federally funded boarding school was Pratt's innovation, the philosophy behind it was nothing new. Eleazor Wheelock, an earlier entrepreneur in the Indian education racket, wrote in December of 1766, "It looks to me more and more as though God designs to make a short work with the Natives, that they will soon be Christianized or destroyed, and that the progress of this will be doubly swift to what it has ever been." ${ }^{.39}$ In another letter to the Earl of Dartmouth, this friend of the Indian further elaborated,

The nations will not make war with us while their Children, and especially the children of their Chiefs are with us-- they can't resist the Evidence we hereby give them to the Sincerity of our intentions towards them ... Many of them begin to be convinced of the necessity of Agriculture, in order to their Subsistence when their resources from the Wilderness fail, (as they certainly must do, when, and so fast, as the English extend their settlements among them). ${ }^{40}$

This connection between Native conversions and land appropriation was inherent from the very start of English colonization. In the first batch of letters to come out of the new settlement in Plymouth, often referred to as Mourt's Relation, one commentator wrote "now it seemeth unto me that we ought also to endeavor and use the meanes to convert them, and the meanes cannot be used unlesse we goe to them or they come to us: to us they cannot come, our land is full to them we may goe; their land is emptie. ${ }^{, 41}$ The French had also intuited the value of such an 
arrangement. Marc Lescarbots, an early French adventurer amongst the Micmac near Port Royal wrote to the Queen in 1610, "I believe that robust and hardy men could live among these people, and do great work for the advancement of the Christian religion. But as to the Souriquois and Etechemins, who are nomadic and divided, they must be made sedentary by the cultivation of the land, thus obliging them to remain in one place." 42

Thus, the drive towards education, beyond its evangelical concerns, becomes clear, and if the overall enthusiasm with which the colonists believed Natives would respond to their religion and their books was greatly exaggerated, it didn't prevent them from continuing relentlessly in the effort. What was perceived by the colonists as a fair exchange-the precious knowledge of the Lord and savior Jesus Christ for parcels of open land that the Indians didn't seem to be using anyway — was never really anything more than a dual infraction in which both geography and culture were forcefully displaced by the propagation of an aggressive European narrative. Just as the Europeans imagined the lands of North America to be "emptie," they posited that Natives had no real culture of which to speak. In both cases the settlers were satisfied to perceive themselves as filling a vacuum, and such an ideology was inscribed within nearly every account of their adventures in a world that they endeavored to make new.

Homi Bhabha, in The Location of Culture, notes that "there is a scene in the cultural writings of English colonialism which repeats so insistently after the nineteenth century-and through that repetition, so triumphantly inaugurates a literature of empire- that I am bound to repeat it once more. It is the scenario ... of the sudden, fortuitous discovery of the English book." Such a discovery is thought to engender a sense of "wonder" in the newly colonized, the "word of God, truth, art [that] creates the conditions for a beginning, a practice of history and narrative ... that [serves to] sustain a tradition of English 'cultural' authority." ${ }^{\not 3}$ In Bhabha's estimation, the moment of contact is a "traumatic scenario," not simply for those who are being colonized, but for the colonist as well. The anxieties of difference engendered by this event 
signal an effort at containment, an attempt to master the particulars of the encounter in an a priori fashion, resulting in the inscribed repetitions of the encounter that we think of as literature or history. But such a representation can "neither be 'original' - by virtue of the act of repetition that constructs it -nor 'identical' - by virtue of the difference that defines it." ${ }^{, 44}$ Particularly in attempts to represent the other, Bhabha finds a constant cross-hatching of slippages in which the signified (colonized other) utterly fails to correspond with the signifier (colonial representation) imposed upon it. In a sense, the cultural encounter leads to differance, or the split subjects of colonization, with both sides experiencing a sort of psychic dislocation, an unstable hybridity, as a result. The colonial scene itself becomes the "innovation of historicity, mastery, mimesis or as the 'other scene' of . . . displacement, fantasy, psychic defense, and an 'open' textuality." Bhabha equates cultural contact with the contact of oral and literate epistemes, paying special attention to the instability of representation within this encounter. It is race, in this equation, that is the unstable signifier, the pharmakon, that operates both within and without, a poison and a remedy. But writing remains the medium through which these processes occur.

Apprehending the unstable nature of hybrid identity is of crucial importance to any effort at negotiating the effects of colonization. It helps to rupture the illusionary binary that Roy Harvey Pearce identified as "savagism and civilization," or a pattern of thinking which labors to "consider the Indian as part of American prehistory," a race consigned to infancy, at once noble and ignoble depending on its whims, but incapable of the sustained reason of the more mature civilization of the European. ${ }^{46}$ As long as such identity constructs are viewed as fixed, or static, the paradigm of assimilation or extinction might be justified. By bringing to our attention the manner in which these constructions unravel themselves, however, we are forced to confront the traumatic ruptures in the historical processes. The book, or the record of the encounter, is itself a marker of hybridity in which the unanticipated anxiety of the encounter is repeatedly rearticulated in attempts at mastery. We might conclude from this that the book, which records 
the moment of contact, is meant to contain the unruly psychological responses to that moment and is presented as the very artifact by which the encounter is mastered. Within these containments, however, are moments of excess and slippage, which make available, in some manner, the materials of what I call unwitnessing.

Bhabha acknowledges "the penetrative power-both psychic and social-of the technology of the printed word." He cites accounts of nineteenth-century missionaries in Middle India who viewed the gospel as such a miraculous entity to the Natives that it was, in effect, "doing its own work." ${ }^{, 47} \mathrm{He}$ does not question the validity of the "wonder" response so much as notice how Christianity itself, as located in the book, becomes a site of hybridity where Native "mimicry" marks moments of civil disobedience. Creek critic Craig Womack, however, seems to take issue with such "postcolonial approaches" that, whatever their value, place so much emphasis "on how the settler culture views the other." He takes a more localized approach, asking "how do Indians view Indians," ${ }^{, 48}$ and he seeks to break down the general perception of a binary opposition that stands between the terms "oral" and "literate," as though the former were an "authentic" Native legacy and the later somehow "contaminated. ${ }^{, 49}$ He writes, "the idea, then, of books as a valid means of passing on vital cultural information is an ancient one, consistent with the oral tradition itself in the case of the Mayans. This example opens up a space for Native intellectual discussion, in the form of textual production, in contact, not competition, with the oral tradition." $" 50$ By considering the means by which Native cultures preserve their own traditions and frame their historical experiences and encounters, Womack is, in a sense, asking that we bypass the colonial archive whenever possible and concentrate on the processes of continuance rather than the processes of cultural infiltration or an express hybridity.

This chapter will begin to examine scenes of contact in American colonization, which is also, I posit, the scene of writing, in hopes of widening our perception of the relationship that Native Americans cultivated with the written word in the immediate wake of colonization. The 
assimilation of Natives into, not just Christianity, but alphabetic literacy lay at the very forefront of European evangelistic endeavors and had lasting effects on the laws, institutions, and human communities that constitute our present reality. Hardly recognized, however, is the idea that Native correspondents left any kind of record of these ultimately violent interactions or that indigenous peoples had any sort of substantial literatures of their own when all this got under way. I contend that the Native encounter with books and letters was neither as mystifyingly persuasive of a dominant European civilization as colonists (and post-colonialists) claimed, nor quite as seamless a coming together as Womack posits. For good or ill, I will argue at the end of this chapter that the appropriation of books and letters, or more specifically, alphabetic literacy, is transformative of one's cognitive engagement with the world. It is the scene of appropriation, anxiety, and most of all self-preservation in the face of stunning devastation. Nevertheless, it should become apparent that Native communities were able to recognize the uses of western writing and regarded it primarily as a tool to negotiate with Europeans, rather than as a magic token of colonial authority. In most cases encounters with European alphabetic literacy became, and were recognized as, negotiations for cultural survival. Writing, of course, might also open up a space for the private self to become manifest, but, such an entity was equally in negotiation with the cultural forces in operation around it in a struggle for survival. In short, Native Americans, in most instances, appropriated the alphabetic literacy of Europeans in a deliberate attempt to preserve the integrity of their cultural structures, not to replace them. As alphabetic literacy enters into Native space $I$ feel it is, in fact, more key than pharmakon. It is a tool, however difficult to master, through the use of which Native communities might proactively engage with the colonizing presence. What is at issue in this act of preservation is not a static authenticity, but rather a fluid continuance, the ability to pass along traditions, and trace them back through one's own cultural frame of mind and historical productions.

This is not always easy to see, however, and the archive of the colonist is produced, as 
Bhabha notes, to suggest just the opposite. Nevertheless, in moments of slippage, or excess, we can see how indigenous views of the encounter, and even indigenous writing, are glimpsed and then elided within the archive itself. In such moments we gain access to the hidden transcripts of colonization and the act of containment taking place in the process. As Jace Weaver notes,

Native survival in the face of internal colonialism and the revitalization of Native traditions attests to the truth of Said's repeated theme that there is always something beyond the reach of dominating systems, no matter how totally they saturate society, and that it is this part of the oppressed that the oppressor cannot touch that makes change possible. $^{51}$

Natives are not only responding to the tool of writing throughout each successive wave of colonization, they are engaging with it, bringing their own practices in relation with both its political and cultural potentialities. In this chapter I examine how the archive makes available such an awareness. It is precisely at the moment that the colonizer attempts to unwitness Native culture, that Native culture, Native writing, Native civilization appears on the periphery of colonial vision.

\section{First Glimpses: Witnessing and Unwitnessing the Materials of Civilization in New Spain}

The first Spanish explorers to reach this continent had little to say about Indian literature, Indian culture, Indian books and writing. As has been suggested, these values were considered to be more or less nonexistent amongst Natives, and if they did become evident, they were quickly subject to a kind of historical as well as corporeal revision. In his classic account of The Conquest of New Spain Bernal Diaz Del Castillo, a foot soldier in Cortes' army, writes of his expeditions first awareness that Aztecan culture was more sophisticated than they had ever imagined. He tells how, upon first reaching the mainland,

they led us to some very large buildings of fine masonry which were, the prayer-houses of their idols, the walls of which were painted with the great serpents and evil-looking gods. In the middle was something like an altar, covered with clotted blood, and on the other side of the idols were symbols like crosses, and all were colored. We stood astonished, never having heard of such things before. ${ }^{52}$ 
This refrain, of things never before heard of, would be repeated as he and Cortes' men first arrived at the capital city of Tenochtitlan in 1521 and viewed "these great towns and cues and buildings rising from the water, all made of stone . . like an enchanted vision from the tale of Amadis. Indeed some of our soldiers asked whether it was not all a dream .. I do not know how to describe this first glimpse of things never heard of, seen or dreamed before. ${ }^{.53}$ Such first glimpses of evil runes, pagan crosses, the wondrous materials of things seen and not seen, were extremely telling in the sense that the "wonder" reaction is reversed. It is the colonist who is startled and led to question the material reality of things, their dreamlike nature. But the colonist is also quick to begin the processes of containment, by which such first reactions will be subdued and reordered.

The very first mention of Native inscription in the European historical archive appears on the periphery of Columbus' commentary in his first journal, a sort of sideways glance that never comes fully into focus. On his fifth day of having made landfall in the West Indies Columbus walked the island he (re)named "Fernandina," admiring the tall trees that reminded him of Andalusia in May and the people whom he found to be "naked" and willing to offer "whatever they possessed" to the visitors. It is here that his crew encounters a "man who wore in his nose a piece of gold about half the size of a castellano on which they saw letters." ${ }^{54}$ It is perhaps all too fitting that letters and gold are bonded to the same material object in this first sighting. The historian Howard Zinn writes how, in the first two weeks of Columbus' journal entries upon reaching the West Indies "there is one word that recurs seventy-five times: Gold." Columbus is angered by the fact that his men, despite the apparent willingness of the Natives to give away their every possession in exchange for trifles, "had not bargained for it and given as much as they asked." ${ }^{, 56} \mathrm{He}$ immediately assumes that the "coin" with its inscription must come from some other, more civilized country and that he might be able to determine something about his proximity to the Asian mainland through this specimen. But, as his men cryptically respond 
"they did not dare to bargain for it." ${ }^{, 57}$ Perhaps this is not only the first sign of writing in the New World, but is also an early indicator that not all is transpiring as smoothly as Columbus' writings generally suggest. What could not be "dared" amongst so "tractable" a people? Certainly his predilection toward welcoming Natives on his boat and then not allowing them to leave again might have provoked tensions of which Columbus had nothing to say at the moment.

Columbus, although he offers no account of presenting the Natives with actual books, made clear that in every land he encountered, "I tell them as much as I can about our blessed faith and the creed of Holy Mother Church." 58 Columbus, of course, wanted nothing less than to fund through his explorations a holy war, whereby "Jerusalem and Mount Sion shall be rebuilt by Christian hands. ${ }^{, 59}$ But the unanticipated obstacle of an entire continent stood between him and this highest of sixteenth-century Christian aspirations, and so his evangelical zeal was fully spent on the Natives of America instead. Tzvetan Todorov notices the paradoxical nature of Christian evangelism in his book The Conquest of America, stating that "Christianity is, fundamentally, universalist and egalitarian. 'God' is not a proper noun: this word can be translated into any language, for it designates not $a$ god . . but the god. This religion seeks to be universal and is thereby intolerant. ${ }^{960}$ For example, when Cortes introduces to the Aztecs his cross and an image of the Virgin during his initial visit to the capital city of Tenochtitlan in 1521, Motecuhzoma attempts to place these symbols of Christianity alongside his own idols of worship. Cortes, however, recoils at this gesture of accommodation and will ultimately seek to replace every material aspect of Aztec religion, including their books, or codices, with a Christian counterpart. ${ }^{61}$ While Motecuhzoma is able to accommodate the symbolic coexistence of two spiritual narratives, Cortes views this as the ultimate degradation of his principles, responding "these idols of yours are not gods but evil things, the proper name for which is devils." He suggests instead that they place a cross over the entire temple and create a separate room for the "image of Our Lady . . . and then you will see by the fear that your idols have of her, how 
grievously they have deceived you. ${ }^{.92}$

The Nahua, in their own records of the fall of Tenochtitlan (today's Mexico City), offer a different telling. In their version (recorded from oral testimony by a handful of Spanish monks and their Indian pupils in order to preserve aspects of Nahuatl history for the colonial record), we learn how the Spaniards responded to Motecuhzoma's hospitality by rashly entering the temples and immediately stripping "the feathers from the gold shields and ensigns. They gathered all the gold into a great mound and set fire to everything else, regardless of its value. Then they melted down the gold into ingots. ${ }^{\circ 63}$ In a sense, the Aztec idols are not destroyed but reduced, transformed into Spanish currency. In the Nahuatl version of the fall, Cortes and his men, after being formally greeted, are invited to witness the fiesta ceremonies. We are told that it is precisely at the point "when the dance was loveliest and when song was linked to song [that] the Spaniards were seized with an urge to kill the celebrants. ${ }^{964}$ One can sense, in this orally remembered version of events, how the tale itself focuses on the disruption of narrative unity, the brutal assault commencing at just that moment when "song was linked to song." Ultimately Motecuhzoma himself represents an affront to Spanish hegemony, and just as the Aztec symbols must be replaced by Christian symbols, so must the Aztec ruling families be violently replaced by Cortes and his descendants. The end result is that, the exchange rate is dreadfully high. For Natives to become a witness to the Christian God, they must, in fact, undergo a violent unwitnessing in which their songs, their books, their relics, their corporeal bodies, and presumably even their souls are brought under containment by the superimposition of Christian forms. The great Aztec libraries are burned to the ground by the Spaniards, an event that Cherokee writer Thomas King characterizes as “devastating as Julius Caesar's destruction of the library at Alexandria.".65

If Columbus, Diaz, and Cortes give us a sense of how Europeans first responded to Native inscription, Fray Toribio Motolinia offers a glimpse into the Native's initial encounter 
with alphabetic literacy. Motolinia was among the first group of twelve Franciscans to travel to New Spain in 1524, and in his book The Indians of New Spain he reports on the degradations of the slave trade that had quickly blossomed in the newly colonized territory under Cortes. The Indian slaves were employed in every facet of labor, but most specifically in the massive dismantling and reconstruction of Mexico City. Motolinia writes of the Spanish that,

so great was their haste, in some years, to make slaves that from all parts of Mexico they brought in great herds of them, like flocks of sheep, in order to brand them. They were not content with those among the Indians are called slaves (for, although according to cruel and barbarous law some may be slaves, in actual truth almost no one is), but hurried the Indians so to produce slaves as tribute - so many every eighty days - that having exhausted the supply of real slaves, they brought their children and their macehuales (who are of a low social class, like farmer vassals) and all whom they could get together, and brought them in, terrifying them into saying they were slaves. The fact that no careful investigation was made and that the branding was cheap produced so many marks on their faces, in addition to the royal brand, that they had their faces covered with letters, for they bore the marks of all who had bought and sold them. ${ }^{66}$

Columbus and Cortes did not come with bibles in hand to teach the Natives the word of God. The printing press itself was only some fifty years old at the time of Columbus' arrival in the West Indies, and bound and printed texts were not yet in wide circulation. The Spanish conquistadors relied more heavily on symbols, the cross itself, and images of the Virgin Mary, and these symbols were wielded as an expression of their power and dominance. But the Natives were indoctrinated into alphabetic literacy by having it burned into their very flesh, an inscription of their condition of servitude that could not be erased, even as ownership changed hands and new inscriptions were added. Motolinia referred to the enslavement of the Natives as the eighth of ten terrible plagues sent by God to chasten the land and "all who dwelt in it, both Natives and foreigners. ${ }^{.67}$ The first two plagues were smallpox and measles. The third was famine. The remaining seven were not biological calamities, but the manmade ones of slavery, taxation, avarice, and factionalism, the result of which was a trail of death so littered with Native corpses that "one could scarcely avoid walking over dead bodies or bones, and the flocks of birds and crows that came to feed upon the corpses were so numerous that they darkened the sun." 
marks of alphabetic literacy, seared on the flesh, must have appeared as a sign of that contagion, a palimpsestic reinscribing of identity transcendent of the mere scars on the surface.

The indigenous world that Europeans so violently attempted to displace was older and more sophisticated-in fact, more like to themselves - than they could ever acknowledge. Its milky beginnings were the stuff of narrative, song, and ceremonies rooted in the organizational features and geographical contours of lived lives. Beginnings were told, danced, chanted, engraved in the heart, but also woven into fabrics, carved on sticks, traced upon birch bark, rock, and deer hides. In some cases the world's creation had even been recorded in books. As the sacred text of the Mayans, the Popul Vuh, would have it, "the beginning of the Ancient Word [originates] here in this place called Quiche," which is in modern day Guatemala. ${ }^{69}$ And for them, too, the world was thought to have been spoken into being,

the fourfold siding, fourfold cornering, measuring, fourfold staking, halving the cord, stretching the cord in the sky, on the earth, the four sides, the four corners, as it is said, by the Maker, the Modeler, mother-father of life - of humankind, giver of breath, giver of heart, bearer, up bringer in the light that lasts of those born in the light, begotten in the light; worrier, knower of everything, whatever there is: sky-earth, lake-sea. ${ }^{70}$

For the Mayans, the earth is formed by far-seeing entities, Sovereign Plumed Serpent in colloquy with Hurricane, who "agreed with each other, they joined their words, their thoughts. Then it was clear, then they reached accord in the light, and then humanity was clear." ${ }^{71}$ What follows in the Popul Vuh are strange tales of birth, violence, wonder, devastation, the origin of traditions, how things came to be. In this it is like the sacred text of Christianity, as the forces of humanity set in motion by their creators attempt, to a certain degree, to reestablish or come back in contact with the perfect order that was the moment of inception, so things on earth might be as they are in 
heaven. The Popul Vuh seems to set in motion ring upon ring of events in which the deeds of Gods are somehow echoed by the deeds of "the midmost seers" "72 whose deeds are then echoed by the first humans awaiting the occasion of the first dawn, whose deeds will, in turn, be reenacted by their descendants. In a sense, the state of being human is coded as a state of being able to name one's creator and thereby engage in an act of creation oneself. Earlier forms of life are dismissed or transformed because, as the Maker, Modeller, Bearer, and Begetters agree, "it hasn't turned out that our names have been named." 73 A species of wooden creatures, or "manikins" thrive for a time but, as it is told, "there was nothing in their hearts and nothing in their minds, no memory of their mason and builder." ${ }^{74}$ These people are wiped out in a great flood, and though they take to the tall trees to escape it, they "were ground down, overthrown," and the destruction of their race makes way for present human life (although monkeys remain as a sign of this previous human work). ${ }^{75}$

It is a mistake to think of the Popul Vuh simply as a text, however, for it is meant to be enacted as much as read, so that the decrees and actions of the gods are rehearsed and held in the hearts of those who participate in the ceremony. As the scribes who compiled the alphabetic text point out, "it takes a long performance and account to complete the lighting of all the 'skyearth." ${ }^{76}$ Such a performance is not regarded as a nostalgic recollection of the world's creation, but a rekindling of the forces that bring light into being and allow it to so remain. As Dennis Tedlock notes in the introduction to his English translation, " if a divinatory reading or pondering was a way of recovering the depth of vision enjoyed by the first four humans, a long performance, in which readers may well have covered every major subject in the entire book, was a way of recovering the full cosmic sweep of that vision." 77

The Pre-Columbian texts of the Mayans and other Meso-American cultures did not consist of a system of phonetic characters organized into signifiers and designed to independently convey information to anyone who happened to be instructed in the deciphering of 
their values. Walter Mignolo observes how the word "word" was nonexistent in the preColumbian Nahuatl language. ${ }^{78}$ He notes that "in all Mayan languages there is no linguistic or semantic differentiation among the words for painting, drawing, and writing." "T9 "Tlacuiloliztli" was the Nahautl expression for both writing and painting. ${ }^{80}$ The figures in texts such as the Popul Vuh or the Chilam Balam ${ }^{81}$ do not dictate verbatim words, sentences, paragraphs, but rather convey a series of associations for those who have been ordained in the corresponding mysteries - they comprise a particular blueprint around which the orator must construct narrative presence.

While Mayan and Aztec culture relied upon hieroglyphic figures with some phonetic indicators to encode their narratives, the Peruvian system of quipu consisted of cotton strings and knots deciphered through tactile contact. Joanne Rappaport describes quipu as a mnemonic device "composed of colored and knotted strings used in Andean culture to recall various categories of information." 82 If hardly recognizable to us today as anything thought of as a book or writing, Mignolo records how sixteenth-century Spanish observers came to accept that "whatever could be done with books in matter of recording the past, of keeping track of the law, of ritual, and of business matters could be also done with quipus. ${ }^{, 83}$ (photos of quipu and Mayan Codex inserted here). ${ }^{84}$

It is perhaps difficult for anyone trained in alphabetic modes of literacy to conceive of the organic and generative possibilities of Mayan writings that were, in their proper context, thought to recreate the conditions of life. A 1978 study of the Codex Mendoza asserts that the script itself was designed to obey "certain strict and formal patterns decreed by custom and religion. In a society in which a parent's expression of joy over the birth of a baby were as rigidly prescribed as a church litany ... there could be no question of a scribe straying into representational art." ${ }^{\$ 85}$ Such an interpretation of Aztec culture, with its practitioners locked into unalterable patterns of ritual observance and behavior that pervaded every aspect of daily life 
helped modern interpreters explain what often seemed inexplicable: the blood rituals of Mesoamerican culture, the cutting out of beating human hearts, the flaying of skin and consuming of the flesh of enemies. In such a version Natives are stripped of human capacities, devoid of warmth and compassion, made to resemble, perhaps, worker bees. But as Don Antonio de Mendoza, the first Viceroy of New Spain and compiler of the Mendoza Codex, himself pointed out, the Natives took so long agreeing on the interpretation of various figures that it slowed his progress in completing the manuscript and his comments were therefore hastily compiled. ${ }^{86}$ What this suggests is not that Native priests and writers were too ignorant to agree upon the particulars of their own screed, but that, perhaps, their rituals and daily lives were more open to interpretation and variation than commentators perceived. One might also read an act of resistance in the disagreement of the priests as they decided amongst themselves what elements of their tradition could be related to the Spaniards. Nevertheless, the figures of the codex emerge as the exact opposite of a liturgy, for there appears not one strict verbatim reading, but the possibility of many readings. As one Nahuatl scholar claims "I sing the pictures of the book/ And see them spread out;/ I am an elegant bird/ for I make the codices speak/ within the house of pictures. ${ }^{\prime 87}$ The codices even allowed for reading across language barriers, as they were accessible to the many different speaking groups of Mexico and Central America. ${ }^{88}$ One might imagine that the daily lives of Mexicans were also less rigid, less violent, less subservient to ritualistic definition than many have presumed, and perhaps, it is our modern interpretations of such lives that are locked in liturgical formulas.

While the possibility of varied and open interpretations of Aztec history and beliefs may have proved an annoyance to a distracted civil magistrate like Mendoza, it does suggest the flexibility and richness of Mesoamerican writing. The figures, or logographs that occupied the codex were to form a path that a priest, trained in the mysteries, would follow in his reenactment of the ceremony. Those who knew the paths were held in highest regard. The book makers, or 
history keepers, were known as "the ones who continually carry us, they guide us, they cause the path to speak to us. They are the ones who put us in order."89 The production of such writings was more aligned with the cognitive processes of an oral culture than one steeped in western writing. Elizabeth Hill Boone suggests that "images in Aztec pictorial histories were fashioned as signal references to an oral story ... Varied events in the histories are reduced to their epitome, their most essential and distilled visual form." ${ }^{.90}$ But if pre-Columbian systems differed from western European notions of writing, they nevertheless comprised reflective and somewhat fluid means of recording and imparting culture. Mignolo notes "both Spanish and Amer-Indians recorded their past as well as their wisdom in graphic and oral forms, [and] both equally treasured their records." $" 91$

\section{Black Robes and Birch Bark: Jesuits Encountering Native Writing in New France}

If writing was, in fact, a viable technology, at least for some of America's indigenous peoples, it is most often represented as an alternative to existing lifeways, a technological threshold to be crossed that led one into the abode of Christianity and western civilization. For obvious reasons, writing had become perfectly analogous with the religious doctrines of the colonist, regardless of the other uses that were made of it. And as Roger Williams' definition of Manittoo wussuckwheke suggests, there was little or no separation between the notions of "writing" and "God's Booke." Religion was the form writing took, and books were talismans of spiritual power that Europeans wielded against Natives in their attempt to impress one set of cultural norms upon another. Axtell, in his book After Columbus, posits that "the ability to read and write was awe-inspiring to the Indians largely because it duplicated a spiritual feat that only the greatest shamans could perform, namely, that of reading the mind. ${ }^{.92}$ In a sense European explorers tried to position themselves as the more powerful shamans, introducing their technologies in a manner designed to trump the spiritual leaders of Native communities in scenes 
reminiscent of Moses taking on the magicians of the court of Ramses II. The desired outcome of these confrontations was to demonstrate how the European God was indeed more powerful, or, in effect, the one true God. As we will see, however, this wasn't always successful. And it is helpful to keep in mind that the association between books and magical powers was a European one as well. The word "grammar" itself was derived from the French "gramayre" which means occult learning or magic. It should be recalled that Europeans were not above a belief in witches and spirits; they felt the great deceiver himself was running loose in the woods beyond their settlements in the new world, and often it was the material object of power, "God's Booke," that they held up against the forces they sensed allied against them. Writing stood at the center of the metaphysical conflict in the new world as both sword and shield.

Brooks refers to alphabetic writing as "one of the most powerful 'beings' brought over from Europe, ${ }^{, 93}$ a neutral force that could be used for good or ill, like stories themselves. Axtell provides a number of examples in which writing is perceived to have talismanic power during early cultural encounters, particularly amongst the Jesuit priests who established missions in New France. One telling incident, taken from the Jesuit Relations, occurs during a smallpox epidemic amongst the Hurons in the winter of 1640. As Axtell relates, "fear and despair swept through the cabins" and "stubborn traditionalists reported dreams in which the Jesuits unfolded 'certain books' on the shore of Lake Huron, 'whence issued sparks of fire which spread everywhere, and no doubt caused this pestilential disease. " 944 In this passage it can be seen that writing is equated with both disease and fire. It is something that spreads and consumes, and once let loose it cannot be contained. It leaves a path of death and destruction in its wake.

Many early tales of a North American Native engagement with writing take a certain pleasure in portraying how the "simple" Natives were duped by their inexperience with the form. Of course such early anecdotes had the desired effect of infantalizing a Native response to writing. ${ }^{95}$ A closer look at the Relations of the French Jesuits complicates this view, however, 
rendering uncertain the power of writing to amaze. In one account, Paul Le Jeune offers a typical assessment of the Native response to his book. He writes,

when I told them we had a book which contained the words and teachings of God, they were very anxious to know how we could have gotten this book,-some of them believing that it had been let down from the Sky at the end of a rope, and that we had found it thus suspended in the air. This simplicity made me laugh. ${ }^{96}$

The Jesuit never pauses for a moment to think that maybe the individuals of whom he speaks are actually having a good laugh at his own simplicity. But one can sense his frustration in the following paragraph in which he bemoans, "if these barbarians would only display some curiosity to know things . . . but they are as cold as marble, and are so imbued with this indifference that you would say they are surprised at nothing." ${ }^{97}$ In effect, then, the author, in a moment of excess representation, contradicts himself by betraying his suspicion that his Native audience is not quite so dumbstruck as he originally implies. They remain impassive to his demonstrations and are, more than likely, ridiculing his presumed connection with divine inscription when they invoke the image of a book being lowered down from the heavens on a rope. Only the Jesuit himself fails to get the joke, but he nevertheless concedes that his discourse has failed to illicit the proper response. In a letter to his superior in France, dated 1637, Le Jeune offers a surprising metaphor as he contrasts the comfort and encouragement he has received from his homeland with the entrenched resistance he faces in New France. He writes "I learned through a great many letters that people of high rank and most signal virtue were contending for us in heaven and upon earth; and it was made evident to me, on a bit of bark or paper, that the demons were let loose and were powerfully opposing our plans." ${ }^{, 98}$ The passage implies that Le Jeune is conscious of two modes of writing, a European writing of letters, as well as an indigenous writing on birch bark, one writing aligned with heavenly forces, one aligned with the forces of Satan, each working in seeming opposition to the other.

In another account which recognizes two modes of writing and consciousness, Le Jeune 
tells how he and a Huron man discuss their peoples' differing versions of an ancient flood. As Le Jeune explains, "they had indeed preserved the account of this deluge, but through a long succession of years they had enveloped this truth in a thousand fables." The French on the other hand "could not be mistaken about this event, having the same belief as our ancestors, since we see their books." Le Jeune argues for the contiguous infallibility of his version by stating "God sent men whom we call prophets, because they learn the truths of God and teach them to men." 99 It was the lack of writing then, and particularly God's writing, that had led the Huron to their misconceptions. As the races of man were scattered in the wake of the flood, some were able to retain the original stories through the dissemination of texts, while others, like the Natives of Canada, only maintained versions of the tale that been corrupted over time through the repetition of oral narratives.

Most remarkable about this encounter, however, is the fact that the Huron man, after listening politely to Le Jeune's entire conversation without ever once offering objection or contradiction, is said to pick up a "pencil" and begin marking on the ground an entire recreation of the history the Jesuit has just unfolded.

"Here is he who made all," said he [the Huron]; "He [God] begins in this place to create Angels and the world; there he created the first man and first Woman; see how the race of men, increasing, divides and offends God; Here is the deluge, here are the prophets," - in short he came up to our own time; then rising, he began to laugh; "I am not surprised at our being tired," said he, "for we have made a long journey." 100

Although the intended point of the passage may be that, without the knowledge of writing Native belief has lapsed into error, through a certain excess of representation Le Jeune opens to us the manner in which the Huron is also writing history. The specific figures of his interpretive sketch remain hidden from us, their inscription in the dirt suggesting their impermanence. Perhaps for Le Jeune they remain unreadable, an inscription founded in error, and in a sense he has already wiped them out for us as effectively as if he had swiped his boot across the Huron's drawings. Nevertheless the scene suggests that the Huron man, at least, has perceived the agenda in back of 
Le Jeune's discourse. Without openly contradicting the Jesuit's assertions, he models the way in which his own people keep traditions intact, positing narrative itself as a kind of journey, a path that one inhabits, using figures like stepping stones to retrace the important stops along the way. ${ }^{101}$

It is doubtful whether Le Jeune is receptive to this example or if he even realizes it is being offered. One senses his frustration with the encounter, however, as he resolves, "it is not thus that one should begin to instruct the nonbeliever; for, since all these things are historical, the mind which has no knowledge of him who has revealed to us these truths remains free to believe or not believe." $" 102$ For Le Jeune such freedom is intolerable. The issue remains fixed on a simple binary of truth and error. His system of thought is virtually incapable of accommodating that which does not conform to his own idea of truth, and he is engaged in an endless task of, if not quite erasing such errors, then containing them, using his written accounts to force experience into some form of compliance with his desires. An undesired effect, however, is that the Huron may be regarded as more a creature of genius than the Jesuit, as he seems able to hold two opposing systems of thought in his mind at the same time.

The country of the various nations of Micmac, Abenaki, Passamaquoddy, Iroquois, Montagnais, Ottawa, and Huron, was said to be called Canada, an Iroquoian word that the explorer Jacques Cartier understood to mean "this is our village." 103 Prior to the arrival of the French on Canadian shores, the indigenous peoples who occupied these lands lived in small wellspaced villages, occasionally fortified by wooden palisades erected in a circle around their dwellings, other times more openly spaced along river valleys with crops of beans, squash, and corn planted in the fields beyond. Many village populations would break into smaller bands, moving deep into the woodlands to hunt and forage through the winter. Most would move again toward water during the seasons when certain fish migrations were anticipated. Fields and woodlands were regularly cleared by fire to make room for planting and to accommodate bunting 
practices. Different villages, as well as different nations, would trade with one another, intermarry, and occasionally fight wars. Historian Richard White, whose book, The Middle Ground, perhaps best exemplifies the relationship between French and Indian in this period of contact, observes that "socially and politically this was a village world," and these villages were held together, as always, by ties of kinship, tradition, and shared narratives that often transcended common designations of Indian nationhood. ${ }^{104}$ (Insert 1610-1791 map of New France).

In the journal of his 1615 voyage, Samuel de Champlain writes of his visit to the "more important" villages of the Huron in what is now Southern Ontario and provides a brief description of their layout. He notes how each town was enclosed within large palisades of wood, and in one case even a triple palisade "thirty-five feet high for its defense and protection."105 Champlain relates that he is welcomed warmly in each of the villages, as such is their custom, and is taken to see the outlying land to survey the corn and other produce. He describes the principal town of Cahiague as being very extensively "cleared up" and containing within its walls some "two hundred large cabins." And he observes how the villagers plant

a great quantity of Indian corn, which grows there very finely. They plant likewise squashes and sunflowers, from the seed of which they make an oil with which they anoint the head. The region is extensively traversed with brooks, discharging into the lake. There are very many good vines and plums, which are excellent, raspberries, strawberries, little wild apples, nuts, and a kind of fruit of the form and color of small lemon. ${ }^{106}$

The description offers some idea of the Native village shortly before the full intrusion of white civilization, invoking a pastoral harmony and civic order that is largely missing from later descriptions, as both the towns and the representations themselves fall prey to colonial ills.

If North American Native communities were not organized in anything so closely resembling European notions of high civilization as the Aztec cultural centers, still they were easily recognizable as towns, most of which were as large and structured as any European village. Champlain is mostly interested in the defensibility and agricultural potential of the regions he visits and offers little insight into the day-to-day dynamic of Native social routines. 
But the villages he describes with their thriving fields and fruited plains run counter to common contemporary perceptions of social organization amongst Native Americans in the northern hemisphere. ${ }^{107}$ In a further description Champlain remarks how he "was struck with wonder" at the gravesites he encounters on his journey. He describes sepulchers made of wood, upon which are carved "the figure of the male or female interred. If it is a man, they add a shield, a sword attached to a handle after their manner, a mace, and bows and arrows. If it is a chief, there is a plume on his head, and some other matachia or embellishment ... If a women or a girl; a boiler, an earthen vessel, a wooden spoon, and an oar."108 Champlain does not actually condescend to read these engravings. It goes without saying that for a people presumed to have no culture there can be no signification other than what is rudely obvious. Lisa Brooks notes, however, how the symbol of the common pot, or "the boiler" as Champlain terms it, had the significance for the Abenakis of "that which feeds and nourishes" the entire family, the village, the wigwam, in effect, the whole community. ${ }^{109}$ It is a metaphor not only for the domestic realm and role of mother, but for the land itself which also sustains and nourishes. In some instances, particularly amongst the Micmac, copper kettles acquired from the French were flattened out and used to line the graves so that they might contain and nourish the spirit on its journey to the afterlife. ${ }^{10}$ Certainly Champlain does not regard these carvings-or the other markings on the graves "painted yellow and red, with various ornaments as neatly done as the carving"" — as writing. But it is interesting that this passage marks a quite rare instance in which Champlain uses the word "wonder" to describe his response to what he sees in this world that is so very new to him.

Writing was not an essentially foreign concept to the Native peoples of the Northeast. It was simply a technology with different cultural applications. Champlain notes that, prior to visiting the villages mentioned above, he discussed his travel plans with a local sagamore who promptly took up charcoal and began to draw out the lay of the land for the Frenchman on a strip of birch bark. ${ }^{112}$ Grave markings, mapmaking, winter counts, and other forms of hieroglyphic 
painting may strike some as unpersuasive examples of written communication until one begins to realize the spontaneous applicability with which the woodland Natives resorted to them in their daily communications. Le Jeune writes in 1637 of the head counts of Huron prisoners the Iroquois left on the wooden shaft of a dismantled cross, to inform their enemies of what had transpired. He recounts how "we studied it carefully" and notes that "they had also fastened this picture to a branchless tree, so that passers-by could readily see it; the different lines indicated the quality and age of the prisoners, as some Savages who were there explained to us."113

This happens to be one of only a few instances in which a Jesuit not only comments upon Native writing, but actually chooses to train his vision upon it and begins to describe its characters in an attempt to translate the intelligence encoded therein. Perhaps this is because the French are engaged in battle with the Iroquois at this moment and the message might be a matter of life and death. Whatever the motivation, Le Jeune describes the message in some detail, noting that two pictured heads that were larger than the others represented "two captains they had in their clutches" and that two others were of "young lads being taken to the Seminary." He observes that they "had made stripes in the form of plumes on the heads of the bravest ones" and that "all these heads were scrawled in red, except one, which was painted in black,-a sign that this last one had been killed, and that all the others were victims destined, as it were, for the fire." 114 The communication must, in fact, be quite long and contain a variety of nuances, including the identification of specific individuals. That it needs to be translated to Le Jeune at all, and the fact that it was read so carefully by his Huron companions, signifies that what is being observed is not simply a mnemonic device, but a detailed communication of information not previously known to those who read it. Nevertheless, Le Jeune cannot refrain from classifying this intelligence once he is done with it, as "grotesque figures (for the Savages are not acquainted with the art of painting)." $" 115$ The writing itself, regardless of its content, is grotesque and has the power to appall him. Brooks calls these messages "awikhigans" usually left on trees 
where passersby would see them. Awikhigans might be used to detail the results of a conflict, the success or failure of a hunt, or any other number of eventualities. Brooks sees Native appropriations of alphabetic writing as an extension of such ancient traditional practices. ${ }^{116}$ For Le Jeune, however, the fact that this communication was carved out upon a desecrated cross could only have added to his sense of overall revulsion.

Le Jeune is ever in danger of constructing a narrative that, while assuming its own cultural superiority, is collapsing around the edges into the borderlands of acculturation. At times it is all he can do to shore up his own center of subjectivity, and the immediate nature of his recollections, written under extreme conditions, often without time for thoughtful editing or revision before being sent off to France, betray moments of representational excess that slip through the master narrative he is in hopes of forwarding. Cornelius Jaenen notes,

it is true that the early observers of Native reactions to contact with Frenchmen had commercial, religious, and military interests in the Amerindians and that they studied aboriginal society largely in order to discover vulnerable points that could be exploited to the achievement of their objectives. Nevertheless, in their records, which were sometimes quite comprehensive, they unwittingly related incidents and conversations which enabled one to reconstruct Amerindian reactions motivated by beliefs and objectives which the chroniclers frequently ignored. ${ }^{117}$

In other words, not only do we glean something of western subjectivity from these narratives, and the extent to which these chroniclers nervously attempted to buttress the architecture of their own predetermined conclusions concerning the Natives, but we also are able to locate within their accounts something of the Native resistance to such concretized worldviews.

The Jesuits first arrived in New France in 1611, following a decree given by King Henry IV who "more solicitous for religion than for commerce, resolved, in the year 1608, to introduce Christian rites into this part of the New World." 118 Early efforts at establishing missions all failed, however, despite Father Baird's 1611 letter asserting that certain missionaries had "baptized about one hundred savages." ${ }^{119}$ Baird is surprised to learn that, of these new Christians, hardly a one knew his own baptismal name, and mostly all kept more than one wife. ${ }^{120}$ This was 
all proof enough to the early Jesuits that instruction must proceed baptism, and both Baird and Enemond Masse agree that learning the language of the Mi'kmacs would be the key to their success. They go so far as to propose the composition of a "Canadian catechism,", but for various reasons their efforts are thwarted and these early missionary efforts are broken up by internal opposition and conflicts with the English. A permanent missionary effort is not established until Paul Le Jeune arrives in New France in 1632 and is placed at the head of the Jesuit missionary efforts there.

Francis Parkman, whose nineteenth-century historical accounts of the Jesuits in New France have probably done more to characterize this mission than any other, noted "these were no stern exiles, seeking on barbarous shores an asylum for a persecuted faith. Rank, wealth, power, and royalty itself smiled on their enterprise, and bade them Godspeed. Yet withal, a fervor more intense, a self-abnegation more complete, a self-devotion more constant and enduring will scarcely find its record on the page of human history." ${ }^{\text {"22 }}$ Parkman is without doubt a studious observer of the period, but one senses how "the page of human history" he is, himself, in the process of constructing, is biased toward the colonizer's worldview. Parkman is in large part responsible for the notion that "Spanish civilization crushed the Indian; English civilization scorned and neglected him; French civilization embraced and cherished him."123 This characterization assumes a tolerance and gentility on the part of the Jesuits that was probably more situational than philosophical. In most ways, their overall attitude toward the Natives of New France differed little from the recorded views of Spanish friars and English missionaries. But the circumstances of early colonization in New France, which was more geared to maintaining trade relationships, called for a different approach. Richard White puts it well by noting that in Canada "missions did not attract Indians; Indians attracted missionaries who usually came to existing settlements.",124

In 1632 Le Jeune helps to establish an outpost at a place called Three Rivers, some thirty 
leagues north of Quebec and a place of trade for the local Natives. But he also becomes aware that it is not enough to place oneself in proximity to the Natives. He writes, "it seems to me that not much ought to be hoped for from the savages as long as they are wanderers; you will instruct them today, tomorrow hunger snatches your hearers away, forcing them to go and seek their food in the rivers and woods." ${ }^{\text {2125 }}$ Le Jeune comes to realize by the fall of 1633 that if he is to make any progress with the Natives, he must accompany them on their winter removals. So, as he colors it, he "crossed the great saint Lawrence river to a cabin of branches, and went every day to school in those of the savages. ${ }^{\text {"126 }}$ His decision yields a fascinating chapter in the Jesuits' history in which Le Jeune can be seen battling to maintain his own cultural moorings while spending six months in isolation with a family of Montagnais (more often referred to today as the Naskapi or Innu, as Montagnais is the name given to them by the French). Although he is a willing participant in this adventure his progress follows closely the patterns of acculturation noticed in many captivity narratives, with its litany of veiled accommodations and subsequent harsh retractions. $^{127}$

Interestingly, one of the members of this small band of Montagnais had undergone a captivity of his own, having been taken to France fourteen years earlier and educated there in the ways and manners of western civilization. His Naskapi name was Pastedechouan, and his baptized name was Pierre Antoine. Le Jeune, however, chooses to refer to him as "The Apostate" as "this wretched young man, who was so well instructed in France, has become an apostate, renegade, excommunicate, atheist, and servant to 'the Sorcerer' who is his brother." ${ }^{128}$ This socalled "Sorcerer" is simply the eldest brother in the family, who, having grown too old to hunt regularly, passes his afternoons in conversation with Le Jeune, tormenting the missionary with jibes, pranks, and with his frank insistence on maintaining a world view different from that of the Jesuit's. A third family member, Mestigoit, Le Jeune most often identifies simply as "the Host," and we are told that he is "a brave hunter and endowed with a good disposition." 229 It is the Host 
who proves, at least at first, to be the most open to Le Jeune's conversation. These three individuals form a kind of triumvirate in Le Jeune's 1634 narrative of the once converted, the unconvertible, and the potential convert.

As Le Jeune removes deeper into the Canadian interior, committed to sharing all the trials and deprivations of this existence while engaging in little of its communal warmth, his enmity with the so-called sorcerer quickly becomes evident. Describing all the unfamiliar conditions of woodland life, he concludes "this wretched man and the smoke [inside the wigwams] were the two greatest trials." ${ }^{\text {"130 }}$ While there is little reason to believe the elder brother/sorcerer shares Le Jeune's feelings of animosity, he emerges as a worthy rhetorical tactician and a slightly mischievous opponent to the Jesuit. Le Jeune characterizes their relationship as one of "open warfare," and yet he is at a loss to account for the good treatment he receives from "these Barbarians." He writes "I thought a hundred times that I should only emerge from this conflict through the gates of death. He treated me shamefully, it is true; but I am astonished that he did not act worse." ${ }^{\text {131 }}$ Le Jeune seems unable to reconcile the Sorcerer's resistance to his teachings with the overall humane treatment he encounters and therefore fails to perceive such an attitude as anything other than abject hostility.

Attempting to make rhetorical inroads within this small community, Le Jeune engages one and all in his Christian conversation. In his own mind it is the language barrier that remains his largest obstacle, despite the fact that the "apostate" is there to instruct and translate for him. But Le Jeune berates "the perfidy of the Apostate, who, contrary to his promise, and not withstanding the offers I made him, was never willing to teach me,- his disloyalty even going so far as to purposefully give me a word of one signification for another." ${ }^{132}$ The Sorcerer, too, would take advantage of Le Jeune's unfamiliarity with the language and "wishing to have sport at my expense, he sometimes made me write vulgar things in his language, assuring me there was nothing in them, then made me pronounce these shameful words, which I did not understand, in 
the presence of the Savages."133 The Sorcerer, far from being in awe of Le Jeune's all powerful books and letters, actually turns these very tools against him in a most comical manner. It is the women who finally take pity on Le Jeune and reveal the trick to him. Nevertheless, Le Jeune finds himself in a situation in which his words, even when carefully written, rehearsed, and translated, often fail to signify, sometimes as a result of the pranks played upon him, but more often because he is intruding upon a discourse community that engages the world differently and has no stake in his customs or metaphysical designs. One wonders that Le Jeune's own foundational beliefs are not irrevocably altered in this six-month period. One can sense how it becomes difficult to maintain the "true word" of the Christian God in this environment, and the book itself, his philosophical and emotional bedrock, begins to unhinge itself from the presumed ligatures of certainty. In a passage that one must read as provocatively blurred and evasive Le Jeune recounts how,

I sometimes thought I was going blind; my eyes burned like fire, they wept or distilled drops like an alembic; I no longer saw anything distinctly, like the good man who said, video hominess velut arbores ambulantes I repeated the psalms of my breviary the best I could, knowing them half by heart, and waited until the pain might relax a little to recite the lessons; and when I came to read them they seemed written in letters of fire, or of scarlet; I have often closed my book, seeing things so confusedly that it injured my sight. ${ }^{134}$

Certainly there is more than just smoke obstructing the eyes here. In a sense, the passage demonstrates how red ink superimposes itself upon the black ink of his breviary, burning like a fire that confuses meaning, even of those lines he knew "half by heart." A transformation is alluded to here, the letters themselves turning from black to red, from ink to flame, and beginning to work in new ways, form new conjunctions, that force him to turn away from his own book. His cryptic Latin insertion (I see men, like trees, walking around) seems to have no place in the passage unless one relates it to an origin myth of many northeastern woodland nations that speaks of the human race first springing from the trees of the forest. ${ }^{135}$

In the following years an attempt is made to keep a seminary "for the little Savages" up 
and running in Quebec, but it seems to have had little success. ${ }^{136}$ At the height of this effort in 1637, Le Jeune can relate the satisfaction of hearing these children sing the Apostle's creed in their own language. He recalls a moment of multi-lingual rapture as "the French, the Montangez, and the Hurons all sing together the articles of our belief; and although they used three languages, they harmonized so nicely that it was a great pleasure to hear them." ${ }^{\text {137 }}$ But disease, hunger, and warfare with the Iroquois disrupt every attempt at instructing the few scattered children who are made to attend, and Le Jeune's seminary has little real influence. Despite his experience with the Apostate, Le Jeune still considers it a profitable investment to send Native children to France for instruction. Of the three he sends over in 1636 only one survives, and from her he receives a letter stating "I am very glad to be in France." She continues, "I hope to have more learning and to cross over to Canada when our Mothers do, to render the debt of hospitality to the women of my nation, if God grants me the grace to do so."138 To my knowledge, this is the earliest suggestion of a Native American's own written words being directly transcribed in North America, and of course, it is perfectly contained within the rhetorical framework with which Le Jeune presents it to us. The Jesuit responds effusively to the letter from this "poor little child," enquiring of her,

who has drawn you from your lowly estate to place you in the affection of nobles? What have you rendered to God for your deliverance from slavery, and for your enrollment among the number of his children? Do you remember the resistance you made when your father placed you in my hands? You wished to escape by force, to run after your misery! You would not believe what your countrymen could not yet be convinced of, that we desired to secure for you the greatest of all blessings. ${ }^{139}$

Le Jeune's misreading of this early specimen of Native letter writing is as egregious as his refusal to read or acknowledge every other form of indigenous literature he encounters during his years in Canada. He perceives the child as having been delivered "from slavery" into the welcoming arms of plenty. As such, Le Jeune cannot perceive the essential plea contained within her correspondence, is utterly blind to the conditions that would engender it, which is nothing more than the pitiful request to be taken back home to her people. 
The optimism Le Jeune expresses in the above passage, largely founded upon his own willful suspension of belief, seems to unravel by the close of 1637 when he writes,

The contagion continued in that country ... the demons were making open war against us. These tribes believe that we poison and bewitch them, carrying this so far that some of them no longer use the kettles of the French. They say that we have infected the waters, and that the mists which issue thence kill them; that our houses are fatal to them; that we have with us a dead body, which serves us as black magic ... They go even farther,- they attack our Savior, Jesus Christ; for they publish that there is something, 1 know not what, in the little tabernacle of our Chapel, which causes them to die miserably. ${ }^{140}$

Le Jeune and the other Jesuits find themselves in the midst of a bitter backlash to their interference, their spiritual impositions and imperial ambitions, which in some ways resembles the beginnings of a revitalization movement. He is scornful of the notion that the French have "bewitched" or "poisoned" the Natives with their teachings, but clearly the indigenous communities have studied the relationship between material trade goods and disease and have come much closer than the French to understanding the cause and effect that lay behind it. Although Le Jeune does not stoop to scrutinize the signs or impart the details to us in any kind of visible way, he leaves us an interesting passage in which an unreadable text is laid out before our eyes. We are told that in July of 1637 , a certain Algonquin came to him with "letters" that spoke of a Captain who was coming down to Kebec to meet with "the Captain of the French." What are these letters Le Jeune speaks of, who composed them, and how are they deciphered? Le Jeune seems to indicate that the messenger who brought him the "letters" is also the one who communicates their content, for he is quoted as saying that this Captain is considered "a grand personage in our country; they say he is a great friend of the Sun, and that he gives letters which prevent one from dying."141

Le Jeune confides that he and the Governor of Quebec have a hearty laugh over this story. It does not occur to them that their compulsive habit of baptizing dying Natives, with a promise of eternal life sealed in the sign of the cross, is little different than the act they mock. 
Similar anecdotes begin to surface, although Le Jeune does not seem to put them together. In a narrative attributed to father Quentin, who was with the Alqonquin in 1636, another episode is offered of a young girl "peculiarly loved by her parents" who falls ill and, in accordance with a dream of her Uncle's, is laid "upon a sheepskin painted with various figures" that the Uncle feels will cure her. The sheepskin is described as painted with "a thousand grotesque figures, canoes, paddles, animals, and such things." 142 In another instance a "Charlatan" insists that a girl will be cured if she is placed upon a blanket "upon which had been drawn pictures of men singing and dancing." ${ }^{\text {"143 }}$ It seems these desperate men were invoking their dreams, and using the power of their traditional caribou coats, or some alternative, to combat the sudden inexplicable disease running through their communities, killing their loved ones. If French writing had spread the disease, Native writing was being used to combat it. ${ }^{144}$

Whether this was the continuance of traditional practices already in place or the beginning of a new healing process born of dire cultural improvisation, these passages suggest how Natives were employing their own symbology as an extension of ceremonial practices to effect change in their worlds. Louise Erdrich, in a recent book on her travels through the lakes and islands of Ojibwe country where the great rock paintings of her ancestors rise out of the waters, posits that the word Ojibwe itself has its roots in the verb "Ozhibii'ige, which is 'to write." 145 The Ojibwe not only made these elaborate rock paintings (which can still be seen today in the Lake of the Woods, straddling the US-Canadian border), but they continue to hold in their possession sacred birch bark scrolls that recount their cosmology, their migrations as a people, and the creation of the Midewegun or Mide Lodge. ${ }^{146}$ Erdrich tells us that Ojibwemowin was "of course a language of memory, an oral language, passed on by community but not written." 147 She suggests that the ancient symbols of the rock paintings were as familiar and recognizable to the Ojibwe tradition as "say, highway and airport and deer crossing signs to contemporary Americans." And yet she is careful to note that they were far more significant than 
that as "they refer to a spiritual geography, and are meant to provide teaching and dream guides to generations of Anishinaabeg." ${ }^{148}$ The Jesuits, while invested in portraying Native culture as a culture of "error," and therefore without proper signification, offer countless instances in their narratives of Natives employing their own forms of writing, however "grotesque" these figures appeared to European observers.

It is almost certain that the symbols that were put to use in the healing ceremonies described above were not, themselves, improvisations, but part of an existing practice of inscription that was communicative rather than aesthetic or decorative. While the Jesuits and other European recorders of Native encounters refused to train their vision on the writing of Natives save in in the most oblique and transitory references, still the existence of such writing is registered in their accounts and can be accorded a concretized presence, if not actually deciphered from our historical distance. Father Brebeuf relates, during one long winter, how the Jesuits themselves took to "reviving the ancient usage of writing on birch bark, for want of paper." 149 Being infinitely more adaptable than many of his peers, Brebeuf employs this birch bark writing to further his instructions in alphabetic literacy for the Native children in his company. ${ }^{150}$ Here Brebeuf can be seen astutely synthesizing his own technology with the technology of the Natives in his presence. And if this birch bark writing is anything like the sacred birch bark scrolls known to be in existence with the Ojibwe, or the wood carvings of the Lenapee's Walum Olum (to be discussed in chapter two), then it seems more than likely that the very purpose of such writings has always been to transmit narratives of cultural origin and spiritual belief.

Such practices have been retained into the twentieth century. One of the more striking examples may be located amongst the Mi'kmaq of Eastern Canada, who, for hundreds of years following contact with the Jesuit missionaries, employed a form of hieroglyphic script for use in their recital of prayers. According to David L. Schmidt and Murdena Marshall, who have edited 
a recent translation of the hieroglyphs, this form of inscription predated the arrival of Europeans and was originally used "for maps and tribal records.", 151 They turn to a $1651-52$ passage from the Jesuit Relations in which Father Gabrielle Druillettes remarks how some Natives "would write their lessons after a fashion of their own, using a bit of charcoal for a pen, and a piece of bark instead of paper ... they used certain signs corresponding to their ideas; as it were, a local reminder, for recalling points and articles and maxims which they had retained."152 Druillette's account tells how the Mi'kmaq quickly embraced this form of expression and "treated their leaflets as sacred relics." ${ }^{\text {153 }}$ The Jesuit Priest Le Clercq noted that these hieroglyphs, far from being highly individualized mnemonic markers, could be deciphered with ease by "Indians who had come from a long distance," $" 154$ suggesting that they had more in common with a form of signification already in place than one developed through interaction with the missionaries. According to the modern day compilers of these artifacts, this system of hieroglyphs would develop into "one of the most formidable scripts in history with an inventory of approximately 2,700 graphemes."155 The Mi'Kmaq called this Komqwejwi'Kasikl, or "suckerfish writing" because the bottom-feeding suckerfish leaves interesting impressions in the river's bed. (picture of hieroglyphs and Naskapi deer hides here) ${ }^{156}$

Le Jeune wished to believe of the Native peoples of Canada that "grace, politeness, the knowledge of the arts, natural sciences, and much less supernatural truths, have as yet no place in this hemisphere, or at least not in these countries." ${ }^{\text {157 }}$ But although these people lived differently than he, and perceived the world differently, his own writings couldn't help but betray how little truth resided in his own declaration. Like his Spanish predecessors, Le Jeune refused to be taken in by the possibilities of an alternative civilization, and his account actively effaces all evidence of the cultural documents of his Native neighbors, even when relying upon them to move his narrative forward. An indigenous method of writing is mentioned, but the imperial gaze rarely lingers upon it or seeks to transcribe its characters. The Jesuits will use the practice of Native 
birch bark writing to their own end, but they will not acknowledge the culture represented in these inscriptions. The result has been the entrenched belief that such writings did not exist and that Native civilization was itself a prehistorical construct hardly fitting of the title. Contained within Le Jeune's own narrative, however, are the strains that pull against such a discursive construction, the excess moments of represented experience that allow for Native culture to appear between the lines as a culture that does in fact know grace, politeness, art, science, truth, and writing. The Jesuits sought to conceal this knowledge from themselves, retreated into their own concretized cultural beliefs, refusing to recognize the transformations of their own characters within the colonial milieu. Like the Spaniards before them, they met each new evidence of a Native civilization equal to their own with a sort of distracted awe. Thus it is that by 1673, when Father Marquette travels down the Mississippi River with La Salle, he has no cognitive precedent for what he encounters along the way. He writes,

While skirting some rocks, which by their height and length inspired awe, we saw upon one of them two painted monsters which at first made us afraid, and upon which the boldest of savages dare not long rest their eyes. They are as large as a calf; they have horns on their heads like those of a deer, a horrible look, red eyes, a beard like a tiger's, a face somewhat like a man's, a body covered with scales, and so long a tail that it winds all around the body, passing above the head and going back between the legs, ending in a fishes tail. Green, red, and black are the three colors composing the picture.

Moreover, these 2 monsters are so well painted that we cannot believe that any savage is their author; for good painters in France would find it difficult to paint so well,--and, besides, they are so high up on the rock that it is difficult to reach the place conveniently to paint them. 158

\section{From Wussuckwhommin to Wussuckwheke: The Transformative Nature of Writing and the Word}

"The rock paintings are alive," Louise Erdrich tells us in her account Books and Islands in Ojibwe Country. ${ }^{159}$ Ultimately this is not so much a matter of faith or conviction as it is an acknowledgement, however difficult to apprehend for the western mind, of the cultural sensibility that lies behind, or resides within, the painted figures and their relationship to how one pursues life within that tradition. Oral culture makes no claims to absolute truths. As such it 
cannot be deconstructed, it cannot mislead, misconstrue, or offer unreliable narrations of events. As Nabokov states, "we are struck again by oral tradition's central strength: the coexistence of multiple versions, whose preservation of options often stands in philosophical and political opposition to the monopolizing inclinations of the non-Indian's print medium."160 In Power and Place: Indian Education in America, Vine Deloria, Jr., and Daniel R. Wildcat speak of Indian knowledge as "the technique of reproducing the cosmos in miniature and invoking spiritual change, which would be followed by physical change."161 Rituals and ceremonies were designed to mirror the workings of the universe as understood by those who had observed and experienced those workings. Writing could be said, perhaps, to adhere to similar rules and perform a similar function. Knowledge is based on place and the experiential relationships gleaned from inhabiting a certain location and engaging with its energies over centuries and perhaps millennia. Robert Warrior, in his book Tribal Secrets, also maintains the "necessity of authenticating human experience with the particular places humans inhabit," the kind of intimate knowledge that only comes from understanding the ecological relationships of a given geographical space and engaging with its landscape on a personal level to the point where it becomes interwoven with one's history, one's own narratives, one's own way of encountering the world. ${ }^{162}$

The point of the preceding chapter is not to construct a narrative in which Indians are regarded as already on board with the tools of a relatively complex western style of literacy before Europeans arrived on the scene. The oral consciousness was comprised of a discrete manner of engaging with the world, largely too expansive for the dictates of alphabetic literacy and western civilization. Western civilization is concerned with containing experience, containing knowledge, or in the words of Vine Deloria, Jr., "forcing natural experience and knowledge into predetermined categories that ultimately fail to describe or explain anything."163 Deloria sees western science and western religion as parsing paradigms obsessed with the ritual of culling the elements into their finest parts, and learning to manipulate them without offering 
any understanding as to the relationships, emotional, spiritual and practical, that necessarily exist between ourselves and these elements. It studies the anatomy of the beast but fails to learn its habits or know its mind. It abstracts information from its geo-specific locality and applies it to all situations alike with the same egalitarian intolerance that, as I mentioned earlier, Todorov attributes to Christianity. It takes the traditional beliefs and narratives of a group of nomadic desert dwellers from twelve thousand years ago and attempts to apply them to the exigencies of life in a completely different environment, a completely different social and cultural arrangement. The indigenous consciousness, as represented by Native American culture, sought engagement with the world and its forces. Its writings were an activity in keeping with such an experiential engagement. It did not seek to categorize or contain, but rather opened up a path for narrative and knowing to proceed along. It is the metaphorical and ritual language for a manner of expressing what experience, grounded in an intimate familiarity with a specific geographical location, makes possible.

In the above paragraph I notice myself shifting in and out of the past tense. This is because alphabetic literacy, western metaphysics, has the habit of superimposing itself over the oral consciousness in seemingly irrevocable ways, just as the new age of information technology we are encountering today, driven by microchips, genetic codes, and the manipulation of subatomic particles superimposes itself over the modern consciousness, interfering with the very mechanics of how we, as human beings, process information and respond to the world in our own turbulent day and age. There are those who say that the book will soon be irrelevant and the mind that produced it relegated to the past tense (although I've yet to see computer screens attached to the backs of church pews). That such a transformation, should it occur, will be the result of something that might be acknowledged as technological advancement should not be a matter of contention. Whether these modes of western technology offer any kind of ethical advancement, however, or in any way improve upon the quality of life on earth remains a vexed and largely 
depressing question. Or at the very least, a question that must be constantly negotiated. The life of human complexity does not reside merely in the sophistication of its tools. The rock paintings are alive if the people, the culture, that recognizes them is alive. Such a culture, however, cannot be expected to exist within the same psychological framework of its ancestors of fifty or five hundred years ago. What Erdrich is hoping to express and nurture within herself, I believe, is an appreciation of the consciousness that formed these images and an engagement with the voices that continue to speak and carry the culture of the rock paintings forward into the future. The language of the people is not contained in their paintings or significations. Neither is the culture. But all are intertwined and vital components to the history and continuance of indigenous peoples.

One way of suggesting the different cognitive engagements with the world as practiced by Native American and European is to simply notice that while Native cultures were able to take up alphabetic literacy rather quickly and regard it as a tool of some value, Europeans, save for in extreme and largely negligible circumstances, remain unable to grasp the intellectual and narrative intricacy of the indigenous consciousness that comprises Native writings. Such writings remained, for most European observers, crude manifestations of grotesque, demonic error, and as such they were simply written out of western memory so that for most of us today, they do not functionally exist. In a sense, the discourse from which alphabetic literacy emerges is one that must commit to tightly managed versions of the truth, must accept, and even encourage, the fact that it is by no means desirable to embrace the totality of experience. Western culture constrains its apprehension of the world to what it feels it can compass within its textual boundaries. This remains an effective means of policing perception and marginalizing resistance-the unmanageable flash points of experience that continue to flare up on the peripheries of consensual knowledge. But it can also deteriorate into a quite limited strategy for engaging with reality in the long term and contribute to the unacceptable levels of violence and suffering in the 
world that we seem to regard as inevitable.

Roger Williams would not attend Narragansett ceremonies for fear of what power such ritualistic engagements with the world might exert over his ever endangered soul. In his own words, "I durst never bee an eye witnesse."164 Williams was a decent, well-meaning man, but his words might easily serve as a motto for the last five centuries of colonialism in the Americas. While western civilization has been obsessive about committing its encounters to the written word, it has been a most selective recorder, seeing what it wanted to see, using writing to confirm its pre-established conclusions, diligently rooting out the errors in the world it viewed as its very own cultivated garden. Williams responds to the Native ceremonies he durst not witness by noting, "the Divell drives on their worships pleasantly (as he doth all false worships)." 165 But he also generously points out that the Narragansett "have a modest Religious perswasion not to disturb any man, either themselves English, Dutch, or any in their Conscience, and worship, and therefore say: Aquiewopwauwash: Peace, hold your peace."166 Williams appeared to be in sympathy with this philosophy. As one who preferred to barter in words rather than impose them, who thought of understanding foreign language and custom as a key rather than a grotesquerie, it was preferable to avoid confrontation when possible. Williams would often be employed as a gobetween when conflicts arose between the colonists and the Natives. As he wrote to the Massachusetts Bay General Court in 1654, "I have been more or less interested and used in all your great transactions of war and peace, between the English and all the Natives, and have not spared purse, nor pains, nor hazards, (very many times,) that the whole land, English and Natives, might sleep in peace securely." Williams openly wondered "whether it be not only possible, but very easy, to live and die in peace with all the Natives of this country." 167 Perhaps it was his ability to accommodate himself to such open systems of thought that allows him, despite the constraints of his own rigid theological outlook, to establish a colony where such freedom of conscience was the bylaw. Interestingly America half forgets this and likes to trace its traditions 
back to the Puritans rather than to the stubbornly individualistic pilgrim they banished to the wilderness.

Williams tells us that the Narragansett peoples drew the word for writing, wussuckwheke, from the root word wussuckwhommin, which means "to paint," for, as he informs, "having no letters, their painting comes the nearest." And this is, in fact, the nearest Williams comes to acknowledging a preexisting system of signs and signifiers amongst the Narragansett. In the emerging power struggle for cultural autonomy between Indians and Europeans, inscription of one kind or another would assume legal authority over the spoken word. The Natives quickly learned that no spoken agreement (or written, as it turned out) was binding. Language had an ephemeral quality in their dealings with the English, and unless marks were made on paper, there was not even the possibility of legal verification. By the time Williams offers his testimony, or key, in 1643 the knowledge of letter writing had infiltrated a language that had known nothing of it, creating the necessity for new words that would have no cause to exist without the impetus, the anxiety, to contain language, and the power therein, in its phonetic form.

The Christian book, as Mignolo suggests, was one that erased even as it espoused, a doctrine that sought to draw a tight circle around contradictory belief and practice and position seraphim with flaming swords at the entryways to such cognitive tabernacles. Although such expediencies were ineffective in terms of soliciting a unified interpretation of God's book amongst Europeans themselves, they nevertheless freed colonial adventurers to liberally declare the "error" of Native beliefs. As one Jesuit remarked, "it is wearisome to recount the tales which they invent concerning the creation of the world." The "author" of such abominable notions could only be "the enemy of the human race" himself whose book needed to be stamped out before it could be further spread. ${ }^{168}$ Upon this pretense alone, Europeans were able to convince themselves that the Natives not only needed their help, but craved it. This is, perhaps, best exemplified by the seal of the Massachusetts Bay Company, in which a leaf-bedecked Native, his 
bow and arrow turned down, is seen gazing at the viewer with the words "Come Over And Help Us" streaming from his lips. In later versions of the seal, the same Native, now donning a cape, has put aside his bow and arrow and picked up a book instead. But the same cry, which was the cry of the Macedonians to the apostle Paul, still issues from his lips. "Come over and help us." And come they did. And they kept on coming. A self-fulfilling prophecy offered up through the simulations of dominance (Insert Seals).

A recent archeological dig in a Pequot cemetery in Ledyard, Connecticut uncovered an eleven-year-old Pequot girl buried in the traditional posture with her body curled in a fetal position and facing southwest. In her possession was a page of scripture carefully wrapped in a medicine bundle. Whether or not the written content of the scriptural passage was relevant to this child's life, and regardless of whether she could read, the material object itself must have been regarded as one of power to find a place in the bundle with which she was buried. ${ }^{169}$ The textual fragment she carried with her to the grave was from Psalms 98:1: "Sing unto the Lord a new song." 170 In seventeenth-century North America the printed text and the skill of alphabetic literacy enter into Native space with both pragmatic and spiritual potentialities. The progression of one word to the next, from wussuckwhommin to wussuckwheke, signaled a linguistic shift, for better or worse, anticipating the more intrusive cultural implications opened up by the further dissemination of European writing or God's Booke. 
${ }^{1}$ Miantonomo (spelled Miantonomu by Williams or sometimes Miantonomi) was one of the principal Narragansett sachems in the early seventeenth century, second in terms of power and influence only to Canonicus, and he was a central figure in Native-European relations during the time of the Pequot War. By siding with the English, he insured the downfall of the powerful Pequot nation. In 1643, however, he would be imprisoned by the English for allegedly plotting a pan-Indian revolt. Whether or not these charges were true, he became caught in a regional power struggle consisting of himself, the English, and the Mohegan leader Uncas. Miantonomo was ultimately handed over to Uncas for execution and it is said that Uncas killed him with a "sharp blow to the head." See Alfred Cave, The Pequot War (Amherst: University of Massachusetts Press, 1996), 167.

2 Roger Williams, "A Key into the Language of America," The Complete Writings of Roger Williams vol. i. (New York: Russell \& Russell Inc., 1963), 159-160.

${ }^{3}$ Ibid., 19-20.

${ }^{4}$ Richard Cogley, John Eliot's Mission to the Indians before King Philip's War (Cambridge: Harvard University Press, 1999), 25.

${ }^{5}$ Williams, $A$ Key, 25.

${ }^{6}$ William Bradford, Of Plymouth Plantation: The Pilgrims in America, ed, Harvey Wish (New York: Capricorn Books, 1962), 166. John Winthrop, The History of New England from 1630-1649, vol. 1 ed. James Savage, (Baltimore: Clearfield, 2003, 1853), 145. Cotton Mather, Magnalia Christi Americana or the Ecclesiatical History of New England, vol. 1 (Hartford, CT: Silas Andrus, 1820, 1702), 521. See "A Letter of Mr. Cotton," The Complete Writings of Roger Williams, vol. 1 (New York: Russell \& Russell Inc., 1963, 1643), 295-311. Morton's quote found in Edwin S. Gaustad, Roger Williams, Lives and Legacies (New York: Oxford University Press, 2005), 89.

${ }^{7}$ Perry Miller, Roger Williams: His Contribution to the American Tradition (New York: The Bob Merrill Company, Inc., 1953), 24.

${ }^{8}$ See Gaustad, Roger Williams, 91.

${ }^{9}$ Patricia Rubertone, Grave Undertakings: An Archaeology of Roger Williams and the Narragansett Indians (Washington: Smithsonian Institution Press, 2001), xii. See also Jennifer Reid, "Roger Williams's Key: Ethnography or Mythology." Rhode Island History 56:3 (1999): 77-87.

${ }^{10}$ Neal Salisbury, Manitou and Providence: Indians, Europeans, and the Making of New England, 15001643 (New York: Oxford University Press, 1982), 190-202. See also Roger Williams "Christenings Make Not Christians." The Complete Writings of Roger Williams, vol. vii (New York: Russell \& Russell Inc., 1963). Here Williams argues against the practice of baptizing natives before they have acquired enough of English culture to properly be called Christians.

11 Williams was forced to flee the Salem colony in the winter of 1636 upon learning that he was to be arrested and shipped back to London due to his refusal to abide by the rules of the Massachusetts General 
Court. He was apparently well received by the sachems Canonicus, Miantonomo, and the Narragansett people and lived amongst them for a number of years before establishing his settlement in Providence. He claims to have purchased the land from the natives "not by moneys nor payment ... but by that language, acquaintance, and favor with the natives, and other advantages which it pleased God to give me." See Roger Williams, "The Letters of Roger Williams." The Complete Writings, vol. vi., 34-35. It wasn't until after this that he designed it might be a shelter "for persons distressed of conscience" (35), and was joined by others. His time amongst the natives has received little treatment because there is little documentation of it. Aside from the brief glimpses we get through his Key into the Language of America and a few references in his correspondences, an intriguing silence surrounds this period.

${ }^{12}$ Williams, A Key, 20.

${ }^{13}$ See Gerald Vizenor, Manifest Manners: Post-Indian Warriors of Survivance (Hanover, NH: Weslyan University Press, 1994).

14 "Quinnihticut" may have been an offshoot or clan of the Narragansett. Either that or it was a specific region that the Narragansett inhabited. It is not often referenced in the literature of the time, although Williams uses it on occasion. Clearly the name "Connecticut" finds its origin in this native appellation.

${ }^{15}$ In a letter to John Winthrop dated 1638, Williams writes "let me humbly beg relief, that for myself, I am not yet turned Indian" (Williams, Writings vol. vi, 101). Although his tone is facetious, he is consciously defending himself against a suspicion that was sure to have circulated amongst his Puritan neighbors. See also Salisbury, Manitou and Providence, 193-199. Salisbury chronicles the events that surround "Williams's immersion in Indian culture" (194). Williams wrote a small tract in 1633 arguing, according to Salisbury, that "the royal patent did not entitle English colonists to Indian land and that such had to be purchased from the natives themselves" (195). John Winthrop ordered this tract burned and there is no extent version of it.

${ }^{16}$ Williams, $A$ Key, 22.

${ }^{17}$ Ibid., 82-83.

${ }^{18}$ Ibid., 78. It is interesting to note that Williams uses this exact quote in a much earlier letter to John Winthrop dated 16 April 1638. In this letter he questions Winthrop's dealings with the Narragansett following the Pequot War and cautions that Miantonomo fears he has been falsely dealt with. He writes "I have engaged your name and my own; and if no course be taken, the name of that God of Truth whom we all profess to honor will suffer not a little, it being an ordinary and common thing with our neighbors, if they apprehend and show of breach of promise in myself, thus to object: do you know God, and will you lie?" (Williams, Writings vi, 92). This quote demonstrates not only the elided political content that sleeps within Williams' Key, but also a suggestion that Williams had begun writing the Key or at least compiling notes for it well before his 1643 voyage to England.

${ }^{19}$ See Williams, $A$ Key, 158. See also William S. Simmons. Spirit of the New England Tribes: Indian History and Folklore, 1620-1984 (Hanover, NH: University Press Of New England, 1986), 38.

${ }^{20}$ For a firsthand account of the Pequot War, and the fort fight of 1637 in which some 600 Pequot men, 
women and children were killed in their enclosed village that was set to blaze by the Puritan colonists, see John Underhill. Newes From America. (New York: Da Capo Press, 1971). See also Cave, The Pequot War.

21 See Leift Lyon Gardener, "His Relation of the Pequot Warres." The History of the Pequot War, ed. Charles Orr (Cleveland: Helman-Taylor Co., 1897, 1660), 142-143. It should be noted that Gardener, who offers us this speech of a gathering native threat under the leadership of Miantonomo, was himself convinced that Miantonomo posed the most imminent threat to the New England colonies. Whether or not Miantonomo had attempted to assemble an army against the colonies, the United Colonies placed him in the custody of his rival Uncas of the Mohegans, with the understanding that Uncas would see to his execution, which he did. It was therefore in Gardener's interests to uphold the charge by attributing such a speech to Miantonomo.

${ }^{22}$ Thomas Hariot, "A Briefe and True Report of the New Found Land of Virginia." The English Literatures of America, 1500-1800, eds. Myra Jehlen and Michael Warner (New York: Routledge, (1588) 1987), 8586.

${ }^{23}$ The Jesuit Relations and Allied Documents ( $J R$ from here on in) vol. 8 (New York: Pageant Book Co. (1635)1959), 113.

${ }^{24}$ Williams, A Key, 150-151.

${ }^{25}$ James Axtell, After Columbus: Essays in the Ethnohistory of Colonial North America (New York: Oxford University Press, 1988), 93.

${ }^{26}$ Williams, $A$ Key, 88.

${ }^{27}$ Pharmakon is the Greek word for "drug," or "medicine," that Socrates uses to describe the nature of written texts in Plato's dialogue Phaedrus. Socrates viewed writing as a corrosive element in the realm of philosophical thought that, like a drug, induced forgetfulness. Derrida, however, finds the term useful as it seems to imply an operative agent that works from the interior and exterior realms of the body and mind at once as both drug and cure, poison and remedy. Jacques Derrida, Dissemination, trans. Barbara Johnson (Chicago: The University of Chicago Press, 1981), 70.

${ }^{28}$ Thomas Mayhew, A Further Discovery of the Present State of the Indians, compiled by Henry Whitfield (New York: Sabin's Reprints (1650) 1865), 4.

${ }^{29}$ Ibid., 7.

${ }^{30}$ See Plato, The Works of Plato, ed. Irwin Edman (New York: Random House, 1956), 323.

${ }^{31}$ Luther Standing Bear. Land of the Spotted Eagle (Lincoln, NE: University of Nebraska Press, (1933) 1978), 27. 
32 Walter Ong, Orality and Literacy: The Technologizing of the Word (London: Routledge, 1982), 132.

${ }^{33}$ One of Ong's contentions is that Socrates, regardless of his objections to written discourse, was utterly reliant upon it. His system of belief was insupportable without the accumulation of inquiries that writing had made available to him. That Plato, the student of Socrates, chooses to disseminate the Dialogues through a written conduit speaks to the rapid acceptance that writing was undergoing, even as Socrates was resisting its technological grasp. Critics of Ong refer to his understanding of orality and literacy as "evolutionary," contending that he views literacy as an evolutionary step forward from orality. This argument obscures the finer point that Ong is making. He does not profess to offer a value judgment between the oral or literate consciousness. His task is to recognize them as two different modes of thought that engage with the world through an entirely different cognitive process. His contention is not that literacy is an evolutionary step forward from writing in the sense of any kind of "civilized" progress, but that a literate state cannot precede orality. The need for making this case may seem superfluous, save for Ong is constructing this argument in response to Derrida's Of Grammatology, wherein it is suggested that "writing" precedes speech. Others see the creation of this divide between oral and literate consciousness an ideologically motivated paradigm.

Craig Womack, among others, seeks to break down this presumed binary. See Craig Womack, Red on Red: Native American Literary Separatism. (Minneapolis: University of Minnesota Press, 1999).

34 Walter D. Mignolo, "Signs and Their Transmission: The Question of the Book in the New World." Writing Without Words: Alternative Literacies in Mesoamerica and the Andes, eds. Elizabeth Hill Boone and Walter D. Mingolo (Durham NC: Duke University Press, 1994), 220.

${ }^{35}$ Peter Nabokov, A Forest of Time: American Indian Ways of History (New York: Cambridge University Press, 2002), 47.

${ }^{36}$ George E. Tinker, Spirit and Resistance: Political Theology and American Indian Liberation (Minneapolis: Fortress Press, 2004), 89.

${ }^{37}$ William Deloss Love, Samson Occom and the Christian Indians of New England (Syracuse: Syracuse University Press (1899) 2000), 3. See also The Federal and State Constitutions, Colonial Charters and Other Organic Laws of the United States, Vol. II, compiled by Ben Perley Poore (Washington: Government Printing Office, 1878), 1888.

${ }^{38}$ Lucy Maddox, Removals: Nineteenth-Century American Literature and the Politics of Indian Affairs (New York: Oxford University Press, 1991), 8.

39 Eleazor Wheelock, An Indian Preacher in England: Being Letters and Diaries Relating to the Mission of the Reverend Samson Occom and the Reverend Nathaniel Whitaker to Collect Funds in England for the Benefit of Eleazor Wheelock's Indian Charity School, From Which Grew Dartmouth College, ed. Leon Burr Richardson (Hanover, NH: Dartmouth College Manuscript Series Number Two, 1933), 193.

40 Wheelock, An Indian Preacher in England, 163.

41 See $A$ Relation or Journall of the beginning and proceeding of the English Plantation at Plimoth in New England, by Certain English Adventurers both Merchants and others (London: Printed for John Bellamie, 1622), 68. This text is often referred to as Mourt's Relation. The author is not certain, but it is 
usually attributed to Edward Winslow and William Bradford.

${ }^{42} J R I, 87$.

${ }^{43}$ Homi Bhabha, The Location of Culture (New York: Routledge, 1994), 104-105.

44 Ibid., 107.

${ }^{45}$ Ibid., 108.

${ }^{46}$ Roy Harvey Pearce, Savagism and Civilization: A Study of the Indian and the American Mind (Berkeley: University of California Press, (1953) 1988), 195-197.

${ }^{47}$ Bhabha, Location, 116-117.

${ }^{48}$ Womack, Red on Red, 11.

49 Ibid., 15.

50 Ibid., 16.

51 Jace Weaver, That the People Might Live: Native American Literatures and Native American Community (New York: Oxford Community Press, 1997), 11-12.

${ }^{52}$ Bernal Diaz, The Conquest of New Spain, trans. J. M. Cohen (New York: Penguin, 1963), 21.

${ }^{53}$ Ibid., 214. Amadis de Gaule was a popular prose romance dating back to the 13 or 14 century, its hero suggesting a knightly code of honor idealized by the Spanish soldier.

${ }^{54}$ Christopher Columbus, The Four Voyages, ed. and trans. J. M. Cohen (New York: Penguin, 1969), 66.

55 Howard Zinn, On History (New York: Seven Stories Press, 2001), 100.

56 Columbus, Four Voyages, 66-67.

57 Ibid., 67.

58 Ibid., 225. 
${ }^{59}$ Ibid., 300.

${ }^{60}$ Tzvetan Todorov, The Conquest Of America: The Question of the Other, trans. Richard Howard (New York: Harper \& Row, 1982), 105.

${ }^{61}$ See Bernal Diaz's account and also Fray Toribio Motolinia, Motolinia's History of the Indians of New Spain, trans. Elizabeth Andross Foster (Westport, CT: Greenwood Press, 1950).

${ }^{62}$ Diaz, Conquest of New Spain, 237.

${ }^{63}$ This can be found in The Broken Spears: The Aztec Account of the Conquest of Mexico, ed. Miguel Leon-Portilla (Boston: Beacon Press, 1962), 68. Leon-Portilla accounts for the existence of these texts by acknowledging "a few remarkable missionaries, particularly Bernardino de Sahagun and Diego de Duran, [who] undertook to gather up whatever they could of indigenous literature. They managed to acquire a few codices that had escaped the flames, but their major accomplishment was to save a great many of the old songs and narratives that were still faithfully remembered after the Conquest." Leon-Portilla, Broken Spears, xlvii.

${ }^{64}$ Leon-Portilla, Spears, 74.

${ }^{65}$ Thomas King, The Truth About Stories: A Native Narrative (Minneapolis: University of Minnesota Press, 2003), 98.

${ }^{66}$ Motolinia, History of the Indians, 42. See also Diego Duran who speaks of the branding of slaves writing that "justly or unjustly, men women and children were taken, branded on their faces, and sold as slaves for the mines or as servants. In those times they even loaded ships with slaves to be carried away from New Spain. I myself met some of them in the homes of my relatives, and they were marked in the face with the name of the man who had sold them" Diego Duran, The History of the Indes of New Spain, trans. Doris Heyden (Norman, OK: University of Oklahoma Press, 1994), 561. Bernal Diaz, in fact, was the custodian of the branding iron in Guazacualco, Honduras, but apparently objected to the practice and petitioned the government to end it. See Motolinia, History of the Indians, 42.

${ }^{67}$ Motolinia, History of the Indians, 38.

${ }^{68}$ Ibid., 43.

${ }^{69}$ See Popul Vuh: The Mayan Book of the Dawn of Life, trans Dennis Tedlock (New York: Simon and Schuster, 1985), 63.

${ }^{70}$ Ibid. 63-64. 
${ }^{71}$ Ibid, 65.

72 Ibid., 69.

${ }^{73}$ Ibid, 67.

${ }^{74}$ Ibid., 70.

${ }^{75}$ Ibid., 73.

${ }^{76}$ Ibid., 63.

${ }^{77}$ Dennis Tedlock. Introduction to Popul Vuh, 29.

${ }^{78}$ Walter Mignolo. "Afterword: Writing and Recorded Knowledge in Colonial and Postcolonial Situations.“ Writing Without Words: Alternative Literacies in Mesoamerica and the Andes, eds. Elizabeth Hill Boone and Walter D. Mingolo (Durham NC: Duke University Press, 1994), 296. Note the inherent problematic then of a text that begins with the "creation of the word." This already indicates a kind of linguistic and noetic shift in understanding the sacred text itself. Mignolo addresses this, so process it through his writings.

${ }^{79}$ Ibid., 293-94. (quoting Reents-Budet).

${ }^{80}$ Elizabeth Hill Boone, "Introduction: Writing and Recorded Knowledge." Writing Without Words: Alternative Literacies in Mesoamerica and the Andes, eds. Elizabeth Hill Boone and Walter D. Mingolo (Durham NC: Duke University Press, 1994), 3.

81 The Chilam Balam, or the "Jaguar Translator," is the sacred book of the Yucatan which has also survived in alphabetic form.

82 Joanne Rappaport, "Object and Alphabet: Andean Indians and Documents in the Colonial Period." Writing Without Words: Alternative Literacies in Mesoamerica and the Andes, eds. Elizabeth Hill Boone and Walter D. Mingolo (Durham, NC: Duke University Press, 1994), 284.

${ }^{83}$ Mingolo, "Signs and Their Transmission," 235

${ }^{84}$ See also Marcia Ascher and Robert Ascher. The Code of the Quipu: A Study in Media, Mathematics, and Culture (Ann Arbor: The University of Michigan Press, 1981).

${ }^{85}$ Kurt Ross, Codex Mendoza: Aztec Manuscript (Barcelona: industria grafica, 1978), 13.

${ }^{86}$ Ross, Codex Mendoza, 13-14. 
${ }^{87}$ Elizabeth Hill Boone, "Aztec pictorial Histories: Records Without Words." Writing Without Words: Alternative Literacies in Mesoamerica and the Andes, eds. Elizabeth Hill Boone and Walter D. Mignolo (Durham, NC: Duke University Press, 1994), 72.

${ }^{88}$ Peter L. van der Loo. "Voicing the Painted Image: A Suggestion for Reading the Reverse of the Codex Cospi." Writing Without Words: Alternative Literacies in Mesoamerica and the Andes, eds. Elizabeth Hill Boone and Walter D. Mignolo (Durham, NC: Duke University Press, 1994), 83.

${ }^{89}$ Mignolo, "Signs and Their Transmissions," 247.

${ }^{90}$ Boone, "Aztec Pictorial Histories," 71.

${ }^{91}$ Mingolo, "Signs and Their Transmissions," 241.

${ }^{92}$ Axtell, After Columbus, 93.

${ }^{93}$ Lisa Tanya Brooks, The Common Pot: Indigenous Writing and the reconstruction of Native Space in the Northeast, A Dissertation Presented to the Faculty of the Graduate School of Cornell University (Ann Arbor, MI: UMI and Proquest Information and Learning, 2004), 6.

${ }^{94}$ Axtell, After Columbus, 91-92.

${ }^{95}$ The 1991 movie Black Robe directed by Bruce Beresford presents a more recent staging of this discursive phenomenon, suggesting that, despite the movies worthwhile attempts at historical accuracy and breaking down of the subject position of the colonist to accommodate the Huron point of view, the stereotypical reaction itself remains quite persuasive. While it is clear that the writers of this film paid close attention to the source material, native writing once again remains invisible.

${ }^{96} J R$ VI, 209.

${ }^{97}$ Ibid., 209-211.

${ }^{98} J R X I, 41$.

${ }^{99}$ Ibid., 153.

${ }^{100}$ Ibid., 157.

${ }^{101}$ Navajo Chanter Frank Mitchell describes the nature of oral narrative and song as "like a trail . . You 
see a trail runs in certain ways, and if you have gone that way more than once, you know every little thing that is on that trail." Quoted in Nabokov, A Forest of Time, 32.

102

$J R X I, 159$.

103 Daniel Richter, Facing East From Indian Country: A Native History of Early America (Cambridge: Harvard University Press, 2001), 26. Jesuit historian Joseph Jouvency notes that Canada is the name the natives give for the St. Lawrence River, "a name thence extended to the whole country." See JR I, 245.

104 Richard White, The Middle Ground: Indians, Empires, and Republics in the Great Lakes Region, 16501815 (New York: Cambridge University Press, 1991), 16.

105 Samuel de Champlain, Voyages of Samuel De Champlain, 1604-1618, ed. W. L. Grant (New York: Charles Scribners and Sons, 1907), 283.

106 Champlain, Voyages, 284.

${ }^{107}$ Champlain records another setting along the banks of the Saco where he "landed to observe their tillage on the bank of the river." He relates the agricultural practices of the locals with surprising detail, writing how they plant "three or four kernels [of corn] in one place, they then heap about it a quantity of earth with shells of the signoc [wampum] before mentioned. Then three feet distant they plant as much more, and thus in succession. With this corn they put in each hill three or four Brazillian beans, which are of different colors. When they grow up they interlace the corn, which reaches to the height of five or six feet; and they keep the ground very free from weeds. We saw there many squashes, and pumpkins, and tobacco, which they likewise cultivate ... Their permanent abode, the tillage, and the fine trees led us to conclude that the air here is better than that where we passed the winter." See Champlain, Voyages, 62-63. The symbiotic relationship between the corn, bean and squash (often referred to as the three sisters in native tradition) is described by Daniel Richter, Facing East, 53-59.

108 Champlain, Voyages, 245

${ }^{109}$ Brooks, The Common Pot, 2.

110 Clara Sue Kidwell, "Native American Systems of Knowledge." A Companion to American Indian History, eds. Philip J. Deloria and Neal Salisbury.(Malden, MA: Blackwell Publishers, 2002), 89-90.

111 Champlain, Voyages, 246.

112 Champlain, Voyages, 282.

$113 J R X I, 215$.

114 Ibid., 215. 
${ }^{116}$ Brooks, Common Pot, 8-10. Brooks writes that "transformations occurred in native writing when the European system of recording and sending words entered native space" (10).

${ }^{117}$ Cornelius J. Jaenen, "Ameriindian Views of French Culture in the Seventeenth Century." American Encounters: Natives and Newcomers From European Contact to Indian Removal, 1500-1850, eds. Peter C. Mancall and James H. Merrell (New York: Routledge, 2000), 71.

${ }^{118} J R I, 207$.

119 Ibid., 161.

${ }^{120}$ Tbid., 163-165.

$121 J R I, 231-233$.

${ }^{122}$ Francis Parkman, The Jesuits in North America in the Seventeenth Century (Lincoln, NE: University of Nebraska Press (1867) 1997), 172.

${ }^{123}$ Ibid., 131.

124 White, Middle Ground, 23.

${ }^{125}$ From The Jesuit Relations and Allied Documents: Travels and Explorations of the Jesuit Missionaries in North America (1610-1791), ed. Edna Kenton (New York: Albert \& Charles Boni, 1925), 50. From now on $J M$ for Jesuit missionaries.

${ }^{126}$ Ibid., 67.

${ }^{127}$ Roy Harvey Pearce was one of the first literary critics to recognize the captivity narrative as a major American literary genre, if not the first genre. Richard Vanderbeets speaks of the patterns of accommodation that colonists typically experienced when held in captivity amongst the natives. These stages included adapting to Native food and traveling rituals, and progressed to assimilation and adoption. The exigencies of captivity in colonial times have received more recent attention from Richard Slotkin, Michelle Burnham, Neal Salisbury, John Demos, June Namais and others. See Roy Harvey Pearce, "The Significance of the Captivity Narrative," American Literature 19:1 (1947): 1-20. Richard Slotkin, Regeneration Through Violence: The Mythology of the American Frontier, 1600-1860 (Norman, OK: University of Oklahoma Press, 1973). Michelle Burnham, Captivity and Sentiment: Cultural Exchange in American Literature, 1682-1861 (Hanover, NH: University Press of New England, 1997). Neal Salisbury, "Introduction: Mary Rowlandson and Her Removes," The Sovereignty and Goodness of God, ed. Neal 
Salisbury (Boston: Bedford/St. Martins, 1997). John Demos, The Unredeemed Captive: A Family Story From Early America (New York: Vintage Books, 1994). June Namias, White captives: Gender and Ethnicity on the American Frontier (Chapel Hill: University of North Carolina Press, 1993). Richard Vanderbeets, "The Indian Captivity Narrative as Ritual" American Literature 43:4 (Jan 1972): 548-562.

$128 J M 48$.

129 Ibid., 69.

${ }^{130} J R$ VII, 55.

${ }^{131}$ Ibid, 61.

132 Ibid., 31.

133 Ibid., 57.

${ }^{134}$ Ibid., 41.

${ }^{135}$ See note 9.

${ }^{136}$ JR VII, 265.

${ }^{137} J R X I, 67$.

${ }^{138}$ JR XI, 97.

139 Ibid, 101.

${ }^{140} J R X I I, 237-239$.

${ }^{141}$ Ibid., 183.

${ }^{142} J R$ VIII, 261.

${ }^{143}$ Ibid., 261.

${ }^{144}$ Caribou coats were painted coats worn by the Montagnais-Naskapi on hunting parties. The coats were 108 
made by the women of the nation according to the specifications of the man whose dream or vision revealed to him the coat's motifs. These coats are thought to give power to the hunter. For more on this see Dorothy Burnham, To Please the Caribou: Painted Caribou-Skin Coats Worn by the Naskapi, Montagnais, and Cree Hunters of the Quebec-Labrador Peninsula (Seattle: University of Washington Press, 1992).

${ }^{145}$ Louise Erdrich, Books and Islands in Ojibwe Country (Washington, D.C.: National Geographic Society, 2003), 11.

${ }^{146}$ Selwyn Dewdney, The Sacred Scrolls of the Southern Ojibway (Toronto: University of Toronto Press, 1975), 32.

${ }^{147}$ Erdrich, Books and Islands, 86.

${ }^{148}$ Ibid., 49-50.

149 JR VIII, 131-133.

150 Ibid., 133.

${ }^{151}$ David L. Schmidt and Murdena Marshall, eds. Mi'kmaq Hieroglyphic Prayers: Reading in North America's First Indigenous Script (Halifax, NS: Nimbus Publications, 1995), 4.

152 Ibid., 4.

${ }^{153}$ Tbid., 6-7.

154 Ibid., 6.

${ }^{155}$ Ibid., 4. The editors of Mi'kmaq Hieroglyphic Prayers believe that this symbology constituted a system that could be deciphered by anyone literate in the discipline rather than a series of mnemonic devices that were inseparable from the ritualized context in which they were traditionally used (4).

${ }^{156}$ Ibid., 2.

157 JR VII, 7-9.

$158 J M$ 357. The painting Father Marquette describes might, in fact, bear some relation to Misshiepeshu, the Great Lion, or underwater panther manitou of Ojibwe legend. The underwater lion plays a part in the Montagnais creation cycle as well. (See Jesuit Relations) 
Erdrich, Books and Islands, 50.

${ }^{160}$ Nabokov, Forest of Time, 94.

161 Vine Deloria, Jr., and Daniel R. Wildcat, Power and Place: Indian Education in America (Golden, CO: American Indian Graduate Center and Fulcrum Resources, 2001), 25.

${ }^{162}$ Robert Warrior, Tribal Secrets: Recovering American Indian Intellectual Traditions (Minneapolis: University of Minnesota Press), 1995.

${ }^{163}$ Deloria, Jr., and Wildcat. Power and Place, 4.

${ }^{164}$ Williams, A Key, 152.

165 Ibid., 153.

166 Ibid., 153.

${ }^{167}$ Williams, Roger. Complete Writings vol. 6, 270-271.

${ }^{168} J R I, 287$.

${ }^{169}$ Hugh Amory, Bibliography and the Book Trades: Studies in the Print Culture of Early New England, ed. David D. Hall (Philadelphia: University of Pennsylvania Press, 2005), 13.

170 Amory, Bibliography and the Book Trades, 21. 


\title{
CHAPTER II
}

\section{AMALECK (or WRITTEN IN STONE): ELIDING INDIGENOUS PRESENCE THROUGH WRITING IN COLONIAL NEW ENGLAND}

\author{
Here still a lofty rock remains, \\ On which the curious eye may trace \\ (Now wasted, half, by wearing rains) \\ The fancies of a ruder race.
}

Philip Freneau

\begin{abstract}
When one who writes was chief, true records were kept. Walam Olum
\end{abstract}

The first thing we Americans need to contain is ourselves. George Kennan

\section{Eden As Ground Zero: Locating Western Epistemologies of Containment}

In a tale often referred to as the "earth-diver" myth, a number of animal helpers are sent into the water in search of a piece of earth they might carry back to the surface in order to create land for humans, animals, and plants to live on. The story is told in numerous Native American traditions, often with slight variations. Arthur Parker, an early twentieth-century Seneca historian and ethnographer, writes of how Sky-Woman, or Iagen'tci, was pushed through a hole in the clouds, left by the uprooting of the celestial tree, and plummeted towards earth. As she fell, the creatures of the watery world below collaborated to cushion her fall. The duck-creatures received her "on their interknit wings," and the great turtle from the underworld was "to arise and make his broad back a resting-place." But there was a need of soil so things might grow. Therefore the creatures, one by one, "dove to the bottom of the water seeking to find earth to plant upon the turtle's back." First the duck went, then the pickerel. Each creature that went down into the 
watery depths failed at its attempt until, at last, the muskrat succeeded in touching bottom with his nose, which proved sufficient, for he was able to "smear it upon the shell and the earth immediately grew," providing a home for the woman from the sky. ${ }^{1}$

This story was overheard and recorded by many a colonial observer as well and was often equated with the biblical tale of the flood. Paul Le Jeune had a version recounted to him by the Huron in 1634. John Josselyn, in his 1675 Account of Two Voyages to New England, tells how one Powaw fled to the White Mountains when the flood came, taking with him a hare, which he then set loose to discover if the waters had yet receded. Some of these narratives must be understood to relate a second flood that mirrors the sky-woman story in important ways. In a version recounted by the nineteenth-century amateur ethnographer, Henry Rowe Schoolcraft, the Ojibwe culture hero, Manabozho, loses his son to the great underwater serpent and gets his revenge by tricking the prince of serpents and killing him. As a result, the remaining serpents fall in pursuit of the trickster hero. Manabozho then "made for the highest mountain, and climbed the highest tree on its summit, when, dreadful to behold, the whole lower country was seen to be overflowed, and the water was gaining rapidly on the high lands." He speaks to the tree, saying "grandfather, stretch yourself," and the tree stretches to its furthest length to keep Manabozho above the flooding waters. Then Manabozho, remembering the story of Sky-Woman, calls upon the animals to dive down "and fetch up some earth, so that I can make some new earth." Many animals fail in the attempt. But the lowly muskrat, once again, succeeds, although dying in the effort, and Manabozho is able to restore the world and create a home for his people. Survival writing. Stories of how culture maintains itself in the face of calamity. ${ }^{2}$

While these accounts, as offered, are mere sketches of belief systems and narratives that, as the Ojibwe writer George Copway once noted, might stretch out over the duration of six months in the telling, nevertheless one might apprehend how in these, and many other Native creation accounts, there is a tendency to view the world of animals, plants, rocks and trees as 
accomplices, brethren even, in the restoration and maintenance of the world. ${ }^{3}$ These stories are indicative of Gaiwiio, Good Mind, which is personified as the grandson of Sky-Woman in the Seneca version of the tale. ${ }^{4}$ Good Mind is responsible for creating all the good things on earth and maintaining balance with all its natural forces. While in the Christian story of the flood animals are rounded up in an ark and kept in a sort of floating zoo, reinforcing man's absolute dominion over the beasts of the field, the Native stories emphasize a partnership with the natural world, a relationship of reciprocity that is threaded into the daily structure of Native lives. Doubtless, such a paradigm is in danger of presenting itself as a species of new-age reductionism, or an essentialist notion that romanticizes a Native relationship with the natural world, having more to do with contemporary wishes than any authentic Native past. However John Heckewelder, who spent a number of years living amongst the Delaware, or Lenape as they call themselves, offered a very similar assessment as a result of his eighteenth-century mission. He comments in his History, Manners, and Customs of the Indian Nations that the Delaware, according to their traditions, are

only the first among equals, the legitimate hereditary sovereigns of the whole animated race, of which they consider themselves a constituent part. Hence in their languages, these inflections of their nouns which we call genders, are not, as with us, descriptive of the masculine and feminine species, but of the animate and inanimate kinds. Indeed they go so far as to include trees, and plants within the first of these descriptions. All animated nature, in whatever degree, is in their eyes a great whole, from which they have not yet ventured to separate themselves. ${ }^{5}$

Regardless of whatever manner of relationship twenty-first-century Native Americans are able to forge with their natural surroundings or enfold into their spiritual embrace of the world, the better part of Native religion, lore, and tradition speaks of an intimate relationship with the earth that transcends a simple equation of reliance and subsistence. At the heart of Native spirituality rests a notion of balance that one maintains with the universe as a whole. This stands in stark contrast to the religion of the European colonizers of North America who, as Vine Deloria, Jr., has noted, tend to view the world as "a vale of tears filled with unexplained human 
tragedies. Animals are definitely placed beneath humans in the hierarchy of things and religious ceremonies seek to purge nature from participation in the rituals . . In many ways the human body is seen as evil. ${ }^{, 6}$ Richard Slotkin, too, comments upon the fundamental difference in the manner in which Europeans and Native peoples narrate their engagement with the natural world, noticing that while Christian myth deplores its entry into the world, as a tragic fall from a gracious, satisfyingly womblike condition, the Indian myth rejoices in "the discovery and in the movement of the world." Slotkin notes that "the exile of Adam and Eve results from their disobedience to their transcendent father ... [whereas] for the Indian it is virtue that leads man into the world."7 Andrew Wiget calls the earth-diver myth "the story of the Fortunate Fall.,"8 Such diametrically opposed systems of representing existence have real consequences in the development and organization of culture, the psychological well-being of a people, and the practical effect of a people upon their environment.

What is striking about the Old Testament creation myth of Adam and Eve is not only its establishing of an oppositional relationship between man and the natural world, but as Slotkin points out, the imposed exile embedded within the narrative. Paradise, a place where balance between the human and natural world is a given and individuals can speak directly to their gods, cannot be regained, save through death. The working assumption is that humanity is barred from reentry into this garden as a consequence of sin. A more secular approach might explore the possibility that Eden is a construction of false nostalgia, positing a period of innocence and peace in human relations that can never be reestablished, and in fact never was given the complex organization of western civilization with all its needs and wants, unevenly distributed resources, diseases, conflicts, weapons of mass destruction, mass populations, and political infrastructures. Hardly entertained, however, is the possibility that the Genesis narrative itself is specifically constructed to keep its practitioners outcast from the garden abode. Eden is not a desirable place to return to, so much as a patch of mental real estate from which western culture has gone to 
extraordinary labors to remove itself, setting seraphims with burning swords at the gate and geographically displacing its location so that it is not to be found in the physical world as we know it. It is a space of genesis and trauma, a gated enclosure meant to contain inconvenient knowledge. It is cognitive ground zero, surrounded by yellow tape, indigenous to no one. In a sense, the Genesis story recounts western culture's first narrative of forced removal.

Were one to apprehend the patterns of narrative energy that radiate from the core of this narrative, necessitating the psychological barriers that have been thrown up around it, one might identify the troubling knowledge at the heart of the story as nothing more than a fear of death. The traumatic event is that self-reflexive knowledge brings along with it a cognition of mortality. Eden is not a state to which we long to return. It is the place we have purposefully displaced to avoid a traumatizing notion. Like the Deganiwidah myth of the Iroquois, the Book of Genesis is one of our earliest trauma narratives (what else can the loss of paradise be, but traumatic?), but unlike the Iroquois narrative it does not propose a strategy, beyond additional sweat and labor, for engaging with troubling truths. As Thomas King points out, "in Genesis, we begin with a perfect world, but after the Fall, while we gain knowledge, we lose the harmony and safety of the Garden and are forced into a chaotic world of harsh landscapes and dangerous shadows." 9 The act of engaging with that world becomes, in Mary Louise Pratt's estimation, a classificatory one. In order to re-impose order on chaos "one by one the planet's life forms were to be drawn out of the tangled threads of their life surroundings and rewoven into European-based patterns of global unity and order. ${ }^{\prime 10}$ This impulse, the act of restoring order through compulsive categorization, is perhaps in accordance with the attempt to keep chaos, or troubling knowledge, at bay. Order is never in fact restored, so much as it is constructed and maintained. Western culture constructs order around the possibility of the textual containment held out by Genesis, continuing to operate along the elaborately maintained lines of space, gender, and race established within its narrative confines. In King's words, "the elements in Genesis create a particular universe governed by a 
series of hierarchies - God, man, animals, plants . . while in our Native story, the universe is governed by a series of co-operations ... that celebrate equality and balance."11 These hierarchies, or lack thereof, are reflected in the laws and governments of these two civilizations. The materials of these stories seep deeply into the cognitive process and culminate in the manners in which our worlds are constructed. The containment of the garden, however, is never perfect, and its leaks, regarded as Satanic infiltrations and influences, must be diligently policed. Therefore, when the so-called New World is officially located by European powers in 1492 and equated with paradise, the notion has already been culturally internalized that Satan runs free within its boundaries and what are needed are aggressive acts of containment of both a rhetorical and physical nature to put the devil back in his box.

The notion of Eden or paradise as a psychological space of containment and its relation to colonialism is an old one. The philosopher John Locke noted that "in the beginning all the World was America," implying not only that the land across the waters was, in fact, as new and unsullied as the first day of creation, but that it was soon to be as populated with corruption and sin as the old world. ${ }^{12}$ When Milton seeks to describe a suddenly vulnerable Adam and Eve being expelled from Eden in Paradise Lost, his mind immediately leaps to these western shores and its inhabitants. He writes "such of late/ Columbus found th' American so girt/ With feathered cincture, naked else and wild/ Among the trees on isles and woody shores." Milton imagines Adam and Eve at this moment as "thus fenced" [italics mine], "their shame in part/ Covered, but not at rest or ease of mind."13 They are, in effect, fenced by the wilderness that had previously sustained them, their minds already grappling with the disorder engendered by eating the fruit of knowledge. But, perhaps most interestingly, in a lengthy 1644 treatise entitled "Mr. Cotton's Letter Lately Printed, Examined and Answered," Roger Williams argues that the church of the Old and New Testaments was always

separate from the world; and that when they have opened a gap in the hedge or wall 
of separation between the garden of the Church and the Wildernes of the world, God hath ever broke down the wall it selfe ... and made his Garden a Wildernesse, as at this day. And that therefore if he will ever please to restore his Garden and Paradise again, it must of necessitie be walled in peculiarly unto himself from the world, and that all that shall be saved out of the world are to be transplanted out of the Wildernesse of world, and added unto his church or garden. ${ }^{14}$

Williams seeks to explain Christian belief, alongside one's actual engagement with the world, as separate spheres of containment that can never intermingle, are in fact antithetical to one another. A hedge, or wall, he declares, must be maintained between the wilderness of the world and the garden of the church. Williams' view is not representative of most of his contemporaries, but it becomes, in some ways, the foundational ideology suggestive of the separation of church and state, which, whatever its virtues, implies the cognitive incongruity between widespread religious belief and the structural organization of western civilization. This notion is echoed by Vine Deloria, Jr., and Daniel R. Wildcat, who note "the deep opposition in Western thought between science and religion is the most critical and fundamental obstacle to integrating modern science and American Indian wisdom born of an experiential metaphysics."15

What Williams sees all too well is the overall structural violence of the system his Puritan neighbors, and by extension all of Christiandom with its various factions, schisms, and pogroms, are forwarding. The totalizing ideology of Christian faith, John Winthrop's wish for a City upon a Hill where religion and government are imagined to be in harmonious accord, is utterly incompatible with the exigencies of living in the New World. Winthrop's city is, by every measure, an ideological containment, and he, despite his perhaps naïve willfulness, cannot help but express as much. In a sermon to his shipmates, delivered as they arrived upon the shores of America, Winthrop vocalizes the anxiety that, if the Puritans fail in their endeavor to live righteously according to their doctrinal beliefs, they "shall shame the faces of many of gods worthy servants, and cause theire prayers to be turned into Curses upon us till we be consumed out of the good land whether wee are goeing." Winthrop, in the construction of his gleaming city, has already anticipated its fall. The forces of chaos are marshaled around it. In his desire to 
"possesse" the "good Land" he has already inscribed the violent expulsion from its cognitive state of grace. ${ }^{16}$

It is telling that Winthrop offers his sermon "A Modell of Christian Charity" from aboard his ship, the Arbella, prior to actually having set foot upon "the good land" he describes. The America Winthrop has in mind is still an imagined one, despite the fact that Winthrop himself will cling most stubbornly to his vision of it throughout his life. Plymouth colony's William Bradford, on the other hand, having had some on-the-ground experience, characterized New England as "a hideous \& desolate wildernes, full of wild beasts \& willd men." 17 America was a place "vast and unpeopled, being devoid of all civill inhabitants." $" 18$ This oft-repeated notion of an "emptie" continent, a "howling wilderness," was persuasive enough to become fully internalized by its new inhabitants over the centuries. When Francis Parkman writes of Le Jeune's adventures amongst the Montagnais he describes "a wilderness of rugged mountain-ranges, clad in dense, continuous forests, with no human tenant but this troop of miserable rovers." 19 No doubt the Canadian landscape loomed forbiddingly enough to Le Jeune, but it was clearly home to his Montagnais "host" who tells him, "see what a beautiful country this is; love it; if thou lovest it, thou wilt take pleasure in it, and if thou takest pleasure in it thou wilt become cheerful." Le Jeune, responding to his journal only, wryly comments, "I took pleasure in listening to the conversation of this poor barbarian."20

Perry Miller, the preeminent authority on the Puritans in the 1950s, argued against the notion that the Puritans saw the world as "new." He makes the case that New England's settlers were more pragmatic and less defined by religious fanaticism than their reputation, and the appellation they've been given, suggests. "These were not-despite their analogies with Moses and the tribes of Israel-refugees seeking a promised land," Miller maintains, "but English scholars, soldiers, and statesmen ... They knew that they would have to take pains in husbandry and business; since the fall of Adam such diligence was obligatory." ${ }^{21}$ They were prepared, in 
Miller's estimation, to face the world as they found it. He finds in Winthrop's sermon a certain practical fortitude for the task that lay ahead, a knowledge that, in regard to hard work and its relation to spiritual redemption, conditions in America would be no different from England. Part of the insistence, and anxiety, of Winthrop's sermon is that things should stay the same, particularly in regard to distinctions of class and gender. Winthrop, in fact, cautioned against ever discovering or encountering anything new in America. Miller asserts that, to the Puritan colonizers, America "was going to be the old, familiar world of sin and struggle: it differed only in that it was vacant (except for a few Indians). ${ }^{22}$

That Miller was not only able to dismiss Native presence on the American continent in such an off-hand manner, but virtually ignore the extent to which the Puritan writers themselves were intently focused upon representing and containing the Native encounter, shows how certain rhetorical conventions, the stock phrase of an "emptie continent," can contain multitudes. It also suggests the layers of denial that Winthrop studiously maintained and in which Miller was willing to participate to a degree. Miller summarizes the Puritan "errand in the wilderness" as a poignant mourning for a lost state that can never be recovered by second generation settlers. ${ }^{23}$ While late seventeenth-century preachers might exhort their practitioners that they had slipped from original purposes, the ideological front had been ceded. For various reasons, the singleness of purpose, the ideological fortitude that characterized the early settlement, has been dissipated and lost.

In contrast to Miller, Sacvan Bercovitch notices how, from the start, the Puritans are, in fact, highly invested in their sense of themselves as refugees. Bercovitch focuses on the ways in which Puritan writers have influenced the American imagination, by typologically equating their "errand" to the exile of the Israelites. The first settlers of New England envisioned the colonial project as a journey through a "desert wilderness," en route to a "promised land." Their descriptions of that land were almost unfailingly equated with biblical landscapes and 
geographies: Canaan, Babylon, Pisgah. In keeping with this vision, their mission, once there, would be equated with the mission of the apostles to convert the heathen who populated this wilderness. ${ }^{24}$ What emerges, however, in both Miller and Bercovitch, is a sense of how America, as an indigenous property, is constantly being displaced, or put in the service of exported epistemologies. Certainly the settlers live on the land, cultivate it, and thrive as a people. But their practices often fail to appreciate the sense of balance and maintenance that had been a part of Native cultivation and stewardship. The settlers would quickly drain the woodlands of its beaver, wolf, and wildcats, not to mention its woods. They would level its forests and pave over its hills and fields. They would organize themselves under biblical injunctions that belonged to the traditional practices of desert nomads who had lived thousands of years prior to themselves in a vastly different environment. The overall result is a widespread sense of alienation from the land, its peoples, and its history.

In the following chapter I demonstrate how the history of English colonization is in a very real sense, a casualty of its own policies of containment before it ever gets written. "The New England Mind" as opposed to "the Good Mind" was one bent on obfuscation and displacement. Deloria and Wildcat suggest that "if one understands this Western self-conscious faith in (1) abstract universal truths and (2) the European moral duty to remake the world (in accordance with these truths) in their own image, then the incredible force of these ideas explains much of human history for the last 500 years." They argue that European systems ignore the "power residing in places" and it is this ignorance, or negation of the particulars of place, that "informs the practice of colonialism.",25

Certainly the settlers sought to remake Indians in their own image, and this becomes one of the driving justifications for colonization, even as it always resolves, as I mention in chapter one, in a paradigm of either assimilation or extinction. Nevertheless, as Margaret Connell Szasz notes, "the efforts to school the Indian lay at the core of the cultural exchange."26 Miller finds 
that "conversion of the Indians is, inevitably, one of the seven purposes" that the colonists themselves acknowledge as their motivation. ${ }^{27}$ But if the Spanish and French were equally committed to conversion, the English, in particular, found themselves invested in at least the idea of spreading not just the gospel, but literacy, amongst the Natives. Szasz writes that "in early Stuart England, Christianization and civilization ... were mutually independent, and when these concepts were applied to the Indians they often came under the general rubric of 'education." 28

Even though "Indian education" is the platform upon which English colonization is founded, the politics of containment, driven permanently into the settler psyche, disallows the possibility of education or cultural knowledge ever flowing in two directions. Native civilization, Native arts, Native systems of knowledge are not disputed or engaged in the colonial period so much as they are cordoned off and made cognitively inaccessible. The Spanish conquistadors sought to destroy every aspect of native civilization that affronted them. French settlers labored to elide Native writing by averting their gaze from what they considered to be a false, devilish script. Indigenous textuality in the English colonies, when acknowledged at all, was conceptualized as the remnant of a former great civilization that had found its way here in biblical times, and had, through the loss of writing, forgotten its roots in western systems of knowledge. Indian civilization is displaced into a mythological Edenic realm, where it cannot be recovered or penetrate the psyche of the settler. If it is noticed to exist at all, it exists as something lost in the past, that can never be reclaimed. As Cotton Mather articulates it, "the natives of the country now possessed by the New-Englanders, had been forlorn and wretched heathen ever since their first herding here, and though we know not when or how those Indians first became inhabitants of this mighty continent, yet we may guess that probably the devil decoyed those miserable salvages hither."29 Although Mather himself scorns this belief, a good many New Enlganders were convinced that the Natives "were the posterity of the dispersed and rejected Israelites, concerning whom our God has promised, that they shall yet be saved." ${ }^{30}$ The 
figure of the Native that endures this framework, the textualized Native as will be presented here most specifically in the person of the Pequot convert Wequash, is but a cipher for English ambitions and agendas, the epitome of Vizenor's "simulations of dominance." Underpinning efforts at colonial containment, however, is the anxiety of an unstable world view that must violently suppress and reshape knowledge of its own historical acts and decisions to maintain itself.

Writing, as it turns out, is not only the means of perpetuating such constructions of history, but it forms the foundation upon which the colonial endeavor resides. While no amount of writing could elide the reality of Natives as a powerful political presence in the early seventeenth century and beyond, it could distort the lens through which military domination was ultimately effected while, simultaneously, cultural notions of western "civilitie" and enlightenment era values were enshrined. The very first texts to come out of the English colonies, such as First Fruits and Williams' Key to the Language of America are largely concerned with representing Natives and, in some measure, controlling the discourse by which the rest of the western world will view their subjugation. Although resistant Natives were not immediately able to "write back" against the grain of western history, residing behind their onedimensional representations were politically engaged figures who inscribed their own presence in the historical moment in ways that defy and transcend European containments.

\section{Moses in America: Lost Civilizations and the Intelligibility of Rock Carvings}

The history of colonialism is the history of how strength defines and rhetorically maintains itself; how the exercise of power is made to seem necessary, appropriate, and even humane; and how the violent excesses of power are discursively dislocated and, in most every case, reconfigured to perpetuate the sense that the colonized bring such violence upon themselves. While power is exercised through force and pressure, the normalization of power is 
exercised rhetorically. Therefore, as Robert Gray asserts in A Good Speed to Virginia in 1609, it is perfectly lawful to make war "upon barbarous and savage people, and such as live under no lawfull or warrantable government" so long as the goal is to "reclaime and reduce those savages from their barbarous kinde of life." ${ }^{, 31}$ In this quite common tautology (still being dusted off on occasion and used today) what makes a people barbarous is the fact that they have no law or warrantable government. The reason they are perceived to lack these things is not because they offer no discernable manifestation of the principles of law and government-the Powhatan confederation was easily recognizable to Gray's countrymen as hierarchical, and under an unquestionably greater civic management than the unruly Jamestown colony-but rather that the people in question have been predetermined to be savage and barbarous. ${ }^{32}$ This equation was reinforced by the unavailable evidence of a written legal code for Native culture. In fact, such an absence would become one more justification for violence, as it was supposed that domination and forced assimilation would help to introduce the writing that might codify the laws, which would then be able to assert a warrantable government. In Vietnam War era parlance, the village needed to be destroyed in order to save it, or as Gray surmises, "those people are vanquished to their unspeakable profite and gaine. ${ }^{, 33}$ Gray is correct in part. The combined elements that make such an equation possible are, in fact, "unspeakable."

The presumed lack of law, culture, art, and religion is the constant mantra of the colonizing regime, and it persists throughout the centuries, for it is upon this supposition alone that violent domination for humanitarian ends remains viable. Europeans were either incapable or unwilling to recognize a system of customs that were circulated and perpetuated through an oral tradition. Law, in order to be legitimate, had to be written down as were the laws of the Judeo-Christian tradition, which were fundamentally structured around the laws God had passed down to Moses, words inscribed in stone. ${ }^{34}$ Located somewhere within this narrative tradition is the decision of so-called "western culture" that oral law was no longer adequate-even God's 
dictums needed to be codified in writing. As Walter Ong suggests, a primarily literate culture "moves speech from the oral-aural to a new sensory world, that of vision." 35 The biblical figure of Moses stands at an interesting discursive crossroads, in which God still speaks to humans, but his words immediately transubstantiate into text. ${ }^{36}$ One of the psycho-dynamics of entering fully into a discourse of alphabetic literacy is that there is a heightened reliance on visual cues, and particularly displaced visual cues bound in signs and signifiers, so that the word becomes effectively inert, or as Ong states, it becomes a "thing" rather than an "event."37 Spoken words cannot have the force of law because they are not considered to hold any true substance, they are ephemeral, untrustworthy, a fractured vessel. The seventeenth-century Puritan evangelist John Eliot articulates this world view in his Indian Dialogues, a document that might be considered the first work of fiction (or at least the first work that acknowledges fictitious content) to be produced in the English colonies. In one of its imagined dialogues, the Wampanoag leader known as King Philip earnestly inquires of the young Indian convert Anthony, "what do you mean by scripture?" The erudite response, although placed in the mouth of a Native speaker, perfectly encapsulates the Puritan mindset concerning the centrality of scripture to spiritual life.

Anthony explains that scripture is

the word and will of God written in a book, where-by we not only hear it with our ears, when it is spoken by others, but we may see it with our eyes, and read the writing ourselves. And this is a great benefit to us, to have God's word and will written. For a word spoken is soon gone, and nothing retaineth it but our memory, and that impression which it made upon our mind and heart. But when this word is written in a book, there it will abide, though we have forgotten it. ${ }^{38}$

The dialogue, once again staged between two Native speakers, is clearly framed to insinuate the ephemeral quality of oral discourse as opposed to the durability of writing.

For anything to become set in stone, codified, legitimized by seventeenth-century European civilization, it needed first to be written down. And, as always, scripture remained the gold standard of authentic inscription, its validity maintained by a host of elaborate constructions, such as the stone tablets of Moses or the psalm quoted by Anthony in Indian 
Dialogues, wherein it is emphasized that scripture or "the words of the Lord are pure words: as silver tried in a furnace of earth, purified seven times. ${ }^{, 39}$ Six purifications would undoubtedly be too little. Eight, perhaps, a tad excessive. Inevitably, though, something is lost in this psychic transaction in which all reliance is transferred to the realm of representation, which is, perhaps, apprehended in the revelation that the tablets Moses brings down from his vision quest in the mountains are initially dropped and broken. It actually takes Moses three attempts to secure God's laws in Exodus, three trips up Mt. Sinai, a pattern of repetitions that has its roots in oral narrative. Even with the advent of literacy the word cannot be perfectly contained, and ultimately, the tablets containing the Mosaic Law, like all God-authored texts, disappear from human sight altogether, begging the age-old question between man and his gods, can you hear me now?

On the other hand, for those reared in the oral tradition, the word resides at the core of human experience and can hardly be separated from the actions to which it coheres. A. La Vonne Brown Ruoff comments on the notion that the word "enables Native people to achieve harmony with the physical and spiritual universe: to bring rain, enrich the harvest, provide good hunting, heal physical and mental sickness, maintain good relations within the group, bring victory against an enemy, win a loved one, or ward off evil spirits." ${ }^{40}$ Ruoff offers the example of a Yokuts prayer in which it is asserted, "My words are tied in one/ With the great mountains,/ With the great rocks,/ With the great trees,/ In one with my body/ And my heart." ${ }^{, 41}$ In other words, words are not merely arbitrary signs meant to represent a more tangible reality, but are in fact, active components of that reality, expected to elicit results in the moment of their utterance. Ong asserts that in the psychic life of a primary oral culture "the way in which the word is experienced is always momentous. ${ }^{, 42}$ Speech cannot be isolated in abstraction from the moment in which it participates. Words are not empty.

One practical way in which this cognitive engagement with speech is reflected in Native 
life is noted by James Axtell, who recognizes how "Indian speakers were respected and never interrupted. ${ }^{, 43}$ The Native peoples of America did not talk over one another because in their world view speech was an event that required the most acute attention. As one early settler of the New England colony, William Wood, observed,

In serious discourse our southern Indians use seldom any short colloquiums but speak their minds at large without any interjected interruptions from any, the rest giving diligent audience to his utterance. Which done, some or other returns him as long an answer. They love not to speak multa sed multum; seldom are their words and deeds strangers. ${ }^{44}$

Culture resides in memory, and to lose the thread of speech or drift off during an oration hazarded the loss of vital information, possibly of life or death consequence. To live within an oral consciousness, then, was to always be at attention-not in a stiff, military posture, but as a matter of habit, a state of being. One was not only awake to verbal cues, but to the cues of the natural world with which one was also always in conversation. European observers were forever astounded and occasionally thwarted by the Native ability to recall former addresses and the particulars of treaties verbatim. Ben Franklin observed that, because they "have no writing," Natives themselves "are the Records of the Council, and they preserve Traditions of the Stipulations in Treaties 100 years back; which when we compare with our Writings, we always find exact. ${ }^{.45}$ Regardless of the mnemonic aids, such as wampum, talking sticks, winter counts, string balls, history baskets, and other "oratorical crib sheets" employed in such ritualized settings, Europeans were more inclined to attribute such abilities to Native alterity, an essential difference that had its roots in the worship of satanic idols. ${ }^{46}$ Even Franklin, in his presumably favorable discourse, is quick to note that Natives have no writing of their own, and therefore their abilities remain quaint curiosities rather than the enduring institutions of a legitimate civilization.

Another likely effect of oral, or Native, consciousness is that, due to a heightened sense of communication with the world, one maintains a direct relationship with the divinities, the 
manitous or spirits that Europeans equated with devils. George Copway would tell how "I was taught to believe that the Gods would communicate with me, in the shape of birds, animals, etc. ${ }^{47}$ Because speech is an event, God's words can not be confined to a textual domain, but exist in the moment, resound in dreams and visions, and are actively entangled in the fortunes of the community. If the English were inclined to pray silently or in hushed tones, a sort of mental exercise that was meant to be experienced privately and in expectation of no audible reply, Natives were observed to sing out to their gods in full voice coupled with demonstrative physical activity, giving every indication of apprehending a response. As Cotton Mather notes, even the Praying Indians, or Indians who had opted to live in organized Christian settlements, prayed "without a form," and he remarks with bemusement what a spectacle it would be should these same Natives attend a white service. Mather writes, "they can pray with much pertinence and enlargement: [but] would much wonder at it, if they should hear of an English clergy, that should read their prayers out of a book ${ }^{98}$

Edward Winslow, a leader of the Plymouth Colony, notes how, in their religious observance of Kiehtan, the Narragansett would "meet together, and cry unto him, and so likewise for plenty, victory, \& co. sing, dance, feast, give thanks, and hang up garlands." He observes of the deity Hobbamock, whom the Puritans most often associated with the devil, that he "appears in sundry forms unto them, as in the shape of a man, a deer, a fawn, an eagle, \& co. But most ordinarily a snake," and to the spiritual leaders of the tribe "he appeared most ordinary [often] and is most conversant. ${ }^{, 49}$ While the English were dismissive of Native beliefs and Native rituals, they did not necessarily consider these communications to be fabricated, but rather had little doubt that Natives were in actual conversation with the devil.

The culture of alphabetic literacy to which the Puritans belonged, regardless of the occasional isolated claim to divine visitation, had more or less closed itself off from such a direct correspondence with the spirit world. Although its scriptural antiquity was fully loaded with such 
encounters, the Puritans themselves had become disconnected. The author of Mourt's Relation notes,

whereas God of old did call and summon our Fathers by predictions, dreames, visions, and certain illuminations to goe from their countries, places and habitations, to reside or dwell here or there ... now there is no such calling to be expected for any whatsoever, neither must any so much as imagine that there will be any such thing. God did once so traine up his people, but now he doth not, but speakes in another manner. . . Now the ordinarie examples of the scriptures reasonable and rightly understood and applied must be the voice and word, that must call us, presse us, and direct us in every action. ${ }^{50}$

A result of all this, one imagines, is that despite its dynamic technological proclivities, in most ways the culture of alphabetic literacy, which we think of as western culture, deceived itself into forging a static engagement with the world based on ostensibly unalterable textualized traditions. Scripture was expected to direct "every action" regardless of its bearing on the exigencies of a given moment. Eric Havelock comments how, in the earliest periods of "stabilization and canonization of the text [he is speaking specifically of the Old Testament here] there was room for the scribes to interpret the unvocalized script in different ways according to their theological inclinations." Once a given reading became orthodox, however, "there came a need to guard it against alteration." Therefore, to a surprising extent, the world that sketched itself out before the colonial eye was alarmingly predetermined. Europeans mostly saw what they had been trained by their cultural upbringing to see, and whatever did not fit comfortably within that design was either made to fit in some roundabout way or effaced through an elaborate project of unwitnessing.

Perry Miller and Thomas Johnson claim that "the Puritans were assured that they alone knew the exact truth, as it was contained in the written word of God, and they were fighting ... To extirpate utterly and mercilessly all other pretended versions. ${ }^{\text {52 }}$ Their proclivity to displace reality in favor of a textualized relationship with the world, while psychologically jarring, would prove, perhaps paradoxically, a highly viable strategy for success and cultural conquest. Westerners exhibited a rigidity of purpose and belief that was at once dangerous and compelling. 
The ability to disregard the evidence of the eyes and ears, ignore nature's signs, displace horrific events, to edit traumatic experience by manufacturing more tenable representations, became both the great strength and the most pernicious psychological weakness of western culture. As one Huron man railed against the French Jesuits amidst the heartbreaking ruins of disease that had swept through his community, "what kind of men are these? They are always saying the same thing, and repeating the same words a hundred times. They are never done with telling us about their Oki, and what he demands and what he forbids, and paradise and Hell." 53 While every civilization has the ability to deceive itself or make self-interested, misguided calculations, western civilization literally turned this into an art form, allowing itself to disregard or displace its genocidal impulses and ecological degradations in favor of a narrow world view that, whatever its limitations, becomes unequivocally written in stone and provides the foundation for colonialism and all its ills. In other words, western civilization over a period of thousands of years of trial and error has convinced itself of the efficacy of discursive displacement, willful unknowing, as a successful survival strategy.

For all these presumed epistemological differences, however, the world of the settler and the world of the Native was never so absolutely individuated. Each was beholden to a like thread of human need and potentiality wound in a community setting, and their respective manners of meeting these concerns only differed in habit and degree. Therefore what differences there were often presented themselves as cause for rhetorical exploitation. And often, the most obvious marker of difference for Europeans intent upon asserting their cultural superiority was their possession of the technology of writing. While European weaponry remained a persuasive indicator of superiority, it often wasn't enough to win the day, and it is doubtful that Native culture would have acquiesced to European power if not for the torrent of pandemic diseases that swept off some $80-90 \%$ of the population on the eastern seaboard, much of this before European settlements were even established. Writing, on the other hand, offered an endless rhetorical realm 
of validity to European endeavor, justifying its ends, providing a tangible backdrop to the entire architecture of western history, values, and beliefs that could be set before the eyes of their indigenous neighbors as evidence of a vast and unshakeable storehouse of cultural goods and knowledge. Native Americans had accumulated a similar wealth of knowledge, history, and lore, but it remained largely inaccessible to European observers, an easily dismissed abstraction that was vulnerable to the more aggressive forms of western hermeneutics. Whenever Europeans were inadvertently made aware of the rich cultural lives of Indians, they were quick to contain such glimpses within a rhetorical framework that denied the legitimacy, or even the very existence, of such evidence.

As has been noted, the Native populations of Mexico and Canada were abundant in all of the recognizable particulars of human culture and expression. Was it any different for the Native peoples of what is now the United States? Before focusing solely on Native Americans entering into the discourse of alphabetic literacy, it seems essential to cultivate some understanding of the engagement with signifying forms that already existed in North America previous to Native Americans picking up the pen and to fully recognize how that engagement was systematically obscured by European print discourse. Certainly the body of firsthand literature built up around every aspect of the colonial endeavor argues persuasively against the idea that Native Americans had any kind of codified art, religion, or science. A partial exception comes from the Dutch Moravian missionary John Heckewelder who, having lived amongst the Lenape, accustomed himself to the language and traditions of these people. Although he repeats the colonial mantra that "the Indians do not possess our art of writing [for] they have no alphabets, nor any mode of representing to the eye the sounds of words spoken," nevertheless, he offers one of the rare observations made by a European that is appreciative of an indigenous system of signification. He notes that the Lenape have,

certain hieroglyphics, by which they describe facts in so plain a manner, that those who are conversant with those marks can understand them with the greatest ease, as easily, 
indeed, as we can understand a piece of writing ... All Indian nations can do this, although they have not the same marks; yet I have seen the Delawares read with ease the drawings of the Chippeways, Mingoes, Shawanos, and Wyandots. ${ }^{54}$

One must search painstakingly through the archives, however, to find a like piece of evidence that Natives kept records of their laws, religions, customs, and histories. The colonizing eye glosses over such evidences as the winter counts of the Sioux (described by Vine Deloria, Jr., as "the psychic life of the community"), ${ }^{55}$ the rock paintings and birch bark scrolls of the Ojibwe, or the petroglyphs that mark the canyon walls of the American Southwest. These often seem merely the exception that proves the rule, and their inscriptions, cognitively relegated to some primitive classification of cave drawing or ancient graffiti, do not obtain. Ethnographer Henry Rowe Schoolcraft, writing in 1836 , expresses surprise even at the fact that Natives kept stories and had "an oral imaginative lore" that passed from generation to generation. ${ }^{56}$ The result is that, for every example of Native record keeping that shows itself, the Walam Olum of the Lenape being the most notorious example, there is a chorus of voices waiting to debunk the authenticity of any such intellectual property. While accounts of the Spaniards and French were able to, at least, glimpse the writing practices of Natives, for the English colonist Native writing is rendered effectively invisible or relegated to the domain of a lost culture.

Roger Williams, whose intimacy with Narragansett culture made him an occasionally serviceable witness, apparently did not locate written symbols in Native life. In a chapter that focuses on "Their Numbers," he comments that "having no Letters nor Arts, "tis admirable how quick they are in casting up great numbers, with the help of graines of Corne, instead of Europes pens or counters. ${ }^{{ }^{57}}$ Like most European observers, Williams is unable to account for the quickness of Native intellect and asks "let it be considered, whether Tradition of ancient Forefathers, or Nature hath taught them Europes Arithmaticke." 58 The reference to an ancient civilization is called upon to explain away the presence of what is, in Williams' mind at least, a European property. Thomas Mayhew recounts how "a long time ago they had wise men, which in 
a grave manner taught the people knowledge; but they are dead, and their wisdom is buried with them." 59 The ancient civilization alluded to was presumed to be one descended from the lost tribes of Israel, which helped to explain how certain Native accomplishments and tendencies were likely to mirror European capabilities. If the Indians knew arithmetic it must have been the result of a held-over wisdom, a vestige of the arts and sciences once practiced by their forgotten western forebears.

As noted in the last chapter, Williams distinguished two different terms in the Narragansett language, wussuckwhommin and wussuckwhekke-"painting" and "writing," respectively-both derived from the same root, but the former belonging to Native tradition and the later a newly coined word as a result of colonial engagement. In his chapter on Native clothing Williams notes that their moose and deer skin attire is commonly wussuckhosu, or painted "with varietie of formes and colours. ${ }^{" 60}$ He will not train his eye too closely upon such "formes," but one wonders if they bear any resemblance to the painted surfaces of the Montagnais-Naskapi hunting jackets discussed in the previous chapter. In a later section of his Key into the Language of America when Williams speaks directly to "their painting," he remarks only of "the foolish Custome of all barbarous Nations to paint and figure their Faces and Bodies (as it hath been to our shame and griefe. Wee remember it of some of our Fore-Fathers).,"61 Again, Williams finds a way to link the custom of face painting to outmoded western traditions, but he fails to offer any description of the manner in which the Narragansett "figure" their faces, leaving the impression that there is no quantifiable art to such practices. The only clues that such a tradition may be more intricate and involved than Williams suggests is evidenced in the lexicon for his chapter on painting where, for a second time, he offers the term wussuckhosu, meaning "a painted coat," and adds "of this and wussuckwheke, (the English Letters, which comes nearest to their painting) I spake before."

In what way, one wonders, are the figures of wussuckhosu "nearest" to English letters? 
The implication, however buried in Williams' circuitous syntax, is that the characters of the wussuckhosu, in their similarity to European writing, are not simply ornamental flourishes but communicative symbols that Williams is hesitant to read. He has already intimated earlier that he was careful not to observe Native rituals firsthand for fear of being a party to blasphemy. How much more dangerous would it be to engage in a textualized encounter with Native belief systems, when texts were the ultimate conveyers of spiritual knowledge, manittowock, God?

In all likelihood, examples of Native writing were met with a certain amount of frequency, but dismissed as a diminished, unnoteworthy thing or attributed to a more sophisticated indigenous civilization of the past, whose vitality had long ago given way to cultural erosion. The English trader Thomas Morton, in some ways a sympathetic commentator on Native peoples and practices of seventeenth-century New England, observed, "it seemes originally, [they] have had some literature amongst them, which time hath Cancelled and worn out of use. ${ }^{.62}$ He offers no suggestion as to what he bases this observance upon, but the language itself, with its allusion to erosion, points to his familiarity with the markings left on certain New England rock formations in the area of his settlement. Why Morton might attribute such markings to bygone generations is difficult to say, unless of course it simply suited his rhetorical purposes. Cotton Mather would note in his Magnalia Christi Americana that "moreover, they [the savages] have little, if any traditions among them worthy of our notice; and reading and writing is altogether unknown to them, though there is a rock or two in the country that has unaccountable characters engraved upon it." ${ }^{363}$

Mather dismisses these intriguing engravings with a stroke of the pen, but it is of interest to note that when he offers his hagiography of John Eliot in his Magnalia, he opens with a strange anecdote that might otherwise seem to have no bearing on the matter. He tells of a group of Middle Eastern shepherds upon Mount Nebo who, pursuing their flocks, come upon a nearly inaccessible cave, wherein they find a sepulcher "that had very difficult characters upon it." The 
shepherds, with the help of local authorities, determine the tomb to be that of Moses, but upon removing the stone, they find the grave empty, and Mather asserts that the conquering Turks later took pains to forever conceal the sight from human view. The anecdote seems to suggest that, in preparing to speak of Eliot and his labors bringing writing to the Indians, Mather is moved to make an association with strange, "difficult characters" carved on stones. "The world would now count me very absurd, if after this I should say that I had found the sepulcher of Moses, in America" Mather jests. ${ }^{64}$ Given his later statement about rocks with "unaccountable characters," however, one might surmise that Mather had discovered enough to arouse troubling questions, instigating an anxiety that forces itself into his conversation on Eliot. If writing was God's gift to Moses, then engraved rocks in New England could only be "unaccountable," either a savage equivalent of the Mosaic revelation or the result of a lost culture, a true civilization that had somehow fallen into savagery.

There are other indicators that colonists were aware of Indian writing and Indian art. John Danforth in 1680 made a meticulous copy of the markings on Dighton Rock, located on the Taunton River in Wampanoag country. Cotton Mather, sending this drawing to a correspondent in England, notes its "strange characters" and "odd shapes" that engender "odd thoughts." $\mathrm{He}$ wryly suggests that the colonists would express their gratitude to their fellows and patrons back home "not less durably, but more Intelligibly ... than what the Indian People have Engraved upon Rocks." ${ }^{, 65}$ William Wood speaks of the "antic embroidering" that would be painted upon deerskins after they were properly dressed. John Josselyn observes "tobacco pipes of stone with their Imagerie upon them." And Edward Winslow would notice the "many curious mats" that were used to cover deceased sachems in Massachusett burial rituals. ${ }^{67}$ What seems apparent in all these scattered and indirect glances is the likelihood that colonial commentators, whatever their intentions, refused to fully see or acknowledge the validity of an existing system of Native signifiers. In many cases, to notice such an entity would either pose a direct threat to nationalistic 
ambitions, or worse, threaten the very structure of religious belief systems that were reliant upon a sense of textual infallibility. This denial, which must be considered a traumatic elision, has had repercussions that continue to shape prevailing notions of Native life and Native civilization, both past and present. When Native Americans pick up the pen it is considered an act of wholesale assimilation rather than the continuation of a traditional performance in a new form. As we will see, nothing signaled a more thorough success of Native conversion to European observers, than the example of the literate, or schooled, Native. The lettered text written by Native hand, whether in English, French, Spanish, Latin, or Greek, provided solid proof, perhaps the only proof, that the individual writer had been lifted out of a state of savagery. The fact that the introduction to print culture appears to be an act of total assimilation, assisted by the benevolent interference of a superiorly equipped cultural force, is heavily reliant on the belief in Native savagery as defined by a lack of culture or writing. To eliminate the cultural artifacts that might challenge such a supposition, however, one must first, as part of the essential act of containment, reveal in some form the very thing that must be subsequently unwitnessed. Roger Williams must mention Native paints and figures before dismissing their relevancy. Cotton Mather must slip in a reference to known points of interest such as the Dighton Rock hieroglyphs before rendering them "unaccountable," or un"intelligible." The failure to do this, to simply ignore such features of Native civilization, would allow them to attain a life of their own and risk the spread of freewheeling rumor, the invalid, uncontained interpretations that threaten to disrupt the master narrative of the dominant culture.

Because the colonists were so efficient at concealing or redefining the existence of Native writing, later commentators were equally convinced that there was no such creature, and when confronted with it, they too either dismissed such findings or attributed them to a much earlier civilization. When Dr. Benjamin Smith Barton made his address on Indian artifacts to the American Philosophical Society on 20 May 1796, he noted that "there are several reasons for 
believing that the ancestors of some of the present races of Indians were acquainted with a kind of Hieroglyphic-writing, very superior to the rude picture-writing now in use among them.., When confronted with several examples of Native writing, including a large bone, recently unearthed, marked with elaborate inscriptions, he speculates "are there no proofs that the rude nations of America have fallen from a more respectable form of society than that in which we currently contemplate them?"69 Further commenting upon a "large stratum of rock" found in what was then Virginia, on the Ohio River, "which is engraven with hundreds of hieroglyphics," Barton concludes that these too were "doubtless very ancient." He conjectures that instruments of iron would have been needed to carve such inscriptions - a supposition that, even if it were so, would just as easily have lead to the inference that they were made after contact with Europeans rather than prior to such a time. ${ }^{70}$

"Curious," "unaccountable," "difficult," "half-worn." These were the kinds of terms brought to bear on any evidence that Natives employed signs in supplementing their oral traditions. The inscriptions found at Dighton Rock on the Taunton River in present-day Massachusetts, first reported by John Danforth in 1680 , were, for years, attributed to everything but a Native agency. They were assumed, variously, to be the work of Vikings, Portuguese, Chinese, and even ancient Phoenicians. Commentators labored to find recognizable patterns from western antiquity in the markings there, assured as they were in their belief that Natives did not leave such records. As one Doctor Webb was noted to say in 1830 , "it is a well attested fact, that no where, throughout our widespread domain, is a single instance of their [Natives] recording or having recorded their deeds or history on stone." ${ }^{, 71}$ Again, an utterly erroneous comment, but one that had been repeated over and over again by colonial observers until it had attained the semblance of truth. Although Schoolcraft would offer a number of contradictory readings of the Dighton Rock inscription over his career as geologist and ethnographer, he made the relatively unusual move in 1839, of submitting a drawing of the rock to Chingwauk, an "Algonquian 
Priest," and Ojibwe political leader, who immediately recognized the symbols and did not hesitate to translate their content. ${ }^{72}$ Characterizing it as muz-zin-na-bik, which Schoolcraft translates simply as "rock-writing," Chingwauk offered a complex reading, telling the history of an "ancient" prophet-sachem and his sister who lead a successful excursion against another Indian nation. Chingwauk's reading provides many intimate details, such as the layout of the prophet's sweat lodge, the totem, or spirit animal, that came to assist him, the number of months he waited in preparation for his vision and strategy, and the number of men who died in the confrontation. Eventually a peace was negotiated, and this too is part of the inscription. ${ }^{73}$ Chingwauk's reading was hardly credited, however, one commentator asserting that "the Indian is no better qualified to interpret petroglyphs" than was Schoolcraft himself. ${ }^{74}$ Edmund Burke Delabarre, in his 1924 publication on Dighton Rock, also dismisses Chingwauk's reading out of hand and offers that the initial marks on the rock were made by the Portuguese sailor Miguel Cortereal in 1511 this despite the fact that Cortereal was thought to have been shipwrecked off the coast of Newfoundland some nine years earlier. In Delabarre's reading, Cortereal survived (and made his way southward), leaving his name and the date on this rock so rescue crews might discover him. In the interim Delabarre posits that Cortereal somehow managed to become chief of the local indigenous peoples who were later inclined to ape his efforts by making their own inchoate markings on the rock. Delabarre even entertains the notion that, as a result of Cortereal's rise to indigenous royalty, he was likely to have been a forebear to Metacom or King Philip who leads the 1676-77 insurrection against the English. ${ }^{75}$ Once again, despite all available evidence, Indian writing is regarded as an off-shoot, mere mimicry, of European writing. It remains a popular researcher's obsession to offer new, complex, and bizarre interpretations of who might have left the markings on Dighton Rock. Interestingly enough, though, if you ask the Wampanoag themselves, the story is one of contact.

According to the Wampanoag elder Manitonquat (Medicine Story), Dighton Rock carries 
the details of a prophecy made by the culture hero of the Wampanoag, Weetucks. This story,

recorded by Edward J. Lenik in 1998, goes as follows:

Weetucks led the people down to the river bank and showed them a large rock... On the smooth southern face of this rock he had . . . carved a large figure, which he told them represented Kiehtan, the Creator. Next to that was a smaller figure which Weetucks said represented their Kiethan's helper first-teacher Maushop. Across the center of the rock he had carved many fantastic shapes, animals and birds and fish and plants that were known to no one. This, he said, represented the vast unknown variety of beings in the Creation. At the eastern edge there were two human beings standing together. The first was looking back towards the Creator and Maushop and the marvelous figures of Creation. But the other was looking away, looking off the rock towards something beyond, toward the east. And over the head of this last person was carved a lightning bolt, pointing down right above him, pointing down to the top of his head.

Weetucks ... Told them of the new way that would come to them from the east, from beyond where the sun rises. He told them that they would follow different ways and that the people of the Morning Light would be tempted to follow these new ways, for they would seem attractive and good. People would actually begin to learn the new ways and forsake the old ways. But eventually it would be seen that these ways were destructive, that because of them the forest and the creatures of the forest, including the human people, would begin to be destroyed. That was what was meant by the lightning bolt above the head of the outer figure on the rock.

Manitonquat concluded by noting that "those who continue to follow in a sacred path, the way of the Creator, and also those who saw their mistake in time and turned around to find Creation's way again, these would survive to help heal the earth and restore the balance of life. ${ }^{, 76}$ (Schoolcraft's picture of Dighton Rock here as well as the picture of Dighton Rock taken by Captain Seth Eastman-grandfather of Charles Eastman).

The same historical layer of skepticism that discredits a Native agency for the carvings on Dighton Rock has been applied to the Walam Olum of the Lenape. The Walam Olum purports to be a record of the Lenape creation narrative and the details of their migration to what is now known as the region of the Delaware River valley. Written in hieroglyphic symbols that were originally said to have been carved out on sticks or wooden tablets, the Walam Olum begins at the dawn of time "there at the edge of all the water where the land ends" and concludes with the arrival of white men, described as "friendly people with great possessions: who are they?"77 (picture of first and last hieroglyphs) Often presented as the only pre-Columbian text of North 
American origin, the Walam Olum seems to pose a solution and a threat to western researchers. ${ }^{78}$ If regarded as genuine, the text provides intriguing clues that suggest the indigenous people of the Americas crossed a land bridge from Asia in some ancient past to arrive upon a raw unpopulated continent. The text poses a threat, however, because it stands (however obscurely) in the face of those who insist that Native civilization was prehistoric and in need of European improvement. In a sense, to offer the Walam Olum legitimacy would be to undermine, in a very concrete manner, the entire colonial enterprise.

Both extreme views, however, play specifically to European expectations, anxieties, and justifications. They are premised on the idea that the text of the Walam Olum, as transcribed by the eccentric naturalist Constantine Samuel Rafinesque in 1836, must be considered a definitive version, set in stone, just as the Old and New testaments of Judeo-Christian traditions are presumed to be (it should be noted that the Lenape, themselves, do not agree about the legitimacy of the Walam Olum). Most treatments of the text have regarded it as such, with the, perhaps, counterintuitive effect of making it easier to discredit. Rafinesque, who mysteriously acquired and then lost the original wooden tablets, claims to have been given a translation of the hieroglyphs in the "Linapi" language, which he then studiously transcribed into English at his own leisure. ${ }^{79}$ Inherent in this process are all the usual problems of amanuensis. How much was the presumed Delaware informant willing to reveal to Rafinesque of sacred songs and traditions? How much of the narrative is misinterpreted or garbled by conflicting cultural codes and desires? How much was the translation whittled down by the time restraints of both the informant and the editor? And how much of the narrative, as told to Rafinesque, was deliberately cast to meet the demands of European audiences and culture? As David McCutchen, who has written the most comprehensive contemporary examination of the Walam Olum, notes, "it was not until well into the twentieth century that the Delawares were allowed to practice their ancient religion legally and openly." This would have created compelling reasons to suppress various aspects of the 
narrative. ${ }^{80}$

The scope, the richness, the potentialities for narrative expression suggested by the hieroglyphic markings can only be guessed at by contemporary readers, and it is doubtful that Rafinesque offers anything like a complete translation of the ceremony that would have accompanied any ritual reading of the Walam Olum. Therefore it is likely that certain aspects of Rafinesque's translation, particularly some of the more Eurocentric portions, were molded either by the Lenape translator or by Rafinesque himself to fit the predetermined expectations of a European audience. The fact that the story ends with white people arriving bearing superior gifts is likely to be an innovation tacked on to please. Certain passages that seem to point to the Asian land-bridge theory are also likely to have been tweaked to meet audience expectations and might just as likely point to an ancient period when large portions of the North American continent were underwater. ${ }^{81}$ Nevertheless, these features of the text, along with the disappearance of the original wooden tablets, have led a number of authorities and scholars to denounce its credibility, the latest being David Oestreicher who in 1996 published an article entitled "The Unraveling of the Walam Olum."

My object here is not to assert or deny the validity of the Walam Olum, but simply to remark on how Oestricher's debunking of it falls into typical patterns of misunderstanding the nature of oral texts and oral traditions. ${ }^{82}$ He first claims that the Walam Olum is "historically unreliable" as its offered migration narrative along with its chronology of sachems seems to contradict the findings of radiocarbon analysis that indicate the Lenape have resided in the northeast for some 12,000 years. The accumulation of generations, as tallied through the lineage of sachems listed in the Walam Olum, simply doesn't conform to scientific estimates based on the dating of archeological artifacts. ${ }^{83}$ As Peter Nabokov cautions, however, "most Indian historical forms are forever 'under construction.' What is deemed traditional, historical, or even sacred to one generation may subtly shift categories in the next, and Indians should not be 
penalized for keeping their histories pertinent." ${ }^{84}$ Undoubtedly this concession will strike some western readers as biased or "cheating," until one considers that a reading of the lineages of the Old Testament would place the creation of the world at some place around the year 4004 B.C. E. We may argue the scientific viability of such a cosmology, as school boards in Kansas and Pennsylvania continue to do (at the time of this writing), but it does not serve to devalue the authenticity of the Old Testament itself as a valid carrier of Christian and Judaic traditions.

Oestricher's next complaint is that many elderly Lenape speakers of his acquaintance did not consider the Walam Olum to be part of their culture at all. There could be many reasons for this, including the possibility that Oestricher's informants were unwilling to speak to him about their traditions. ${ }^{85}$ It may also be the result of the simple fact that those he spoke to were themselves unaware of the tradition that linked Lenape belief to the Walam Olum, probably for the same reasons that most white people deny such associations. Indian writing is not presumed to exist, history ignores it, and in many cases the Lenape are susceptible to a white hegemonic framing of history. What should be clear by now, however, is that the Lenape did transpose their traditions into written hieroglyphic symbols, and by whatever title one chooses to call such texts, and however such texts were interpreted, they were in fact a part of Lenape history and ceremonial life, as acknowledged by Heckewelder and others.

Finally, Oestricher notices how the idiomatic structure of the Walam Olum suggests that Rafinesque's translation was first composed in English and then translated into Lenape, rather than the other way around as logic would dictate. He writes, "I find the text was filled with preposterous grammatical constructions and fractured words ... Replete with crossed-out Lenape words that had been replaced with others that better matched his English 'translation." " 86 This again seems to assume a pre-Columbian text that has actually been preserved in its original form and syntax from pre-Colombian times (a wooden text is not likely to last so long, I think). Oestricher offers not a single specific example to support his claims, however, and even if he did, 
it only suggests that Rafinesque, like most white editors of Native texts, took the liberty to construct a translation that accommodated his own aesthetics and preconceptions. In other words, once one gets around the notion of a "pure" text, what we realize is that the Walam Olum, and other Native texts that perform in a similar cognitive framework, is a device for the transmission of oral traditions, and only as vital, detailed, and relevant as the culture that maintains it.

Oestricher concludes that the entire 1836 "forgery" was composed as a veiled attack on the then controversial Mormon church, which had been founded by Joseph Smith a few years earlier. This is, perhaps, the most convincing claim that Oestricher makes given the similarity of how the Walam Olum and the Mormon Bible came into view and the historical and geographical proximity of the editor/authors. Smith claimed to have discovered golden tablets buried on a hill in upstate New York written in the "language of the Egyptians," and that they were later translated for him by the angel Moroni who visited Smith in his Philadelphia home. The result is that the Mormon religion is also built upon the age-old assumption that the Native peoples of America were the descendants of the lost tribes of Israel, and the tablets were presumed to be missing chapters of scripture, once again God's writing, carried to America from the old world and faithfully preserved in Europe's most prized element, gold. Oestricher notes that "like Rafinesque's Walam Olum, Smith's original tablets had vanished without a trace, leaving only his copies to posterity. ${ }^{, 87}$ What seems likely, however, is that if Smith found anything at all, he found another specimen of Native textuality similar to what Barton, Heckewelder, Rafinesque, Schoolcraft, Copway, and others have described. This is the logical conclusion; in fact, the only conclusion one must draw, discounting the possibilities of blatant falsehood or delusion. How might Smith's tablets have been translated if a Native American such as Chingwauk, or Manitonquat, schooled in the system of indigenous signifiers and narratives, had been presented with them rather than an angel with no training in Native writing systems? Because European culture found Native texts unaccountable, however, Smith attributed what he found to Egyptian 
hieroglyphs of divine emanation and founded what is today one of the world's fastest growing religions. ${ }^{88}$ (Ironic or what?) The fact that Rafinesque lost the original tablets or sticks that held the symbols of the Walam Olum will continue to cast some quantity of doubt upon its validity until, as with the Mormon origin narrative, as with the Old Testament story of Moses, it becomes the narrative of a people too numerous and too powerful as a political entity to dismiss out of hand.

In the end, the Asian land bridge theory that the Walam Olum appears to espouse is probably one favored by Europeans more than Native Americans. As F. David Peat notes, in a book entitled Blackfoot Physics, "we should always be cautious when Western scientists project their own world view upon Indigenous peoples. Their general assumption is that cultural exchange always came in one direction, from Europe or possibly Asia into the New World."89 One might read the Walam Olum, however, without assuming that the crossing of the Bering Strait is a given feature of its content. What the Walam Olum does assert is that, in ancient Lenape traditions, as in the traditions of many other North American nations, there was a great flood over the land "so that the water ran and ran, spreading in hollows, penetrating here, and penetrating there, destroying something here and destroying something there." 90 In the Rafinesque version it is the trickster hero Nenabush, "grandfather of people, grandfather of men," who defeats the underwater serpents responsible for the flood, and then, upon the back of a great turtle, performs the necessary rites to "repair" the watery world. Dry land is once again restored upon the turtle's back so that the people might live. ${ }^{91}$

\section{Captive Audiences: New England's Early Native Students or First Fruits}

As nineteenth-century historian W. Deloss Love observed in his book on the life of Samson Occom, Indian education remained "a common article of the immigrant's creed." Love was among the first to point out that all the charters for the various English colonies, beginning 
with the Virginia Company charter in 1607 , contained a clause relating to Indian education. As Love notes, this provision is echoed again and again, including, of course, in the charter of the Massachusetts Bay Company with its suggestive seal of the leaf-bedecked Native asking the Pilgrims to "come over and help us." So often is this summons associated with the particularly Puritan aspects of colonization that we forget the language was precisely that used by the less spiritually ambitious Jamestown settlement as well. While the Virginia settlements lacked the spiritual dedication to Indian education that certain individuals in New England were able to muster, the settlement claimed at least one convert in Pocahontas, who, according to Paula Gunn Allen, ordered her own initiation into the "order of the Christian lodge" in the conscious role of cultural intermediary ${ }^{93}$ Her education into alphabetic literacy, if it hadn't already begun, was eminent when she died in Gravesend, England, in 1617, on her way back to America.

As was the case with the Jamestown settlers, the New England colonists found the reality of training Natives in English customs and manners more complicated than they had initially envisioned. Who could have anticipated from across an ocean that Natives, raised "naked" and far from the civilizing light of Christianity, were perfectly happy with their cultural practices, had loving families, had durable networks of kinship and trade, and found comfort and security in their traditions, both spiritual and cultural? In the early days of the Plymouth settlement the colonists were more in need of Native assistance than the other way around. In fact it took nearly twenty-six years before the colonists could begin to implement their charter claims to help the Natives, and this was only after disease and the Pequot War of 1636-37 had altered the overall balance of power in New England, leading John Robinson, the Puritan elder still residing in Leyden, to exhort his wayward flock, "Oh! How happy a thing had it been, if you had converted some before you had killed any." 94

As one peruses the titles of Puritan tracts devoted to educating the Natives and bringing them into the fold of Christian knowledge titles such as New England's First Fruits or "The 
Glorious Progress of the Gospel Amongst the Indians of New England"-one receives the impression intended by their authors that this was a process of infinite patience and persuasion. Such titles serve to conceal the violence and cultural destructiveness that lay behind these initiatives. In the final analysis, the art of persuasion had little to do with Natives converting and adopting English customs. More instructive, and indicative of the overall process, was the original kidnapping of Pocahontas by Samuel Argall in 1612, and Virginia Colony's Governor Gates' decree that other Native children should be kidnapped and brought up in English homes with the purpose of educating them. ${ }^{95}$ The language of the propaganda tracts, however, like the language of the charters before them, served to provide institutional cover for reprehensible acts and proved effective in the practice of soliciting money from English patrons for colonial endeavors.

The persuasiveness of such language has a tendency to reverberate through the ages, particularly for those who have compelling reasons to wish to believe it. The nineteenth-century historian Love adequately details the phases of Indian education in colonial New England and is sympathetic to the plight of Native Americans in general, but participates in the common prejudices of his era, failing to recognize the cultural validity of existing Native American traditions and assuming that those who sought to educate the Indians were, by their very vocation, enlightened individuals with humane goals. Therefore, it is without irony that he reports of Governor Endicott's decree in 1637 to board young Native students in English homes, and how "a general desire was awakened among them to know the God of the English and imitate their government and institutions. " $"$ Love acknowledges that these first eager students happened to be captives of the Pequot War. But the fact that they were survivors of a very deliberate massacre, resulting in the near extinction of the Pequot as a people, is not given its due. How these events might have influenced the so-called "general desire" of the young Natives to be Anglicized is anybody's guess, but the process of boarding and educating children who 
were the human detritus of a war of unprecedented violence on the North American continent could not have occurred without friction or misunderstanding.

Some of that friction can be located within the many tracts that celebrate these events, regardless of how the language used attempts to get around it. New England's First Fruits is a 1643 pamphlet written to promote the early evangelical successes of the New England colony while simultaneously raising money for the newly established university situated in what was formerly New Town, but what was now called Cambridge. The tract begins by providing a catalogue of converts who, like the early Jesuit converts, mostly consisted of the dead and dying. The children who had come into the English homes as a result of Endicott's 1638 decree following the Pequot War became, by default, the most hopeful plants, as they were virtually powerless to change their situations. As the authors of First Fruits relate,

Divers of the Indian Children, Boyes and Girles we have received into our houses, who are long since civilized, and in subjection to us, painful and handy in their businesse, and can speak our language familiarly; divers of whom can read English, and begin to understand in their measure, the grounds they heare, and of the word read and expounded in our Families, and are convinced of their sinfull and miserable Estates, and affected with the sense of Gods displeasure, and the thoughts of Eternity, and will sometimes tremble and melt into teares at our opening and pressing the Word upon their Consciences. ${ }^{97}$

The language, on the one hand, would like to imply a seamless transition, the children being "long since civilized" and under "subjection." When dealing with Puritan discourse, however, it is often difficult to unthread the language of spiritual debasement which was a staple of their conversion process, from the language of trauma. Was it merely a convention to suggest that one should "tremble and melt into teares" at the thought of eternity or was this accompanied by an actual physical manifestation of visceral grief? And if the tears and trembling should be taken literally, was such a response an effect of Christian doctrine upon the souls of the young captives or, perhaps, the likely reaction that one might experience following a traumatic event? The children in question had been ripped from their homes, removed from their cultures, and in some cases had either witnessed, or at least experienced, the deaths of their mothers, fathers, and other 
relatives. Subsequently they were forced to labor in English homes, a condition of servitude that probably differed little from institutionalized slavery. It would require very little imagination to consider how threats of eternal damnation in hellfire might be equated with the burning deaths of loved ones at the 1637 Pequot fort massacre in Mystic, described by William Bradford as "a fearfull sight to see them frying in the fryer, and the streams of blood quenching the same." 98 "First Fruits" tells of "An Indian Maid at Salem, [who] would often come from the Word, crying out with abundance of teares, concluding that she must burne when she die, and would say, she knew her selfe naught for present, and like to be miserable forever, unlesse free Grace should prevent it. ${ }^{.99}$ Again, a desire for Christian grace provides anecdotal cover for what seem to be the traumatic repetitions experienced by certain Native captives and their response to the psychological violence of having God's word pressed "upon their consciousness."

In a sense it becomes a moot point whether the trembling and tears experienced by Native youths are a result of a foreign cultural discourse being pressed upon them or of the psychic scarring of the recent past. Either event constitutes the kind of narrative rupture that is significant of trauma. For the Native youths who appear in tracts such as First Fruits there is no outlet to communicate their feelings, no community of listeners who will legitimate their experience or honor their narratives. The process of silencing affects not only their claim to experience but the very ability to speak in the language and idiom of their childhoods. The palimpsestic process of having the word pressed upon the consciousness signifies the writing over of cultural memory, the insinuation of a constructed set of norms over the accumulative sequence of experiences that preceded such an event. For the captive children to "witness" the Christian God they must unwitness the experiences, the beliefs, the cultural assumptions that have led them to this moment, a forced amnesia that was unlikely to have taken hold without serious breakdowns both mental and physical. But when Puritan observers recorded these moments, they put their own traumatic displacement on display by insisting upon a version of 
reality that bluntly denied violent truths and conformed to the overall shape of their hegemonic desires. This insistence meant not only silencing the Native youths who might tell it differently, but silencing their own historical engagement with these events. Young Native captives were not mourning their tragic losses. They were visibly shaken and distressed by the blinding truths of Christian doctrine. Their tears and cries were not acts of resistance, but cries to heaven. The descriptions that serve the rhetorical purposes of this discourse are probably not meant to be purposefully deceptive. They merely seek to tie one set of cultural responses to the normative responses of Puritan belief. This is accomplished however by maintaining an established narrative framework that bluntly disallows any other reason for the described responses than the presumed joy of converting to Christianity.

The fact that the process of "educating" Native youths was not as seamless as First Fruits implies was bound to suggest itself in any number of ways, regardless of the framework within which colonial commentators attempted to place it and the even more pressing silence that generally surrounds it. While a dozen or more tracts were written focusing on the education of the Natives in seventeenth-century New England, there is nary a description in any of these accounts of just how that education was administered, what methods were used, and exactly how the youths responded. Typifying the invisibility of these students, the erasure of their presence as individuals, is a remark made by John Winthrop in his History of New England wherein he states that, following the smallpox epidemic of 1633, he kept a young Neponset orphan in his home, one of three children who survived. As he glibly reports, he named this luckless orphan "KnowGod, (the Indians' usual answer being, when they were put in mind of God, Me no know God." ${ }^{100}$ His very name becomes a callous symbol of the blatant reversals in practice by the colonists, wherein an expression of Native resistance is twisted into one of affirmation. One assumes that the child passes away as Winthrop makes no other mention of him.

Even the most successful students, however, who would serve as interpreters or continue 
on to help John Eliot in his translations of scripture and other writings into the Algonquian language, generally go nameless or surface only briefly in the archives, like earth divers themselves, coming up for air at sparse intervals. Eliot wrote in 1648 that "there is an Indian living with Mr. Richard Calicott of Dorchester, who was taken in the Pequott Warres, though belonging to Long Island; this Indian is ingenious, can read; and I taught him to write, which he quickly learnt, though I know not what use he now maketh of it."101 This unnamed youth, later identified as a Montauk named Cockenoe, provided the key into the Native languages that Eliot needed to jumpstart his mission to the nearby Massachusett nations. But his contributions barely register in Eliot's writings, and his name appears not once. Cockenoe ultimately abandoned English learning and made a career for himself back on Long Island as a translator between the Indians and the English in a number of land deals. He remained a liminal figure for the rest of his years, moving in and out of Native space and finishing his days as a sailor on the whaling boats that shipped out of New England and New York. ${ }^{102}$ In Eliot's short passage, however, one senses the resistance Cockenoe offered to Eliot's teaching. Eliot states, "I know not what use he maketh of it," betraying that Cockenoe, despite his skill at appropriating English literacy, ultimately refused to assist Eliot in his work and deployed his talents for other purposes.

Cockenoe's example is unusual in the sense that he seemed able to make his own choices or proved valuable enough in other capacities to free himself of servitude to Eliot's schemes. He proves an early example of a Native who used writing to his own advantage. Others were not so lucky. Many captives of the Pequot War were sold into slavery in Bermuda. ${ }^{103}$ Those who were put into English households, far from being accepted as members of the family, were used as servants and forcefully kept from returning to their own people, their own communities. Winthrop reports in 1637, following the war, that "there were sent to Boston forty-eight women and children. There were eighty taken, as before is expressed. These were disposed of to particular persons in the country. Some of them ran away and were brought back again by the 
Indians our neighbors, and those [we] branded on the shoulder." 104

Such accounts work against the gentle missionary language brought to bear on the very same situation in "First Fruits," wherein it is unequivocally asserted that, as far as can be discerned, the Native youths are "much in love with us, and cannot indure to returne any more to the Indians." 105 Winthrop again offers a contrary glimpse in his history in a short passage that relates how the young Natives who were "in our families were much frightened with Hobbamock (as they call the devil) appearing to them in diverse shapes, and persuading them to forsake the English, and not to come at the assemblies, nor to learn to read etc." ${ }^{106}$ Far from hearing devils, these Indian children being kept in captivity and forcefully assimilated were probably expressing a desire to maintain some connection to their traditional belief systems while attempting to process the violent uprooting from their homes and families. What emerges in all of these accounts is the unavoidable conclusion that New England's "first fruits," the first crop of educated Natives in the colonies, far from being willing subscribers to a new belief system, were prisoners of an unjust war, kept in bondage and servitude against their wills, and forced to comply with English spiritual beliefs regardless of the psychic toll.

\section{Paradise Lost Again: Unwitnessing the Pequot Massacre in Puritan Accounts of the Pequot War}

The Pequot War was launched for specious reasons that were strongly contested even in their time. It was a preemptive strike that, as with most preemptive strikes, had severely ratcheted up the perceived threat it was so aggressively seeking to tamp down. In his study of the war, Alfred A. Cave reminds us that "Puritan writers advanced interpretations of Pequot character and intentions based on prejudice and supposition rather than hard evidence." ${ }^{107}$ But at the heart of the confrontation lay the matter of who would control the wampum trade in the northeast. In a journal passage of 1633 , one can almost see the gears turning in Winthrop's head as he notes of Pequot land that "there they had store of the best wampum-peak, both white and blue. The 
Indians there are very treacherous people." William Bradford, governor of Plymouth colony, saw it differently and wrote to Winthrop at the onset of hostilities, accusing him of having "occasioned a war, etc. by provoking the Pequods, and no more." ${ }^{108}$ Winthrop took exception to this, of course, and was quick to conflate the presumed Pequot threat to a threat posed by all Indians. He replied to the leaders of Plymouth that if the Pequot were not subdued than that would incite "all the Indians of the country to join to root out all the English." 109 The conquest of the Pequot would not only secure control of the flow of wampum, which was used as currency in the fur trade with interior indigenous nations, but it would also allow for control of the Connecticut River waterway, which would facilitate travel and trade into the fur-producing regions. Naturally it would free up more land for colonization as well. Captain John Underhill's 1638 account of the war is given the subtitle "A discovery of these places, that as yet have very few or no inhabitants which would yeeld speciall accommodation to such as will plant there." As such it is as much real estate brochure as it is a narrative of military conquest. ${ }^{110}$

The war began with a series of minor skirmishes, leading eventually to the capture of two English "maids" in an assault by the Pequot at the fledgling colony in Wethersfield, Connecticut. Although the maids were eventually ransomed unharmed, their capture provided the rhetorical outrage needed to justify later acts. By 1637 the English were able to consolidate their alliances with the other Native groups in the area, with the help of Roger Williams, and prepared to strike a decisive blow, culminating in English and Narragansett troops advancing upon a "palisadoed" Pequot village at Mystic. The fort was surrounded and set on fire during the assault, allowing the English to trap the enemy while flames consumed the roughly six to seven hundred men, women, and children within the village walls. Anyone attempting to leave the fort was shot. ${ }^{111}$

A famous illustration of the Mystic fort massacre (accompanying Captain John Underhill's account of the battle) says something about the way in which this conflict was processed by the settlers. It offers an aerial view of the fortress, a circular structure erected of 
tree trunks stripped of their branches and pounded into the earth, with neat rows of huts placed within, each sprouting a precise little lick of flame. Surrounding the fortress in perfect concentric ripples are first an English battalion, their weapons firing, and secondly a ring of Narragansett warriors, each in a like posture with arrows drawn. The exterior of the map is decorated with tiny hills and trees that close around the site of carnage with the uniformity of a wallpaper pastoral. While there are a few neatly staged groups of English and Indians engaged in hand to hand combat at each pole of the battle scene, these in no way upset the perfect symmetry of the illustration.

Very few depictions of slaughter achieve such aesthetic balance and proportion. One might refer to the de Bry Workshop illustration of the 1622 attack of the Powhatan Confederacy against the Virginia colony for a contemporary equivalent in which the degradations and confusion of battle are rendered quite graphically. The frontispiece for the 1656 London edition of Bartolome de las Casas' The Tears of the Indians offers even more horrific examples of the casual dismemberment, flaying, and roasting alive of Indian bodies by the Spaniards. In each of these cases there are strong political incentives to want to bring attention to the horrors being perpetrated. But the lasting image of the Pequot War has a mandala-like beauty, its vision of order and symmetry purposefully abstracting what must have been a frightening scene of chaos and horror (insert pictures of Mystic massacre and Las Casas illustration).

The various contemporary accounts of the war perform a very similar function of trying to distill imagined order from chaos - to construct a narrative of false or inverted continuity from an incident of rupture. But the act is one that is fraught with an excess of anxiety and tortured explanations. Philip Vincent writes of the massacre that "Pity had hindered further hostile proceedings, had not the remembrance of the bloodshed, the captive maids, and cruel insolency of those Pequets, hardened the hearts of the English, and stopped their ears unto their cries. Mercy mars all sometimes; severe justice must now and then take place." ${ }^{112}$ Here we find a 
compelling expression of how a massacre performs the exact opposite function of the condolence ceremony. Warm hearts of flesh and blood become hardened, the ears must be "stopped," justice itself becomes "severe," and mercy is "marred." Vincent deliberately minimizes the carnage in his relation, grossly underreporting English casualties, and stating "the whole work ended ere the sun was an hour high." ${ }^{113}$ Interestingly, it is only after the massacre is narratively wrapped up in his account that he offers an objective, ethnographically minded description of the Pequot fort which demonstrates how sight, too, is obstructed. He writes:

Let me now describe this military fortress, which natural reason and experience hath taught them to erect, without mathematical skill, or use of iron tool. They choose a piece of ground, dry and of best advantage ... Here they pitch, close together as they can, young trees and half trees, as thick as a man's calf of his leg. Ten or twelve foot high they are above the ground, and within rammed three foot deep with undermining, the earth being cast up for better shelter against the enemy's dischargements. Betwixt these palisadoes are divers loopholes, through which they let fly their winged messengers ... The space therein is full of wigwams, wherein their wives and children live with them. These huts or little houses are framed like our garden arbors, something more round, very strong and handsome, covered with close-wrought mats, made by their women, of flags, rushes, and hempen threads, so defensive that neither rain ... nor yet the wind, though never so strong, can enter. ${ }^{114}$

The brief battle scenes that Vincent relates speak nothing of woman and children and elide the presence of neat little houses and garden arbors, but what cannot be described amidst the scene of battle is offered in repose, as though all were whole again, and one might admire the domestic warmth and utility of this scene. The strange effect this description has, coupled with the earlier description of the massacre, is to perform a task similar to that of the aforementioned illustration. It labors to restore pleasing, dispassionate order to a scene of abject terror. In a sense this construction mirrors the function of paradise in the Genesis narrative. It encircles a most troubling truth with a pleasing outer barricade and places flaming swords around the perimeter. The Mystic fort becomes something like cognitive ground zero, an event that must be contained and culturally forgotten, even as veiled repetitions of its violent undoing will surface again and again in the literature of the colonists. The fact of the slaughter, its provocations and violence, prove so troubling that it becomes quickly understood that the Pequots themselves must be made 
to disappear.

Captain Mason, one of the leaders of the engagement, and the one who credits himself with the inspiration of setting fire to the fort, writes:

Thus was God seen in the Mount, Crushing his proud enemies and the Enemies of his People: They who were ere while a Terror to all that were round about them, who resolved to Destroy all the English and Root their very name out of this Country ... bring the Mischief they plotted, and the Violence they offered and exercised, upon their own heads in a moment: burning them up in the fire of his Wrath, and dunging the Ground with their Flesh: It was the Lord's Doings. ${ }^{115}$

Mason views this moment as not only an expression of God's will, a predictable gesture, but of an all-out battle for the privilege of historical existence, as the losers will have their very names rooted from the country or ground into the earth. As he states further on, "The Pequets were then bound by Covenant, That none should inhabit their Native country, nor should any of them be called Pequots anymore."116 Mason decrees that the privilege of conquest was to write the Pequots out of existence, to blast them into the margins, so to speak. Little did he know that the Pequot War would provide a catalyst for Natives acquiring alphabetic literacy in the colonies and that the Pequot themselves would continue in name and fact long after Mason's death and his own tumble into relative obscurity. Nor could he have predicted that it would be a Pequot minister named William Apess who, in the nineteenth century, would pick up the pen and use it to restore the elisions in the historical narrative that commentators like Mason, Winthrop, and others had purposefully crossed out.

Of the many narratives relating to the Mystic fort fight, only John Underhill's even remotely suggests that the violence cut both ways and that the scenes of horror described by its other witnesses could not be so readily contained as hoped. As noted, Underhill is no less a land speculator than his compatriots, and he sees the war as an opportunistic event by which more land is opened for settlement. Neither does Underhill have any explicit doubt that God's will is being manifested in this attempt to blot out the Pequots, in both name and corporal presence, from the face of the earth. Nevertheless, in the wake of the battle, he notes that "Great and 
doleful was the bloudy sight to the view of young souldiers that never had beene in Warre, to see so many soules lie gasping on the ground so thicke in some places, that you could hardly passe along." $" 17$ Underhill feels obliged to relate that the Narragansett who had joined in the battle came to him afterward, and like the young English soldiers, cried "mach it, mach it; that is, it is naught, it is naught, because it is too furious, and slais too many men."118

The overall violence of the Pequot massacre was questioned in its day, prompting Underhill to suggest a justification for the slaughter, in which he states, "It may be demanded, Why should you be so furious (as some have said) should not Christians have more mercy and compassion?"119 The answer, of course, was that the acts of certain enemies are so vile, savage, and reprehensible that they do not warrant God's mercy and that, in these times "the scripture declareth women and children must perish with their parents." ${ }^{120}$ How it is that the Pequot achieved such terrible fame remains unclear, particularly as Underhill notes only a few lines later that Indian war is such that "they might fight seven yeares and not kill seven men." ${ }^{21}$ The congenial commentator William Wood had observed only a few years earlier that the Pequot were "a stately, warlike people, of whom I never heard any misdemeanor, but that they were just and equal in their dealings, not treacherous either to their countrymen or English, requiters of courtesies, affable towards the English."122 It is hard to imagine, then, what the Pequot might have done to suddenly attain an infamy requiring the kind of biblical injunction that Underhill levies upon them. One wonders at what point do the labels "vile, savage, and reprehensible" revert back to their accusers, and are they always in danger of doing so as long as agency is suppressed?

That Underhill seeks to contain the violent episode, and pulls a counter narrative out of the very flames of destruction, can be seen in the sermon he launches into preceding the account of the battle. Although this is no doubt a construction that submits an a priori relating of events, it is telling for its repetition of the fiery disaster and the "truths" it disgorges. He is meditating on 
the topic of courage and facing the afflictions of war, when he asserts, "let the ends and aimes of a man be good, and he may proceed with courage: the bush may bee in the fire, but so long as God appeares to Moses out of the bush there is no great danger." ${ }^{\text {"23 }}$ Underhill seems to intuit how, in this act of disproportionate violence, God's presence will be called upon to inscribe a more palatable historical judgment than the event itself could possibly merit. From out of the fire appears God to Moses, but he offers no special commandments (certainly not "thou shalt not kill"). In fact, he remains silent, which is perhaps judgment enough.

In subsequent references to the Pequot war, the particulars of the Mystic fort massacre would be squelched, but the reference to flames somehow always resurfaces, like the materials of a half-remembered nightmare. Samuel Danforth, brother to John Danforth who copied down the inscription of Dighton Rock, would write in his almanac for 1649 ,

But by \& by grave Monanattock rose, Grim Sasacus with swarms of Pequottoes, Who smote our hindermost, whose arrows stung, Who vowed with English blood their ground to dung. But Mystic flames \& the English sword soon damps This rampant crue, pursues them in their swamps, And makes them fly their land with fear and shame: That th' Indians dread now is the English name. ${ }^{124}$

The flames in this account are "Mystic," a clever play on words that suggests the locale as well as God's agency in burning down the Pequot village. The authors of "First Fruits," as they recounted the many blessings of the colony, were thankful for such "peace and freedome from enemies, when almost all the world is on a fire that (excepting that short trouble with the Pequits) we never heard of any sound of war to this day."125 These authors compare the Pequots with the nation called Amaleck, a biblical tribe defeated by Moses and his followers as they wandered through the desert. ${ }^{126}$ Such efforts to narrate the event of the Pequot War were, no doubt, read eagerly by a Puritan community who were not so much in need of "newes" as they were desirous of a cognitive framework within which they could begin to process this momentous event. The construction of such scenes seems to follow closely the pattern of what Richard Slotkin has 
called a "regeneration through violence," in which the savage nature projected upon the indigenous peoples of the land is acted out by the so-called civilized forces who are then reaffirmed and revitalized by their acts. But it left observers back home in England feeling somewhat uneasy as to the colonial objectives, prompting Roger Williams to wonder in his $A$ Key into the Language of America "what Indians have been converted" in New England? ${ }^{127}$

To fulfill their charters and ensure continued funding, the colonists found themselves, in the wake of the Pequot War, under pressure to demonstrate at least some proof of good faith towards their contractual mission. Williams felt the only way to make progress was not to teach the "savages" to speak English, but to go amongst them and learn their languages. The Key was written largely in response to the claims of Native conversions made in First Fruits, and Williams uses the tract to specifically address "that Great point of their Conversion so much to bee longed for, and by all New-English so much pretended."128 Implicit in this tract was a sense that the settlers of Plymouth and Massachusetts Bay Colony had failed in every way to follow through on the stated intention of their charter to civilize the Natives.

First Fruits had used for its case study of progress the example of a Pequot named Wequash, who, as stated by the authors, is actually the "occasion of writing all the rest." Wequash, although by his own admission formerly dismissive of English men and godsreferring to their deity as a "Musketto (mosquito) God,"-was nevertheless "perswaded" otherwise after witnessing the slaughter of his people at Mystic in 1637. From that point on Wequash seems to have undergone a transformation. It is asserted that he now desired to know the Christian God and "this conviction did pursue and follow him night and day, so that he could have no rest or quiet because hee was ignorant of the Englishmans God: he went up and down bemoaning his condition, and filling every place where he came with sighes and groanes."129 Once again, what we might today recognize as post-traumatic stress disorder was interpreted by the settlers of Wequash's time as a sort of exemplary spiritual awakening. But the particulars of 
Wequash's conversion seem suspect, even as related in the propagandistic tract from which it is drawn. Although he apparently wanders the countryside declaiming heathenism and extolling the awesome might of the English God, he acquires little solace from this function and seems unable to cast off a diminished regard for himself.

Quite possibly it is nothing more than his broken and submissive aspect that endears him so well to the colonists. The authors tell us,

his manner was to smite his hand on his breast, and to complain sadly of his heart saying it was much machet (that is, very evill) and when any spake with him, he would say, Wequash, no God, Wequash no know Christ. It pleased the Lord, that in the use of the meanes, he grew greatly in the knowledge of Christ, and became thoroughly reformed according to his light, hating and loathing himselfe for his dearest sinnes which were especially these two Lust and Revenge. ${ }^{130}$

The result of Wequash's lamentable condition is that he falls ill and suspects that he has been magically poisoned by his enemies. On his death bed, we are told, he commended his soul to the care of Christ and bequeathed his child to the care of the English for "education and instruction." 131 Although the authors of First Fruits leave no question that Wequash meets his reward in heaven, having "suffered Martyrdome for Christ,"132 still it is his acquired docility that impresses. If Wequash is the example that inspired this tract on the spiritual success of the colonies, it serves as more unintended proof that New England's "First Fruits," far from being the harvest of a civilized education, were, in fact, the wasted ruins of absolute warfare.

Roger Williams, in the introduction to his Key, directly responds to the major claims asserted by the authors of First Fruits by recounting his own experiences concerning this very same Wequash. Williams contests the claims made regarding Wequash's conversion, stating, "I dare not be so confident as others. ${ }^{.133}$ Williams, it just so happens, was present at Wequash's death bed and spoke to the Pequot concerning the condition of his soul in his final hours. According to Williams, Wequash "replyed in broken English: Me so big naughty Heart, me heart all one stone!" This picturesque remark was undoubtedly in response to the scriptural passage Puritan evangelists were fond of quoting, Ezekiel 36:26, which reads, "I will give you a new 
heart and put a new spirit within you; I will take the heart of stone out of your flesh and give you a heart of flesh." Wequash seems to have adamantly rejected such an offer, preferring his preChristianized heart. In response to his exclamation, Williams briefly delves the psychic nature of Wequash's condition, reflecting on these "Savory expressions . . . from compunct and broken Hearts, and a sense of imward hardnesse and umbrokenesse."134 It is interesting to note Williams' repetition of the word "broken" in describing everything from Wequash's "broken English" to his "broken heart" and "inward unbrokenesse." The later "unbrokenesse" seems to allude to Wequash's ultimately unrepentant state. But there can be little doubt that Williams feels himself to be regarding an otherwise shattered spirit. What ultimately makes Wequash broken is his unwillingness to break.

Wequash was a Pequot who, at some point, had a falling out with Sassacus, the Pequot sachem, and came to affiliate himself with the Narragansett instead. Williams describes him as a "sachem" in his letters to Winthrop, and indeed, Wequash may have been the leader of a small village of Pequots who, either due to politics or blood ties, had grown closer to their Narragansett neighbors. ${ }^{135}$ He would become a guide to the English during the devastating attack on the Pequot stronghold in Mystic and is, perhaps, the individual that Captain John Underhill quotes as characterizing English style warfare as "mach it, mach it, that is, it is naught, it is naught, because it is too furious, and slais too many men." Wequash, (his name means "swan" according to Samuel Drake) being a Pequot himself, would have had particular cause for reviling the heavy bloodshed and probably would not have anticipated the scale of the slaughter he belped unleash upon the people in the village at Mystic. He would apparently make a grab for power in the confusion and disarray directly following the war, but after a falling out with Miantonomo, he seems to become a disenfranchised player in the power struggles that follow. ${ }^{136}$ Left to wander "up and down" the settlements invoking the English God in a state of self-loathing and fear, Wequash becomes the inspiration for two of the earliest New England manuscripts and a 
contested figure in the battle over who would frame the overall experience in the colonies. His importance as a rhetorical tool is drowned out, however, by Eliot's later successes with conversion, in which event, Wequash came to be seen as a someone who turned on his own people rather than a feather in the cap of New England's missionary endeavors. Catherine Maria Sedgwick, who retells the story of the Pequot massacre in her 1827 novel Hope Leslie, notes that the colonists were "guided to us by the traitor Wequash."137 Samuel Drake, in his 1841 Biography and History of the Indians of North America, described him simply as "Wequash, the traitor. He became a noted praying Indian, after the Pequot War, and was supposed to have died by poison." 138 The historical Wequash seems to have been unable to escape the traumatic ruptures of his own experience, however, not to mention the pressures of occupying a liminal space between cultures, and so he is pulled back to his homeland, close to the site of the horrific massacre, wellspring of his affliction.

Alphabetic literacy is a neutral entity without cultural affiliations, but its effects are transforming, and these transformations had been endured and mastered by western civilization over a period of thousands of years. When the Puritans typologically justified their own actions in the Pequot War by drawing upon the biblical example of Amaleck, they were demonstrating their knowledge of this, as well as their cultural dexterity with such a tool. The Puritans had learned from the Israelites that writing was an act of erasure as well as inscription, but that was still only half the lesson. As related in Exodus, once Amaleck was defeated by the Israelites, "the Lord said unto Moses, Write this for a memorial in a book, and rehearse it in the ears of Joshua: for I will utterly put out the remembrance of Amaleck under heaven" (Exodus 17:14). The passage does not state why the Israelites went to war with these people. It does not say who the Amaleck were, where they came from, what might have been their crime, their motivation, their reason for having passed this way. In fact, they are only mentioned long enough to note that they were defeated and put out of remembrance. Most likely they were the people indigenous to that 
patch of desert. They were a warning, an ill omen, a lesson in the consequences of manipulating history, and far from disappearing, they would resurface again and again, like a recurring nightmare, as the passage concludes with the oracular awareness that such a nation never vanishes and "the Lord will have war with Amaleck from generation to generation" (Exodus, 17:16).

John Eliot will cheerfully assert, time and again, that the Natives "are very desirous to have their children taught, which is one argument that they truly love the knowledge of God."139 But such an argument only meant that, for better or worse, certain Natives were being forced by circumstances beyond their control to engage with European practices, to acquire efficiency in their tools, and to internalize their norms. The great majority of Native communities remained outside of this engagement, but they were conscious that the power balance had shifted in New England and that they would have to make positive moves to ensure that their communities remained intact, their traditions preserved. If the first Natives to learn reading and writing in New England were captive children, Native leaders would soon decided to acquire this tool for themselves.

Any transitional period is also a period of vulnerability, and as witnessed in the representation of Wequash in two promotional tracts concerning Native education, the liminal space between cultural discourses can prove a poison, a pharmakon, capable of turning warm hearts to stone. Wequash, too, was a citizen of Amaleck, his brokenesse and unbrokenesse part of a ruptured binary that was the very status of life in what had become, for him, liminal, rather than Native, space. And the Pequot would be remembered for centuries to come as the fiercest of the New England tribes, the flames of their massacre rendered again and again in colonial literature, but always in so vague a manner as to suggest agency had been taken out of the hands of the colonists and placed in the lightning-bolt-hurling arms of God. Even Sedgwick, who offers the most sympathetic view of the Pequot when describing the massacre of the fort at Mystic, 
ultimately absolves the colonial venture, noting the Puritan fathers had "their feet planted on the mount of vision, and they saw, with sublime joy, a multitude of people where the solitary savage roamed the forest the forest vanished, and pleasant villages and cities appeared the tangled footpath expanded to the thronged high-way-the consecrated church planted on the rock of heathen sacrifice." Her vision is very much entangled in the paradigm of assimilation or extinction for the native, and she suggests that if the Puritan fervor for this project was an enthusiasm, "it was an enthusiasm kindled and fed by the holy flame that glows on the altar of God. ${ }^{\prime 140}$ Such a framework, insisting on the violent nature of the Pequot, and the inevitability of colonial dominance, gave license to later historians such as Ola Winslow to justify this egregious violence, asserting that the Pequot were butchered in such a way because "this was a battle after the Indian fashion." 141 Notwithstanding the Indian point of view that cried "mach it, mach it ... it is naught, because it is too furious and slais too many men." 
${ }^{1}$ Arthur Parker, Seneca Myths and Folk Tales (Buffalo: Buffalo Historical Society, 1923), 59-73.

${ }^{2}$ A form of the earth-diver narrative also exists amongst the Iroquois and other northeast Indian nations, in which a women falls from the sky world where she had been digging for medicinal roots around a great tree. As she plummets, the amphibious creatures of the water world below devise a plan to help her, and one by one they plunge to the depths of the ocean in search of oehdah, or dirt. In some versions it is the muskrat who finally succeeds in scoring a piece of the ocean floor and bearing it to the surface. In others it is the mink or the beaver. They bring up the dirt and place it on the back of the turtle so that the world may be restored, while a flock of loon slow the descent of the sky-women and bring her softly to rest upon the turtle's back. Sky-woman replenishes the world's plants and trees with the roots she had grasped in her hands in her initial fall. There are many versions of this story, and in some sky-woman is pushed through the hole in the sky by her husband in response to a suspected act of infidelity. In another she is asked to uproot the tree and falls in through the hole in the world that she has made. My sources for these versions are The Oneida Creation Story, eds. Demus Elm \& Harvey Antone (Lincoln, NE: University of Nebraska Press, 2000). David Cusack, Sketches of Ancient History of the Six Nations (Lockport, NY: Turner \& McCollum, 1848). And Paul A. W. Wallace, White Roots of Peace: The Iroquois Book of Life (Santa Fe, NM: Clear Light Publishers,1946). Basil Johnston, The Manitous: The Supernatural World of the Ojibway (New York: HarperCollins, 1995), 10-13.

${ }^{3}$ Copway writes that "I have known some Indians who have commenced to narrate legends and stories in the month of October, and not end until quite late in the spring." George Copway, The Traditional History and Characteristic Sketches of the Ojibwe Nation (London: Charles Gilpin, 1850), 96.

${ }^{4}$ Parker, Seneca Myths, 64-65.

${ }^{5}$ John Heckewelder, History, Manners, and Customs of the Indian Nations Who Once Inhabited Pennsylvania and the Neighboring States (Philadelphia: Publication Fund of the Historical Society of Pennsylvania, 1876), 254.

${ }^{6}$ Vine Deloria, Jr., God is Red, A Native View of Religion (Golden, CO: Fulcrum Publishing, 1992), 153154.

${ }^{7}$ Richard Slotkin, Regeneration Through Violence: The Mythology of the American Frontier, 1600-1860 (Norman, OK: University of Oklamhoma Press, 1973), 46.

${ }^{8}$ Andrew Wiget, Native American Literature (Boston: Twayne Pulishers, 1985), 10.

${ }^{9}$ Thomas King, The Truth About Stories: A Native Narrative (Minneapolis: University of Minnesota Press, 2003), 24.

${ }^{10}$ Mary Louise Pratt, Imperial Eyes: Travel Writing and Transculturation (New York: Routledge, 1992), 31.

${ }^{11}$ King, Truth About Stories, 22-23. 
${ }^{12}$ Quoted in Homi Bhabha, The Location of Culture (New York: Routledge, 1994), 116.

${ }^{13}$ John Milton, "Paradise Lost." in The Norton Anthology of English Literature, 7th edition, vol. i. ed. M. H. Abrams (New York: W. W. Norton \& Company, 2000), 1985.

${ }^{14}$ Roger Williams "Mr. Cotton's Letter Lately Printed, Examined and Answered." The Complete Writings of Roger Williams vol. i (New York: Russell \& Russell Inc, (1644) 1963), 108.

${ }^{15}$ Vine Deloria, Jr., and Daniel R. Wildcat, Power and Place: Indian Education in America (Golden, CO: Fulcrum Resources, 2001), 33.

${ }^{16}$ John Winthrop, "A Modell of Christian Charity," in The Heath Anthology of American Literature. 5th ed. vol. A, ed. Paul Lauter (New York: Houghton Mifflin Company, 2006), 317.

${ }^{17}$ William Bradford, Of Plymouth Plantation: The Pilgrims in America, ed. Harvey Wish (New York: Capricorn Books, 1962), 60.

${ }^{18}$ Ibid., 40.

${ }^{19}$ Francis Parkman, The Jesuits in North America in the Seventeenth Century (Lincoln, NE: University of Nebraska Press, (1867) 1997), 112.

${ }^{20} J R$ VII, 191.

${ }^{21}$ Perry Miller, The New England Mind: From Colony to Province (Cambridge, MA: Harvard University Press, 1953), 5.

${ }^{22}$ Ibid., 4-5.

${ }^{23}$ For a condensed articulation of Miller's thesis see Perry Miller "Errand into the Wilderness," William and Mary Quarterly 10, no. 1 (Jan. 1953): 3-27.

${ }^{24}$ Sacvan Bercovitch, The American Puritan Imagination: Essays in Revaluation (New York: Cambridge University Press, 1974).

${ }^{25}$ Deloria, Jr., and Wildcat, Power and Place, 36.

${ }^{26}$ Margaret Connell Szasz, Indian Education in the American Colonies, 1607-1783 (Albuquerque: University of New Mexico Press, 1988), 4. 
${ }^{27}$ Perry Miller, The Puritan Mind, 7.

${ }^{28}$ Szasz, Indian Education, 53.

${ }^{29}$ Cotton Mather, Magnalia Christi Americana, or the Ecclesiastical History of New England From its First Planting in the Year 1620, Unto the Year of Our Lord, 1698 vol. 1 (Hartford, CT: Silas Andrus Publisher, 1820, 1702) 503.

${ }^{30}$ Ibid., 506.

${ }^{31}$ Robert Gray, A Good Speed to Virginia (New York: Da Capo Press, 1970, 1609), 19.

32 As to the unruliness of the Jamestown colony in its early years, much has been written, but John Smith's words perhaps sum it up best when he asserts that it was only the help of the natives and particularly the agency of Pocahontas that preserved "this Colonie from death, famine and utter confusion; which if in those times, [it] had once beene dissolved, Virginia might have line as it was at our first arrival to this day." John Smith, The Travels and Works of Captain John Smith, President of Virginia and Admiral of New England, 1580-1631 (Edinburgh: John Grant, 1910), 532.

${ }^{33}$ Gray. Good Speed, 20.

${ }^{34}$ We see a certain atavistic reliance on this foundation to Judeo-Christian law in the modern day insistence of certain Christian fundamentalist judges who wish to place stone facsimiles of the Ten Commandments in their courtrooms. On the day that I write this, the Supreme Court has ruled that a six-foot granite monument of the Ten Commandments can remain outside the Texas Capital under the vague justification that such an edifice hearkens to legal rather than religious traditions. Charlie Savage, "Supreme Court splits rulings in Commandments: Display allowed in Texas not in KY," Boston Globe, June 28, 2005, sec A1.

${ }^{35}$ Walter Ong, Orality and Literacy, The Technologizing of the Word (New York: Routledge, 1982), 85.

${ }^{36}$ As Derrida points out in "Plato's Pharmacy," it has long been understood that writing was a gift given from the Gods. According to Nicholas Hudson "writing was thought to have been created by God at the beginning of the world, and to have a close relation with the natural universe." Nicholas Hudson, Writing and European Thought 1600-1830 (Cambridge, UK: Cambridge University Press, 1994), 9. A common belief of the 17 and 18 centuries was that writing was bestowed to bumans when God spoke to Moses on Mt. Sinai. Daniel Dafoe wrote in 1726 that a Divine power impresses "those Words on the two tablets of stone and at the same time no doubt instructed Moses in the reading of them, and in the knowledge of their sounds; so we have unquestioned authority to assign the knowledge of Letters, and the Art of writing them to a Divine original" (Hudson, 77). See also Jacques Derrida, Dissemination, trans. Barbara Johnson (Chicago: University of Chicago Press, 1981), 75.

37 Ong, Orality and Literacy, 91. 
38 John Eliot, John Eliot's Indian Dialogues: A Study in Cultural Interaction, eds. Henry W. Bowden and James P. Ronda (Westport, CT: Greenwood Press, 1980, 1671), 139.

39 Ibid., 142.

40 A. LaVonne Brown Ruoff, American Indian Literatures: An Introduction, Bibliographic Review, and Selected Biography (New York: The Modern Language Association of America, 1990 ), 7.

41 Ibid., 7-8.

42 Ong, Orality and Literacy, 73.

43 James Axtell, After Columbus: Essays in the Ethnohistory of Colonial North America (New York: Oxford University Press, 1988), 92.

44 William Wood, New England's Prospect, ed. Alden T. Vaughan (Amherst, MA: University of Massachusetts Press, 1977, 1634), 110. Vaughan translate the Latin to mean "many but much" and adds "by which Wood apparently meant 'they say much in few words."”

${ }^{45}$ Benjamin Franklin, "Remarks Concerning the Savages of North America," in Heath Anthology of American Literature vol. A. ed. Paul Lauter (Boston: Houghton Mifflin Company, 2006), 822.

${ }^{46}$ Peter Nabokov, A Forest of Time: American Indian Ways of History (Cambridge, UK: Cambridge University Press, 2002), 158-159.

${ }^{47}$ George Copway, Life, Letters, and Speeches, eds. A. LaVonne Brown Ruoff and Donald B. Smith (Lincoln, NE: University of Nebraska Press, 1997), 87. Copway also relates how his people would often hunt at night and were "so expert, and possessed such accuracy in hearing" that they were able to deliver a precise killing blow "with no other guide than the noise of the deer in the water" (78). Again this seems to suggest a sound-based relationship with the world.

48 Cotton Mather, Magnalia Christi Americana, 518.

49 Edward Winslow, "Good News from New England." CMHS vol ix, sec. series 2 (Boston: Charles C. Little and James Brown, 1815), 92.

${ }^{50}$ A Relation or Journal of the beginning and Proceeding of the English plantation Setled at Plimoth In New England by Certaine English Adventurers Both Merchants and Others (London: John Bellamie, 1622), 65-66.

${ }^{51}$ Eric Havelock, Origins of Western Literacy (Toronto: The Ontario Institute for Studies in Education, 1976), 38. 
${ }^{52}$ Perry Miller and Thomas H. Johnson, "The Theory of the State and of Society," in Essays on American Colonial History, 2 ed. Ed. Paul Goodman (New York: Holt Rinehart and Winston, Inc. 1972), 119.

${ }^{53}$ Quoted in Parkman, The Jesuits in North America, 211. These words, recorded by Le Mercier, were spoken during a counsel of the Huron called to determine the cause of all the sickness that had invaded their country. Naturally, the Jesuits who were present were viewed as the problem, and as Parkman relates, it was suggested that sorcery was behind it. Perhaps a better explanation is that the natives simply were astute enough to realize that these diseases coincided with the arrival of the Jesuits and that none of their traditional medicines had any effect. Although the Huron "adduced a prodigious mass of evidence" to show that the Jesuits were the cause of disease, Parkman tells how the Jesuit Brebeuf stood up and "in a few words exposed the absurdities of his statements" (210). No matter that the Huron were correct in their surmise, history still perceived them as a people without science and therefore "absurd" in their conclusions.

${ }^{54}$ Heckewelder, History, Manners, and Customs, 130.

${ }^{55}$ Quoted in Nabokov, Forest of Time, 160.

${ }^{56}$ Henry Rowe Schoolcraft, Indian Legends, ed. Mentor L. Williams (East Lansing: Michigan State University Press, 1991), 15. He writes "in the long period in which these tribes have been subjects of observation, we are not aware that powers of this kind [lore-keeping] have been attributed to them."

${ }^{57}$ Roger Williams "A Key into the Language of America," The Complete Writings of Roger Williams vol. 1 (New York: Russell \& Russell Inc, (1643) 1963), 53.

${ }^{58}$ Ibid., 54.

${ }^{59}$ Thomas Mayhew, A Further Discovery of the Present State of the Indians, compiled by Henry Whitfield (New York: Sabin's Reprints (1650) 1865), 8.

${ }^{60}$ Williams, A Key 145.

${ }^{61}$ Ibid., 207.

${ }^{62}$ Thomas Morton, New English Canaan (New York: De Capo Press, 1969, 1637), 19.

${ }^{63}$ Mather, Magnalia Christi Americana vol. 1, 505.

${ }^{64}$ Ibid., 477.

${ }^{65}$ Cotton Mather, "The Wonderful Works of God Commemorated," Early American Imprints, series 1: 
Evans Digital Display (2006): 4, http://infoweb.newsbank.com.

${ }^{66}$ See Wood, New England Prospect, 108. Josselyn, "Two Voyages to New England," CMHS series 3, vol. $3,306$.

67 Winslow, "Good News From New England" CMHS series 2, vol. 9, 96.

${ }^{68}$ Benjamin Smith Barton, "Some Remains of Antiquity," Transcriptions of the American Philosophical Society O. S. iv (1799) 195.

${ }^{69}$ Ibid., 182.

${ }^{70}$ Ibid., 195.

${ }^{71}$ Edmund Burke Delabarre, Dighton Rock: A Study of the Written Rocks of New England (New York: Walter Neale, 1928), 109.

${ }^{72}$ Chingwauk, also known as Shingwaukonse (Little Pine), was a noted Ojibwe, leader and a "high-ranking Medig" or prophet. He was the keeper of a number of sacred birch bark scrolls of the Ojibwe which he apparently had destroyed or concealed just before his death. Schoolcraft also reported that he would keep private scrolls of his personal visions which were sometimes used as evidence that he had foretold certain events. See Michael Angel, Preserving the Sacred: Historical Perspectives on the Ojibwa Midewiwin (Winnipeg: University of Manitoba Press), 28-29.

${ }^{73}$ For a full reading of Chingwauk's translation see Delabarre, Dighton Rock, 114-116.

${ }^{74}$ Ibid., 119.

${ }^{75}$ Ibid., 165-186.

${ }^{76}$ Edward J. Lenik, Picture Rocks: American Indian Rock Art in the Northeast Woodlands (Hanover, NH: University Press of New England, 2002), 133-134.

${ }^{77}$ These passages are found in the text of the Walam Olum or Red Score, The Migration Record of the Lenni Lenape or Delaware Indians (Indianapolis: Indiana Historical Society, 1954), 9 and 207.

${ }^{78}$ David McCutchen calls it "the only surviving history of pre-Columbian times north of Mexico. See David McCutchen, The Red Record, The Wallam Olum: The Oldest Native North American History (Garden City Park, NY: Avery Publishing Group, 1993), xii.

${ }^{79}$ See McCutchen, The Red Record, 8. 
${ }^{80}$ Ibid., 13.

${ }^{81}$ See Fred Wiseman's Voice of the Dawn for a sense of the Abenaki lore that arises from the remembrance of the "Champlain Sea." Fred Matthew Wiseman, The Voice of the Dawn: An Autohistory of the Abenaki Nation (Hanover, NH: University Press of New England, 2001), 18.

${ }^{82}$ David McCutcheon's book length treatment of the Walam Olum concedes that there is no mention of the Red Record in any of the writings to emerge out of the missionary efforts amongst the Delaware, or by any other white visitors. Heckewelder's references to Delaware Hieroglyphs does not necessarily prove the validity of the Walam Olum as a true text of the Lenape. The closest possible account of something like the Walam Olum comes from William Penn who writes of witnessing a ceremony in a sweat lodge where the acts of the nation were recounted in song. McCutcheon does note that many native religious practices are kept secret from white ethnographers and therefore we may never know one way or the other. McCutcheon, The Red Record, 180. What seems important to me however is to simply acknowledge that the Lenape preserved their traditions in carved mnemonic symbols and to begin to come to terms with how we might weave this understanding into our teaching of Native American History and Native American literature.

${ }^{83}$ David Oestricher, "Unraveling the Walam Olum" Natural History (Oct. 96, vol. 105 issue 10), 2.

${ }^{84}$ Nabokov, Forest of Time, 26. Walter Ong also speaks of this in Orality and Literacy, concluding that in oral cultures "the integrity of the past was subordinate to the integrity of the present." He cites the instance of the Tiv in Nigeria whose orally remembered genealogies differed significantly when compared forty years later to the genealogies that had been recorded by their British colonizers for court records. As I have been at pains to demonstrate, however, memory has political biases in cultures that define themselves as literate as well as in cultures that have been perceived as primarily oral. See Ong, Orality and Literacy, 4749.

${ }^{85}$ George Copway writes "there is an unwillingness, on the part of the Indians to communicate many of their traditions" George Copway (Kahgegagahbowh), Life, Letters, and Speeches, ed. A LaVonne Brown Ruoff and Donald B. Smith (Lincoln, NE: University of Nebraska Press, 1997, 1850), 89.

${ }^{86}$ Oestricher, "Unraveling the Wallam Olum," 2.

${ }^{87}$ Ibid., 3.

${ }^{88}$ Henry Rowe Schoolcraft notes of native, or "Algic" writings that they bear "quite a resemblance to the Egyptian, express a series of whole images without adjuncts and stand as general memoranda to help the recollection and to be interpreted according to the mythology, customs, and arts of the people." Schoolcraft, Indian Legends, 10.

${ }^{89}$ David Peat, Blackfoot Physics, A Journey into the Native American Worldview (Grand Rapids, MI: Phanes Press, 2002), 104. 
${ }^{90}$ Walam Olum 41.

${ }^{91}$ Ibid., 35-50.

${ }^{92}$ W. Deloss Love, Samson Occom and the Christian Indians of New England (Syracuse: Syracuse University Press, (1899) 2000), 4.

${ }^{93}$ Paula Gunn Allen, Pocahontas: Medicine Woman, Spy, Entrepreneur, Diplomat (San Francisco: HarperCollins, 2003), 158.

94 Quoted in William Kellaway, The New England Company, 1649-1776. Missionary Society to the American Indians (Westport, CT: Greenwood Press, 1961), 3.

${ }^{95}$ Gunn Allen, Pocahontas, 57. Sir Thomas Gates, Governor of the Virginia Colony, requested in 1609 that the colonists "procure from them [the Natives] some convenient number of their children to be brought up in your language and your manners." Quoted in Szasz, Indian Education, 53.

96 Love, Samson Occom, 7.

97 "New England's First Fruits," Eliot Tracts. ed. Michael P. Clark (Westport, CT: Praeger, 2003), 59.

${ }^{98}$ Bradford, Plymouth Plantation, 184.

99 "New Englands First Fruits," Eliot Tracts, 60.

100 John Winthrop, History of New England from 1630 to 1649, vol 1 (Baltimore: Clearfield, 2003, 1853), 148.

101 John Eliot, "The Glorious Progress of the Gospel Amongst the Indians of New England Manifested By Three Letters, Under the Hand of that Famous instrument of the Lord Mr. John Eliot," Eliot Tracts. ed. Michael P. Clark (Westport, CT: Praeger, 2003), 160.

${ }^{102}$ Cockenoe was identified by William Wallace Tooker in his short book Cockenoe de Long Island: John Eliot's First Indian Teacher and the story of his career from the early records (New York: Francis Harper, 1896).

103 Winthrop, History, 279.

104 Ibid., 278. 
Winthrop, John. History, 305.

107 Alfred, Cave, The Pequot War (Amherst: University of Massachusetts Press, 1996), 3.

108 Winthrop, History, 238.

${ }^{109}$ Ibid., 260.

${ }^{110}$ John Underhill, Newes From America (New York: Da Capo Press 1971, 1638) Title Page.

${ }^{111}$ For contemporary accounts of the Pequot War see History of the Pequot War, ed. Charles Orr (Cleveland: Helman-Taylor Co., 1980, 1862).

${ }^{112}$ Philip Vincent, “A True Relation of The Late battell fought in New England, between the English and the Pequet Salvages." History of the Pequot War, ed. Charles Orr (Cleveland: Helman-Taylor Co., 1980, 1862) 137.

${ }^{113}$ Ibid.,104.

${ }^{114}$ Ibid., 105

${ }^{115}$ John Mason, "A Brief History of The Pequot War: Especially of the memorable Taking of their Fort at Mistick in Connecticut in 1637," History of the Pequot War, ed. Charles Orr (Cleveland: Helman-Taylor Co., 1980, 1862) 35 .

${ }^{116}$ Ibid., 40.

${ }^{117}$ Underhill, Newes From America, 39-40.

118 Ibid., 43.

${ }^{119}$ Ibid., 40.

${ }^{120}$ Ibid., 40.

${ }^{121}$ Ibid., 40. 
${ }^{123}$ Underhill, John. Newes From America 36.

124 Quoted in George Parker Winship, The Cambridge Press, 1638-1692 (Freeport, NY: Books for Libraries Press, 1946), 65.

125 "New Englands First Fruits," Eliot Tracts, 74.

126 "New Englands First Fruits," Eliot Tracts, 74.

${ }^{127}$ Richard Cogley, John Eliot's Mission to the Indians Before King Philip 's War (Cambridge, MA: Harvard University Press, 1999), 25, and Williams, A Key 27.

128 Williams, Roger. $A$ Key, 25.

129 "New Englands First Fruits," Eliot Tracts, 61.

${ }^{130}$ Ibid., 62.

${ }^{131}$ Ibid., 62.

132 Ibid., 62.

${ }^{133}$ Williams, $A$ Key 26.

134 Williams, $A$ Key 27.

${ }^{135}$ Roger Williams, The Complete Writings of Roger Williams vol. 6 (New York: Russell \& Russell, Inc., 1963), 22.

${ }^{136}$ Ibid., 47-57. See also Samuel Drake, Biography and History of the Indians of North America, From its First Discovery (Boston: Benjamin B. Mussey \& Co., 1841), 149-174. (Wequash meaning Swan, 166).

${ }^{137}$ Catherine Maria Sedgwick, Hope Leslie, ed. Mary Kelley (New Brunswick, NJ: Rutgers University Press, 1987, 1827), 48.

${ }^{138}$ Drake, Biography and History of the Indians, 160. 
139 John Eliot, "The Light Appearing More and More Towards the perfect Day or a Farther Discovery of the Present State of the Indians in New England." Eliot Tracts, ed. Michael P. Clark (Westport, CT:

Praeger, 2003).

${ }^{140}$ Sedgwick, Hope Leslie, 73.

${ }^{141}$ Ola Winslow, Master Roger Williams, A Biography (New York: The Macmillan Company, 1957), 150. 


\section{CHAPTER III}

\section{PRAYING INDIANS, PRINTING DEVILS: CENTERS OF INDIGENIETY WITHIN COLONIAL CONTAINMENTS}

Behold, ye Americans, the greatest honour that ever ye were partakers of! This Bible was printed here at our Cambridge; and it is the only Bible that ever was printed in all America, from the very foundation of the world.

Cotton Mather speaking of the Eliot Bible written in the Massachusett Language

It were to be wished that both in Grammar Schooles, and in our Colledge also there should be appointed by yourselves a fit salary for schoole maisters and Tutors in the College for every Indian that is instructed by them to incourage them in the worke, wherein they have to deale with such nasty salvages.

Charles Chauncy

President of Harvard, 1664

Almost any day the students, when passing through the Yard, could peer through the windows of the Indian College, and watch the Indian 'devil' James Printer sweating at the hand lever.

Samuel Eliot Morison

\section{Setting Up Shop: Harvard's Indian College and the Mission of John Eliot Amongst the Natives of New England}

Harvard's Indian College is a little known, little discussed cultural experiment of the mid-sixteen hundreds. Apparently the first brick building to be constructed at the fledgling campus, it was described by the Superintendent of Indian Affairs, Daniel Gookin, in 1674 as "a structure strong and substantial, though not very capacious . . . large enough to receive and accommodate about twenty scholars with convenient lodgings and studies." The intention was 
that these hoped for Native scholars would learn enough of Christian doctrine to take back to their own people and become teachers themselves. Although the plan failed miserably in its stated goals, it set the stage for future endeavors to follow a similar course, as the means and the ends were always, in fact, mutually exclusive. "Who hath despised the day of small things?" (Zach.4.10) the Puritan fathers of New England were fond of asking when referring to their fledgling efforts at educating and converting Natives. ${ }^{2}$ For they knew their efforts to be small, and sure to strike their moneyed patrons overseas as half-hearted at best. Of their poor record they begged, "wonder not that wee mention no more instances at present: but consider, First, their infinite distance from Christianity, having never been prepared unto by any Civility at all. Secondly, the difficulty of their Language to us, and ours to them; their being no Rules to learn either by." Embedded in the 1643 tract on Indian Education entitled New England's First Fruits, this plea for patience came some twenty-two years following the Puritans' first landing in Plymouth with their stated intention of coming over and helping the Indians. The argument was that, if Natives weren't being converted at an acceptable rate, it was due to their own barbaric lifestyles, an overall lack of civility that remained an impediment to Christian learning, and compounded by the difficulties of their language. Although the colonists would noticeably renew their sense of mission in the next two decades as a handful of missionaries attempted to learn the Native tongue, the resulting Indian College would never house more than four or five students, and only one Native American student, Caleb Cheeshateaumauk, would actually graduate from Harvard a streak that was maintained well into the nineteenth century. ${ }^{4}$

A recent excavation of the site of the Indian College unearths no artifacts that might suggest a Native American occupancy, no emblems of syncretism such as the medicine bundle containing scripture found with the exhumed remains of the Pequot girl, no beads of wampum, no arrowheads, no pipes, pots, baskets, blankets or fragments of texts printed in the Algonquian language. What the archeologists on the site did excavate, however, were twelve pieces of 
seventeenth-century type. ${ }^{5}$ This type would have belonged to the first printing press in the English colonies which was, either by fate or design, housed in the Indian College building from roughly 1655 when the college was erected, until 1692 when Samuel Green, the steward of the Cambridge Press, died. What at first glance appears to be an arbitrary and, perhaps, ironic intersection of historical interests, on further investigation reveals an almost inevitable association. The early histories of both institutionalized education and printing in the colonies were irrevocably bound to the lives of Native Americans. The oldest and most revered colleges in the United States were instituted with the implicit intent to educate "those poore Indians, who have ever sate in hellish darknesse, adoring the Divell himself for their GOD." ${ }^{6}$ In more than one case, the seed money for such institutions was generated by Native fund raisers traveling to England who, by the sheer novelty of their presence, were able to effectively solicit donations for their stated cause. This was the result of Pocahontas' visit to England in 1616 and it would be the result of Samson Occom's tour of the motherland some one hundred and forty years later to raise money for Dartmouth College. In other cases, as with the founding of Harvard, funds were raised by the mere report of successful Native conversions, even if such reports were thoroughly challenged and debunked by other witnesses, as was the case with the claims made concerning Wequash. The end result of all this was that, as historian Laura Stevens notes, "the history of the British mission ... was one in which words outweighed deeds and textual production exceeded conversions." ${ }^{, 7}$ As with the entire colonial project, colonial institutions of higher learning failed in their mission to administer to the needs, both spiritual and educational, of the Native individuals who either sought or were extended their patronage. Native presence was generally tolerated only long enough to garner the proper sympathetic responses needed to fund such endeavors, and then routinely and unceremoniously discarded. As one historian summed up the venture in 1720 , "the Indian College . . . 'tis now converted into a Printing-House, by the direction of the said Corporation; it being found impracticable to persuade the Indian Youth to a 
Love of Learning."

Embedded in the above statement is not only a sense of how quickly an isolated experiment in Indian education gave way to entropy, but also a suggestion of how closely the press became linked to, if not quite supplanting, Native American presence in colonial America. The Cambridge Press though often regarded as an arm of the college, was never much more than a subsidiary of John Eliot's campaign to bring the gospel to the original inhabitants of the area. ${ }^{9}$ It was Eliot who staffed the press, with both English and Native workers, and it was Eliot who insured its relative stability over the years, keeping it funded through his constant efforts to print texts in the Algonquian language. A perusal of the titles printed by the Cambridge Press over its fifty year run would offer to any neophyte a surprising catalogue of unaccountably long, indecipherable entries, and help to illustrate the unlikely extent to which printing in the colonies was inscribed in red ink. ${ }^{10}$ Even though such publications remained in the culturally coercive domain of the colonial endeavor, the very fact that the press was housed in the Indian College suggests a certain cohabitation of interests, and demonstrates something of the complex negotiations between the textualized ambitions of the colonists and the real lives of those who were being colonized.

The inner workings of the Indian College offer a surprisingly apt manifestation of the notion Larzer Ziff articulates in his book Writing in the New Nation, wherein he describes the paradoxical manner "in which the represented self contended with the immanent self both in social conduct and written narratives," 11 in the formation of the US. Ziff notices the imperial implications of such a phenomenon, as the eventual proliferation of presses and the wide dissemination of printed material on American shores led to a construction of national identity that often steam-rolled over the "immanent" social exigencies of both individuals and cultures. What was "immanent"-in this case the social reality for Native Americans in the colonies—was systematically upended by the institutional propaganda of the colonial state. One of the most 
powerful representations to emerge from this process is, of course, the ever present trope of the vanishing Native. Nevertheless, Ziff's argument allows that an "immanent" condition exists and sustains itself in defiance to the represented conventions. From within this locus of resistance, or perhaps from the interstices between sign and signification, Gerald Vizenor has offered his concept of the "Postindian Warrior," who will replace the simulations of dominance with simulations of survivance-representations that speak to a positive and affirming narrative of Native history, culture and presence. As Vizenor and others have made clear, manifest manners continue to infect our cognitive engagements with both the past and present, working to normalize a system of thought that relegates all Native culture to a romanticized past, even in the face of continued, albeit politically inconvenient, Native presence. ${ }^{12}$ The project of eliminating or countermanding such preconceptions and cognitive habits must ground itself in the furtherance of new and unconventional narratives, but some aspect of the endeavor relies upon a respectful interpretation of what has gone before, an engagement with the past that seeks to take into account the overall complexity of human experience. Vizenor seeks the "immanent" Native identity of the past in "shadows of remembrance" that cast their forms beyond the absence of the real, or the void that has been left us by colonial unwitnessing. ${ }^{13} \mathrm{He}$ is appropriately wary of print history and cautions that "to hover over the traces of the presence in literature is not an ecstatic vision." 14 But perhaps print history itself is transformed, acquires a new signification, when interpreted through a postindian lens. Looking back to the interesting dynamic that located the first press of the colonies directly in a space constructed for Native Americans offers an opportunity to reconsider the role Native Americans played in the early colonial period and how Natives negotiated for their own cultural interests and representation of identity both within and without the totalizing network of the colonists' print discourse. Natives, of course, were not involved in the decisions of what went to print in Cambridge, but, as I hope to elaborate in this chapter, they were involved in nearly every aspect of the actual printing, and only one man, a 
Nipmuck named James Printer, can be said to have attended the operations of the Cambridge Press from start to finish. Arriving at this awareness, marking the incongruity of it, does nothing to alter the colonial past, but it does suggest a path by which our engagement with the past can begin to break containment and posit a new narrative launching pad, disrupting the traumatic gaps that have produced scab-like lesions over the collective memory of this country.

Much of what we now know about the initial attempts by New England colonists to educate and Christianize the Natives can be found in a collection of promotional literature that is probably best summed up as the Eliot Tracts. Although Eliot was not responsible for the authorship of each of the ten or eleven texts that comprise this collection, he remains the dominant force behind them and contributed to most of them. Eliot had come over to New England in 1631 and found a post as teacher and sometime preacher at Roxbury. Although not a prominent figure in his early days in the colony, he seems to have emerged as a useful political ally of Winthrop's government. As the New England colony found itself nearly split apart during the antinomian crisis of the mid 1630 's, Eliot remained a steadfast voice for authoritarian control, surfacing in the records as a harsh critic of Ann Hutchinson during her trial, and an outspoken proponent of the controversial Pequot War. ${ }^{15}$ Once the colony had stabilized itself again under Winthrop's government, Eliot seems to have worked behind the scenes to help organize the founding and maintenance of Harvard College. It was as a central component to this campaign that First Fruits was published in England in 1643 detailing the reported conversion of Wequash and invoking pity for "those poore Heathen that are bleeding to death to eternall death" all for lack of good Christian learning. While the first portion of First Fruits was dedicated to the questionable successes at Indian conversion, the second half detailed the progress of the college, in its fourth year then, offering a summary of the rules, expectations and disciplines to be mastered. The publicity generated by the tract managed to raise roughly three hundred and thirtyfive pounds, thirty-five of which purportedly went toward the cause of supporting Indian 
education and the other three hundred toward the college itself. ${ }^{16}$ The propaganda tracts that followed First Fruits detailed the forays of Eliot, the Mayhews of Martha's Vinyard, and a few other scattered missionaries, into the so-called wilderness to bring the word of God to his lost people. As noted by Michael B. Clark, editor of the recently published first edition of these collected documents, The Eliot Tracts serve as a "comparatively modest but important counterpart to the Jesuit Relations in New France and to the missionary work described as part of the conquistador narratives of New Spain."17

As traditionally narrated, John Eliot, glowingly referred to by his contemporaries as the apostle to the Indians, single-handedly broke the lethargy surrounding the colonial venture and its intended charter to civilize the Natives by venturing out to the nations bordering the United Colonies in the 1640's, and winning them over with his tireless question and answer sessions in which he effectively challenged Native belief systems and won the sachems over to Christian logic. So effective were Eliot's exhortations that it was reported "what floods of tears fell from the eyes of several among those degenerate salvages" upon hearing his sermons. ${ }^{18}$ Eliot's enduring claim to fame, however, lay in the 1663 publishing of Mamusse Wunneetupanatamwe Up-Biblum God Naneeswe Nukkone Testament Kah Wonk Wusku Testament, or the Christian bible translated into the Algonquian language. This work allowed him, along with a few conscripted Native students of "exceptional" ability, to disseminate the gospel in Native space and convince his converts to settle into "praying towns" where they would cultivate the land, live in houses, domesticate animals, and attend service on Sundays. To his contemporaries such as Cotton Mather, Eliot was "a most blessed and a most holy man."19 His accomplishments were roundly admired, and it was only through the resistance of "several of those nations which refused the gospel" ${ }^{20}$ that the work of civilizing the Natives was unraveled. The revolt of 167576, led by King Philip, the son of Massasoit, was largely believed to have dissolved the praying towns and to have scattered Eliot's converts so that nothing remained of his evangelical work. 
Following the war the scattered remnants of New England Natives were imagined to have slowly faded from the scene, driven out by a world that no longer had any place for them, melting away, as historian W. Deloss Love would write, "like snow in the springtime." 21

As I said, that is the traditional narrative. Settler tradition. Simulations of dominance. What should become apparent, however is that the indigenous nations that signed on to Eliot's plan, both before and after King Philip's War, had their own motives quite separate from those articulated by the colonists. The idea that any of Eliot's sermons actually moved the local Natives to spontaneous conversions or uncontrollable tears is somewhat ludicrous, particularly when one takes into account that Eliot could only barely speak the language at the time of this being reported. Even if he had been able to speak it, however, the esoteric content of his delivery would have been all but incomprehensible to his audience. And even had the Cohannet Natives to whom he first preached perfectly grasped what Eliot was saying, it was never very likely that Native communities would utterly reconfigure long held belief systems in acknowledgement of Christian superiority, no matter how effective a single sermon. Nor did Native converts suddenly huddle into praying towns and turn to sweat-of-thy-brow style agriculture in a gesture of abject capitulation to English power. Much of New England's Native population outright refused the idea of the praying town, and there is ample evidence that those who did congregate into praying towns held onto many of their traditional practices.

The term "praying town" itself is the coinage of colonial interests and needs to be either done away with entirely or reinterpreted through a different framework. The term solidifies a notion that the members of such a community had unambiguously offered themselves up to the devotional practices of the Christian faith, and what more, implies that "prayer" itself was their dominant activity. The term is a powerful containment, subsuming everything that falls within its discursive properties, and whitewashing, or othering, the Native presence that remains at its locus. But as I hope to demonstrate, praying towns were still very much locations of Native 
presence and traditional activity. If we are to retain the misnomer of "praying" we must regard it outside of its Christian context, and think instead of the more universal practice of prayer, as perhaps, the Natives who congregated in these towns were invested in praying for peace and stability more than Jehovah. By holding such a definition in mind, we might begin to remove "praying" from the brackets that surround it and offer it back up from without the rhetorics of colonial containment.

The actual motives behind Natives of New England moving into praying towns has been the subject of a long ongoing debate, but the main points of contention remain, in many ways, rhetorical, even if the driving ideologies of the various commentators veer off in different directions. Harvard historian Samuel Eliot Morison saw John Eliot as a devoted and charitable worker who should be admired despite his Quixotic commitment to a questionable cause. His summation, in keeping with early twentieth-century academic thinking, is that "Eliot did nothing more than ease the passing of a doomed race."22 Morison acknowledges, however, that the monies appropriated for Native education often wound up funding projects that bore little relation to their intended destination. Francis Jennings in his The Invasion of America projects such schemes over Eliot's entire career, portraying him as a charlatan and profiteer who lined his own pockets rather than channeling funds meant for Indian education toward their proper purpose. ${ }^{23}$ The Massachusett leader Waban, who becomes the first Native to acquiesce to the strictures of the praying town system, is also regarded as an opportunist or false sachem, who joins with the English to acquire personal power. ${ }^{24}$ Jennings concludes that Eliot manifested no genuine interest in Native conversion until 1647 when an annuity became available through one Lady Armine in England. While the annuity coincides somewhat with the visible beginnings of Eliot's mission, it ignores the fact that Eliot must have been studying the language for some time prior to this date in order to prepare himself to deliver a sermon in the Algonquian language in October of 1646. Richard Cogley takes a more charitable view asserting that Eliot actually saw 
his cause as a way of protecting the Indians from aggressive land-grabbing settlers, and observes that the first attempts at establishing praying towns were closely linked to the wishes of Natives to hold onto the land that was left to them. ${ }^{25}$ James Axtell notes that Natives converted to Christianity because it provided a "comparatively better" answer to the spiritual exigencies they were facing at the time. Although he concludes that the brand of Christianity adopted by the New England Natives "often lay very lightly on the surface of their lives," still the only choice remaining after pandemic disease, war, and political disenfranchisement was to "revitalize on the spot or die as a culture." The result of such pressures was the adoption of syncretic forms of worship that, while perhaps a disruption of pre-contact traditions, nevertheless promised the preservation of ethnic identity and continued holdings of ancestral lands. According to Axtell, Natives took what they needed of Christian doctrine to survive, and no more. ${ }^{26}$ Salisbury, too, describes a people so thinned and threatened by the 1640's that they hunkered around the English for protection. ${ }^{27}$

What lies at stake in most of these arguments are the motives of the missionaries and the degree of cultural disruption endured by Native peoples at this time. Individual motives are notoriously difficult to read, although my own assumption is that Eliot, for better or worse, grew into his job to a certain extent. Although hopelessly biased toward his own cultural foundations, he desired in his own way to do good for the Native peoples within his sphere of influence. Cherokee scholar George Tinker asks in his book Missionary Conquest; the Gospel and Native American Cultural Genocide, "how could these dedicated spiritual figures [the missionaries in question] not see the role they inevitably played in the exploitation or the political manipulation of the tribal peoples of America?"28 This remains the vital question of imperialism and cultural hegemony, as pertinent today as it was three hundred and fifty years ago. And yet, why not ask the same of Waban who might have resisted Eliot's advances as other Native groups, like the Narragansett, the Mohegans and others did at the time? Tinker, like Jennings, suggests that by 
elevating Waban's authority, Eliot was undermining the Massachusett sachem Cutshumoquin who had previously shunned Eliot's missionary appeals. But Waban himself was under extraordinary pressure. It is difficult to discern just how much of Native hierarchy was disrupted by the praying town system, however, because when Natick is ultimately established as the first of these towns in 1653, Cutshumoquin himself emerges as the leader and Waban is designated with the lesser title of "councilor of fifty." In effect, both kept their traditional seats within their own tribal hierarchy. Is it possible that Waban and Cutshumoquin were working in concert, playing good Indian, bad Indian? Or that they held different opinions but came together in the face of pressing political choices the best way they knew how? The answers to such questions reside in the shadows of remembrance to which Vizenor refers. Is it possible to delineate their forms and draw new suppositions, removed from the old stale narratives we have been handed? And is it possible that the missionaries, understanding the cultural pressures being brought to bear on Native communities, in some cases were offering the only solution available short of violence, no matter how complicit it made them in an overall scheme of white European dominance? Eliot, himself, would plead in the preface to his Indian Dialogues, "suffer not the English to strip them of all their lands. ${ }^{29}$ The pragmatic choices of a particular historic moment can have the effect of leaving ideological preferences in the dust, and the arguments tend to become circular. But the arguments must not necessarily conform. What is important is that we find a means of airing them out so that, even given the difficultly of discerning them through the colonial containments by which they come to us, we might hear two parties speaking instead of simply one. This is the theory of the condolence ritual, and I shall try in this chapter to hear both sides of this old story, in order to remove the stale dust of ages.

There can be little if any doubt that Natives congregated into praying towns as a cultural expediency. How they retained their own traditions within this system, the ligaments of language, culture and cognition that formed their group identity, remains largely unavailable to 
us. The fact that the missionaries, like Eliot, Mayhew and Gookin were complicit in an act of cultural containment and erasure should not be in any way brushed aside, but also does not preclude a case by case evaluation of their personal efforts and intentions. The so-called praying towns and the Indian College, however, were as much Native space, as they were spaces of colonial containment. I will argue in this chapter that Natives like Waban, James Printer, and Caleb Cheeshateaumauk, author of the first extant example of a Native's alphabetic writing in North America, were involved in acts of continuance as well as accommodation when they engaged with European cultural conditions. When encountering the traces of their presence left within the archival troves, we ourselves are brought into a space of containment, where texts reside within texts, fragments remain fragmented, and Native agency is thoroughly encircled by the discursive boundaries maintained by the colonist. But by allowing a Native-friendly framework to project itself over these archival materials, thereby reconfiguring the contextual boundaries, containment can be broken and previously underlooked agendas can begin to surface. Written texts and fragments like Caleb Cheeshateaumauk's 1663 letter to Robert Boyle, or the speeches transcribed in Eliot's "Tears of Repentance" have something to tell us about Native lives in seventeenth-century America. Many Native individuals did learn to read and write in New England at this time, both in English and in their own language, even while they maintained the ligaments of their own traditions. Some, as I have previously stated, were captive children forcefully assimilated and given no choice in the matter of conforming to English ways. Others acquainted themselves with western literacy as a conscious survival strategy. In either case, I argue, these individuals were engaging with a system of power negotiation that they hoped would benefit themselves and their communities in the years to come. We have assumed their discourse is more revealing of the invasive settler consciousness that was internalized at this moment, the pharmakon working its intrusive magic, rather than anything relevant to the lives and minds of traditional Native communities. But $I$ hope to present a framework for analysis in which these 
texts might be reconsidered for what they say about Native presence and Native concerns in colonial America.

Although The Eliot Tracts comprise the most comprehensive record of missionary outreach in seventeenth-century New England, they lack the vital narrative immediacy and surprising detail of the Jesuit Relations. These tightly focused missives rarely allow themselves to stray from the master narratives of their Puritan authors to either take in the scenery, both human and natural, or appreciate the picturesque nature of the encounters described. Eliot, Thomas Shepherd, Thomas Mayhew and the other authors involved were more concerned with framing promotional talking points than maintaining any fidelity to the complexity of human interactions. The general framework of the earliest tracts is to describe an encounter in which a sermon is offered to a group of Natives, and then to detail the questions and answers that followed. Occasionally the rudiments of Native customs and beliefs are given a halting description, or the actions of a few exceptional converts might be highlighted, but the unerring agenda of these writings was to garner patronage by recording "progress," and little attention was given to anything that detracted from that vision. Nevertheless this tight ideological focus is compromised, fortunately I think, by complications of translation and transcription. As Eliot attempts in the later tracts to shepherd his heathen flock into the official embrace of the church, he relies more and more upon the transcribed confessions of his converts. These transcriptions, often taken on the spot by a Native translator, offer an intriguing glimpse into the mindset of the praying Indians who negotiated this tricky cultural terrain. Although their responses are often formulaic, they reflect a hybrid dialogue of conflicting concerns and agendas, and might be considered Native oratories, translated by Native editors. While they are originally published to suggest the readiness of the participants to be accepted into the church, an entirely separate agenda presents itself in these texts - an agenda that was to remain one of the crucial touchstones of Native sovereignty. The praying Indians, as I mean to demonstrate, hoped to keep their 
traditional lands and regarded their compliance with Christian doctrine as a formality towards achieving such an end. Eliot, in the meantime, proceeded to printing documents in the Algonquin language, as though the texts themselves somehow offered an accounting of the authenticity of Native conversions.

What did it look like as all this printed material made its way into Native space in colonial America? How was it conveyed, and how improbable must it be that the very same word that the colonists hoped to bestow upon the Indians in their efforts at hegemonic control originated, through the operation of the Cambridge Press, from an ostensibly Native space as well? These questions, if asked at all, have generally been asked from the perspective of the colonist, although a handful of scholars, including Lisa Brooks, Jill Lepore, Hilary Wyss, Margaret Connell Szasz, and Neal Salisbury have attempted to re-envision the dynamic. If the enterprise remains an emblem of colonial domination, there is nevertheless cause to suspect that Natives had something to gain in this exchange as well, and were not simply passive receptors of a new discursive medium. Alphabetic writing and its dissemination through printed texts was one of the most powerful tools the colonists brought with them to Native America. If it was unable to offer the immediate satisfactions made available through other trade goods, it nevertheless defined the parameters upon which the ultimate battles for cultural identity would be, and still are, waged. When the Natives of North America encountered printed texts all available evidence indicates they understood they were encountering manittowock, or power.

\section{A Town Called "Rejoycing": Establishing the "Praying Town" on Native Space}

The community of Massachusett and Nipmuck Natives living in the village of Cohannet (present day Newton, MA) in October of 1646 probably heard the welcoming cry rise up prior to actually seeing the white men entering the village that morning. Whether or not they were expecting the visitors, a meal was most likely prepared of parched or boiled corn from the recent 
harvest to feed the guests. ${ }^{30}$ The leaders of the community would have gathered to hear what the "knife men" or English, in their beards, long frock coats and black collars, had to say. And the women and children would have gathered as well to see what gifts the white men would bring.

Without a doubt, the Massachusett were a people in crisis in the 1640's. They had seen their numbers decimated by a series of unknown diseases in the last twenty years, with heavy epidemics in 1616 , and again in 1633 . The dead had piled up so quickly that there hadn't been time to offer proper burials, to go through the established rituals and mourn in the traditional manner. ${ }^{31}$ Such devastation had been unknown. The dead took with them their stories, their knowledge, their power. There hadn't been time to pass it all along in the ceremonial way. Having been intermittently at war with the Narragansett and Mohegan, the Massachusett now found themselves increasingly unable to defend their own interests. ${ }^{32}$ As a result they had creatively sought to establish relations with the newly arrived Europeans, resulting in an uneasy peace over the last twenty years and a steady loss of ground. It was probably understood that, for better or worse, these were times of historic change, and on that October morning their eyes may have fastened momentarily upon the black, leather-bound books prominently displayed in the hands of the approaching travelers. They were not unfamiliar with the preferred discourse of their settler neighbors, and although the persistence with which this discourse was advertised may have struck the Cohannet villagers as inexplicable, and perhaps rude, they resigned themselves to extending a polite audience, as was their custom. Among those who waited to hear what the English would say were Waban, the principal leader of the village, and his son, Weegramomenit, also known as Thomas Waban, who was roughly sixteen years old at the time and stood there "among the rest of his Indian brethren" although "in English clothes."

According to the 1646 tract "The Day Breaking, if not The Sun Rising of the Gospell with the Indians in New England," a sermon was delivered that day, its focus on the ten laws that the English purported to hold above all others, for they had been passed down to men directly by 
God, written upon cold hard stone by his own finger. Most important of these ten laws was the notion that, above all, the English God was to be regarded as the most powerful. The Massachusett thought they knew something of this God, and believed that he was, in fact, powerful, but that he was a "moosquantum," or angry God. The English often heard this to mean he was a "muskeetoo" God, regarded by the Natives as small and annoying. Following the sermon the English were curious to know "whether all of them in the Wigwam did understand or only a few." The villagers responded as one that they had understood well enough. Then the English encouraged them to ask questions. This was greeted at first with silence, but finally, apprehending what was desired, it was asked how it came about that one might speak with the Christ Manitou in the book. The English responded evasively, saying "if they were able to read our Bible, the book of God, therein they should see most cleerely what Jesuschrist was." But because they could not do this thing the Natives might try to "sigh and groane, and say thus; Lord make me know Jesuschrist, for I know him not." Again, we must assume, the villagers simply nodded.

The session went on for some three hours, after which the English expressed that they were weary. Waban, had all along just one question he intended to ask, but he had no intention of being rude, and as was customary he waited until he was quite sure the English had concluded their discourse before asking it. As the authors of the "The Day Breaking" recount it,

the chiefe of them seeing us conclude with prayer, desired to know when wee would come again, so wee appointed the time, and having given the children some apples, and the men some tobacco and what else we then had at hand, they desired some more ground to build a Town together, which wee did much like of, promising to speake for them to the generall Court, that they might possesse all the compasse of that hill, upon which their wigwams then stood. ${ }^{34}$

The difficulty in this passage is in discerning whose agenda is being articulated here at the conclusion of this particular session. The opening page of "The Day Breaking" seeks to assure the reader that "he that pen'd these following Relations, is a Minister of Christ in New England, so eminently godly and faithful, that what he here reports, as an eye or an eare witnesse, is not to 
be questioned. ${ }^{35}$ That such a statement is there at all attests to the rampant anxieties concerning the reliability of written discourse that lay submerged in the European consciousness at this time. The anxiety was deeply enough rooted that bearing false witness was one of the ten prohibitions of the English religious code. Nevertheless, we must question the integrity of much of the dialogue as offered. Although something approximating the text may have taken place, the opportunities for misunderstanding were enormous and the pressures to manufacture a successful and coherent encounter were equally present. The dialogue, as offered, is wooden and unnaturally precise. The Native audience is made to ask the very questions that the English are most eager to answer. But Waban's final question is framed in such a way as to stand outside the bulk of the recorded dialogue. Having been asked following the distribution of English gifts, which generally signaled the close of the session, it holds a separate status which seems to imply that it was not quite central to the concerns of the colonizers, but an afterthought, inserted as the English were preparing to leave.

Nothing had been written prior to this about setting aside guaranteed tracts of land for Natives willing to convert. This is not to say that it hadn't been discussed, however, and the writing on the wall appeared perfectly legible to Waban. The English had established a policy of vacuum domicillum meaning that any lands not being used, according to the English interpretation of "use," automatically fell into the possession of the Crown. The English, while aware of the tricky legalities of simply claiming foreign land as their own, did not necessarily let this prevent them from doing it anyway, and regarded it as a "remarkable" blessing that God had "swept away great multitudes of the Natives by the small Pox a little before we went thither, that he might make room for us. ${ }^{336}$ William Kellaway asserts that Native claims to land were recognized by the English only if there were "improvements" made there-on, which meant clearing the land for agriculture and building permanent dwellings. In such a case allotments were presumably granted. But Kellaway also observes the problems inherent in such a system, 
noting that "to the nomadic Indian the allotment must have seemed as incomprehensible as the English claim to the soil of America by right of discovery. ${ }^{\text {37 }}$ Nevertheless, from Waban's point of view, the implications seem clear. He is not concerned with the religious content of the visit so much as he is interested in receiving some assurance from the English that they will not encroach further on his lands. While the author of "Day Breaking" is fixed upon the idea that the Natives desire a "town" of their own, this is more than likely a poor translation. What Waban desires is to keep the lands that have always belonged to him and his people. He wishes for the land upon "all the compasse of that hill, upon which the wigwams then stood." And he seems to understand that he must attain such an assurance in writing. ${ }^{38}$

While Eliot is often credited for the inspiration of rounding the Natives up into praying villages, he in fact appears to be following the lead of Waban who agrees to engage with Christian discourse for the price of receiving some guarantee of retaining Massachusett lands. If anything, the settlers seem interested in moving the Natives to a new location further west, as is expressed in later tracts. ${ }^{39}$ In a sense Waban has gained the best of this bargain, for he must ask no tangible sacrifice from his villagers. He offers no promise that he or his people will become Christians (in fact he explicitly expresses his doubt that such a thing will come to pass), but only that they will welcome more visits from the Christians. In return he bargains to keep the lands that he already inhabits. And temporarily, at least, the General Court seems to comply by officially granting the lands to which Waban lay claim. Waban did give up one thing, however. He did "voluntarily offer his eldest son to be educated and trained up in the knowledge of God, hoping as hee told us, that he might come to know him, although he despaired much concerning himself; and accordingly his son was accepted and is now at school in Dedham."40

The "Day Breaking" tract appears to recount the first tentative moves toward Native education in the colonies, discounting the fact that Thomas Mayhew had already made significant inroads with the Natives of Martha's Vinyard by this point. It also appears evident, 
however, that some aspects of the 1646 visit were pre-determined. After all, if we can take any of this at face value, then Waban's son was already dressed in English clothes at the time of the meeting and attending school. Quite possibly he has assisted Eliot in the translation of the sermon delivered, although this role is often attributed to one Cockenoe, a Montauk captive of the Pequot War who was "indentured" with Richard Callicot at the time, and whom Eliot cited as his first language tutor. ${ }^{41}$ Either way, we must acknowledge that Waban's compliance, to some degree, had already been anticipated when Eliot and his cohorts arrived on that day in October.

True to their word, Eliot and his compatriots returned to "the wigwam of Waawbon" no less than two weeks later to attempt another sermon and to resume the obtusely metaphysical series of questions and answers they had begun in the first meeting. In the give and take that followed not only was the matter of how to best serve and worship God discussed, but apparently the Natives were curious to know why the sea was made of salt, and why the water was higher than the earth (whatever that means). There is no indication of whether or not they were satisfied with the answers provided. Perhaps within their own cosmology were stories to explain such things and they wished to see how the English answers would either correspond or differ. The Massachusett held to a tradition that the world had been flooded once, and that one Powaw, having foreseen this event, fled to the White Mountains where he and his people weathered the storm and then repopulated the earth. Others believed that the beaver was their father, having restored the earth by scoring mud from the bottom of the sea and placing it on the back of a turtle. ${ }^{42}$ At any rate, the English answer in each case amounted to the equally unscientific claim that it was "God that made them so." 43

When the missionaries came again a third time on 26 November of that year, following the preliminary talk, it was stated by the Natives once more that their only "great desire this time was to have a place for a Towne." By this time, the authors tell us, the General Court had already been moved to "purchase so much land for them to make their towne in which the Indians are 
much taken with." The court, however, was still in the process of "considering where to lay out their towne." In other words, a removal was being considered from the start. The Natives, "not knowing anything," were anxious to receive some official confirmation from the General Court that their traditional lands had actually been granted to them. ${ }^{44}$ Eliot had already supplied them with tools and provisions in "hope" that they might begin "improving" the land. ${ }^{45}$ But all along Eliot kept from the villagers the knowledge that they would not necessarily remain on these grounds. Nevertheless the English chose to mark the occasion by deciding on a name for the new town, disregarding the fact that it already had a name. They settled upon "Noonantenum," meaning "rejoicing," "because they hearing the word, and seeking to know God, the English did rejoyce at it. ${ }^{, 46}$ The English concluded their visit with the recitation of a short prayer in the local language that read "Amanaomen Jehovah tehassen metagh/ Take away, lord, my stone heart." 47

\section{Shadow Printer: The Invisible Native Hand on the Lever of the Press}

Before the English left on this third encounter in November of 1646, four young children were placed in the hands of the missionaries by a prominent Native named Wampas to receive an English education. ${ }^{48}$ These children, according to the authors, were promised "acceptance and an education of them either in learning or in some other trade of life." The authors of "Day Breaking," it seemed, were not quite sure how to dispose of the children put in their charge, noting that "they are not yet placed out because it is most meet to doe nothing that way too suddenly. ${ }^{, 49}$ But the choice for a home for two of the Native youths seems to have landed on Henry Dunster, the first president of Harvard College. Dunster had become recognized as a proponent of Indian education, particularly efforts at teaching the Natives in their own language, and much of the fund-raising surrounding this endeavor was being channeled directly through the college. ${ }^{50}$ One of the children Wampas handed over to the English must have been his son, John Wampas, whose checkered career would include a brief stint at Harvard, a stint in colonial 
prison, and a career as fugitive mariner. Although it is difficult to prove with absolute certainty, another of the young children handed over that day was probably James Printer. Yet another may have been Job Nesuton who would later help Eliot with the translation of the Old and New Testaments.

Despite their different surnames, I feel there is reason to believe that James and Job were brothers (obviously "Printer" is a later designation given to James when he came into his trade. He is probably the first Native of New England to acquire an English surname from his employment). Eliot, in a 1669 letter to Robert Boyle in England, notes that James Printer had a brother named Job, described as "teacher at Ogquonikongquamesit" and noted to be "one of your scholars at Cambridge."51 Job Nesuton was most often regarded as an interpreter for Eliot, but would have been qualified to teach at any point in his long career with the English. Cogley, however, asserts that Job was a Neponset who served as a schoolteacher in 1656, "presumably at Natick," but perhaps elsewhere. ${ }^{52}$ Since Natick seems to have had an abundance of literate Natives in its midst in the 1650 's and Ogquonikionquamesit was only some fifteen miles down the road, it doesn't seem unlikely that Job would have been dispatched to the later town to assist with the work there. The possibility that James Printer and Job Nesuton are brothers is obfuscated because the phrasing of Eliot's 1669 letter is circuitous, and Daniel Gookin leaves this detail out when he lists the members of Printer's family in a later text. But by the time of Gookin's writing, Job Nesuton had been killed, a casualty of the first major battle of King Philip's War, which might explain why the name of Job does not appear in relation to James in Gookin's 1677 account. ${ }^{53}$ Overall there is a great deal of confusion surrounding names and tribal affiliations in this period, and I have no desire to add to it, but the careers of James and Job so closely parallel one another that it strikes me as a strong possibility that they were related.

There is also some reason to believe, however, that James, also known as Wowaus, had already been placed in an English home prior to the Nonantum visits. ${ }^{54}$ Samuel Eliot Morison 
notes that in October of 1646 Dunster wrote a letter to the Massachusetts Council asking for compensation for expenses paid toward his boarding of two Indian children, Jonathan and James. The letter offers an audit of what was spent and tells us that the two boys were provided with sixteen pounds worth of food, sixty-four pounds worth of clothing, and that both became ill early on in their residency for some five or six weeks. Dunster also notes that he spent 60 pounds on James' schooling. If the dates offered by Morison are correct, then James was brought to Dunster prior to Eliot's trip to Cohannet. But it also seems probable that the "Jonathan" mentioned is John Wampas, and therefore another one of the children most likely to have been offered up at the Nonantum lectures. Probably it is the chronology offered in "Day Breaking" that is off. Whatever the case, Dunster seems not to have been happy with these "hopeful young plants" and the expenses that accompanied them. He wrote to the governing council that "the Indians with me be so small as that they [are] incapable of the benefit of learning as was my desire to impart to them, and therefore they being an hindrance to mee and I no furtherance to them, I desire they may be somewhere else disposed of with all convenient speed." The magistrates of New England agreed to compensate Dunster some twenty-two pounds for his efforts, but were silent on the matter of how to dispose of the two Indian boys. ${ }^{55}$

It may have been understandable that Dunster, despite his stated advocacy for Indian education, didn't want two Indian children cluttering the works. He had only a few years earlier married one Elizabeth Glover and inherited not only her five children from a previous husband, but a bouncing baby printing press that she had brought to America with her in 1638 . To establish a press in New England had been the goal of her first husband, the Reverend Jose Glover. Glover died on the passage over, however, and the press was maintained for the next few years by Stephen Day at the house of Elizabeth Glover. Stephen Day, a locksmith by trade, land speculator at heart and printer by conscription, oversaw the printing of the first published materials in New England including The Freeman's Oath, a 1639 almanac, The Bay Psalm Book, 
and the first Harvard Commencement theses. Although trained by Glover and brought over as an indenture, Day proved a less than adequate printer and did not find approval with the tightly reigned-in Puritan community in New England. When Elizabeth Glover married Dunster in 1641 the press became Dunster's own private venture, whether he desired it or not. To complicate matters further, Elizabeth Glover (now Dunster) died in 1643 after bearing Dunster a son. Dunster remarried the next year, and soon another baby was on the way. ${ }^{56}$ To summarize, somewhere in the years of $1645-46$, Dunster, along with overseeing the fledgling college, had to make room in his newly erected house for his first son and five step-children through Elizabeth Glover, a new baby from the second marriage, a printing press, and two Indian youths that he didn't know how to "dispose of ." Morison notes that the press presumably "occupied the ground floor of a lean-to or addition on the north side" of the house. Quite possibly the two Indian boys were made to sleep in the same room alongside the press, as there would have been a lack of space and the lean-to was probably built as a servants quarters to begin with. ${ }^{57}$

If Dunster wished to unload the children on someone else, he may have been discouraged by the fact that money being allocated to the college from Parliament, according to a 1649 proclamation, was inextricably tied up in the encouragement of "the preaching and propagating of the Gospel of Jesus Christ amongst the Natives, and also for maintaining of schools and nurseries of learning, for the better educating of the children of the Natives." 58 Thus his boarding of the two children remained a public relations gesture that had been, from the start, the most effective manner of winning money from England for support of the college. Perhaps another incentive, as Cogley asserts, was that the money raised by the Weld-Peters commission which was responsible for the publication of New England's First Fruits, had gone towards building Dunster's new house rather than any demonstrable help for the Natives. Therefore he owed his present quarters to the very cause of Indian education. ${ }^{59}$ This was undoubtedly what had motivated Eliot to bring the children to him in the first place. 
As for the press, Stephen Day proved unmanageable and unreliable in his office as printer, and his son Matthew was quickly hired in his place to run the operation. Matthew Day, died only three years later, however, leaving the bay colony with a press but no one to run it. And yet it did keep running, even without the famed Samuel Green, who was to step in soon after and take over the day to day business of keeping it going. Samuel Green has become something of a beloved figure in colonial lore, fondly described by Morison as "one of those popular, versatile, faithful and energetic characters necessary to the good conduct of any college town. ${ }^{\prime 60}$ Rarely, however is he commended for his skill as a printer. Green wrote to John Winthrop Jr. in 1675, that "printing was the employment I was called unto when there was none in the country to carry it along . . . and although I was not used unto it yett being urged thereunto by one and another of place did what by my own endeavors and help that I gott from some others that was procured, I undertook the work. ${ }^{.61}$ Even his phrasing punctuates some of the difficulties he might have faced as printer.

As George Parker Winship notes in his 1946 history, The Cambridge Press, Mathew Day died on May $10^{\text {th }}, 1649$. Green took over the press in October. But some ghost printer seems to have kept things going in the interim as the summer of 1649 saw the publishing of the Harvard Commencement Programs in the absence of a proprietor. Winship imagines that some journeymen who had been with the press all along managed to get these publications out, but doesn't trouble himself to offer up any likely candidates. Green himself admits to the help from "some others that was procured," but also offers no names, nor is there any record of anyone being compensated for such work. There is good reason to believe that this invisible, unpaid printer who kept things running was none other than James Printer. Gookin would write some years later that James, unlike his brothers, "was bred among the English, and employed as a press man in printing the Indian bible. ${ }^{962}$ If Printer had been living with Dunster, as most historians assume, and had been placed there to learn a trade, as Eliot insists, then it seems more than likely 
that he was trained by Matthew Day and had actually acquired some remedial printing skills in the three years that he had slept in the same house as the press, and possibly in the same room. That he remains an invisible presence is not surprising, as any Native contributions to the workings of the colony were bound to be overlooked. In fact, the very invisibility of this interim printer, or the historical shadow cast in his place, suggests that James was the immanent presence behind it. James, who would have been roughly eleven or twelve at the time of Day's death, and had probably learned to read and write a little English in the fledgling grammar school Eliot established in Cambridge, ${ }^{63}$ was old enough, and probably experienced enough at this point, to have gotten the job done. Certainly it was considered no great feat for Ben Franklin to have done as much when he was a printing devil in his youth, working for his brother. ${ }^{64}$

Szasz, in agreement with the historical consensus, writes that "one of the most remarkable aspects of Green's long and successful career was his association with James. By teaching this young Nipmuc the skills of the craft, he insured Indian involvement in one of the most crucial aspects of the Massachusetts publishing venture. $" 65$ I would posit, however, that it was James Printer who trained Green, a man who, by his own admission, knew nothing of printing when Dunster singled him out for the job in 1649. In fact, prior to taking over the press, Green had been a general handyman around the campus, prominent in the militia, and at various times doorkeeper to the House of Deputies, clerk of writs, stationer, and college barber. ${ }^{66}$ Eliot, in particular, seemed to have had a "boiling zeal" against the current fashion of wearing one's hair long, associating this fad among the white students with a Native "vanitie and pride." As a result, Morison informs us of how "Sergeant Green, the college printer, took charge of college hair-cutting in the early days, ${ }^{, 68}$ a detail that offers a slight glimpse into the overall role Green filled on campus and his allegiance to the administrators. That Green's status as printer would initiate a publishing legacy stretching for generations and accounting for much of the earliest and most important documents of the colonial period, owes more than a bit to blind chance, and the 
assistance of one barely perceptible "printing devil," whose contributions became absorbed in the identity of his white master. ${ }^{69}$

By 1650 a new charter for Harvard, signed by Dunster and then governor Dudley, was incorporated for "the advancement ... and to the maintenance of ... all other necessary provisions that may conduce to the education of the English \& Indian youths of this Country in knowledge: and godliness." ${ }^{70}$ As Harvard struggled to establish itself as an institution it increasingly acknowledged the utility of attaching itself to goals of Native education. In 1651 Dunster proposed that the building for the Indian College be funded. The Indian College was the first brick building at Harvard, described by Gookin as "strong and substantial but not very capacious," costing between three and four hundred pounds, and "able to accommodate about twenty scholars with convenient lodgings and studies."71 Morison writes that here "it was hoped Indian youths might acquire a university education, which (through some obscure workings of the academic mind) was confidently expected to qualify them as teachers and converters to their pagan brethren." ${ }^{.72}$ Morison ultimately acknowledges that the project to school Natives was disrupted by disease and war rather than any lack of ability on the part of Native scholars. Nevertheless, his condescending tone reveals just how deeply seeded were preconceived notions concerning the intelligence of Natives and their ability to enter so-called civil society, even as late as $\mathbf{1 9 3 6}$ when he wrote his history of Harvard. Morison also intimates that many considered the construction of the Indian College as "merely a blind to get a new building." have had the alternative motive of needing a place to house his long term boarders, and the rising generation of Native students who had been studying all along at the local grammar school (Insert lay out of the Indian College Building as imagined by H. R. Shurtleff, in Morrison 345).

The Indian College was built sometime between 1654 and 1656, the general period of its construction interestingly coinciding with a number of concurrent events. First of all, Dunster resigned as President of Harvard in 1654, and was replaced by Charles Chauncy in November of 
that year. ${ }^{74}$ Dunster was more or less forced out of his position following legal troubles that concerned the royalties of the printing press, and claims by the Glover family the original owners of the press - that they were entitled to a share of its overall profits. Forced out of his home in the winter of the following year, Dunster moved his family to Scituate, leaving the press behind. ${ }^{75}$ One wonders if the in-coming Harvard President inherited Jonathan and James as well. There is no record of either of them throughout this period. Probably they divided their time between their homes in Hassenimesit and Cambridge. Nevertheless, the new President seems to have regarded the inherited printing press in his quarters as a nuisance, even describing it as "dangerous and hurtful," words more commonly used to describe Indian "savages" than printing presses. Therefore the press was moved to the new Indian College building probably in the spring of $1655 .{ }^{76}$ This was most likely a solution of greatest convenience since not only was there a noticeable amount of vacant space in the two-story, thirty by twenty foot building, but this would allow the Native printer, James, to continue living in direct proximity to the press and keep it maintained. ${ }^{77} 1654$ also happened to be the year that the first text in the Native language, The Indian Primer, was printed by Eliot, presumably with the help of Job and James. Chauncy was never a champion of the project of printing texts in the Native language and probably considered it a major inconvenience to have such an operation ongoing in his own quarters. This was one more reason to have it, and its associates, relocated. Once the press was situated in an Indian space, with an Indian printer and Indian translator on board, it could continue its production of texts in the Indian language unabated.

James Printer does not emerge in the archives again with any reasonable certainty until 1659 when it is noted by the commissioners of the New England Company that "two of the Indian youthes formerly brought up to reed and writ are put apprentice; the one to a carpenter, the other to Mr. Green the Printer." 78 This doesn't necessarily mean, however, that James was actually made an apprentice in 1659 , but merely that the commissioners chose to remark upon his 
"apprenticeship" at this point as they were in the process of soliciting for a new press with which to make the first Indian Bibles. It may be that James had finished studying at Corlett's grammar school by this point and could turn his full attention to his designated trade. But to call him an "apprentice" implies a codified relationship that was not truly open to Native American youths. As nineteenth century historian and antiquarian book dealer Samuel Drake notes in his Biography and History of the Indians of North America, James was still considered an "apprentice" when he later became swept up in the conflict known as King Philip's War in 1675. Drake wryly comments that "if after an apprenticeship of sixteen years one could not leave his master without the charge of absconding, at least, both the master and the apprentice should be pitied."79 In all likelihood, James" "apprenticeship" was a full twenty-six years in the making. James, with his skill in printing and his ability to read and write in both English and Massachusett, was probably on hand for the printing of the 1654 Indian Primer, and therefore was like to have had a hand in every text produced in the Indian language from the Cambridge Press over a fifty-three year period.

All the while that James was learning the printing trade and teaching it to Samuel Green, Job Nesuton was learning more specifically to read and write, and was busy teaching the Massachusett language to Eliot. Job had probably received some two or three seasons of schooling at one of the secondary schools in the colony by the time Eliot announced in 1650 that "I have one already who can write, so that I can read his writing well, and he (with some pains and teaching) can read mine. ${ }^{980}$ Eliot had made it clear in his letters to the newly established, London based, Society for Propagation of the Gospel in New England, that "I do very much desire to translate some parts of the Scriptures into their language, and to print some primer in their language wherein to initiate and teach them to read, which some of the men do much also desire." But Eliot was quick to note that, despite the fact that he had been dabbling in the Massachusett language for some four or five years, he had "yet but little skill in their language . . 
. I must have some Indians, and it may be other help around me to try and examine Translations, which I look at as a sacred and holy work, and to be regarded with much fear, care, and reverence." 81

Salisbury intimates that it was the Indian interpreters who were responsible for the actual translations of the biblical texts, with Eliot merely spearheading the project. ${ }^{82}$ And Szasz strongly asserts that "for too many years this Indian contribution to the publications has been ignored." 83 These scholars have appropriately sought to locate and recognize the high degree of Native input into this colonial endeavor. In response to their remarks, however, Richard Cogley has sought to realign the discussion once more, acknowledging that such contributions took place, but arguing that Eliot, himself, must have done the actual translating as the texts in question "required a command of English and a theological erudition that no Native at the time possessed." ${ }^{84}$ Cogley does a good job bringing to light the interpretive complexities of this massive undertaking, noting how words like "horse," "brass" "psalm" and others had no equivalent in the Algonquian. The word "lattice" for instance, was substituted with the word "eelpot," as the Native eelpot seemed closest in design. There was no verb to be in the Algonquian language, which created many challenging problems. A passage in Matthew referring to "ten wise and foolish virgins" was transformed into a male-gendered reference, chastity being a masculine virtue in the culture of the New England Natives. ${ }^{85}$ Absent from Cogley's overall assessment, however, is the acknowledgement that it would have taken a similarly sophisticated internalization of the Massachusett language to effect the translation, particularly if Native audiences were to have any hope of overcoming cultural differences and grasping its content. Just as the Native translators were not expertly fluent in English and the esoteric conceptual framework of Judeo-Christian traditions, Eliot was hardly fluent in Algonquian and the spiritual and traditional equivalents that were brought to bear in juxtaposing such disparate cultural realities. One can only surmise then that the translations were a truly collaborative effort. 
Regardless of the fact that Eliot openly admitted his need for constant assistance in completing this work, never does he cite by name the individuals who assisted him on specific projects. They too are historical shadows, their forms filled in by years of historical inquiry and research. We know from an accounting bill sent to the New England Company in 1662 that Job was paid for his help as "interpreter," to Eliot. ${ }^{86}$ And in his 1677 An Historical Account of the Christian Indians in New England, Daniel Gookin remarks upon Job's death that "he was a very good linguist in the English tongue, and he was Mr. Eliot's assistant and interpreter in his translations of the Bible, and other books of the Indian language. ${ }^{87}$ Gookin's comment, alongside other references to the help received, point to the fact that the work of translating all of these materials into the Native language was not the work of a single white man, nor, is it likely, a single Native interpreter. John Sassamon, whose apparent murder would spark the events leading up to King Philip's War, probably had a hand in some of the translation before he abandoned the project to become the personal scribe of King Philip. Cokenoe must have been involved in some early translation work as well. And James Printer was apparently indispensable in bringing these materials to press. Job, however, seemed to have been the mainstay in the Indian translations over the years, despite a few isolated incidents of his, to use Eliot's term, "backsliding."

Eliot, as is clear in his comments concerning transcription in "Tears of Repentance" and elsewhere, simply did not possess enough fluency in the Algonquian language to receive sole credit for the accomplishment of translating the bible. Even as late as 1683 when the second edition of the bible was proposed, Eliot wrote to the commissioners "we have but one man, viz. the Indian Printer, that is able to compose the sheets, and correct the press with understanding." 88 The translations had to have been a joint venture in every way, requiring as much Native input as English. While it shouldn't be surprising that Eliot's name alone appears on the frontispiece of these works (along with Samuel Green's as printer), the Indian translations 
were the handiwork of Native individuals whose labor and input went largely unnoted.

\section{Tears and Testimonies: “Tears Of Repentance" and Eliot's Indian Dialogues}

The Natives who placed themselves in proximity to English rule often found themselves in a thankless and precarious situation. As Wampas expressed it, "because we pray to God, other Indians abroad in the countrey hate us and oppose us, the English on the other side suspect us, and feare us to be still such as doe not pray at all." ${ }^{\text {89 }}$ The political and psychological pressures attendant upon such a situation, when added to the other psychological pressures these communities had already withstood, must have created an atmosphere of nearly unbearable tension. Even Waban, who seems to have led the movement of Natives congregating into praying towns, testified in 1652, "when the English taught me of God (I coming to their Houses) I would go out of their doors, and many years 1 knew nothing; when the English taught me I was angry with them." 90 This statement, offered up in the 1653 tract "Tears of Repentance," allows a compelling glimpse into the conflicted state of Native conversion. While Eliot continued to conjure up seamlessly optimistic assessments of the emerging dawning of Christianity amongst the Natives, Waban and others, when allowed to speak in a different context, presented a much more complicated response. More than likely, contained within Waban's brief pronouncement is a world of turmoil. One intuits a rift in the public visage and the private one he wears when "out of their doors." Within the confines of Puritan print discourse Waban remains a dedicated convert, a precious "first fruit," but in private he wrestles with the cultural tensions he has taken it upon himself to bear. This separation between the eminent and the idealized Native is made apparent somewhat when one contrasts Eliot's testimonial of Native confessions, "Tears of Repentance," with his fictional missionary primer "Indian Dialogues."

In 1651 it was decided that the Nonantum Natives who had signed on to Eliot's 
missionary outfit should be relocated, and 2,000 acres of land were opened up for that purpose in nearby Natick. Little has been said concerning how such a move, even a move of only some fifteen miles, might have resounded with the Natives themselves or effected their political infrastructure. George Emery Littlefield, in his History of the Cambridge Press concluded simply that "the Indians were favorably disposed toward this proposition and soon became anxious to remove." .91 Cogley writes that the "Nonantum Natives were pleased with the location" and notes that John and Robin Speene, two prominent praying Indians of the time, held an "inheritance" there. He states that "Wamporas" or Wampas "also approved of the location." Ma2 Many, however, were still very much attached to the ancestral lands they thought had been promised them at Cohannet, or Nonantum as the colonists preferred to call it (although it could no longer be considered a place of "rejoicing," but rather a cause for mourning). Waban seems to have opted to remain silent on this subject in "Tears of Repentance," although it remains clear from his earlier statements made in "Clear Sunshine" and "Glorious Progress," that he had lobbied to remain in Nonantum. While "Tears of Repentance" is a tract published directly in the service of Eliot's missionary endeavors, it reveals some of the growing tensions arising from coerced conversions and removals.

The notion of Native "tears" in relation to Christian conversion had already become a popular convention by the 1650 's, suggesting to European audiences the pitiful state of a godless people, and the utter despondency with which they embraced the Christian faith. But the convention also speaks to how Natives searched for a response to Christian doctrine from within their own cultural response mechanisms. In certain settings, many Native peoples would express themselves through ritual tears, meant to demonstrate the reciprocation of grief and mourning. Mary Jemison, an eighteenth-century white women held captive by the Seneca, recalls how the Native women who adopted her burst into tears at their first meeting, to demonstrate that they at once mourned for their lost brother and accepted Jemison as a replacement for their loss. ${ }^{93}$ The 
sixteenth-century Spanish conquistador Cabeza de Vaca recalls the violent tears of the Natives who greeted he and his men when they washed up shipwrecked and naked on the shores of modern day Galveston, Texas (still a cause for weeping today). ${ }^{94}$ Ceremonial tears in response to Christian teaching must have somehow seemed an appropriate response to the grief-wracked message of death and sin that informed the words of the English missionaries. But it was a response perpetually misunderstood and sentimentalized by the settlers.

On 13 October 1652 a number of converts (a term that must be applied loosely here), were brought together in front of a small committee of church elders in Natick to offer confessions and demonstrate the depth and comprehension of their gospel learning. Waban was one of five who testified. The text offers two confessions for each of the Natives who spoke that day (save for Waban who, for reasons unexplained, is only represented by one testimony), the first having been written down prior to the meeting, and the former having been presented extemporaneously on the day of the meeting. It is a bit of a mystery why dual confessions were deemed necessary, although perhaps the first written testimonies were composed because, as Eliot suggests, his converts "were daunted much to speak before so great and grave an assembly." 95 If so, this would have been a rare inhibition for Native elders accustomed to delivering orations and speaking in councils. Perhaps Eliot felt some anxiety concerning the ability of his converts to stick with the script, and hoped that the confessions might be read in lieu of live performances. Or perhaps he mistrusted his own skill as translator, as it was his job to record the confessions as they were being spoken. At any rate, the council of elders who had come to witness the proceedings voted to do away with the pre-scripted versions, and so, even though both versions ended up in print, only the live testimonies were actually offered that day.

One might justifiably wonder if Eliot and the Native confessors shared the same rhetorical objectives, as the testimonies offer little evidence of sincere conversion. At the very least, however, the Natives had been drilled in particular aspects of the confessional ritual, and 
therefore focused upon their sinfulness, expressing the types of sins that were presumed to be a staple of the Native diet such as uncontrollable lust, greed, and devil worship. Such failings, of course, had everything to do with how Europeans misinterpreted Native customs, and nothing to do with any sort of individual transgressions, therefore offering the confessors little space for personal reflection as to what these "sins" signified or how they might be repaired. A broadside printed at the Cambridge Press in 1660 entitled "Christians Oonoowae Sampoowaonk" or "A Christian Covenanting Confession," although printed after the proceedings in "Tears," offered the script for a proper confession, as Eliot saw it, in both the Indian and English languages. It called for an explicit declaration of one's love of God, intoning "I believe with my heart and confess with my mouth," and offering some foundational passages of scripture that would be helpful in such a situation. The broadside concluded with an sample testimony that read:

For these causes, wee that dwell in this towne called are gladly willing to bind our selves to God, to remember the Sabbath day and keep it holy, so long as we live. And also to bind ourselves to each other, to meet together every Sabbath day (when it may be done) to doe all our Sabbath day Services, prayers \& c. according to the word of God, the holy Spirit of God helping us. By this Gospel covenant, we doe give ourselves and our Children to Jesus Christ, to walk with him in Church order so long as we live. ${ }^{96}$

The objectives of such a statement were clear. As Salisbury notes, "Indian converts were expected to renounce their individual and collective pasts and to adopt a new identity created for them by the representatives of an entirely foreign culture., 97

If the script, as articulated in the broadside, was not followed, the proceedings at Natick, nevertheless, offered a most pleasing display of self-loathing by a people presumed to be savages, and prevented the audience from dwelling on other, more troubling or ambivalent aspects of the confessions. For instance, Waban begins his testimony admitting to having wished to be a sachem and a "witch" before the English came, and claims that he desired riches for himself and harbored evils in his heart. All this would have been met with approval. Yet he concludes his speech by noting that, "I do not truly pray to God in my heart: no matter for good words, all is the true heart; and this day I do not so much desire good words, as throughly to open 
my heart: I confess I can do nothing, but deserve damnation; Only Christ can help me and do for me. But I have nothing to say for myself that is good." 98

Such a confession could hardly have met with the specifications for church admittance, nor does it seem so designed. Salisbury feels that part of the task for the Native confessor was to recognize "how just it is for God to deny them the knowledge of Jesus Christ," $" 99$ but in a post-script to Waban's speech, Eliot notes that the confession was "not so satisfactory as was desired." Waban, however, proves an adept orator. He demonstrates a sophisticated understanding of the expectations of the ritual, performing contriteness in the face of English religious customs while saying nothing that isn't ostensibly true. If he desires Christ on some level, and recognizes human failings and desires, nevertheless he lays bare the sentiments of his heart, wherein he does "not truly pray to God," enfolding this statement within an acceptable framework of repentance. Although Cogley refers to Waban's confession as "incoherent"100 Waban's performance is, in fact, one of measured engagement, diplomatically threading the needle between English conventions and his own goals for his people.

Waban may have made concessions to Eliot and the English in a grab for power outside the recognized bounds of Native succession, but it becomes apparent that Waban was influential enough in his own right to be a necessary figure for the English. As such the English find themselves having to overlook his lackluster spiritual awakening. As Eliot remarks, "his gift is not so much expressing himself this way, but in . . Ruling, Judging of Cases, wherein he is patient, constant and prudent insomuch that he is respected among them." Apparently those very gifts were on display in Natick that day, and being used in relation to the ceremony in question. As one auditor noticed, Waban "spake these latter expressions with tears," ther theby expressing his sincerity even while denying any personal acceptance of Christ.

The post-script notes following some of the speeches give us a glimpse into aspects of the oral delivery that go missing from the pre-scripted testimonies. Waban's tears, probably in 208 
keeping with certain ritualized aspects of oral performance, are one example of this. We learn in another post-script note that the next speaker, Monequassun, seems to have been cut off by Eliot in the middle of his speech, Eliot perceiving he had taken too long in his delivery. Monequassun, like Waban, confesses that, of Christ "my heart of my self cannot believe," and it is not long after this unsettling revelation that Eliot decides to terminate his performance. Although the auditors were unable to understand what the Natives were saying until Eliot read the words back from his own notes, they apparently were aware that Monequassun's delivery had been cut short, and Eliot was forced to explain himself. He writes that the great assembly "understanding nothing he [Monequassun] said, only waiting for my interpretation, many of them went forth, others whispered, and a great confusion was in the house and abroad." One wonders if Monequassun's physical gestures helped stir the audience into such great confusion, if he expressed anger or disappointment at being interrupted, or if the "great confusion" was simply a result of Eliot's putting an abrupt end to his oration. Either way, it seems to have been conveyed to the audience that something was amiss. Perhaps Eliot was not so much concerned with the length of the speech as he was with the content. Not only does Monequassun deny any acceptance of Christ in his heart (a denial that is conspicuously absent from the pre-scripted version), but he folds into his testimony a protest against being moved from Nonantum. He confesses that the only reason he agreed to hear God's word at all was because "I loved the place of my dwelling [Cohannet], and therefore I thought I wil rather pray to God" than run away. In the pre-scripted version he asserts "being called to confess, to prepare to make a Church at Natick, I loved Cohannet ... I was not willing to follow Christ to Natick," and he repeats this sentiment in his oral testimony saying, "hearing that we must make a town in Natick, and gather a Church at Natick, my heart disliked that place ... I was much troubled because I had not believed Christ, for I would not follow him to make a Church." 102

Monequassun was "schoolmaster" at Natick and had learned to read and write despite 
the sacrifices such an acquisition demanded. He tells of his struggle, asking "how should I, my wife, and child be cloathed, if I spend my time in learning to reade?" But his heart was apparently in conflict, and he acknowledges that he ultimately accepted the conditions of the praying town only after his wife and child died of disease while still at Nonantum (Rejoicing). Monequassun was clearly an anguished and eloquent figure, who had employed his natural talents to investigate what was within the English teachings. On that day in Natick he was prepared to deliver an oration that not only addressed the concerns of the Puritan elders in attendance, but laid out his own concerns and misgivings as well. The forum may have appeared to him as something more than a confession. It may have appeared a rare opportunity to speak directly to Puritan authorities. Amongst his own people it would have been unthinkable to arrest such a speech in mid-sentence. Eliot, however, shut off Monequassun's words before they could do further damage to his own agenda. ${ }^{103}$

The conclusion of the elders and auditors who had sat through the 1652 orations that day was one of cautious encouragement. While it was concurred there was reason for optimism, the sanctioning of the Natick church was put off for a later time. The so-called "praying town" would have to wait another eight years before a church was finally established to go along with it in 1660. The text of "Tears of Repentance" remains something of a curiosity, however, as it inhabits the rhetorical boundaries between Native and colonial agendas. While certain Native speakers like Waban and Monequassun were more skilled at holding their rhetorical ground and inserting their own concerns into the discourse, the other speeches also register tensions. One of the testimonies, that of Ephriam, goes so far as to conclude, "I do not truly in my heart repent, and I think that God wil not forgive my sins ... I pray outwardly with my mouth but not my heart." ${ }^{\text {"104 }}$ This subversive statement stood in open defiance to the sentiment offered in Eliot's 1660 broadside script that rehearsed, "I believe with my heart and confess with my mouth." Surely these lines from Romans 10:10 had been drilled into the confessors. William of Sudbury, 
also known as Nataous, father of James Printer, concludes his testimony with the stinging words, "I am angry with myself, because I do not believe the word of God, and gospel of Jesus Christ." ${ }^{\text {105 }}$ Such statements hardly fulfilled the promise of the tract's title page which advertises a "manifestation of their Faith and Hope in Jesus Christ and the Work of Grace upon their Hearts." 106 Nevertheless, the Native tensions in "Tears of Repentance," couched as they are in the linguistics of Christian piety and framed on either end by validating letters from Eliot, Thomas, Mayhew, and Richard Mather, failed to fully register to their English audiences who were simply impressed that such a forum could even take place in the American wilderness.

Ironically, for the auditors to approve of the Natives' confessions would make of them "visible saints" in Puritan parlance, and this would stand at direct odds with the overall project of making Indians "invisible." Nevertheless the revelation of such widespread discontentment amongst the praying Indians reflects the conditions under which "Tears of Repentance" and "A Further Account" were written, the spontaneous nature of the spoken testimonies, and the conventions of the Puritan church which called for a precise accounting of its admission process, as it was crucial for the auditors to sift through the confessions for intimations of divine grace. Naturally some issues arise concerning the reliability of Eliot's translations and transcriptions, but Eliot, himself, seems to have been attuned to many of our contemporary concerns of amanuensis, and in his notes to "Tears" we can begin to apprehend the anxiousness with which he dotes on these proceedings. He comments that

in writing and reading their Confessions, I have not knowingly, or willingly made them better, than the Lord helped themselves to make them, but am verily perswaded on good grounds, that $I$ have rendered them weaker (for the most part) than they delivered them; partly by missing some words of weight in some Sentences, partly by short and curt touches of what they more fully spake, and partly by reason of the different Idioms of their Language and ours. ${ }^{107}$

One might imagine that Eliot was inclined to downplay the moments of obvious resistance and to give more detail to statements that conformed more conspicuously with church doctrine. Such an understanding reveals, in part, just how crucial it was for skilled orators like Waban to negotiate 
a steady path, so that his words might be recorded, and his meaning remain intact without giving pause and allowing Eliot a reason to lift his pen from the page or cut short his speech. Nearly elided in the tract, however, is the fact that Eliot was not directly translating the words of the confessors himself. In one place only he notes that "oft I was forced to inquire of my interpreter (who sat by me) because I did not perfectly understand some sentences." ${ }^{108} \mathrm{I}$ am inclined to imagine that the interpreter was Thomas Waban, although it may have been any of Eliot's cadre of Indian helpers. He had intended to use Job Nesuton as interpreter except, Nesuton had fallen out of Eliot's good graces for having intoxicated the son of Totherswamp a day or two prior to the proceedings. ${ }^{109}$ The fact of a Native interpreter on the stage suggests that the translations were likely more faithful to the actual words delivered, than if a white interpreter, alone, were involved. Therefore "Tears of Repentance," as spoken by Natives and translated by a Native, has as much claim to being an authentic Native text as many an other "as told to" document, and perhaps more of a claim. Its model, including the moments of resistance that exist side by side with rehearsals of Christian doctrine, would be closely followed in one of the earliest documents to be written and published by a Native nearly two hundred years later, William Apess' 1833 tract, The Experiences of Five Christian Indians of the Pequot Tribe. ${ }^{110}$

One can sense the obvious contrast between what is expressed in "Tears of Repentance" and what the colonists desired to be expressed in a later tract entitled Indian Dialogues, the first conscious work of fiction (perhaps fantasy is not too strong a word) produced and published in the colonies. Eliot admits up front in this 1671 tract that the dialogues are "partly historical, of some things that were done and said, and partly instructive, to show what might or should have been said, upon the like occasion." In a sense the Dialogues are a correction for tracts like "Tears of Repentance" that never seemed to go off completely as planned. One of the central characters in Indian Dialogues is, in fact, Waban, who appears to be a composite of Waban the elder, his son Thomas Waban, and no Waban that ever was. When we first encounter him, he is sauntering 
through the forest and comes upon another Native, one Peneovot. After an opening volley of forced small talk Waban, hurrying to the point, bursts out with it that,

I am a praying Indian. I have left our old Indian customs, laws, fashions, lusts, pauwauings and whatever else is contrary to the right knowledge of the true God, and of Jesus Christ our redeemer. It repenteth me of all my fore-past life, the lusts, vanities, pleasures, and carnal delights that were formerly very sweet and very delightful to me, are now bitter as gall unto me. I hate and loathe them. All the works of darkness in which I was wont to take pleasure, I do now forsake and abandon. I am come into the light. I now see things as they are indeed, and not as they seemed to be in the dark. I now know the word of God, which showeth me the way of eternal life ... I now know Jesus Christ, who hath died for us, to procure a pardon for us, and to open a door and way of eternal life and salvation for us. Into this way I have entered. Herein I walk, and I have promised to God, that I will live and walk in this way all the days of my life. ${ }^{111}$

It is quite probable that if Eliot could have placed the words directly into the mouth of Waban in "Tears of Repentance," then this is what would have been said. Perhaps even more fantastical than Waban's speech, however, is the response it garners from Peneovot, who immediately exclaims, "Oh, I am surprised, I am amazed. You have ravished my soul. You brought a light into my soul. I wonder at myself. Where have I been? What have I done? I am like one raised from out of a dark pit." ${ }^{.12}$ The only thing apparently missing from this scene is Waban offering his companion a friendly jar of Grey Poupon. These Natives, far from representing anything of flesh and blood, bear a striking resemblance to the one dimensional Native in the Massachusett Bay Colony seal who has turned down his bow and arrow and is waving the Puritans over to come and offer their much needed help. They are products of Puritan fantasy, human creatures that offer up no psychic resistance to the challenge of a newly opened cultural paradigm. In a sense, Indian Dialogues lays bare the cognitive rift still very much in place some fifty-one years after initial contacts between Puritans and Indians. While the actual Waban is all too aware of the difficult philosophical terrain between the two cultural discourses and negotiates it with studied care, Eliot continues to see Native culture as a hot bed of human error so fundamentally base that it has no viable defense, no ready response to the superimposition of Christian values.

Not only is the Waban of Indian Dialogues a fully converted, card carrying member of 
the Puritan church, ready to spread the gospel amongst the Indian nations, but this Waban, perhaps like Thomas Waban, can read and write and therefore can speak authoritatively of scripture, quoting passages at will. He is revitalized, irrepressible, reborn. By comparison, the Nipmuck sachem, Nishohkou, upon whom Waban trains his later discourse, is portrayed as listless and culturally enervated. He laments that Waban "can read and understand these things. I am old and cold and dry, and half dead already. I have not strength enough left to be whetted to a new edge." Nevertheless in Indian Dialogues he accepts Waban's preachings without argument and offers his children up for English education. ${ }^{113}$

In the final interaction of Indian Dialogues even Philip Keitasscot whom we are to understand is the Wamponoag leader King Philip or Metacom, is quickly turned round by the missionary's conversation, prompting him to enquire, "I perceive also that in your worshipping of God morning and night, you read in that book. I pray tell me what book that is? What is written in it? And how do you know it is the word of God?"114 Once he is reassured that converting to Christianity will not cause him to forfeit the tributes due him as sachem, he withdraws all opposition, exclaiming "I feel your words sink into my heart and stick there. You speak arrows. I feel that you wound me, but I do not think you hurt me. Nor do you mean me any hurt, but good." 115 Such a sentiment, placed in the mouth, injected into the very body of Philip, again shows the utter disregard for the types of tensions that were coming to a boil at this particular moment, as the real Philip, far from seeing the light, would declare all out war on the colonists just a few years after Indian Dialogues was published. In the wake of the war Cotton Mather would re-envision the same encounter within a new framework, informed by Philip's ultimate resistance. In his Magnalia Christi Americana, Mather recounts,

it was particularly remarked in Philip the ring-leader of the most calamitous war that ever they made upon us; our Eliot made a tender of the everlasting salvation to that king; but the monster entertained it with contempt and anger, and after the Indian mode of joining signs with words, he took a button upon the coat of the reverend man, adding, That he cared for his gospel, just as much as he cared for that button. ${ }^{116}$ 
Certainly both textualized Philips were mere ciphers employed to feed the current agenda or prevailing sentiment of the colonists. Philip, or Metacom, would probably become the most textualized Native figure in American letters, surpassing Wequash, and each time being employed as a vehicle for the shifting ideologies of America's process of self-identification.

\section{Thresholds of Change: Caleb Cheeshateaumauk's "Honoratissimi Benefactores"}

For the Natives of New England the years leading up to King Philip's War were years of hardship and mourning. When Waban delivered an oration in the Christian mode he would observe that "we have many at this time sick in body, for which cause we do fast and pray this day, and cry to God . . . we have a great many diseases and sicknesses in our souls." Locating avenues of Christian discourse that bore some relation to the exigencies of his people, he would speak of Christ as a "Physitian," who "healed men's bodies but he can heale souls also." Waban called on Christ to "heale all our diseases of soul and body."117 Whether or not Waban had fully accepted Christianity as a spiritual belief system, he indicates a willingness to appeal to the God of the Europeans in a time of hardship. Rhetorically he seeks a path by which he might invoke Christian concerns and combine this with a healing message rooted in the concerns and beliefs of his own people. Christ, like a shaman in Native tradition, is called upon to play the roll of spiritual leader and healer to draw out the sickness that has invaded the souls of so many. He is a powerful figure who crosses barriers between spheres of reality and prepares one's passage into the next world

But to appeal to Christ at all in New England was also to welcome in the technological invasion of writing. By the 1660 's there were a number of Natives in New England who were conversant in the concepts of western literacy, capable of reading and writing in their own language, and a few who were even capable of translating between the two languages. As early as 1647 , following Eliot's first successful mission, the colony had passed an ordinance requiring 
that "schools for the education of youth be settled and continued among them." 118 That meant that some Native students had spent upwards of thirteen years with at least some exposure to European teaching. In Martha's Vinyard, Thomas Mayhew had been preaching Christianity to the Natives since 1643, and had quietly racked up some successes of his own amongst the Wampanoag there, particularly through his association with Hiacoomes. Hiacoomes was an Indian of no particular influence on Martha's Vinyard, described by some as "slow" in speech, a "mean" person, "scarce worthy of notice," but who responded to Mayhew's instruction and deliberately took on the sachems of his Island, apparently prevailing through a number of extraordinary circumstances to gain power and authority within that community during a time of sickness and mourning. ${ }^{119}$ His eldest son Joel would be among the first Native students to attend Harvard. Still, it is difficult to gauge the kind of progress in education that was made in these years, aside from the recognition that it was all, of course, "glorious." Eliot was still seeking money from Parliament for schooling in 1650 when he wrote

Let me, I beseech you, trouble you a little further with some considerations about this great Indian work which lyeth upon me, as my continual care, prayer, desire and endeavor to carry on, namely for their schooling and education of youth in learning, which is the principal means for promoting of it for future times ... We must have special care to have Schools for the instruction of the youth in reading, that they may be able to read the Scriptures at least. ${ }^{120}$

Certainly by 1651 schooling had taken hold to a certain degree as Eliot writes,

it hath pleased God to stirre up the hearts of many of them this winter to learne to read and write, wherein they do very much profit with a very little helpe, especially some of them, for they are very ingenuous. And whereas I had thoughts that we must have an Englishman to be their Schoole-Master, I now hope that the Lord will raise up some of themselves. ${ }^{121}$

As a result of these many encouragements the Indian College was built in 1655 or 56, with some expectation that Indian scholars would be rising up through the ranks to attend classes at Harvard. If the building wasn't soon put into use, perhaps it was, as Daniel Gookin cited, because even though "the design was prudent, noble, and good ... it proved ineffectual to the ends proposed. For several of the youth died after they had been sundry years at learning, and 
made good proficiency therein. Others were disheartened and left learning, after they were almost ready for the college. And some returned to live amongst their countrymen."122 For Native youths a sudden removal to Cambridge meant exposure to a cosmopolitan breeding ground of germs and viruses for which they had no genetic immunity. And, of course, many who survived the initial biological onslaught, could readily discover other reasons to forsake a Puritan education and melt back into their respective communities. The prospect of permanently boarding in Cambridge, away from the comfort of kinship networks and familiar traditions, in order to devote oneself to an exacting textualized relationship with the Christian world, must have appeared on the horizon like the most oppressive of black clouds. Surely it was adequate to have learned enough of the alphabetic system so that one could read, write a little, and confirm the details of a recorded land transaction. A residency at Harvard, on the other hand, would have entailed mastering Latin, Greek, Hebrew and extensive coursework in the classical western traditions of Rhetoric, Physics, Metaphysics, Ethics, and Logic. ${ }^{123}$ Such a life is not for everyone, in any culture, and none of this was likely to be put to any practical use back in their own communities where entirely different notions of these schools of thought were practiced. As a result, what had at first seemed a hopeful harvest to the Puritan educators was soon winnowed down to two or three potential prospects. In 1658 Harvard president Charles Chauncy would testify

that two of the Indians that are trained up at the grammar-Schoole in Cambridge of New England, whose names are Caleb and Joel, were called forth upon tryall at the publick Commencement before the Magistrates and Elders, and in the face of the Country, and thereupon very little warning gave good contentment (for their time) to them that were present, being examined by the Praesident of the Colledge in turning a part of a chapter in Isaiah into Latine, and shewing the construction of it so that they gave great hope for the future of their perfecting. ${ }^{124}$

Can there be any doubt that the Isaiah passage in question spoke of exchanging hearts of stone for a new heart of flesh and blood?

Joel Hiacooms and Caleb Cheeshateaumauk were Wampanoags of Martha's Vinyard 
who would enter Harvard's Indian College in 1661 . They had been schooled on the Vinyard by Peter Folger, maternal grandfather to Ben Franklin, and then sent to Elijah Corlett's grammar school in Cambridge in 1657 or 1658 . One wonders if they were classmates with Job Nesuton, James Printer, John Wampas, Monequassen or any other of the praying Indians who might have attended during this decade. It seems probable that many of these individuals would have been acquainted by the time Caleb, Joel, and John Wampas enrolled at Harvard. They would have been approximately the same age, have moved in similar circles, and might have felt some sort of affinity for one another, regardless of their different tribal affiliations. ${ }^{125}$ Certainly James Printer would have been working the press in the Indian College at this time, and probably boarding there as well, when Joel and Caleb became residents. Nipmucks and Wampanoags had close tribal relations and shared many of the same traditions. There is little reason not to think that a companionship would have been forged amongst them. Although it isn't precisely evident when Wampas entered the school, he and James Printer both had relations in Cohannet. Job Nesuton might also have made regular appearances, as he was assisting Eliot with the translation of the first "Indian Bible" which was being put to press at this time.

These youths must have understood the precarious nature of their times and would have had a rare appreciation of the particular burdens of occupying a liminal space in the heart of the colonizer's stronghold. One wonders if they shared stories in the evenings, told jokes, gambled or did any of the other things that college students generally do. Or were their lives so overshadowed by their conflicted upbringings and the pressures placed upon them as representatives of their people, pulled from their homes and struggling to master a foreign discourse, that they were inadvertently estranged from one another? Had they shared similar experiences, either growing up in such close proximity to the English, or in keeping with the traditional aspects of their cultures? Did they keep medicine bundles, or share tobacco that they themselves had grown and harvested? Did they hunt for food, or lament their absence from home 
during ceremonies such as the green corn dance at harvest time? In Wampanoag tradition youths of a certain age were sent out on something like a vision quest, in which they would seek communion with animal, or guardian spirits - manitou. Such a quest might involve fasting and the imbibing of hallucinatory mixtures that facilitated dreaming and visions. ${ }^{126}$ There is no way of knowing whether the occupants of the Indian College had passed through such ceremonies, or if they partook of another kind of vision quest in which they sought the power of the English God. In Wampanoag tradition, a hero figure named Weetucks had performed miracles and was said to have walked upon the water. ${ }^{127}$ According to Wampanoag lore it was Weetucks who had carved the symbols on Dighton Rock, advising his people to maintain their ways in the oncoming rush of colonization. ${ }^{128}$ Was it possible to pray to Christ and Weetucks at the same time, or to see one within the other? One wonders if they kept journals, wrote letters. Had they learned the writing of their own people, and did they ever take to composing in that symbology over the long nights in their dormitory? ${ }^{129}$

The Indian College was more than a just a liminal space, however, where individuals labored to internalize and synthesize the codes of competing cultures. It was a space of production. As house to the Cambridge Press it was a place of textualized production, full of the noises and smells of a printing house, and for nearly the entire time that Caleb and Joel were there, its sole (soul) product was the Indian bible. According to Littlefield the printing of the New Testament had begun in 1660 and the printing of the Old Testament was not finished until sometime in 1663. A 1660 letter from the New England Company requested that, for the "happy progresse" of the project, "all other business [be] laid aside that might hinder it." 130 But the Indian College was also a place where identity was being manufactured and refined, the Native students as its soul product, giving hope, as Chauncey wrote, for "the future of their perfecting." Gookin spoke in glowing terms of Joel Hiacooms, forwarding an opinion of him as a good scholar and a pious man, as I judge. I knew him well for he lived and was taught in 
the same town where I dwell. I observed him for several years, after he was grown to years of discretion, to be not only a diligent student, but an attentive hearer of God's

word; diligently writing the sermons, and frequenting lectures; grave and sober in his conversation. ${ }^{131}$

But as we know, the face that a Native showed to the colonizer was not the same face shown in private or amongst his/her own people. Nevertheless, whether a product, or the image of a product was being manufactured, the Indian College stood as the point of production.

Perhaps the residents of the Indian College also viewed their tenure as a time of production and transformation within the framework of their own cultures. The Natives of the northeast maintained a belief in the thresholds between worlds, such thresholds often existing in close metaphorical association with geographically disparate changes in the landscape, such as where land meets sea, earth meets rock, or forest meets open space. The crossing of these thresholds, whether in dream or some other visionary state, could be regarded in correspondence with physical, spiritual, and social transformations. Those who had formed the most powerful relationships with their manitous, known as shamans or powwows, could bring these transformations about as an act of will and enter into the upper spirit world or the underwater realms most associated with dangerous or uncontainable powers. In keeping with such notions, all space, whether social or natural, was negotiated in terms of its cosmological significance and relation with other realms. Lodges and longhouses were built in accordance with their place in the cosmos and were designed to represent symbolic thresholds between worlds. The sweat lodge in particular was placed in special relation to the spiritual center of a people. ${ }^{132}$ The Indian College building might have felt to its occupants like a threshold too, if not between worlds, then between epistemological walks of life. Although, perhaps not in the ways that their English "benefactors" regarded it, in some respects the Indian students were at Harvard seeking transformation, and a redefined relationship with the powers that made up their universe. This understanding was probably lodged deep inside of them with no real need to be articulated to their English patrons. But they may have held such an understanding in common amongst 
themsleves. They were engaged in a process of restoration. Whatever they brought back to their people would be threaded into a cultural framework with the design to clothe and protect a people who had experienced great hardship. While their communities may not have been in full agreement with the path they chose, they could see evidence that transformations were actually occurring. Within their own lodgings the European's writing had been transformed into the Algonquian language, largely as a result of their own agency. Sheets upon sheets of it emerged fresh from the press every hour. James Printer would finish each day with the ink still permanently smeared upon his hands. It seems likely to me that the Natives at Harvard Indian College would have bound together in this moment, recognizing that they stood in the center of something momentous, and would have depended upon one another for emotional support. Whatever allegiances they may have forged, however, would shatter into waves of grief, as only Printer and John Wompas, of all these young men, would survive the tumultuous times directly ahead.

Only one document is extant from this period to suggest Joel and Caleb's proficiency as scholars at Harvard. On Nov. 3rd 1663 John Winthrop Jr. wrote a letter to Robert Boyle in England containing a handwritten text said to have been composed by Caleb Cheeshateaumauk under the heading "Honoratissimi Benefactores." The short letter within a letter was a demonstration of the progress being made at Harvard's Indian College, and was part of an appeal for continued funding of the newly erected institution. "Honoratissimi Benefactores" is the first of only two known texts to have survived Harvard's early experiment in educating the local Natives, the second coming some twelve years later, penned by a Native named Eleazor who was the last of the praying Indians to attend Harvard. ${ }^{133}$ Cheeshateaumauk's composition is, at once, a testament to the rigors of the program at Cambridge and an emblem of its ultimate failure. But it also poses problems in terms of locating Cheeshateaumauk's agency within the letter itself. Not only is the text in Latin, the language of the western scholarly elite, but it is peppered with 
references to Greek mythology, the "ancient philosophers," and Christian ideology. The stated goal of the letter is to illuminate "the way of truth and of life" in the Lord Jesus Christ, and to honor the English patrons who have supported (or, perhaps, it is hoped, will continue to support) this most worthy endeavor. ${ }^{134}$

The first paragraph of the letter proceeds as follows.

Most honored benefactors,

Historians tell us of Orpheus, the musician and outstanding poet, that he received a lyre from Apollo, and that he was so excellent with it that he moved the forests and rocks by his song. He made huge trees follow behind him, and indeed rendered tamer the most ferocious beasts. After he took up the lyre he descended into the nether world, lulled Pluto and Prosperina with his song, and led Eurydice, his wife, out of the underworld into the upper. The ancient philosophers say that this serves as a symbol to show how powerful are the force of virtue of education and refined literature in the transformation of barbarians. They are like trees, rocks, and brute beasts, and a substantive change must be effected in them. They have to be secured like tigers and must be induced to follow. ${ }^{135}$

That Cheeshateamauk's letter would have appeared as an impressive proof of progress for its intended audience back in England seems certain. The letter is problematic, however, for any number of reasons. One might ask if it is an authentic text that can be accurately attributed to Cheeshateaumauk. Was the letter a product of his own mind, his own pen, or something dictated to him by his white overseers? And even if we assume the letter to be authentic, its content, at least on a surface reading, seems to defeat any assumption that a Native identity or sense of indigenous tradition has survived the educational pilgrimage from orality to literacy. As a cultural artifact it reads as a particularly impenetrable example of a subsumed discourse, leading some critics to assert that any attempt "to ascribe undercurrents of traditional Indian cultures to these works does not make sense."

Let us first take Cheeshateamauk's letter at face value. The letter works within a motif of western classicism, suggesting that the Greek bard Orpheus, through the animating powers of his music, "made huge trees follow behind him, and indeed rendered tamer the most ferocious beasts." In case there was any doubt, Cheeshateaumauk makes it clear that here-in lies a useful 
metaphor relating to his own experience. He writes, "the ancient philosophers say that this serves as a symbol to show how powerful are the force and virtue of education and refined literature in the transformation of the nature of barbarians." Furthermore, Orpheus' powers to spread cultivation and refinement are, in a later paragraph, directly likened to the efforts of the colonists, alongside their honored English benefactors, to educate "us pagans" who formerly were "naked in soul and body, alien from all humanity, led around in the desert by all sorts of errors."

Quite possibly Cheeshateaumauk, like many an other student, was conscious of assuming a particular role when he wrote this letter of thanks and praise, and was fully aware of the academic forms and expectations that accompanied the assignment. He was probably even well aware of the pragmatic expectations, and the use to which his letter would be put. If one can assume, for a moment, that Cheeshateaumauk is performing a role, putting on a suit of clothes, so to speak, that he has learned to wear over a period of years, and knowing full well that he will shed them when he is finished and return to his more comfortable skin, then we might also see where his own cultural leanings might be reflected in the text-the Native skin beneath the colonial paint, so to speak.

Orpheus stands in as the bearer of literary civilization in Cheeshateaumauk's letter, but it is interesting that a character from an oral tradition was chosen to fulfill this role. While this is perhaps unintentional, it might be by way of a certain sympathetic recognition or familiarity that Cheeshateaumauk chooses not only a non-literate figure to represent the gift of literacy, but one who is particularly noted for being the keeper of oral traditions. William S. Simmons, who has extensively studied and recorded the folklore and myths of northeastern Natives, writes that "Indian converts traced aspects of Christian belief and practice to aboriginal sources, thus representing change as continuity with their own past." ${ }^{.137}$ As a bard, Orpheus would have trafficked in stories and songs chanted in a communal setting. His gift is recognized as "excellent" which we may recall was the common exclamation of the Native when they 
recognized something as "Manittowock, or God." And by "moving the rocks and trees" and taming the wild beasts with his song, Orpheus might be regarded as performing the very role of shaman or powwow, who also calls upon the power in rocks, trees and other spirit guardians. As William Wood commented in his New England's Prospect, the "powwow" Passaconaway was reported to be able to make "the water burn, the rocks move, trees dance, metamorposize himself into a flaming man."138 Such performances were not simply meant to elicit amazed responses from their audiences. Many Natives of the northeast saw themselves in a specific kinship relation with natural objects, enlisting their power in ceremonies and rituals. Far from being inanimate objects, trees were regarded by many Native peoples as their ancestors.

The trip to the underworld would have been recognized as the shaman's ability to cross thresholds and enter into other realms. Such feats were not only ingrained in Native belief systems, but were a staple of stories and legends. Jarold Ramsey has written that "the Orphic story, of a hero's unsuccessful quest to bring back a loved one from the Land of the Dead, is

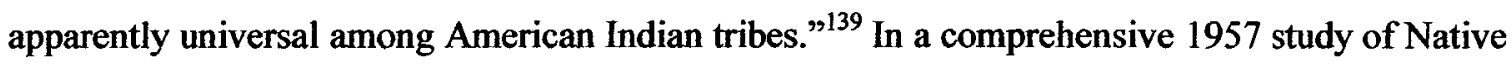
traditions that resemble the Orpheus narrative, Ake Hultkrantz concludes that such legends are "connected with shamanistic ideology" and have their roots in the role of the Shaman, or medicine man, as healer, or one who guards against "soul loss." 140 Such a narrative, particularly in a time of such inexplicable sickness and death, might have served the function of consoling the grief of a people, while observing the ritualistic necessities of accompanying spirits to the afterworld, even if they ultimately could not be brought back home. Knowing the path and how to avoid obstacles between worlds remained an important feature of this narrative. As one ethnographer notes, "singing after a death was an advantage to a traveling soul for it illuminated the trail, and according to the Haida, permitted the soul to enter its new abode with its head up." 141 It probably is worth noting that the Christ narrative performs a similar function, in that Jesus, the "phisitian" travels between life and death, and illuminates a path to redemption that 
had been barred since the time of original sin. Caleb may have been conscious of these similar functions and drawn upon them, deliberately or not.

Finally, it is of note that Orpheus is ultimately dismembered, and, according to some traditions, his head is carried off to its island home, still singing. If the figure of Orpheus has been interpreted as the harbinger of western civilization, the story is more strongly suggestive of the endurance of cultural narratives whose stories and songs survive despite violent ruptures and displacement. A later Wampanoag tradition has it that the head of King Philip was secreted away after his death and buried between Taunton and Mt. Hope. Simmons reports that "every three generations the ghost of Philip walks abroad, and reveals to a medicine man this spot."142

I do not mean to suggest that Cheeshateaumauk was consciously toying with all of these allusions (although I do not discount such a possibility), but only that the details of Orpheus' life may have been what drew Caleb to the tale in the first place. He is quite possibly engaging in a process of weaving the elements of two traditions together in an attempt to locate common ground. Such a process may have informed the manner in which his kin on Martha's Vinyard approached Christianity from the very start. Either way, there is something of a cognitive lapse in the parable as written, for if the Orpheus of ancient times clearly induces a passive transformation through linguistic charms, it remains to be explained why Cheeshateaumauk's "barbarians" need to be "secured like tigers and must be induced to follow." In this slippage we may detect something of the internal struggle of Cheeshateaumauk's own experience. Perhaps he was not so much charmed by European culture as dragged kicking and screaming.

Cheeshateaumauk's narrative, considered to be the first extant writing by a Native American from the North American continent, cannot be read strictly as one of continuance. Clearly it is infected with "manifest manners," the rhetorical conventions that, whether intentionally or not, play into the master narrative of a white European hegemon that views its destiny on the American continent as manifest. Certainly Caleb is not explicitly writing about his 
community, tribal sovereignty, or the strengthening of Native traditions. There was no venue for Caleb to publish such things in seventeenth century New England, even if he wanted to. Nevertheless his short missive, plucked from the embers, so to speak, of a largely forgotten episode in history, stands at the forefront of a Native presence that is endeavoring to open up such a discourse in the only medium that seems to matter to its aggressive neighbors. Caleb's intentions are always to return to his community, to live with his people, and, perhaps, spread the word of the Christian bible. But it shouldn't be doubted that such an engagement with Christianity will be folded into traditional practices as well, and Caleb's letter offers some awareness of the syncretic forms that will take root in future communities and future discourses.

Caleb was the only Native American to graduate from Harvard's Indian College. According to Gookin, not long after he took his bachelor of the arts in 1665 , he "died of a consumption in Charlestown ... where he wanted not for the best means the country could afford, both of food and physic." Joel Hiacooms returned home to Martha's Vineyard before his commencement to visit his father and kindred, but his ship apparently wrecked near Nantucket on the return trip. Gookin writes that, in all probability "the people in it came on shore alive, but afterwards were murthered by some wicked Indians of that place," and he laments "thus perished our hopeful young prophet, Joel."143 The incidents surrounding Joel's death remain vague. Apparently the ship in question carried both English and Wampanoag passengers, and it is unclear whether Joel's status as a "praying Indian" had any role in his death, or if he was merely the victim of unfortunate circumstances. The trial at Nantucket consisted of a joint court of English and Wampanoag officials, with the Wampanoag leader Philip called in from the mainland to oversee the proceedings. The offending Indians were hanged. ${ }^{144}$ The deaths of Joel and Caleb did not signal the absolute end of the Harvard Indian College, but it was a symbolic end and the building was probably never again used for its originally stated purpose.

King Philip's War, the pan-Indian assault from 1676-77 organized and led by the 
Wampanoag sachem, Philip or Metacom, would be understood by the Puritans as the last word on Native and English relations within New England's colonial boundaries. The Natives were supposed to have disappeared in its wake, like snow in springtime, just as the Pequot's were rhetorically erased following the Pequot War. Of course they didn't go away. Isolated communities of Native Americans struggled to maintain themselves on the ground still available to them. The Pequot and Mohegan nations remained neutral throughout the war and their communities were still intact in the aftermath, if in a more tightly enclosed ring of colonial presence. Waban and Thomas Waban, who had both endured a long winter of interment on Deer Island throughout much of the war, returned with their people in the spring of 1676 to live on a patch of land offered by a Mr. Thomas Oliver along the Charles River outside of Cambridge. Waban, in his seventies by now, was sick with dysentery and close to death. But he recovered his health before the summer was out and lived for another eight years, well into his eighties. ${ }^{145}$ Joseph Tuckapawillin, James Printer's brother, had spent time with the Nipmucs during the war, and later separated from them, being found by the English and taken to Deer Island. This same Joseph may have been the Nipmuck Gookin refers to as being "taken prisoner in Plymouth Colony, and sold for a slave to some merchants in Boston, and sent to Jamaica." This was the fate of many Natives following King Philip's War, including Philip's own wife and son. The taint of slavery that surrounds the fate of so many Indian lives at this time added an entirely new dimension to the statement "come over and help us." Joseph would have finished his days in the West Indes, had not Eliot intervened and had him brought back again. Even back in the colonies, however, he was "held as before, a servant; though several that know the said Joseph and his former carriage, have interceded for his release but cannot obtain it."146

As for Joseph's brother James Printer, he would spend at least some of the war with a group of Narragansett who kept in their custody one Mary Rowlandson, who's 1682 captivity narrative, "The Sovereignty and Goodness of God," is one of the more famous texts to come out 
of this period. Jill Lepore, in her study of King Philip's War, The Name of War, supposes Printer is responsible for a note left on the post of a bridge for the English to read after the sacking of Medfield in 1676 . The note read "Know by this paper, that the Indians that thou hast provoked to wrath and anger, will war this twenty one years if you will; there are many Indians yet, we come 300 at this time. You must consider the Indians lost nothing but their life; you must lose your fair houses and cattle." ${ }^{147}$ Lepore notes how this message, and others like it, left on trees and posts, communicated a Native awareness of the English attachment to property and material things, and therefore emphasize their destruction. ${ }^{148}$ They also appear to function as awikhigans, or the hieroglyphic messages that Natives of the northeast left one another on trees to recount the success or failure of war parties and hunting trips. Printer, incidentally was also responsible for writing the ransom notes that Philip sent to the colonists when bartering for Rowlandson's release.

Following the war, Printer, like every other repatriated praying Indian, was made to swear an oath of fealty to the English, and Lepore notes that he was asked by the general Court to bring in "some enemies heads" to prove his devotion. There is no record of Printer having performed this horrific absolution. But he was apparently reinstated into colonial life, and probably did, as Lepore suggests, set the type for Rowlandson's 1684 narrative, thereby inscribing his own name and deeds into the colonial archive. Though Samuel Green died in 1692, James was still working the press in 1709 when he was asked by the New England Company to produce a new translation of the Psalms. Samuel Seawall, then the Superintendent of Indian Affairs to the colonies would write "James Printer is chiefly taken up in Printing and gains a youthfull cheeriness in your service." 149 In an unprecedented move, Printer's name would appear on the frontispiece of the 1709 Massachusetts Psalter next to the name of Bartholomew Green, son of Samuel Green, in final acknowledgement of the central role he played, over a fifty year period, in the establishing and maintenance of a press in the colonies (image of frontispiece). 
Gookin writes that the Deer Island refugees remained on Thomas Oliver's land through the summer of 1676, and then "scattered to places adjacent, to work for the English in harvest time. But toward October they removed; some to the falls of Charles river, and some settled about Hoanantum Hill; not far from Mr. Oliver's, near the very place where they first began to pray to God, and Mr. Elliot first taught them, which was about thirty years since."150 Hoanantum was none other than Nonantum, or a place of rejoicing, formerly known as Cohannet. Here Anthony Speen, having come full circle, built a large wigwam, reclaiming what had been the spiritual center of his community back in his childhood days before the coming of the English.

Lepore wonders how it is that, of all the praying Indians who had acquired literacy and were capable of writing independently, not one left an account of the war, a history as seen from the Native perspective. In response to her own question, she speculates that the consequences of literacy for Native Americans in seventeenth-century New England were deadly, and she draws upon the life of John Sassamon, the so-called Indian martyr, whose death was the catalyst for the war, as a case study. Certainly there were hazards for those who found themselves in the liminal space between colonial and Native culture. The question still lingers, however. African Americans, enslaved for generations, and systematically distanced from kinship and community networks, were often able to acquire literacy within a system that strictly forbade it, and many slaves lived to write involved narratives of their lives and the vicious institution within which they had been reared. Perhaps the reason that Native Americans saw little need for this in the seventeenth century is because they still retained their own historical and cultural traditions, within their own communities, and did not seek to disseminate those histories amongst the white community. Even if they had, the colonial community was incapable of hearing it or seeing it. But certainly Native accounts of King Philip's War were told and retold in Native space long after the war was over.

To engage in writing and print discourse was to move the narrative from Native space to 
colonial space, a dangerous enterprise that risked the integrity of Native agency, Native forms of giving and receiving knowledge, by containing such expressions within colonial contexts. In many ways, the praying Indians themselves have become a text within a text. Their lives and words have been sandwiched into the propagandistic discourse of the settler population, so that their own speech seems to turn against them. Nevertheless, Waban and others, by engaging with European literacy, had bought themselves a generation of peace and relative stability-no small accomplishment in violent and uncertain times. When war did break out, Natives started writing back. Just little notes at first, left on bridge posts and trees. They wanted the English to understand that they hadn't started this war after-all, that they had negotiated for peace and done everything in their power to sustain agreeable relations, and it was the English with their houses and cattle and bibles that had stirred things up and made life untenable. Such protestations survive as fragments, or containments, texts within texts, preserved in the service of a colonial agenda. And yet their composition occurred in circumstances that allowed for the first historically visible manifestations of a breaking of containment on the part of Native peoples.

As for the Indian College, Samuel Seawall would lament in 1698 that "the old Brick College, Commonly called the Indian College is pull'd to the ground." Like the great libraries and temples of the Aztecs, this Native space was reconstituted, its bricks collected and employed in the erection of yet another edifice of European intellectual hegemony, Stoughton College. ${ }^{151}$ Discarded in the rubble of its dismantling were the remnants of type from the old Cambridge Press that had been used to disseminate the Christian word in the Algonquian language. 
'Daniel Gookin, "Historical Collections of the Indians of New England," Collections of the Massachusetts Historical Society (CMHS) vol. 1 (Boston: Munroe \& Francis, 1806, 1674), 176.

2 See "First Fruits" title page. "First Fruits," The Eliot Tracts, ed. Michael P. Clark (Westport, CT: Praeger, 2003, 1643), 57.

3 "First Fruits." The Eliot Tracts, 58.

${ }^{4}$ Morison says that Eleazor was the last Indian to enroll at Harvard in the years of the Indian College as part of the class of 1679. He left a tribute in verse behind to Thomas Thatcher, his teacher, and signed it "Eleazer, Indus Senior Sophista." The elegy was written in Latin and Greek. Eleazor died before graduating. A later native student, Benjamin Larnell attended the class of 1716. Harvard president Leverett described him as "An acute Grammarian, an Extraordinary Latin poet, and a Good Greek one. Larnell also died while attending." See Samuel Eliot Morison, Harvard College in the Seventeenth Century (Cambridge, MA: Harvard University Press, 1936), 196 and 357.

${ }^{5}$ Hugh Amory, Bibliography and the Book Trades: Studies in the Print Culture of Early New England. ed. David Hall (Philadelphia: University of Pennsylvania Press, 2005), 35.

6 "First Fruits." The Eliot Tracts, 58.

${ }^{7}$ Laura M. Stevens, The Poor Indians: British Missionaries, Native Americans, and Colonial Sensibility (Philadelphia: University of Pennsylvania Press, 2004), 3.

8 This quote originated in Neal's History of New England, (1720), and can be found in John W. Ford, Some Correspondence Between the Governors and Treasurers of the New England Company in London and the Commissioners of the united Colonies in America The Missionaries of the Company and Others Between the Years 1657 and 1712. ed. John W. Ford (New York: Burt Franklin, 1970), xx.

9 Amory calls it "a tool of the government and of John Eliot's mission to the Indians." Amory, Bibliography and the Book Trades, 111.

10 Samuel Eliot Morison writes that roughly 100 books were printed at the Indian College location. "of which fifteen were in the Indian and eighty-five in the English language." Morison, Harvard College in the Seventeenth Century, 349. As a result of the long Indian words and the disproportionate abundance of consonants, special type had to be ordered for these printings, so that the equipment itself was geared toward the publishing of native tracts, further suggesting how the business of the press was determined by native concerns. See William Kellaway. The New England Company 1649-1776: Missionary Society to the American Indians (Westport, CT: Greenwood Press, 1961 (127 and 152).

${ }^{11}$ Larzer Ziff, Writing in the New Nation: Prose, Print, and Politics in the Early United States (New Haven, CT: Yale, 1991), $x$. Ziff has opened up a most relevant discussion on this phenomenon in Writing in the New Nation where he asserts that the immanent self was in constant negotiation and competition with the represented self that flourished with the blossoming of print discourse in the US. Although Ziff focuses on the era leading up to, and overtaking the creation of the United States, he points out early on that this 
phenomenon was at its most virulent in relation to Native Americans, noting "the imperial scale" by which representations of Indians were forged to replace and annihilate real Indians (x). Although the idea that Indians were, in fact, annihilated must be corrected, the proximity of the first Printing Press to a space constructed to hold and culturally contain natives is certainly a result of the process he articulates.

12 See Gerald Vizenor, Manifest Manners: Postindian Warriors of Survivance (Hanover, NH: Wesleyan University Press of New England, 1994) and in particular his conversation of "Postindian Warriors" pages 1-44.

${ }^{13}$ Vizenor, Manifest Manners, 65.

14 Ibid., 23.

15 For Eliot's contributions to the prosecution of Anne Hutchinson see The Antinomian Controversy, 16361638: A Documentary History. ed. David D. Hall (Durham: NC, Duke University Press, 1990), 311-388 (see p. 346 in particular for Eliot's strong censure of Hutchinson). In Winthrop's journal for 27 Nov, 1634 it is noted that the governing council deemed it necessary to censor Eliot for speaking out too strongly against an initial peace negotiated with the Pequots. Eliot was asked to apologize and publicly reconsider his position. John Winthrop, History of New England from 1630-1649 vol. 1. ed. John Savage (Baltimore: Clearfield Company, 1996, 1853), 179.

${ }^{16}$ Clark, The Eliot Tracts, 9. See also Morison, Harvard College in the Seventeenth Century, 340-341.

17 Clark, The Eliot Tracts, 3.

18 Cotton Mather, Magnalia Christi Americana or the Ecclesiastical history of New England from its First Planting in the Year 1620, Unto the Year of Our Lord, 1698 vol. 1 (Hartford: Silas Andrus, 1820), 510.

19 Ibid., 491.

20 Ibid., 514.

21 W. Deloss Love, Samson Occom and the Christian Indians of New England (Syracuse: Syracuse University Press, 2000, 1899), 19.

${ }^{22}$ Samuel Eliot Morison, Builders of the Bay Colomy (Boston: Houghton Mifflin Co., 1930), 306.

${ }^{23}$ See Francis Jennings, The Invasion of America, : Indians, Colonialism, and the Cant of Conquest (Chapel Hill, NC: University of North Carolina Press), 233 and more generally 228-253.

24 Ibid., 241. 
${ }^{25}$ Richard W. Cogley, John Eliot's Mission to the Indians Before King Philip's War (Cambridge, MA: Harvard University Press, 1999), 4 and 52.

26 James Axtell, After Columbus: Essays in the Ethnohistory of Colonial North America (New York: Oxford University Press, 1988), 49-54. Specific quote on 54.

27 Neal Salisbury, Manitou and Providence: Indians, Europeans, and the Making of New England, 1500 1643 (New York: Oxford University Press, 1982), 184.

${ }^{28}$ George E. Tinker, Missionary Conquest: The Gospel and Native American Cultural Genocide (Minneapolis: Fortress press, 1993), 16.

29 John Eliot, Indian Dialogues: A Study in Cultural Interaction. Eds. Henry W. Bowden and James P. Ronda (Westport, CT: Greenwood Press, 1980, 1671), 60.

${ }^{30}$ Kathleen Bragdon calls this nokake, a flattened corn bread, and notes that it probably resembled the tortilla. Kathleen J. Bragdon, Native People of Southern New England 1500-1650 (Norman OK: University of Oklahoma Press, 1996), 104.

31 In Of Plymouth Plantation William Bradford wrote that they found the people near where they settled being "dead \& abundantly wasted in the late great mortalitie which fell in these parts about three years before the coming of the English, wherein thousands of them dyed, they not being able to burie one another; their sculs and bones were found in many places lying still above ground, where their houses and dwellings had been; a very sad spectacle to behold. William Bradford, Of Plymouth Plantation: The Pilgrims in America, ed. Harvey Wish (New York: Capricorn Books, 1962), 78. Also John Josselyn's 1675 account of Two Voyages to New England in which he claims "the Massachusets were very populous, having under seven Dukedoms or petti-Sagamorships, but by the plague were brought from 30,000 to 300 ." John Josselyn, "An Account of the Two Voyages to New England." CMHS vol. 3, series 3, 294. Winthrop speaks of "a great mortality amongst the Indians" in 1633 in Winthrop, History of New England, 137-138. Writing sometime around 1637 Thomas Morton would observe "the hand of God fell heavily upon them, with such a mortall stroake, that they died on heapes, as they lay in their houses and the living, that were able to shift for themselves would runne away, \& let them dy, and let there Carkases ly above the ground without buriall." Thomas Morton. New English Canaan (New York: De Capo Press, 1969, 1637), 22.

32 See Samuel G. Drake, Biography and History of the Indians of North America, From its First Discovery (Boston: Benjamin B. Mussy \& Co., 1841), 118.

33 The tract in which this occurs is generally attributed to Thomas Shepherd, although it may have been Eliot as well. Perhaps we should consider it as authored by a composite of the two. But following tradition: Shepherd, Thomas. "The Day Breaking, if not The Sun Rising of the Gospell with the Indians in New England." The Eliot Tracts. ed. Clark, 83. According to Daniell Mandell, Thomas Waban's Indian name was Weegramomenit and he would occasionally use this name in court records throughout his life. Daniel Mandell, "Standing by His Father': Thomas Waban of Natick, circa 1630-1722." Northeastern Indian Lives 1632-1816. ed. Robert S. Grumet (Amherst: University of Massachusetts Press, 1996),171. 
34 Thomas Shepherd. "The Day Breaking," The Eliot Tracts, 87.

35 Ibid.,82.

36 From "First Fruits," The Eliot Tracts, 74.

${ }^{37}$ Kellaway, The New England Company, 85.

38 Cogley, John Eliot's Mission to the Indians, 57. Cogley takes this to mean that the lands of the Massachusett had been greatly diminished already, perhaps to the size of a town. Waban does not make this distinction however. When he speaks of possessing the lands where their wigwams have always stood, he is referring to more than just the small plot of land before them. As for needing this land allotment in writing, the tract entitled "The Clear Sunshine of the Gospel" suggests that the natives desired "an able faithful man in Concord to record and keep in writing what they had generally agreed upon." Shepherd, Thomas. "The Clear Sunshine of the Gospel Breaking Forth Upon the Indians in New England." The Eliot Tracts, 114.

39 Shepherd, Thomas. "The Clear Sunshine," The Eliot Tracts, 114. The sachem of the Nonantum natives is asked "why hee desired a towne so neare, when as there was more room for them up in the country." The sachem seems to have replied that if they moved up-country the people would not be so inclined to hear the word of God.

40 Shepherd, Thomas. "The Day Breaking," The Eliot Tracts, 83. Cogley wonders if this eldest son is the same Thomas Waban who would come to prove such a strong presence in the Natick settlement in later years, suggesting that the son at Cohannet, at the time of Eliot's first visit, would have been too old. Others seem to find no discrepancy here. See Cogley, John Eliot's Mission to the Indians, 279.

41 For details on the life of Cockenoe see William Wallace Tooker, John Eliot's First Indian Teacher and Interpreter, Cokenoe de Long Island, and the Story of his Career (New York: Francis Harper, 1896).

42 See Josselyn, "An Account of the Two Voyages to New England." CMHS, 301.

43 Shepherd, "The Day Breaking," The Eliot Tracts, 90.

44 Ibid., 97

45 Stated in a letter from Eliot to Shepherd, 24 September 1647. See George Emery Littlefield, The Early Massachusetts Press 1638-1711 (New York: Burt Franklin, 1907), 172.

46 Shepherd, "The Day Breaking," The Eliot Tracts, 97.

47 Ibid., 98. 
48 This Wampas would later be publicly reprimanded for beating his wife. In his dying speech, recounted by Eliot, he remembered that he brought four children to Eliot, one of them his own son, and prayed that they would remain in their English homes and learn the ways of the Christian God. Eliot Tracts 127 and 222-223.

${ }^{49}$ Shepherd, Thomas. "The Day Breaking," The Eliot Tracts, 96.

${ }^{50}$ See Thomas Lechford's "Plain Dealing" in which he asserts that Dunster "deserves commendations above many; he hath the plat-forme and way of conversion of the natives indifferent right, and much studies the same, wherein yet he wants not opposition, as some others have also met with ... He will make it good, that the way to instruct the Indians, must be in their owne language, not English; and that their language may be perfected." Thomas Lechford, "Plain Dealing: or Newes From New-England" CMHS ser 3, vol. 3, (1642) 105-106. It isn't clear what Dunster did to earn this praise, but Lechford may simply be referring to a reputation that Dunster has established for himself within the small community. It seems that the "opposition" others have met with is a reference to Roger Williams who led the move to learn the native languages.

${ }^{51}$ See Ford, Some Correspondences of the New England Company, 28-29.

${ }^{52}$ Cogley, John Eliot's Mission to the Indians, 118.

${ }^{53}$ Daniel Gookin, An Historical Account of the Doings and Sufferings of the Christian Indians in New England in the Years 1675, 1676, 1677 (New York: Arno press, 1972-1836) 477. In Gookin's earlier tract "Historical Collections" he leaves a blank where, according to Eliot, Job's name should be, apparently unable to remember who is teacher at Okommakamesit. See Gookin, Daniel. "Historical Collections," 186. Drakes' History of the Indians of North America doesn't mention Job as a brother of James. I believe this is because he drew from Gookin in this instance, or simply missed the reference in Eliot's earlier letter. See Drake, Samuel G. Biography and History of the Indians, 115. Subsequently, many using Drake as a source have missed this possible connection. Kellaway refers to Job Nesutan as "an Indian of Long Island" but here he is surely confusing him with Cockenoe, Eliot's earlier translator who was Montauk. See Kellaway, The New England Company, 123. There is still no proof that Job, brother of James, is Job Nesutan, but when one considers the trajectory of their careers and how closely they are both connected with Eliot's work in transcribing and printing Indian documents, it seems a real possibility. Both James and Job Nesutan arrive on the scene at the same time in 1645 or 1646 and Szasz asserts that Job Nesutan was among the natives at Nonantum in 1646 who heard Eliot's sermons and entered into English education. Margaret Connell Szasz, Indian Education in the American Colonies, 1607-1783 (Albuquerque: University of New Mexico, 1985),113. Perhaps James' father, Naoas, a leader amongst his people, saw the utility of sending his boys to the English to be schooled just as Waban, Wampas and Powhatan had done. Or perhaps by accommodating English wishes, he saw his way to becoming a leader. Naoas (or Nataous ) may have been leader at Hassanemessitt, but he was also one of the orators in Eliot's "Tears Of Repentance," and plays a role in seeing the church of Natick established. Gookin, forgetting that he has placed Nataous as "deacon of the church" in Hassanemessitt in his "Historical Collections" refers to him again as a ruler of Natick in the same tract. ("Historical Collections," 184 and 185) Clearly there is much confusion in these accounts and Gookin, despite his familiarity with many of the individuals in the praying towns, is either drawing from faulty memory, or not quite aware of the interchangeable posts and maintenance of kinship relations within and between the praying towns. 
${ }^{54}$ I have yet to figure out where the "Wowaus" designation comes from. Szasz uses it but leaves no clear reference of where she gets it. It is not in Drake's Book of the Indians of North America as her footnote suggests, (Szasz, Indian Education, 115 and 280. I suspect the name is a corruption of Naoas, or Nataous, which is the native name of James' father, who is also referred to as William of Sudbury. See John Eliot, "Tears of Repentance: or A Further Narrative of the progress of the Gospel Amongst the Indians in New England," The Eliot Tracts, 273.

${ }^{55}$ Samuel Eliot Morison, The Founding of Harvard College (Cambridge, MA: Harvard University Press, 1935), 313-314.

${ }^{56}$ Morison, The Founding of Harvard College, 344-347. Also Littlefield, The Early Massachusetts Press, and George Parker Winship, The Cambridge Press 1638-1692 (Freeport, NY: Books for Libraries Press, 1946).

${ }^{57}$ Morison, The Founding of Harvard College, 346.

${ }^{58}$ Kellaway, The New England Company, 14-15. See also Morison, The Founding of Harvard College, 320-322.

${ }^{59}$ Cogley, John Eliot's Mission to the Indians, 69.

${ }^{60}$ Morison, The Founding of Harvard College, 348.

${ }^{61}$ Quoted in Winship, The Cambridge Press, 113.

${ }^{62}$ Gookin, "Historical Collections," CMHS, 185.

${ }^{63}$ Eliot made an accounting of the funds he had received to Winslow in 1649 , stating that "five pounds I gave to a grave women in Cambridge who taught the Indian Children last year. It is not clear precisely when Elijah Corlett's grammar school first opened to Indian students. Littlefield, The Early Massachusetts Press, 178.

${ }^{64}$ Franklin is apprenticed to his brother James in 1717 at the age of twelve. Benjamin Franklin, "The Autobiography of Ben Franklin," The Heath Anthology of American Literature, vol A, ed. Paul Lauter (Boston: Houghton Mifflin Company, 2006, 1791), 835.

${ }^{65}$ Szasz, Indian Education, 117.

${ }^{66}$ Morison, The Founding of Harvard College, 348.

${ }^{67}$ Shepherd, Thomas. "The Day Breaking," The Eliot Tracts, 99. 
${ }^{68}$ Morison, Harvard College in the Seventeenth Century, 86-88.

${ }^{69}$ Morison notes that "almost every printing and publishing house in New England can trace its ancestry to the little college 'printery' operated by the Days and Greens." Morison, Harvard College in the Seventeenth Century, 352.

${ }^{70}$ Morison, Harvard College in the Seventeenth Century, 5-6.

${ }^{71}$ Gookin, "Historical Collections," CMHS, 176.

${ }^{72}$ Morison, Harvard College in the Seventeenth Century, 341.

${ }^{73}$ Morison, Harvard College in the Seventeenth Century, 341.

${ }^{74}$ Morison, Harvard College in the Seventeenth Century, 309-320.

${ }^{75}$ For details see Morison, Harvard College in the Seventeenth Century, 298-319

${ }^{76}$ Morison, Harvard College in the Seventeenth Century, 46. Morrison posits that the press may have been kept in a separate Printing House until 1659 when a new press was brought over to assist in the making of the Eliot bibles. Either way it seems likely to me that James remained with the press at all times.

${ }^{77}$ The dimensions of the building offered in Morison, Harvard College in the Seventeenth Century, 342.

${ }^{78}$ Quoted in Szasz, Indian Education, 116.

${ }^{79}$ Drake, Biography and History of the Indians, 114.

${ }^{80}$ Eliot, "The Light Appearing more and More towards the perfect Day or A farther Discovery of the present state of the Indians in New-England." The Eliot Tracts. Ed. Michael P. Clark (Westport, CT: Praeger, 2003, 1651), 206.

${ }^{81}$ Ibid., 187.

${ }^{82}$ Neal Salisbury, "Red Puritans: The 'Praying Indians" of Massachusetts Bay and John Eliot," The William and Mary Quarterly, $3^{\text {rd }}$ Ser., Vol. 31, No. 1 (Jan., 1974), 42.This suggestion occurs in a footnote of Salisbury's article in which he says "I am indebted to Frank Seibert for pointing out to me that the Indian assistants, rather than Eliot himself, did the actual translating." 
Szasz, Indian Education, 115.

${ }^{84}$ Cogley, John Eliot's Mission to the Indians, 119.

${ }^{85}$ Ibid., 121.

${ }^{86}$ Gookin, "Historical Collections," 218 . Szasz says he was paid 10lb per anum from the year 1650 to King Philip's War, but I have not seen these records. Szasz, Indian Education, 114.

${ }^{87}$ Gookin, "Historical Account," 444. Job died fighting alongside the English in the first major battle of King Philip's War. Gookin writes "the loss of such a useful and trusty man was great in the forementioned respects."

${ }^{88}$ See Drake, Biography and History of the Indians, 115.

${ }^{89}$ Shepherd, Thomas. "The Clear Sunshine," The Eliot Tracts, 136.

${ }^{90}$ Eliot, "Tears of Repentance," The Eliot Tracts, 271.

${ }^{91}$ Littlefield, The Early Massachusetts Press, 176.

${ }^{92}$ Cogley, John Eliot's Mission to the Indians, 105.

93 The Iroquois in particular were known for taking "mourning captives" to replace family members who had died in battle or by disease. In the scene related by Mary Jemison to her editor, James E. Seaver, Jemison has just been turned over by her original captors to a group of Seneca. She recounts how "I had been in that situation but a few minutes, before all the Squaws in the town came to see me. I was soon surrounded by them, and they immediately set up a most dismal howling, crying bitterly, and wringing their hands in all the agonies of grief for a deceased relative." James E. Seaver, A Narrative of the Life of Mrs. Mary Jemison. ed. June Namias (Norman, OK: University of Oklahoma Press, 1992-1824), 76.

${ }^{94}$ Cabeza de Vaca writes of the natives that "with the great grief and pity they felt upon seeing us in such a desperate plight, all of them began to weep loudly, and so sincerely that they could be heard a long way off, and this lasted more than half an hour; and certainly, to see that those uncivilized and savage men, like brutes, were so sorry for us, caused me and others in our company to feel still more grief and the full realization of our misfortune." Alvar Nunez Cabeza de Vaca, Castaways, The Narrative of Alvar Nunez Cabeza de Vaca. ed. Enrique Pupo-Walker, trans. Frances M. Lopez-Morillas (Berkeley: University of California Press, 1993-1555) 42.

${ }^{95}$ Eliot, "Tears of Repentance," The Eliot Tracts, 269.

${ }^{96}$ Broadside entitled "Christians Oonoowae Sampoowaonk" or "A Christian Covenanting Confession" see 
L. G. Starkey Bibliography of Cambridge Press, unpublished University of Virginia Dissertation, 1949, 240-244. Found on Early American Imprints, Series 1: Evans Digital Library. http://infoweb.newsbank.

97 Salisbury, "Red Puritans." 47.

98 Eliot, "Tears of Repentance," The Eliot Tracts, 271-272.

${ }^{99}$ Salisbury, "Red Puritans," 48.

${ }^{100}$ Cogley, John Eliot's Mission to the Indians, 128.

${ }^{101}$ Eliot, "Tears of Repentance," 272.

${ }^{102}$ Ibid., 277.

${ }^{103}$ Monequassun's testimony appears in Eliot, "Tears of Repentance," The Eliot Tracts, 274-279. Eliot's post-script is on 279 .

${ }^{104}$ Ibid., 294.

${ }^{105}$ Ibid., 274.

${ }^{106}$ Ibid., 251.

${ }^{107}$ Ibid., 283.

108 Ibid., 282.

${ }^{109}$ Eliot, "A Late and Further Manifestation of the Progress of the Gospel Amongst the Indians in New England," The Eliot Tracts, 306.

110 See Hilary Wyss, Writing Indians: Literacy, Christianity, and Native Community in Early America (Amherst: University of Massachusetts Press, 2000), 156.

111 John Eliot, Indian Dialogues, 96.

112 Ibid., 96. 
113 Ibid., 112.

114 Ibid., 134.

115 Ibid.,130. Eliot is anticipating what seemed to have been an actual concern of some of the principal sachems of New England, although the root cause of that concern was deeply misunderstood, having nothing to do with greed and everything to do with tradition. While it is true that the sachems collected tribute of strings of wampum from neighboring sachems and petit-sachems, the misunderstanding is grounded in the European notion of wampum as currency when in fact it was a component of ritual exchange with strong ties to the condolence ritual practiced by the Iroquois.

116 Mather, Magnalia Christi Americana, 514.

117 Quoted in Eliot, “A Further Accompt of the Progresse of the Gospel amongst the Indians in New England," The Eliot Tracts. Ed. Michael P. Clark (Westport, CT, Praeger, 2003, 1659), 333. Waban exhorts upon this theme again in "A Further Account," 374-376.

118 See Shepherd, Thomas. "The Clear Sunshine," The Eliot Tracts, 132 and Daniel Gookin, "Historical Collections," 178.

${ }^{119}$ Bernd Peyer, The Tutor'd Mind: Indian Missionary Writers in Antebellum America (Amherst: University of Massachusetts Press, 1997), 42. Also Experience Mayhew, Indian Converts: or Some Account of the Lives and Dying Speeches of a Considerable Number of the Christianized Indians of Martha's Vineyard in New England (Ann Arbor, MI: University Microfilms International, 1992) and Henry Whitfield, A Further Discovery of the Present State of the Indians in New England (New York, Sabin's Reprints, 1865 (1651).

${ }^{120}$ Henry Whitfield, "The Light Appearing," The Eliot Tracts, 187.

${ }^{121}$ Henry Whitfield, "Strength Out of Weaknesse; or a Glorious Manifestation of the Further Progresse of the Gospel among the Indians in New-England." The Eliot Tracts. Ed. Michael P. Clark (Westport, CT, Praeger, 2003, 1652) 241.

122 Gookin, "Historical Collections," CMHS 172.

123 "First Fruits," The Eliot Tracts, 72-74.

124 Eliot, John. “A Further Accompt of the Progresse," The Eliot Tracts, 353.

125 It is uncertain how many natives actually attended at this time, but only Joel ,Caleb, and John Wampas appear on the records. 
${ }^{126}$ William S. Simmons, Spirit of the New England Tribes: Indian History and Folklore, 1620-1984

(Hanover, NH: University Press of New England, 1986), 38-45.

${ }^{127}$ Roger Williams. "A Key Into the Language of America," The Complete Writings of Roger Williams, vol 1 (New York: Russell \& Russell Inc. 1963, 1643), 24.

${ }^{128}$ See Chapter Two.

${ }^{129}$ Walter Meserve deserves credit for asking such questions as early as 1956 in his article "English Works of Seventeenth-Century Indians." He notes that if the writings of native students had been preserved "they might include descriptions, letters, diaries and observations as well as poems and essays." He reflects that the writings that do exist might "effectively supplement the writing of contemporary white men and women." 276 . He also notes that native writings constitute a highly interesting and significant part of early historical American literature." (265). I couldn't agree more. See Walter T. Meserve, "English Works of Seventeenth-Century Indians," American Quarterly, Vol 8, No. 3 (Autumn, 1956).

${ }^{130}$ Littlefied, The Cambridge Press, 192.

${ }^{131}$ Gookin, "Historical Collections," 173.

${ }^{132}$ Kathleen Bragdon. Native People of Southern New England, 191-193. 219-220.

${ }^{133}$ Morison notes an Eleazar "Indus Senior Sophista" of the Harvard Class of 1679. He wrote an elegy in Greek to Thomas Thacher, his teacher, that reads Dust holds your body, but your name will never parish on earth, famous in our and in future ties; and the soul, flying from your limbs, ascends steep heaven, mingling, immortal, with the immortal spirits." Morison, Harvard College in the Seventeenth Century, 196-197. While nothing seems to be known of this Eleazar, Daniel Gookin briefly mentions an Eleazar who fought alongside the colonists in King Philip's War and who distinguished himself by rescuing a British soldier from Philip's armies. See Gookin, An Historical Account, 477-478.

${ }^{134}$ Wolfgang Hochbruck and Beatrix Dudensing-Reichel, "'Honoratissimi Benefactores' Native American Students and Two Seventeenth-Century Texts in the University Tradition." Early Native American Writing, New Critical Essays, ed. Helen Jaskoski (New York: Cambridge University Press, 1996) 5.

${ }^{135}$ This translation from the Latin was is from Hochbruck, and Dudensing-Reichel, "“Honoratissimi Benefactores," 5 .

${ }^{136}$ Hochbruck, and Dudensing-Reichel, “"Honoratissimi Benefactores,” 5.

${ }^{137}$ Simmons, Spirit of the New England Tribes, 67.

${ }^{138}$ William Wood, New England's Prospect. ed. Alden T. Vaughan (Amherst: University of Massachusetts Press, 1977), 100-101. 
139 Jarold Ramsey, "From 'Mythic' to 'Fictive' in a Nez Perce Orpheus Myth," Traditional Literatures of the American Indian: Texts and Interpretations, ed. Karl Kroeber (Lincoln: University of Nebraska press, $1981), 25$.

140 Ake Hultkrantz, The North American Indian Orpheus Tradition: A Contribution to Comparative Religion (Stockholm: The Ethnographical Museum of Sweden, 1957), 208.

${ }^{141}$ Quoted in Hultkrantz, The North American Indian Orpheus Tradition, 249. The source cited is an 1893 report on Dakota grammar by S. R. Riggs.

142 Simmons, Spirit of the New England Tribes, 141-142.

${ }^{143}$ Gookin, "Historical Collections," CMHS 73.

144 See David J. Silverman, Faith and Boundaries: Colonists, Christianity, and Community Among the Wampanoag Indians of Martha's Vineyard, 1600-1871 (New York: Cambridge University Press, 2005), 92-93.

${ }^{145}$ Gookin, "Historical Accounts," CMHS, 517-518.

146 Ibid., 449.

${ }^{147}$ Jill Lepore, The Name of War: King Philip's War: King Philip's War and the Origins of American Identity (New York: Vintage Books, 1998), 94 and Gookin, "Historical Accounts," 494. Gookin's note is slightly different than Lepore's copy and I offer his version here.

148 Lepore, The Name of War, 95.

149 Quoted in Kellaway, The New England Company, 153.

150 Gookin, "Historical Accounts," CMHS, 518.

${ }^{151}$ Samuel Seawall, The Diary of Samuel Sewall vol. 1, 1674-1708. ed. M. Halsey Thomas (New York: Farrar, Straus, and Giroux, 1973), 394. 


\title{
CHAPTER- 4
}

\section{BENEATH THE WAVE: THE MAINTENANCE OF NATIVE TRADITION IN HIDDEN TRANSCRIPTS, 1700-1768}

\begin{abstract}
And here town records, old tattered, time-worn, weather-stained chronicles, contain the Indian sachem's mark perchance, an arrow or a beaver, and the few fatal words by which he deeded his hunting grounds away.
\end{abstract}

Henry David Thoreau

And the stories have built a new house.

Wendy Rose

Leave me not to Practice the Works of these People.

Samson Occom

\section{Diving Into The Wreck: Locating the Hidden Transcripts of Resistance in Native Writings of the Eighteenth Century}

In her history of the Mohegan Nation, The Lasting of the Mohegans, Melissa Jayne

Fawcett recounts a story told her by Bill Wakole, an elder of the Sac and Fox Nation. In this story Wakole relates how

when the Europeans first came to the Eastern shores, it was as if a giant tidal wave had hit the people and knocked them all flat. As the wave made its way west, the devastation was not as strong. As the waters subsided, there were no obvious signs of life along the eastern shore, so it was assumed that all the creatures who had lived there, before the wave came, were dead and gone. But after a while, tiny bubbles were seen on the surface of these eastern waters, and it was realized that the creatures of the eastern shore had not died at all. They had simply learned to live underwater. These creatures-among whom were the Mohegans - are now rising to the surface. They are wise creatures, for they have learned to live well within the wave that now surrounds them. Their experience beneath the wave has made them strong, and they are destined to grow and prosper. ${ }^{1}$

Survival writing. As with the earth diver myth related in chapter two, this narrative offers a 
metaphorical explanation of how culture, tradition, maintains itself in the face of calamity. The arrival of Europeans, the phenomenon often referred to as "contact" that brought with it war and disease in untold measure, is likened to a tidal force that seems to obliterate everything in its path. But in fact, Native culture is itself the earth diver, remaining submerged just long enough to ride out the initial force of the wave, only to restore itself again in the surface world once the flood has subsided. This is not only a story of survival, but one of continuance, for if indigenous traditions appear vanquished in this underwater time, it is only that they have fallen out of sight for a while, they have sheltered somewhere beneath the frothing white wave of European hegemony, until able to breach into sunlight once more, stronger, wiser, intact. It is a story of continuance for it frames itself within the existing narrative/myth structure of Algonquian culture. It recalls narratives central to indigenous literary traditions, and places them in the service of regeneration in contemporary times. The telling of the story is part of a process that reenergizes life in the present. The retelling of the story, I believe, helps to affirm and perpetuate that regeneration.

In this sense the story is more than metaphor. Or it is metaphor working at its fullest capacity to both invoke and provoke, to operate simultaneously as representation and the perceived current of lived experience. Certainly Natives persevered and survived in the era following contact, but as detailed in the last chapter, eastern indigenous culture was constrained to take on new forms, to reorganize itself in unfamiliar ways, and to present a face to the outside world that might appease the aggressive expectations of an ever expanding European population base. With indigenous culture rendered virtually invisible to the colonist, the political assertion was facilitated that "all the creatures who had lived there, before the wave came, were dead and gone." The process was one of elaborate and violent unwitnessing with the dominant culture refusing to acknowledge that which threatened the fabric of its own emerging national narrative. The construction of the colonial archive with its inherent ability to maintain this illusion, to 
suppress what it could not bear to incorporate in its self-inscribing, and to contain that which must not insinuate itself into official memory, reinforced the illusion that indigenous civilization was vanishing, had in fact vanished, was never there to begin with.

Wakole's narrative brings back into focus the illusory nature of this assertion. While Native culture may have been forced in many ways to assume the role of its own demise, still it maintained itself in its submerged state until such a time when "it was realized that the creatures of the eastern shore had not died at all." As with many indigenous narratives, this tale does not draw a marked distinction between the human and animal worlds. "All the creatures" of the eastern seaboard are taken into account in the telling, as they are equally threatened by the enveloping wave, equally engaged in the subsequent act of renewal. Even European culture, for which the wave is both simile and metaphor, remains a passive presence in the story once having fulfilled its violent and inchoate task. Though it is the fact of European presence that catalyzes the violence, the colonial perspective becomes folded into the larger perspective of the storyteller so that the all-consuming European gaze is effectively averted. There is no determinate voice to notice how "there were no obvious signs of life" in the wake of the flood, or how "it was assumed that all the creatures who had lived there ... were dead and gone." The narrative stands outside the gaze of human agency, achieving a tone that is at once non-judgmental, all inclusive, and yet extremely cognizant of the political exigencies it invokes. It affirms, in some sense, Craig Womack's notion that oral tradition (understanding this to be an oral narrative that Fawcett has paraphrased for us in writing) "has always contained within it the level of political critique."2 Or, to further quote Womack, "from the Indian worldview, the song contains the medicine that sets the cure into motion."3 On the surface level, or the perspective of the keepers of the archive, there is no cohesive narrative explaining how Native culture maintained itself through the colonial invasion until present times. Native identity, in terms of political and national continuity, simply ceased to be. This perspective has had significant implications for indigenous 
nations attempting to establish themselves within the hegemonic containment of tribal recognition. But Wakole's explanation begins to elaborate how continuity occurs beyond the purview of the archive when he observes of the eastern seaboard nations that, "they had simply learned to live underwater."

That Eastern Algonquian culture now makes its impressions above water, on dry earth once more, might be confirmed by the presence of Native Studies programs in universities, the calls from Native scholars to locate and study the intellectual traditions of their tribes (and of American Indians in general), in the continuing revival of indigenous languages, the maintenance of reservation schools that work from within the parameters of tribal tradition, or in the economic revival that has taken place amongst Mohegan, Pequot and many other nations, in part assisted by the opening of casinos on their lands. But these are still tentative steps, often, if not always, essayed on contested ground. As Fawcett writes, "today, Mohegans walk along the eastern shores mindful of the time they spent below the surface of the Great Wave." ${ }^{.4}$ Fawcett herself, as tribal historian for the Mohegan, is mindful of the fact that while Natives remained an actual presence on the land throughout this "wave-time," the stories preserved in the "voices of grandmothers and grandfathers" that make up the oral tradition of all nations, were "whispering lessons," barely audible in their submerged state. ${ }^{5}$ The brutal fact of western hegemony is that it either silenced or shouted over many of these traditions, both advertently and inadvertently. The act of restoring narrative, and removing tribal histories and languages from their sites of containment (submersion), is perhaps the most vital step in a healing process for the Native cultures of America. It is not simply the recovery of such histories and traditions - which for many were never truly gone but, in fact, covered-so much as the restoration itself that remains vital, the act of allowing these stories to breach into sunlight and the insistence that they have a place in the overall narrative that is the record of human experience on this planet. No longer underwater. No longer forced to wear the death mask. Intellectual sovereignty cannot be defined solely as the 
shared knowledge base of a small group of people, even if it must begin as such. If intellectual sovereignty is a term to be taken seriously, and perhaps it is not the most accurate indicator of what is wanted, still it must be something that is acknowledged from without as well as from within. Sovereignty must be recognized. Having our stories acknowledged by others is an essential part of the process of wiping the tears from the eyes, cleaning the grit from the ears, removing the obstructions from the mouth.

Like the oral traditions that spent time under the wave, noticeable only when "tiny bubbles were seen on the surface of the eastern waters," the written testimonies, the inscribed transactions of Natives who put pen to paper for deliberate reasons in previous centuries, might be considered part of what Fawcett calls the "chain of duty and remembrance that links contemporary Mohegans to their ancient past." If there is a difficulty in engaging with these texts, or fully recognizing them as part of a Native tradition of survival and resistance, it is a difficulty that comes from our having encountered them so firmly within the colonial containments through which they have surfaced. In some ways these texts are like the bubbles mentioned above -isolated expulsions of oxygen indicative of a greater, richer life still residing unseen beneath the wave. But the more scholars engage with these texts and relocate them within a tradition of Native continuity, the more the texts in question begin to resist the parameters of their former containments. As Robert Warrior notes

although we may have no immediately accessible tradition that informs us how to confront present challenges, we do have many examples of Native writers and scholars who have confronted similar situations. When we take that tradition seriously, I will argue, we empower our work ... we are doing something that Natives have done for hundreds of years. ${ }^{7}$

Warrior observes that "Native written intellectual tradition reaches back at least to Samson Occom's missionary writings in the 1700 's" and, as I hope I have demonstrated, perhaps even earlier. ${ }^{8}$ Warrior is not suggesting that anyone should become slavishly dependent upon such traditions from where-ever they emerge, but that components of a tradition be recognized, based 
on "what humans have created and how they created it." For, in fact, this is all tradition is, regardless of its implications to identity and culture: a human construction delineating a path through life founded in practice, belief and ritual, considered by many to be good. Alphabetic literacy became a part of Native American tradition in seventeenth-century America and, in fact, was a vital tool in the act of withstanding an epoch of violence and loss brought on by the colonial encounter.

The story of the wave is a story of continuance, but it also serves to illustrate, at least partially (or perhaps paradoxically), an effect of what Jacques Derrida calls "archive fever." Archive fever is the impulse, or instinct, that necessitates the construction of an external house of memory, a domicile where memory is officially stored and inevitably molded into the shape of the desire of those who determine to house such memories. The archons, or those who are the guardians of these deposits, alone "have the power to interpret the archives . . . these documents [that in effect] speak the law: they recall the law and call on or impose the law." ${ }^{\prime 10}$ But the archive also hides from itself its authoritative, or patriarchic, agenda. As Derrida immediately elucidates, the word archive itself shelters its linguistic roots, the notion that within the Greek "arkheion" which means "house or domicile," and "arkhe," which means both "government" and "to rule," are suggested both the place of power and the will to power. But the contemporary use of the word archive typically suggests something more neutral and forgets its lineage to power. This is called up, as well as partially forgotten, in the notion of the "ark of the covenant," the lost archive that remains, nonetheless, the "house of law" and source of authority for Judeo-Christian culture.

The idea that the archive seems to harbor both memory and forgetfulness is useful for a number of reasons. The presumably neutral archive brought under our interpretive lens contains deposits of both colonial and indigenous memory. But because what has been housed there is catalogued and maintained by the authorizers of a particularly monologic set of skills and beliefs, 
the materials that have been preserved, under house arrest so to speak, work in the service, both advertently and inadvertently, of that power or set of laws. This is not to say that impressions resistant to this power do not inscribe themselves within the archival records. They are either there or they are there in absentia. Just as with the Pequot Nation whose name was supposedly expunged from history, the wrath of God burning its very inscription from memory, such impressions must first be acknowledged on some level before they can be forgotten. ${ }^{11}$ The burn mark remains. Native culture, Native civilization in general, appears and impresses itself in a similar manner. It may seem to have languished under the wave (which for all intents and purposes may be considered the archive itself), but it had to be inscribed before it could be elided. Thus the archive maintains a substrata of suppressed memory. As Derrida notes, "if one is under the impression that it is possible not to take this into account, forgetting it, effacing it, crossing it out, or objecting to it, one has already confirmed, we could say even countersigned (thus archived), a 'repression' or a 'suppression."”12

One point we might draw from all this is: that which is archived works toward the production of a deliberate field of knowledge. It constructs thought and tradition in accordance with the powers of the house of archive. Whatever works in resistance to that field of knowledge, thought, and power, is stricken or immolated. But as Derrida notes, the crossed out inscription retains some kind of presence, and he gestures toward Freud to apprehend the resiliency of such suppressed knowledge. In The Interpretation of Dreams Freud ponders the implications of literary production and its close association to dreamwork, observing that "the dream-thought created by the suppressed wish completely escapes the censorship and is transferred to the dream without alteration."13 The suppressed wish of the colonist is that he may be forgiven his transgressive acts of violence in the service of land appropriation. And so an Indian figure emerges in the colonist's literature who is at once in league with colonial power and yet selfcognizant of its need to vanish from the newly emerging tableau of western civilization. This 
figure, a product of manifest manners, takes its vanishing into its own hands, displacing colonial agency, eliding the acts of violence that were necessary to perform this removal in history. And the dream creation is regarded as the central figure of a new, quintessentially American, literature. ${ }^{14}$ As noted in the previous chapter, Larzer Ziff calls upon such a paradigm to show how America, as a nation, is written into being by displacing what is immanent, what is essential and of the soul, with what is represented. ${ }^{15}$ And so Native civilization is displaced by the figure of the Native as represented in American literary productions. The other side of the coin becomes the figure of the cruel, bloodthirsty heathen who stands in opposition to everything civilization is presumed to represent. But this figure, in fact, serves the same purpose as the noble savage. In Derrida's words, we do not like to be reminded "of the undeniable existence of an evil which seems to contradict the sovereign goodness of God." Therefore we construct a place for such impulses within the archive that "exculpate God: evil for evil's sake, diabolical evil, the existence of the Devil can serve as an excuse for God, because exterior to him." In Derrida's formulation it is the Jew who becomes the depository of such impulses. But for the colonist it is the Indian. ${ }^{16}$

But the story of the wave offers us disparate continuities: first the apprehension, enforced by archival memory, of suppressed Native culture, and second, the insistence from beneath the wave of the non-archival, or extra-archival, presence of Native continuance. I believe the story of the wave acknowledges the effect of the archive to cross out or unwitness Native culture, at least for a time. But from beneath the wave, we are told, that culture persists and grows stronger. Derrida would assert that such a claim then becomes part of the archive itself and is either folded once more into the totalizing authoritative memory of the archival house or subjected to yet another round of suppression. Perhaps these are one and the same, given the nature of the archive. Native presence, always there in the act of vanishing, is the cultural residue that can only escape censorship as dream imagery or what Gerald Vizenor sometimes refers to as 
"the tease of presence." 17 Another interpretation, however, is that of anthropologist James C. Scott who suggests the possibility of a "hidden transcript" that remains untraceable to power, even while expressing itself both publicly and privately. It is a transcript of resistance that maintains itself beneath the surface of the wave even as expressions of its existence bubble to the top.

According to Scott, in Domination and the Arts of Resistance, "every subordinate group creates, out of its ordeal, a 'hidden transcript' that represents a critique of power spoken behind the back of the dominant." ${ }^{\prime 18}$ This critique, far from being an ineffectual venting of frustration or acting out of resistant fantasies, forms the parameters of resistance that define the privileges even the most oppressed populations negotiate for themselves on a daily basis from within the realms of power. Scott acknowledges the inherent problems of delving into the archive, which is "consecrated to the official 'public transcript," as a means of interpreting so-called marginalized (submerged) cultures and their forms of resistance. He correctly observes that resistance within the archive is always "mediated by the interpretation of dominant elites." But he also perceives the strategies that resistant groups employ to subvert such mediation.

One way in which subordinate groups cover their tracks is by appearing to contribute to the authorized transcript. The result of this is that resistance is always present and always masked. Scott concludes that, for the sake of the official transcript, a resistant slave will always strike the appearance of the model slave, a poacher will always present the face of the peaceful respecter of property, a tax cheat will always file a form that looks proper on the books, etc. ${ }^{19}$ "The social evidence will almost always represent a confirmation of the status quo in hegemonic terms. ${ }^{20}$ By the same token, a Native who lives according to her/his traditional beliefs, within a colonized space, will most likely wear the mantle of Christian conversion. Resistance may be fully anticipated and even assumed, but historically speaking, it remains difficult to pinpoint its source. A public transcript is always offered that conceals the hidden. 
While Scott does not directly address the issue of Native American resistance, I have suggested a number of occasions in the previous chapters in which resistance might be interpreted as having donned the mask of assimilation. The matter is complicated, however, by the recognition that the powerful elites also have both a hidden and a public transcript distinct from that of the disenfranchised, and their agenda is equally difficult to interpret with certainty. In some cases, perhaps in every case, the resulting representation becomes a confused signifier, failing as it must, to strike its signified. Homi Bhabha finds in this continual distortion and displacement the very materials of hybridity, which is not defined by resolution between two cultures, but in the constant slippage of definitions, leading to what he calls a "split screen in which the self and its doubling is apprehended."21 As I interpret Scott's analysis, however, the screen is quadrupled. Double consciousness reverts back, in the sense that the representational modes of those in power, while vivisecting the other, are performing a similar operation upon their own collective psyches, creating a world in which it is impossible to bring into focus the particulars of their own historical experience. This is confirmed by psychiatrist Judith Herman's conviction that "repression, dissociation, and denial are phenomena of social as as individual consciousnesses."22 Perhaps a suggestive example of this is the representation of Philip in Eliot's Indian Dialogues in which the Wampanoag sachem, on the eve of launching a major assault against colonial presence, emerges as a fully realized fantasy of the tractable Christianized Indian (see chapter 3). Such a representation clearly works in the service of the underlying ideological agenda of the colonist to remove Native presence from the land, but it also suppresses the causes for what would be Philip's eventual resistance (resulting in a particularly aggrieved sense of shock and horror on the part of the English who failed to fully anticipate the extent of Native antipathy to their cause).

What we might draw from all this is a sense that while the culture in the position of dominance engages in a systematic process by which the traditional Native is crossed out to 
make way for the assimilated model who is on the path to vanishing (in effect using red ink to affect an elision), the entity beneath that strike-mark posits a life and identity of its own that always retains the potential to erupt back into historical notice. Philip might very well have been dissuaded from rebelling against the colonists, and in such a case, his place in the archive would have been fixed to the representation of him that Eliot and others were pleased to imagine prior to his insurgency. But Philip did revolt, in effect forcing the hidden transcript into public view, and disrupting what had been the contribution to the public transcript offered by disenfranchised Natives up until that point. Once rebellion occurs neither the transcript of the elite nor of the disenfranchised can remain hidden and all are free to inscribe their sentiments openly. Interesting things occur in these moments of excess. One example of this might be seen in Thomas Wheeler's 1676 account of the battle of Brookfield during King Philip's War in which the colonists, under siege, have their darkest suspicions about Native Christianity confirmed. Wheeler writes that, they continued shooting \& shouting, \& proceeded in their former wickedness blaspheming the Name of the Lord, and reproaching us his afflicted Servants, scoffing at our prayers as they were sending in their shot upon all quarters of the house And many of them went to the Towns meeting house (which was within twenty Rods of the house in which we were) who mocked saying, Come and pray \& sing Psalms, \& in Contempt made an hideous noise somewhat resembling singing. ${ }^{23}$

The choice of the Wampanoag warriors to mock Christian worship in this situation of reversal suggests a perfect unmasking, even though it is a colonist who provides the insight. While previous relations we have encountered were inclined to describe the ululations of Native worship as "hideous," and their adoption of Christian hymnody as nothing less than miraculous, here the hymnody is made "hideous" again as it becomes fully appropriated by the voice of the other. It is not the content that has changed so much as the context. The mask has been pulled away and the face of resistance openly displayed. In some sense this explains why, in texts by Mary Rowlandson and others of the time, there is a particular hostility directed towards Christian or praying Indians. ${ }^{24}$ The suspicion of the hidden transcript has always been there. But it was 
diffuse in its defiance, indeterminate, difficult to trace back to any single origin. It became a floating signifier, engendering suspicion, uncertainty and hostility. As James Axtell notes, Christianity for Natives "often lay very lightly on the surface of their lives." ${ }^{25}$ But wherever that surface was maintained it remained difficult to crack its code and so the dominant culture constructs psychic barriers against reading through the transcripts of resistance even while in the act of striking out any knowledge of its presence.

In reading the mask of subordination and instituting its own rituals of hegemonic control the powerful ultimately become convinced by their own theater of dominance, staging productions for themselves that perpetuate and enforce this image. History is deliberately constructed to conform to the production and, barring the violent outburst of rebellion, the keepers of its narrative are unlikely to acknowledge any disruptions to the fabric even from within their own archive. And if such disruptions should be noted, they are quickly forgotten once again, driven offstage by the continued assertions of the dominant script. Scott wonders if this dynamic constitutes a kind of "self-hypnosis within ruling groups to buck up their courage, improve their cohesion, display their power, and convince themselves anew of their high moral purpose. ${ }^{26}$ Because we, us down here, mere spectators in the theater, are always, at any given moment, existing within the scope of prevailing powers, it must seem that such power is totalizing and that every arrangement, every discursive particle, is in some way obliged to accommodate it. We are always at once the audience and participants in this production. But power itself is always shifting and reconstituting itself in the face of unrelenting pressure, even from those who consent to be contained within its parameters. At any moment we could stand up en masse and boo. Scott notes, in particular, that "oral traditions, due simply to their means of transmission, offer a kind of seclusion, control, and even anonymity that make them ideal vehicles for cultural resistance." 27 As a discourse it is not necessarily outside the theater, but it remains invisible to those on stage, obscured by the stage lights, one supposes. Womack gives an 
interesting example of this, noting how most "non-Native Oklahomans assume that Indians have all been assimilated, not realizing that these ancient ceremonies continue right under their noses, just outside the small rural eastern Oklahoma towns they live in." Womack defines such ceremonies (in this case, the Turtle's medicine song that becomes a feature of the Creek Stomp Dance) as "part of an ongoing vibrant nationalism" that remains integral to a sense of tribal identity. ${ }^{28}$ This does not resolve the issue of whether or not, as Michel Foucault insists, power creates a place for resistance and accommodates it within its system. But it does suggest that, just as the individual is driven by a set of urges that leave no trace of themselves in conscious memory, power is motivated, and in some respect governed, by the very substrata of resistance that it has unwittingly repressed.

In this chapter I will look at a number of late seventeenth and eighteenth-century texts that, while appearing as components of the "public transcript," speak, in part, to the hidden transcript of resistance and continuance in Native New England. As Natives make their first autonomous entries into the western archive, they are consciously molding their message to conform to the discourse of the colonizer. But I will argue that such forms are deployed to serve the agenda of a hidden transcript that allows for Native culture to survive in this time beneath the wave of colonization. I do not argue that the texts appearing in the archive are deliberately masked or attempt to misrepresent a point of view. I do argue, however, that for these texts to appear at all in the public record, they must be constructed in a certain manner, hyper-aware of the particular discursive avenues of expression that remain open. In such a manner are they able to perform in the theater of dominance while keeping in mind cultural objectives understood by the hidden transcript and which necessitate the need for the public appearance in the first place. I will begin by looking at early land transactions written in the Massachusett language and recently translated by Kathleen Bragdon and Ives Goddard. These writings afford us a glimpse into the internal workings of Native communities at Natick and on Martha's Vinyard, as well as a few 
other Native strongholds in colonial New England. I will conclude with an examination of the writings of Samson Occom, focusing mainly on his 1768 a "Short Narrative of My Life." Occom emerges in America's revolutionary period as a Christian leader of the Mohegan and a figure fully capable of negotiating the textual exchanges between colonizers and Natives. Within the textual productions of these Native spaces, I will be looking especially for the discursive practices that allow them to appear in the public transcript while working to preserve indigenous tradition.

\section{“This Indian Land": Writings in the Massachusett Language and Sustaining Native Space}

By many accounts, Native literacy, alongside Native resistance in New England, melted away in the wake of King Philip's War "like snow in the springtime." ${ }^{29}$ King Philip's War seems to serve as one of those interesting historical markers whereby the dominant culture attempts to erase any suggestion of continued Native presence past a particular point. It simplified the task of historians over the first two hundred years of this country's existence to allow this formulation to stand, although in her book Dispossession by Degrees, Jean O'Brien adeptly demonstrates how Natives didn't simply fall off the face of the earth following the war, but were, in fact, gradually squeezed out of their land holdings, and economically and socially marginalized through legal (and extra-legal) maneuvers over the period of a century. It is not simply by chance that the maintenance of this inaccuracy was facilitated by archival records ostensibly kept to provide an objective historical accounting of the period. O'Brien notes that property transactions in Natick, in which Natives were systematically divested of their lands, were well documented in the decades after King Philip's War, but "by the end of the eighteenth century neither the English minister nor the English town clerk took care to record the beginnings and ends of Indian lives." ${ }^{30}$ One might suppose that such record keeping habits were not purposefully imposed, but 
rather arose organically out of the situational make up of the times. Whether or not this is so, the records themselves comprise a discursive construct that could only "reproduce the extinction narrative that has dominated the traditional account of Natick."31

Following King Philip's War, a great deal of the Native population of southern New England was either sold into slavery, forced into indentured servitude, or corralled into a few small enclaves or plantations to be kept under colonial surveillance. ${ }^{32}$ Harold W. Van Lonkhuyzen argues that, in this period, the adoption of new rituals conforming to Christian systems of belief supplied "a new rationale for society, indeed a new cosmos," in which Native identity was irrevocably altered. ${ }^{33} \mathrm{He}$ states that "the continuing processes of internal and external change in the post-war period rapidly dissolved the social organization underpinning Indian identity. ${ }^{34}$ In this formulation, Natives brought irreversible changes upon themselves by craving European goods and buying into the "praying cult" that European missionaries offered as a strategic escape from the traditional domination of sachems. Natives were "undone in their desire to interact with the English while maintaining their traditional social structure and goals." 35

Such a conclusion undoubtedly holds some truth and should not be reflexively dismissed in an effort to forge a more proactive view of Indian agency in colonial New England. I would suggest, however, that the summation has a rhetorical leaning that favors a still stubbornly Eurocentered reading of the situation, having more to do with discursive habit than any pronounced cultural bias on the part of the author. Another way of reading indigenous presence in Natick in this period is to recognize the town as a center of Native influence within a colonial containment, that far from disappearing or assimilating itself into irrelevance, achieved a level of brief autonomy following King Philip's War. With the passing of John Eliot in 1690 there was no one person committed to performing the kind of outreach at Natick that insured a continuation of European style worship. Kathleen Bragdon and Ives Goddard report that church membership fell 
in this time to only seven men and three women, more or less confirming just how "lightly" Natick converts wore their Christianity. ${ }^{36}$ Nevertheless the town remained under Native leadership until the 1720 's, with Thomas Waban maintaining a central role in the government and keeping town records in the Massachusett language. Might these records, as translated by Bragdon and Goddard in their compilation, Native Writings in Massachusett, also be considered a hidden transcript - for who, indeed, could read this archive outside the community itself, save for a small and dwindling number of missionaries who had schooled themselves in the language? The records Waban kept detail a regularity of affairs in the daily life of the village, outside the realm of Anglo oversight, that defies the historical perception of Native community and culture melting into the water table in a single season. ${ }^{37}$

The Native records at Natick offer some insight into the smoothness and apparent confidence with which affairs were run during this period. A few sources have made much of an apocryphal story in which Waban, the elder, boasting of how he handled drunk and quarrelsome Indians, claimed he would "tie 'um all up, and whip um plaintiff, and whip um fendant, and whip um witness. ${ }^{\prime 38}$ In this account Waban is made the agent of colonial wish fulfillment, firstly taking the violent act out of colonial hands and personally meting out punishment to deserving Indians, and secondly by acknowledging that all Indians must be guilty of something and therefore ought to be treated as such regardless of their position in the legal process. The most severe judgments meted out in the translated town records at Natick, however, concern a five shilling penalty levied on the town representatives themselves for failing to appear at an appointed meeting, ${ }^{39}$ and six shillings awarded to one Moshontanum for an apparently false accusation made against her. ${ }^{40}$ There is no mention of any other punishments, corporal or otherwise, and one suspects the practice of whipping drunken Indians was more in keeping with Puritan notions of retribution than Waban's. ${ }^{41}$

Of course the Natick Indians were unable to retain complete legal autonomy and many of 
their affairs were presided over by the colonial courts. Most of these cases involved accusations of theft and drunken disorderliness. A deposition filed by the citizens of Dedham in 1680 asserted that the Natick Indians "rob us of our corn and other provisions out of our fields; that cattle in the woods have been torn by their dogs . . . and in their drunken fits [they] have affrighted some women. ${ }^{, 42}$ Such accusations, vague and hard to prove, demonstrate the level of distrust toward the Indian that had been fanned into open hatred during the war and persisted well into the next century and beyond. On top of these accusations, it was claimed by the colonial residents of Dedham that the Natick Indians were "proud and surly," refusing "to take notice of an Englishman if they meet him in the street. ${ }^{, 43}$ If these complaints were subjective in nature and difficult to verify, they nevertheless helped to undermine Native jurisdiction by insinuating that the Natives "cannot govern or have any command" over their own people. 4

While the external colonial documents suggest discord and relative anarchy within this Native space, internal proceedings seemed to have occurred without rancor. The Natick documents written in Massachusett mostly concern the results of town elections and the parceling out of land to Native citizens, alongside various other land transactions. An allotment that appears to have been granted by the town in 1720 affords a glimpse into the tenor of these proceedings. It reads,

Then the proprietors jointly and willingly released one piece of land (it lies at the south side of this house and this river) to the one named Muttassonshq or Susannoh, the wife of Josiah Ephriam. And that land lies between the boundary of Samuel Commacho and the northwestern corner where the fort used to be, and from that straight towards the northwest to the boundary further on, the boundary of Andrew Ephriam, and between that: that land towards the north up to the river, about 20 acres or perhaps less. And this has been lovingly given to Muttassonshq. She has that property forever. By Thomas Waban, Town Clerk here. ${ }^{45}$

Despite the more or less official and pragmatic tone of this document, it allows us to, perhaps, make some tentative observations into the life of the town in this period of partial autonomy. For instance, it tells us that women were allowed to possess land in their own name in Natick. While English law allowed women to own land only under special circumstances, such as when a 
husband passed away with no son to assume the title, ${ }^{46}$ the above document suggests that Muttassonshq's husband is still alive and that she will, nevertheless, have sole title to the land in question. We might also notice that no currency appears to exchange hands in the offering. The "proprietors," who we may believe are the town authorities, collectively "release" the land to Muttassonshq, suggesting something of a hybrid articulation of collective and private ownership. In fact, of the fifty-one documents dealing with land transactions that Bragdon and Goddard translated from the Natick Town Records, only one mentions a monetary exchange, and this seems to occur outside the realm of the town's authority as Waban records how a certain stretch of land was allotted to one John Thomas "but he sold that for three pounds." We also learn from the above document that, although the woman who is allotted her own tract of land has a baptized name, "Susannoh," she is clearly known by her Native name of Muttassonshq. "Susannoh" seems to appear as an after-thought, in recognition of the official nature of the document and an acknowledgement of the external authority for which such documents are ostensibly kept. That such an authority has momentarily averted its gaze might be implied by the notice of "where the fort used to be," which suggests that surveillance has lapsed. A "pallisadoed" fort was one of the original structures of the town, as proposed by Eliot, but there is further mention in the town records of a stone fort, which might suggest that a more recent military outpost was erected at some point during or after King Philip's War. Either way, it appears to be in disuse.

And finally we notice that the parcel of land is given to Muttassonshq "lovingly," and that she is bequeathed that property "forever." The adverb "lovingly" is not be found in any of the other recorded allotments, but it allows us to imagine, at least, a sense of community and warmth in these transactions that bespeaks a relative period of peace and security. The word "forever," which appears in a great many of the Native documents, assumes that the land will remain in the hands of its original owners for perpetuity despite the hard lessons of the last one 
hundred years spent as neighbors with the acquisitive-minded English.

That such claims to perpetuity were bound to come under threat might be apprehended, however, in a 1715 decree stating "now no one (shall) sell any more wood to the English from this time. If anyone henceforth contrarily does that, he sells trees to the English, he shall pay twenty shillings for one tree. This was done. By Thomas Waban Town Clerk here. This is a law." The decree is under-signed by Samuel Abraham, Josiah Speen, and John Wamsquon. We do not know the exact circumstances that would require such a law to be passed, but we can readily imagine that a process is being set in motion in which unfair dealings with the English lead to disputes that often result in Natives losing land and rights in English courts. Daniel Gookin's son, also named Daniel, who took over some of the preaching duties once both his father and John Eliot had passed away, came to operate the saw mill at Natick in the 1690's. He seems not to have been valued by the indigenous community in the same manner that his predecessors were, however, and in a 1695 deposition he was accused by the Natick residents of encroaching beyond his allotted lands. Nevertheless, by 1696 Gookin had acquired some 1,700 acres of Natick real estate. ${ }^{48}$ The injunction against selling wood to the English was more than likely an attempt to curtail the plundering of Native resources by acquisitive-minded colonists like Gookin Jr. As always, the best way to avoid such circumstances was to avoid the lure of commerce with the colonists altogether.

A final point about the Natick town records as compiled by Thomas Waban is that nowhere is there a mention of God. The topic simply doesn't arise despite the fact that the matter of religious belief was central to nearly every document produced by Native peoples prior to these writings. If the Wampanoag and other Native groups who found themselves in Natick in the late seventeenth and eighteenth centuries had indeed constructed "a new cosmos," as Van Lonkhuyzen suggests, it was a cosmos less affected by Christian ritual than by the pressures of maintaining culture within a colonial containment. Native ritual, belief, and practice were not 
bound to remain static throughout this period, any more than European practice and belief remained static. The struggle for survival imposes its own norms on one and all, and the world made new by European presence imposed new normative values on European and Indian alike. But the achievement of yet one more generation of cultural unity and relative peace was no small thing, in this or any other time, and in Natick, at least, there seems to have been a forty to fifty year period in which the Wampanoag, alongside other Native individuals who resided there, carved out a quiet path of continuance.

The documents translated in Goddard and Bragdon attest to the thread of Native literacy that continues into the eighteenth century and how it begins to achieve a certain autonomy from the immediate concerns of the colonists. Their compilation of records suggests that, to a significant extent, written documents had come to stand alongside of verbal agreements for Natives, not just in Natick, but throughout New England. ${ }^{49}$ The authors estimate that, by 1698 , $30 \%$ of Natives living in praying towns had acquired some form of literacy, and that this was comparable to the number of English settlers who could read at the time. Literacy for the Natives, however, was of a "restricted" type, mostly referring to an ability to read, not necessarily accompanied with the ability to write, and was limited to the Massachusett language, which naturally meant there were few actual texts available for consumption. ${ }^{50}$ Certainly no texts were produced in this period comparable to the variety of narratives and broadsides the English were churning out as a matter of cultural habit in the seventeenth century. And by the 1720's the argument for publishing texts in the Native dialect that Eliot had hammered into being had few remaining adherents. ${ }^{51}$ But the surviving documents in the Massachusett language from this period, while mostly of a pragmatic nature, suggest that Native peoples who had acquired literacy still found occasion to use this skill in settings that were not exclusively concerned with dealings with the colonists. In fact, in some cases these writings offer a glimpse into the syncretic usage of oral and literate traditions, what Bernd Peyer refers to as "orature," that continued with 
the Massachusett speaking Natives who, by the end of the 17th century, were using written documents in their own language to record their land dealings, not only with the colonists, but amongst themselves. ${ }^{52}$

Bragdon and Goddard maintain that a particular form of transaction referred to as "recorded oral land transfers" were written documents that recorded oral exchanges of former transactions. This is partly evidenced by the appearance of quotation marks in these documents that "no doubt insured the legitimacy of the written versions" by reinforcing their origins in oral agreement. Bragdon and Goddard suggest that these records offer us insight into the nature of traditional oral exchanges and "demonstrate the validity of verbal agreements after the adoption of literacy." 53 In one such document we have the landholder voicing the words, "I do not sell this land, but I bequeath this Island Mashinneah, entirely, everything (of) land, all trees, and all grass and everything that is there; I bequeath it all to my four children." The speaker goes on to emphasize once more, "my bequest is not sold, this island forever, as long as the earth exists, but only they use it, these four children of mine, and in all their posterity forever and ever as long as they have descendants. This is my true declaration." 54 There is an insistent idea expressed within this document that the land remain in the hands of those who have traditionally held it. The speech act seems intent upon denying the concept that the land is being sold-a strictly European notion. Instead, I feel, it stresses a sense of continuance, a prerogative of usage that has always been and always should be. The transaction has both the sense of an oration and a dynamic engagement with the present. "I do this," the speaker is quoted as saying, "I Quateattashshit." 55 With his words he is making it so. Many of the documents that Bragdon and Goddard translated are invested with a similar quality of spoken exchanges and the insistence that these agreements, whether understood to be written or not (as some, at least, were written after the fact), would be binding micheme micheme, "forever and ever."

Another interesting document written in the Massachusett language, was a 1752 petition 
by the Mashpee to their self-proclaimed overseers in Boston. Though the document is written, it is clearly transcribed from a speech rather than composed in the act of writing, and in keeping with the tradition of treaty oration, there is frequent repetition, with the communal "we" employed throughout. What results is, perhaps, an event unique to the North American continent of the eighteenth century: a Native oration that has no attendant audience. The document earnestly beseeches its Boston overseers to hear its plea, crying "Oh! Oh!, gentlemen, hear us now, Oh! ye, us poor Indians ... Oh! Hear our weeping, and hear our beseeching you, Oh!” The cadence, which might sound peculiar to us and certainly strange to the conventions of alphabetic literacy, strikes one as doubtless in keeping with traditional oratorical practices, despite its having been transcribed, and despite the inclusion of certain obsequious rituals of English-Indian relations. What the document establishes is a right of tribal ownership, regardless of the fact that a few members of the Mashpee community acted as sole agents in selling the land out from under the rest. It reads,

what they conveyed to you was this piece of land. This was conveyed to us by Indian sachems. Our former Indian sachems were called Sachem Wuttammohkin and Sachem Quettatsett, in Barnstable County, the Mashpee Indian place. This Indian land, this was conveyed to us by these former sachems of ours. We shall not give it away, nor shall it be sold, nor shall it be lent, but we shall always use it as long as we live, we together with all our children, and our children's children, and our descendants, and together with all their descendants. ${ }^{56}$

Although the Mashpee have acquired the tools of literacy and now attempt to gain political leverage through its application, they refer back to traditional oral arrangements as legal precedent, "that unwritten tenure of nomadic tribal authority," as indeed this is their only recourse. ${ }^{57}$ They insist upon the legitimacy of a tribal understanding of land occupancy, reaffirming that they shall use the land forever "unless we all peacefully agree to give it away or sell it. But as of now not one of all of us Indians has yet agreed to give away, or sell, or lend this Indian land, or marsh or wood. Fairly then, it is this: we state frankly we have never conveyed them away." 58 
The apparently traditional understanding conveyed in this document might easily lead us to forget that these, too, are so-called "praying Indians," who had presumably turned away from communal land ownership, in favor of individual lots that the owners might do with as they pleased. What is repeatedly reaffirmed, however, is that the individuals who sold property to the English had no right to do so under Native custom. Any decision to sell land this Indian land, consisting not only of farmed lots, but of marsh and wood-needed to be made collectively, and as is clearly stated, "we never have conveyed them away." It is further asserted that they "shall always use it as long [as] Christian Indians live. We shall use it forever and ever." 59 The Mashpee Indians would continue to fend off white speculators, squatters and thieves from their lands, using whatever means were available to them, and have managed to maintain their presence in Mashpee to this day despite unrelenting challenges from their white neighbors.

Natives who lived in praying towns in the late seventeenth and early eighteenth centuries, despite having adopted a semi-literate culture, managed to retain certain vestiges of their former traditional life. As David Silverman puts it, if they were becoming Christians, "by any reasonable standard, it was a distinctly Indian kind." system of communal decision making, often presided over by leaders who were still part of traditional ruling lineages. ${ }^{61}$ Christiantown, one of the praying towns at Martha's Vineyard, maintained a "dancing field" where ceremonies continued to be held. ${ }^{62}$ As the above document demonstrates, land was often understood to be held in severalty and not by allotment. At least until the nineteenth century residents spoke in their traditional languages, and literacy was used to secure legal ownership of lands and solidify a sense of tribal identity. ${ }^{63}$ One document in particular, drawn up by the Gay Head Indians of Martha's Vineyard, contains a provision that the signers "with all our children and all our (common) people, have agreed that no one (shall) sell land. But if anyone larcenously sells land, you shall take (back) your land, because it is forever your possession." In this short but poignant document the word "forever" appears no less than 
twelve times. ${ }^{64}$ It speaks not only to the cultural tensions from without the Gay Head community, but the extreme pressure from within as sachems were sometimes tempted to sell off vast tracts that were not previously thought to be individually "owned."

In the instance cited above, the sachem of the Gay Head Indians, Josiah Mittuk, had sold off all his land to Thomas Dongan, then Governor of New York, in 1687 for thirty pounds. But the people rejected the sachem's authority to make such sales, referring to the above quoted document that had previously forbade the selling of land. The Gay Head Indians were able to reach into their own archival records and offer resistance to a transaction that was made against the collective will of the people. David Silverman writes that, in the wake of the legal wrangling that followed, surrounding Wampanoag communities began to submit their own written proclamations that forbade the selling of land, challenging the rights of English tenants who had established themselves throughout the island. Silverman, who does a wonderful job of piecing together this fragmented history, notes the possibility that the Wampanoag of Martha's Vineyard were "shrewdly playing the colonists' old game of manipulating the printed word" by producing documents on the spot that they nevertheless maintained were decades old. Or perhaps these documents were produced along the lines of the oral agreements that were understood to still be in place within the Wampanoag communities themselves. ${ }^{65}$ In this example and others, the Natives of Martha's Vineyard were attempting to assert the legitimacy of their own separate archive, but ultimately the power of the archive resided where power was. The English denied the legitimacy of the Wampanoag claims in 1703 on the basis that they had not "been proved in due Form of law, nor drawn up in Form as is usual among the English. ${ }^{966}$ Although they were unable to reverse the decision of the English courts, the Gay Head Indians remained firm in their assertion that they, as a people, had never forfeited their lands, and that, by their own laws, it was illegal for them to do so. The whole situation was troubling enough to the English authorities to persuade The New England Company to purchase the Martha's Vineyard lands back from 
Dongan and draw up new terms of leasing arrangements with the Natives there.

\section{Evangelism and Eye-strain: Samson Occom's Native-Centered Vision of Evangelism}

The problems facing Mohegan in the mid eighteenth century were very similar to those facing the Natives at Martha's Vinyard. Where-as the Martha's Vinyard Natives attempted to rely upon former oral agreements to contest the purchases of the English, however, the Mohegan carried the ball a step further into the colonial court. The career of Samson Occom, while perhaps complicated by his lifelong affiliation with the Presbyterian church, and his perceived status as "the Indian Moses," offers a study in how Native communities in this time began to negotiate the public and private realms of colonized space. ${ }^{67}$ Interestingly, the "Moses" appellation is in reference to the exodus Occom helped to initiate, in which many New England Natives relocated to Oneida territory in the late eighteenth century. But Occom might also be remembered in some circles for initiating an engagement with alphabetic literacy in many Native communities, in a sense performing this other function for which Moses was remembered.

Occom's only publications in his lifetime, his entries into the public transcript, were a sermon that he delivered at the execution of a fellow Mohegan, Moses Paul, in 1772 ( $\mathrm{A}$ Sermon preached by Samson Occom, Minister of the Gospel, and Missionary to the Indians at the Execution of Moses Paul an Indian), and a book of hymns in 1774 entitled Collection of Hymns and Spiritual Songs. The appearances of these texts in the public transcript suggests that they were well-formulated performances of Native compliance and assimilation. If they gestured towards the hidden transcript of Mohegan tradition and resistance in any way, it was in a manner subdued enough not to upset the colonial establishment or the printing offices of Timothy Green, grandson of Samuel Green, who brought editions of both of these texts into print. That both publications were quite successful in their time attests once again to their level of conformity to colonial expectations. 
The narrative of how Occom came to ascendancy as a prominent Native figure of his time has been obscured somewhat by the framing of this event as part of the overall narrative of Eleazar Wheelock's founding of Dartmouth College, and the fuzzy traditions of Native advocacy that still adhere to this institution. The narrative begins with Eleazar Wheelock following in the footsteps of John Eliot and foreshadowing Richard Henry Pratt by opening a charity school for Indians in 1754 , where he would train young Natives to act as missionaries who would venture out into the wilderness and convert their fellow heathens. Occom stands out in this effort as Wheelock's first and only success. Occom's career, which received overall, a warm reception in his day, has been chronicled since the late nineteenth century, starting with well-researched and sympathetic biographies, first by William DeLoss Love in 1899, and again by William Harold Blodgett in 1935. Both authors are invested in perpetuating a narrative that viewed the civilizing of Natives through Christian doctrine as both necessary and inevitable, leading to the familiar "assimilation or extinction" narrative. Love writes "it is hardly possible that an Indian, with all the defects of his race, could grow to the full stature of a civilized man without struggles against his hereditary weaknesses. ${ }^{168}$ Nevertheless their focus on the particulars of Occom's life begins to apprehend the ruptures in that discourse, and Love is able to concede of Wheelock that "the father at Lebanon had not dealt kindly by his Indian son. ${ }^{, 69}$ Despite the blatant paternalism ingrained in such statements, the authors both come to a similar awareness of how the civilizing program was rigged against Occom. Both Love and Blodgett also performed a surprising and valuable service in printing a large portion of Occom's journals and letters, allowing Occom to speak "in his own voice."

It would have to wait until contemporary times, however, before Occom's life would receive a critical reassessment. Bernd Peyer would be the first to publish Occom's "A Short Narrative" in 1982, and in a summarization of Occom's life in American Indian Quarterly that same year, he labels Occom "the "father" of modern Native American literature."70 Nevertheless, 
Occom's writings are mainly regarded as belonging to a genre of literature regarded by Arnold Krupat as "salvationism," or a discourse subsumed by the monologism of colonial hegemony. Hilary Wyss, whose 1998 Writing Indians, takes a sustained look at Occom's removal to the Brotherton community in Oneida, recognizes the bold gesture of Native independence in this move, but I feel is overly critical of the missionary and racial dichotomies she perceives in Occom's relationship with the Oneida and African American communities of his time. David Murray and Dana D. Nelson, while also noting the inherent resistance in Occom's writings, both question Occom's ability to forge an "autonomous expression or an authentic voice." isn't until Jace Weaver reevaluates Occom's life in That the People Might Live, that we begin to receive an unqualified assessment of Occom as a Native advocating for Native causes. His voice is not subsumed, in Weaver's notion, but "communitarian," wholly invested in the project of preserving his community of Mohegan. ${ }^{72}$ Approaches the consider Native intellectual sovereignty a legitimate force have allowed for a new lens with which to interpret Occom's work. This has been pursued, most fruitfully I believe by Lisa Brooks who performs extensive archival research on Occom's career, and regards his contributions from Native space. Informed by perspectives made available from such a vantage, we see how the story of Occom's life begins to reverse itself in various ways.

Although it has been historically acknowledged that it was Occom who came to Wheelock on December 6, 1743, and not the other way around (Love exclaims with surprise "so it was Occom who sought out Wheelock and not Wheelock who sought out Occom"), ${ }^{73}$ still we are often left with the sense that Occom was a lone operative, working in isolation from his people, drawn like a moth to a brighter flame. Even his name, Occom, or Ockham, if we can trust Love on this point, meant "on the other side" in the Algonquian language. ${ }^{74}$ It seems to have been a given that, to cross over to Wheelock's side of the woods, Occom must have necessarily abandoned his own traditions, his own heritage. Occom, himself, offers the story in the familiar 
framework of a religious conversion narrative, beginning his 1768 "A Short Narrative of My Life" with the declaration "I was born a heathen and brought up in heathenism," and with the rest of the Mohegans, "lived a wandering life." After having been exposed to the teachings of the itinerant New Light ministers sometime around 1740, he "was Awakened \& Converted ... \& Continued under Trouble of Mind about 6 months; at which time I began to Learn the English Letters." Putting his trust in the life and salvation of Jesus Christ, he felt "the Distress and Burden of my mind was removed, and I found serenity and Pleasure of Soul, in Serving God." Under these conditions Occom reached the conclusion that "if I Could once Learn to Read I would Instruct the poor Children in Reading, -and used frequently to talk with our Indians Concerning Religion." Having had some knowledge of Wheelock, and knowing that he instructed English youths, Occom had "a great Inclination to go to him and be with him a week or a Fortnight, and Desired my Mother to Ask Mr. Wheelock, Whether he would take me a little while to Instruct me in Reading." 75

Taken up to this point, Occom's narrative demonstrates a facility in the desired language to use if one were a Native American in eighteenth-century New England, hoping to make an impression on local authorities upon whom one trusted for financial resources and institutional backing. More so than Waban and his other indigenous predecessors, Occom seemed to have mastered and internalized the language of Christian conversion, striking a tone that was neither overly devotional nor utterly debasing, but recognizing the desired movement from a state of abject darkness to one of superior light. Occom's contemporary and acquaintance, David McClure, put it in terms even more suited to the rhetorical conventions of colonial powers. In his Memoirs of the Reverend Eleazar Wheelock, he writes that Occom,

was of the Mohegan nation, and born a pagan. Living in the vicinity of the English, he, in 1741, at the age of eighteen, became acquainted with the Christian religion, forsook the vices of his countrymen, and became devout and zealous. He was deeply affected by the deplorable ignorance and vices of the Indians, and was industrious in qualifying himself to teach and reform them. ${ }^{76}$ 
In other words, the literature of the time, to which Occom contributed, seems to emphasize a deliberate divide between Occom and his fellow Mohegans who still dwelt in "deplorable ignorance." Perhaps the only indication in these brief notices that Occom himself does not perceive such a dramatic split can be found in his above admission that he "used frequently to talk with our Indians Concerning Religion." Not "exhort" or "preach," but "talk." If the colonial powers preferred to regard Occom as coming into exclusive dialogue with themselves, Occom still saw himself in dialogue with his own people. But as with Pocahontas, Caleb Cheeshateaumauk, James Printer, Thomas Waban, and many others before him, he has been sent out as an emissary to "Learn the English Letters," a skill that he can take back to his people and attempt to use to their advantage.

Despite his tendency to privilege a Christian worldview and allude to certain troubling Eurocentric conventions in his public writings, Occom viewed himself as a Mohegan first, and his considerable intellect and energy were applied towards furthering Mohegan goals to the best of his abilities. As Margaret Connell Szasz has noted, Occom was a member of the Mohegan Tribal Council before he reached the age of twenty. He was active in his community and served under the sachemships of both Ben Uncas II, and Ben Uncas III. ${ }^{77}$ Before leaving for England he was seen by the colonists as the most visible agitator in the Mason Land Case, which had been the cause of a great deal of controversy in southern New England throughout the eighteenth century. The general details of the Mason case will be dealt with more fully in chapter five, but, as with the Martha's Vineyard Wampanoags, and the Mashpee Indians, the basic materials for the conflict involved the selling of land by the sachem Ben uncas, without the explicit consent of the Native community. It must be noted that Occom seems to have aligned himself with those of the Mohegan nation who were against the sale of lands from an early date. Lisa Brooks observes that the mark of young Occom can be found on a Mohegan/Niantic petition dated September 1736, wherein it is stated that the "whole body of them did renounce Ben Uncas as Sachem ... 
And by virtue of these presents, we do disapprove of and make void whatever Ben Uncas has acted or may act in the capacity of Sachem or King over us in the conveyance of any lands, rights, and privileges whatsoever belonging to us." ${ }^{, 78}$ Fawcett tells us that when the colonial government refused to recognize the popularly elected sachem at Mohegan, the majority of the tribe chose to recognize no sachem at all. Mohegan itself split into two factions divided between Ben's Town and John's Town, a rift that would continue to fragment an already embattled community. ${ }^{79}$ In many ways, the dynamic that had served the colonists so well in parceling out Native lands to settlers at Martha's Vineyard, was playing out in Mohegan too, with the same predictable result. The people found themselves at odds with the recognized sachems who were siphoning off their lands, and traditional Native hierarchies were being forcefully splintered.

Occom most certainly already knew how to read and write by the time he came to Wheelock's to be tutored in 1743 . He had learned these skills on his own, or with the help of English neighbors, as he claims in his narrative. But he hoped to advance his learning, and in the first passage of a journal that he started that year (a journal he would continue to keep intermittently for the remainder of his life), he wrote in an already strong hand that he had come to Wheelock's "to learn something of the Latin tongue and was there about a week." ${ }^{, 80}$ His journal details his frequent comings and goings between Wheelock's and Mohegan while offering few peripheral details or internal musings. Perhaps he hoped to learn Latin because it was used in so many legal documents. Or perhaps he had other motives. Occom didn't seem to feel much of an inclination to unburden his thought process in his personal writings, but preferred, for the most part, to keep a simple record of his travels.

Occom stayed on with Wheelock just shy of four years, although, by his own account, he was sickly for nearly a year of this time. At other times he was involved in the seasonal subsistence routines of his community. Love suggests that, according to local tradition, Occom stayed in a "hut," or more probably a wigwam that he built somewhere on the periphery of 
Wheelock's property, while he was attending school. ${ }^{81}$ But his comings and goings were frequent. He wrote how on Sept. $17^{\text {th }}$ of 1744 "A bunch of Mohegan's go to Montauk, LI" and that they were "kindly entertained" there. Already beginning to think, or at least write, like a missionary, he noted "there was some stir amongst them." ${ }^{\text {.82 }}$ The expedition to Montauk was almost certainly part of a seasonal ritual, and not simply a random excursion. Montauk was known for its fishing and hunting grounds and had been a traditional fall destination for the Mohegan. ${ }^{83}$ For Occom, however, the trip to Montauk was of particular interest as he would soon elect to enter into this community, first as teacher, and later as kin.

The expectation was that Occom, having proven himself a promising student, would continue on to Yale, but after four years under Wheelock's tutelage, he claimed that excessive "eye-strain" had hampered his studies. Love tells us that "indeed he at length so overstrained his eyes by his earnest application to his books that he was unable to take the course which had been designed in preparation for the ministry." $\$ 44$ Perhaps a "smoky wigwam" was not the ideal place to conduct a crash course in western civilization and its practices. Or perhaps Occom had his own ideas about how he wanted to use the education that had been extended him. But it was no easy matter to disentangle himself from the colonial/missionary machinery once having implicated himself in its process. Our old friend, The Society for Propagating the Gospel in New England, had taken on the charge of defraying Wheelock's expenses for Occom's education, and wondered if Occom couldn't be kept occupied by "engaging in manual labor" until the time that his eyes recovered, and in the meantime they would kindly "allow what is necessary toward effecting a cure." ${ }^{\text {} 85}$ There seems to have been definite resistance to the idea of Occom, after having personally benefited so much from the charity of the Society, simply branching off on his own.

Perhaps we have to strain our own eyes as well, to see how Occom, himself, negotiated such conflicts. If there was, as Love suggests, a "misunderstanding," concerning Occom's career 
opportunities, that misunderstanding most certainly lay in the lap of the "Society" which presumed to dictate Occom's future for him. It is assumed from Occom's later writings concerning salary inequities in his "Short Narrative" that he went to Montauk with the understanding that he would be compensated for his efforts. But the possibility exists that Occom was simply making a rhetorical point about the imbalance of pay retroactively. Occom's decision to go to Montauk appears to have been made by himself alone, following a 1749 fishing trip during which the people there invited him to be their teacher. In all likelihood he asked for and expected no external recompense for his efforts. The fact that he stayed on for upwards of eleven years bears this out. In his narrative he writes not only that the Montauk were "very desirous to have me keep a school amongst them," but that he "left it with them to give me what they Pleased; and they took turns to Provide Food for me."86 By his own account, then, the terms of his stay were agreed upon between himself and the Montauk. Occom warmly entered into the patterns of community, kinship, and subsistence that were in accordance with his own upbringing and with ongoing traditions at Montauk. He lived in a wigwam, farmed his own land, moved as the community moved, kept a school for the children (and probably the adults as well), tended to the sick and provided church services and counsel. He married Mary Fowler sometime around 1752 , entering into one of the more influential families of the Montauk region. In his 1761 report to the Colonial Government entitled "An Account of the Montauk Indians on Long Island," he offered a description of a traditional marriage, observing how, "young people and others are allowed to choose companions for themselves. When a young couple conclude to have each other, they acquaint their parents of it, or near relations: and they assist them in it, they generally make a feast \&c. Sometimes the couple themselves make a small feast, and so call few neighbors to eat and drink with them. ${ }^{, 87}$ Marriage is the very first issue Occom addresses in this account ("I shall begin with their MARRAIGES" he writes) ${ }^{88}$ and one wonders if he isn't describing the particulars of his own marriage ceremony in this passage. He became, in the words of Brooks, 
"father, teacher and minister," and a "leader of the community." ${ }^{89}$ Only after a number of years, as Occom's family grew and his chores as spiritual leader expanded, did he perceive that he was performing a valuable service for the Society and bring up the issue of recompense.

As for the Society itself, it was unwilling to loose it's grasp on Occom and in 1750 Wheelock wrote him that, "if you are well to pursue your studies I can't but think it advisable to return to them." He concluded the letter by suggesting that Occom "watch against pride \& selfesteem." Apparently Occom's "eye-strain" had yet to remedy itself because he did not return to his studies. Or at least not in the official capacity that was hoped for by his professed mentors. We have little evidence to tell us what Occom read or if he continued to read at all beyond his correspondences and his excursions into scripture. Occom did, however, take up the trade of bookbinding during his time at Montauk, and it can only be assumed that this occupation allowed him to pursue a course of study on his own, regardless of his professed ailment. When Occom built his house at Mohegan, a visiting David McClure would note that adjoining the guest room was Occom's “library of a handsome collection, brought by him, principally from Great Britain."91 That he continued to remain intellectually engaged with reading and writing throughout his life is evidenced by a 1792 edition of The Writings of Thomas Paine, in which, within the list of subscribers, appears the name "Samson Occom, Brotherton, NY."92

Despite Occom's continued resistance to the wishes of Wheelock and the Society, he remained too valuable a figure for them to simply brush off and cut their losses. So in the summer of his eighth year as the defacto minister to the Indians at Montauk, Occom was given an ordination hearing so that he might continue his work in a more official capacity. That this event was of some significance to Occom as both a personal and a moral victory is perhaps signaled by the fact that it occasioned his most comprehensive journal passage to date, on July 13, 1757. Nevertheless, for various reasons it took yet another two years for Occom's official ordination as a Presbyterian minister to occur, on Aug 29, 1759. Love notes that on this occasion a text was 
given to Occom from which he was to compose a trial sermon. ${ }^{93}$ The text was Psalms 72.9 which reads, "they that dwell in the wilderness shall bow before him; and his enemies shall lick the dust." While such a text probably felt like a natural fit to the Suffolk Presbytery that ordained him, the passage was likely to have driven home for Occom an acute sense of double consciousness. We do not know how he negotiated the subtleties of this assignment, fulfilling the obligations of Christian rhetoric while raising the aspect of his people as, perhaps, something more than savage dust-lickers bowing to colonial dogma. Although he gamely delivered the sermon and received the blessing of the church, his concluding remark in his journal that day bore the traces of ironic reflection, as he penned "thus the solemnity ended, Laus te Deum."94

Once having been ordained, the Society asked of Occom to begin a ministry to the Indians of Oneida in what was still considered to be the wilderness of present day upstate New York. Occom set out on this mission in the summer of 1761, accompanied by his brother-in-law David Fowler. Although his journal of this period breaks off abruptly as he reaches his destination, of interest is a passage dated June 14 as he and Fowler headed south towards New York City in order to catch a ferry back north up the Hudson River. Coming within five miles proximity of the port city, Occom and Fowler were held back on account of a small pox scare. But they were close enough to observe, as Occom writes, the sight of "drunkards Realing and Stagaring in the Streets, others tumbling off their Horses ... And [if] ever a People under the Heavens spoke Hell Language these people did, for their mouths were full of Cursings, Prophaning God, Holy Holy Name-I greatly mistake if these are not the sons and Daughters of Belial." And all this on a Sabbath day. Either the spectacle of white urban life made a huge impression on Occom, or he had been forewarned that the city would present a scene slightly contrary to what Christian practice demanded of its practitioners, and he felt obliged to confirm such an apprehension. I find it unlikely that Occom had yet to witness, firsthand, the strains of hypocrisy that fairly spilled over the lid of colonial dogma where ever one cared to look. But 
perhaps he had yet to see it to such a degree, and he prayed to his God, "Leave me not to Practice the Works of these People." ${ }^{95}$

I wonder if Occom's ordination sermon, in which he was forced into an exhortation rooted in the civilization/savagery binary of his colonial professors, wasn't still on his mind when he penned in his journal that day in New York, "I have thought there were no heathen but the Wild Indians, but think there is some English Heathen, where they Enjoy the Gospel of Jesus Christ. Yea I believe they are worse than ye Savage Heathen of the Wildernesse." If such an observation plays into a colonial rhetoric of savagery and civilization, it also worked to reverse the equation. Occom writes this as though the reaction were spontaneous, a private revelation. But Occom's habitual reticence, viewed alongside such occasional outbursts, takes on a new context when one understands that his journals had a second audience. In a letter from Wheelock to the Reverend George Whitefield dated Nov 25, 1761, Wheelock writes, "My black son Mr. Occom has lately returned from his Mission to the Onoyadas, and the last week I had the Pleasure to see him with one of that nation (who designs to winter with him and Learn the English Language \& teach Mr. Occom Mohawke) and I was agreeably entertained by Mr. Occom's Journal." ${ }^{.96}$ We might understand from this that, at least up until this trip to Oneida, Wheelock was in the habit of reading Occom's journals (and also in the habit of obscuring Occom's ethnicity if it suited his mood, casting him in the same category as the "black" slaves he kept on his estate). If so, then Occom's silences take on a more meaningful weight, and his rare effusions might be seen in a more strategic light. What this unveils for us is yet another layer of transcription that shifts between the hidden and the public, delineating not only the levels of colonial surveillance under which Occom performed, but hinting at the edges of a resistance in which Occom not only subverts the colonial binary within an acceptable framework, but (as evidenced in Wheelock's letter), can be seen forging separate alliances from both without and within the missionary context. One wonders what sort of relationship Occom forged with the 
Oneida representative with whom he winters. Was this part of his own diplomatic endeavor that would lead to his eventually carving out a place for himself in the territory of the Iroquois? And who else but for Wheelock does he write in his journal, "I am glad there is one defect in the Indian Language and I believe in all their Language i.e. they can't curse or swear or take god's Name in Vain in their own Tongue." 97 This observation, expressed for the first time in his journal that day outside the city of New York, would become a repeated theme of Occom's that he would often include in his sermons to mixed Native and white audiences.

The first mission to Oneida lasted only nine weeks in the summer and early fall of 1761 . Even in such a brief time, however, Occom was able to effect a meaningful connection. Not only did a member of the Oneida nation return home with him, but Occom, himself, returned with a belt of wampum put in his trust by a congress of leaders from the Iroquois Confederacy. The wampum belt signified that the parties involved wished to reaffirm their relationship with the English so that they would be bound "fast together in perpetual Love and Friendship." "98 That Occom was still fluent in the cultural traditions of exchange between Native peoples is evidenced by a claim made by Nathaniel Whitaker some years later while both he and Occom were on their way to England. Whitaker asked that the "religious belt" be procured as "it would be of great use to us as Mr. Occom remembers the Speech." ${ }^{99}$ The Mohegan people had long stationed themselves at the source of the wampum trade, and the protocols of its exchange, including the use of wampum as a mnemonic device to recall oral testimony, were probably still well understood by Occom's generation. The passage suggests that Occom was fluent in at least two cultural literacies.

As a missionary, Occom was able to present an idea of English Christianity that did not stand in absolute contrast to Native practice. Although he understood well enough the oppositional binaries under which colonial rule asserted itself, and knew how to articulate his spirituality under sincere and acceptable terms, Occom's own rhetoric was designed to erase such 
binaries or ease their tensions. He had a facility for drawing the hierarchal imperatives of Christian dogma into a space of Native engagement, writing in his account of the Montauk that "they had a notion of one great and good God, that was over all the rest of the gods, which they called CAUHLUNTOOWUT, which signifies one that is possessed with supreme power."100 After death, he maintained, their souls departed westward, "where the righteous, or those that behaved themselves well in this world, will exercise themselves in pleasurable singing and dancing forever."101 Any English reporter, including even Roger Williams who wrote in quite similar language of Narragansett belief systems, would have been repulsed by the whiff of paganism embedded within the image of eternal "singing and dancing," and have chosen an adjective other than "pleasurable" to describe such an afterlife. But Occom's gentle and engaging discourse, as we shall see, offered a syncretic approach to Native and English rhetorical traditions, an approach that was apparently as effective amongst Native peoples as it was with the English. Occom would make brief return trips to the Oneida in 1762 and 1763 , but this final mission was cut short by the outbreak of the event known as Pontiac's War. When he returned home to Mohegan he was able to secure a post teaching to the Niantic in Connecticut and so Occom took this opportunity to move himself and his family back to the country of his birth after having lived away for well over a decade.

There can be little doubt that, when Occom returned to Mohegan, he quickly established a leadership role for himself within the community, despite the fact that he hadn't actually kept a permanent residence there for some twelve years. His very presence seems to have helped galvanize an already tacit resistance to ongoing colonial encroachments made at Mohegan. Occom, merely by setting up shop as he had elsewhere as both teacher and minister, siphoned off whatever cooperation had been afforded the white missionary efforts at Mohegan, as led by David Jewett, and the school master, Robert Clelland. Clelland appears, by all accounts, to have been ineffectual as schoolmaster, and Jewett held property in Mohegan that he stood to forfeit if 
the Mason Land Case went to the Natives. Both were inclined to see Occom as a threat and Clelland wrote to Wheelock in February of 1763 that "Mr. Occom is to be over with his family this Spring and drive Mr. Jewett \& I from Mohegan."102

The letters surrounding this new conflict seem to suggest that even the English population at New London preferred Occom over Jewett. As Wheelock would write to Whitefield on Oct 10, 1764,

the breach between Mr. Jewett and Mr. Occom grows wider-Mr. Jewett's People and a great Number from other neighboring Parishes flock to hear Mr. Occom on Lord's Day at Mohegan \&c the Effect of which you may easily guess. And Mr. Jewett is like to lose all his Land in the parish, if the Indians there should gain their point in their Suit against the Government in an old affair called Mason's Case lately revived ... This together with their Controversy with their School Master has made a great Ferment among them, and Mr. Occom is blamed by some that he will advise the Indians [and] that he will suffer the English to flock to hear him.

As Wheelock's letter supposes, Occom, upon returning home, had re-engaged with the Mason Land Case. The various conflicts swirling around Mohegan found an inevitable point of intersection in these proceedings. The community was fractured. Ben Uncas III, sachem by colonial fiat only, had become little more than a pawn in the interests of the European power structure of the region. The missionary hierarchy at Mohegan and New London, put in place by The Society for the Propagation of the Gospel, was economically invested in the disenfranchisement of Mohegans from their land. And Occom stood in the middle of it all, not as one representing the religious practices of a foreign culture, but as an advocate for the continued cohesiveness of Mohegan community. If the people preferred him over Jewett as spiritual advisor, and over Uncas as counselor in political affairs, it had the effect of destabilizing the entire colonial power structure at Mohegan. As Wheelock saw it, this occasioned a clamor that "spread through the government, and almost everyone cried out against Mr. Occom as a very bad, mischievous, and designing man." 103

Perhaps it is not too cynical, then, to suggest that Wheelock found a means of getting 
Occom out of the picture when it was determined to send the Indian preacher to England in 1766 to raise money for a proposed Indian College. The idea seems to have been floated out as early as 1764, when one Charles Smith, an associate of Wheelock's and one time headmaster of Wheelock's school, suggested "would it not be best to send Mr. Occom with another Person home a begging?" Smith astutely noted that "an Indian minister in England might get a Bushel of Money."104 Wheelock quickly embraced this notion, even while disseminating derogatory comments about Occom to anyone who might listen. In a letter to John Brainerd he asserts that "the blow" given to his school by "sending Mr. Occom back from New York was beyond any it has received from the first." But in the very next breath he advises Brainerd to keep quiet about the plans of "Mr. Occom going with you" to England. ${ }^{105}$ Wheelock at once admits to the symbolic and practical indispensability of Occom, even while acknowledging him as the single largest threat to his own endeavors.

Before Occom could be sent to England, an attempt had to be made to smooth out the controversy that had been built up around him. Occom himself must have sensed the utility of this, and felt that his traveling to England would be worth the hardships risked, because he voices an appropriate degree of regret over his actions, in order to clear a path for himself. The Board of Connecticut Correspondents (a board of Connecticut representatives overseeing Wheelock's missionary efforts, and of which Wheelock was a member, in league with the Society for the Propagation of the Gospel), had accused Occom of misconduct towards "the overseers in the Affair of leasing the Indian Lands, and some proud and haughty Threatenings to turn Episcopalian ... And disrespectful Treatment of the Reverend Mr. Jewet, and illegal proceedings again the School Master at Mohegan, and engaging in the Mason Controversy." ${ }^{106}$ Of all these charges he was acquitted save for the one of most significance to the board which was the charge of meddling in the Mason land case. Of course, it wasn't in anyway illegal for Occom to be involved in this case. It was simply inconvenient from the point of view of the Board. With this 
understanding, Occom offered a carefully worded apology which is transcribed as follows:

Although as a Member of the Mohegan Tribe, and, for many years, one of their Council, I thought I had not only a natural and civil Right, but that it was my Duty, to acquaint myself with their temporal affairs; Yet, I am, upon serious and close Reflexion, convinced, that as there was no absolute Necessity for it, it was very imprudent in me, and offensive to the Public, that I should so far engage, as, of late, I have done, in the Mason Controversy: which has injured my Ministerial Character, hurt my Usefulness, and brought Dishonour upon Mr Wheelock's School and the Correspondents. For this imprudent, rash, and offensive Conduct of mine, I am heartily sorry, and beg Forgiveness of God-of this honorable Board of Correspondents, of whom I ought to have asked farther Advice - and of the Public; determining, that I will not for the future act in that Affair, unless called thereto and obliged by lawful Authority.

The apology is quite thorough, and has been characterized as "humble" and an example of "the firm hand which Wheelock maintained over his disciples." 107 And yet it is worth pointing out that it also has a number of dry, almost sardonic, touches that are typical of Occom. He makes a point of establishing the fact that his involvement in the Mason Case was not only his legal right, but, as he perceived it, a "duty." And although he allows that "serious and close Reflexion" has convinced him that there was no "absolute Necessity" for such conduct, nevertheless he has succeeded in establishing his own context for his actions and positioning himself as a representative of Native space rather than simply a pawn of the Committee. He concludes to not act further on the case "unless called thereto and obliged by lawful Authority," but as he has already made clear in letters to William Johnson and the King of England, he firmly believes that the Mohegan have that lawful authority, and it is the colonial correspondents who have no rightful claim to Mohegan lands. Therefore, it is by no means a stretch to conclude that Occom had promised absolutely nothing. The apology is a means to an end for Occom, the public transcript that allows him to pursue the next step of his career, while at the same time suggestive of the hidden text of Native resistance to colonial power. While this text is clothed in appropriate English language, its inherent tensions cannot be utterly erased. It is reported by Ben Uncas that Occom, himself, "told a squa he had outwitted the ministers" 108 in this event. While this may have been mere hearsay, a rumor Uncas put in motion to further damage Occom's reputation, the 
fact stands that Occom did continue to pursue his involvement in the Mason land case in England and elsewhere and as Brooks relates, this "revelation gives weight to the subtext of Occom's confession, which asserts the primacy of his nativity and his obligation as a councilor to his community." 109 Nevertheless, his way had been cleared to go to England and it was decided that he would be accompanied by Nathaniel Whittaker who was minister of the church at Norwich, CT.

Occom, despite the undeniable tensions inherent in his self-presentations, was ever conscious of the persona he was forwarding in his writings and the social operations it performed. ${ }^{110}$ The first draft of his "Short Narrative" was written as he set out for England in the fall of 1765 , amidst claims from his detractors that his "heathen" credentials were forged. A campaign was underway suggesting that Occom, rather than converting to Christianity in his late teens, had been raised and educated in the Christian religion from birth. Like many non-whites who sought to appropriate and master the white lexicon, Occom proved too expert at his endeavor and therefore found his origins contested. ${ }^{111}$

Occom was placed in the position of emphasizing his "Indianess" to a largely foreign Christian audience that knew nothing about Native culture or customs. As he wrote in the shorter 1765 draft of his autobiography, "Since there is great miss Representation by Some Concerning my Life and Education; I take this opportunity to give the World in few Words, the true Account of my Education." Whether with a sense of irony or not, he bluntly overstates his "heathenism," and speaks in abject terms of his pre-Christian life spent wandering "up and down in the wilderness." He claims, "I was born a Heathen in Mmoyouheeunnuck alias Mohegan in N. London-North America. My Parents were altogether Heathens, and I was educated by them in their Heathenish Notions." He notes that "my Parents in particular Were very Strong in the Customs of their fore Fathers."112 Because his goal was to raise money for the proposed Indian School, he felt compelled to present himself in the manner that he knew to be most efficacious 
toward achieving this goal. When he extended this autobiographical sketch upon his return from England in 1768 , he would leave many of these troublesome phrases intact, but the tone of his account became much more openly critical of the white-European practices that had pressured him into making such concessions.

Still, as Occom waited to set sail from Boston doubts persisted. In a letter to Wheelock, written shortly before his ship sets sail he comments that the Boston Commissioners of the Society for the Propagation of the Gospel "think it is nothing but a Shame to Send me over the great Water ... They further affirm, I was bro't up Regularly and a Christian all my Days, Some say, I cant Talk Indian, others Say I cant read-In short I believe the old Devil is in Boston to oppose our Design. ${ }^{, 113}$ The letter demonstrates the difficult position Occom was in, as an Indian who had embraced Christianity as a political and spiritual path. The arguments against him were mainly of the notion that he was not Indian enough. He must labor to convince those concerned with the mission that he was the genuine article, sprung from the heart of heathenism, despite his refined outer appearance, and it probably began to dawn on him that, as he entered onto a larger stage, a more nuanced performance was required of him. I find it unlikely, for instance, that Occom was in the habit of calling the ocean "The Great Water," but such turns of phrase seem to have crept into his rhetorical mode and became part of the syncretic discourse, or orature, he was adopting as a Native skilled in alphabetic literacy.

But to Occom's credit, he didn't overly pander to such expectations. Occom seems to have been of an abnormally solid character, never argumentative, willing to make certain rhetorical concessions when it suited his purposes, pleasant and engaging in his personal interactions, but in most ways certain of the manner in which he presented himself. He was who he was. And the fact that he felt personally invested in this trip to England might be suggested by the fact that, rather than characterizing it as solely Wheelock's scheme in his letter, he refers to “our Design." He further writes, "I have a Struggle in my Mind At times, knowing not where I 
am going, I don't know but I am Looking for a Spot of ground where my Bones must be Buried, and never to see my Poor Family again, but I verily believe I am called of God by Strange Providence and that is Enough." 114 Perhaps he was familiar with the story of an earlier Native representative sent to England named Pocahontas who never made it home, and whose bones were interred far from the land of her own people at Gravesend. Interestingly, as Occom and Whitaker waited to ship out, we learn that the ship was being held up because of the complications of the Stamp Act controversy and an embargo taking place. There was unrest in the port city. Occom, an Indian dressed as an Englishman, waited to ship out to London. But when he returned, it would be to white men dressed as Indians, throwing tea in the harbor, and calling for a new political power structure in the colonies.

\section{“An Undoubted Call”: A Native Agency For Occom's Tour Of England}

Occom set sail on December 23, 1765 and reached Bricksham, England safely on February 3 of the new year. As he made his way to London he seems to have been impressed, but also steadily appalled by the severe disparity between rich and poor that he witnessed, the overwhelming opulence of the noble classes and the absolute squalor of London's beggar class. He pondered "what great difference there is Between the Rich and the Poor-and What Difference there is Between God's poor and the Devil's Rich." In the streets he noticed "some Cursing Swaring \& Damning one another, others was hollowing, Whestling, talking giggling, \& Laughing, \& Coaches and footmen passing and repassing, Crossing and Cross-Crossing, and the poor Begars Praying, Crying, and Beging upon their kness." ${ }^{\prime 15}$ It seems safe to say that Occom was impressed by the dichotomy between haves and have nots, and in some ways found this a striking comparison to what he understood of the social inequities back home. It may not have escaped his notice that wealth was largely determined by who could claim title to the land. After being brought to watch the pageantry of Queen Charlotte's birthday, he commented to himself in 
his journal, "o Lord God Amighty let not my Eyes be Dazled with the glitering Toys of this World."116

Occom's trip to England was a financial success and something of a public relations coup for Wheelock, despite the fact that Nathaniel Whitaker, the other half of this missionary tandem, was poorly received and quickly overshadowed by Occom's presence. If Indians were a common enough sight in the colonies they were still something of a novelty to the Englishman. And Occom was ever aware of the fact that he was putting on a dog and pony show, even if he refused to fully pander to such expectations. The fact is, he was well liked in England. People came to see one thing but were gratified by the unexpected something other that Occom delivered. One can sense the inherent tension between expectation and the actual thing in a 1767 letter by Reverend Peter Jillard to Wheelock that reads,

It was right to send over Mr. Occom, as a Specimen of the benefit of ye School-As far as I hear he pleases in every Town \& city - So much simplicity appears in the man: So honest, guiless a Temper, with Seriousness in his public Service; So well he speaks in publick, $\&$ so well he acts in private among his friends $\&$ mankind, that he engages their hearts. ${ }^{17}$

The English people were willing to pay good money to see an "authentic" Indian, and although Occom may have subverted their expectations, he nevertheless pleased. The growing demand for Occom amongst the evangelistic set might be intuited in a dialogue recounted in Occom's diary on July, 131766 . He writes, while he was at tea "I seriously asked Mr. Cocks who was to preach at Mr. Whitefield's, he with all gravity Said Mr. Occom, Mr. Occom? Says I, yes, says he, I know nothing of it, says I again, it is So Concluded, says he-so I immediately went, and Preach'd to a Multitude of People, and the Ld gave me Some Strength." 118

Occom was clearly reveling in his success, but he seems to have remained focused on his reasons for being in England, and he never lost sight of the fact that his family was at home, struggling in his absence. A number of plaintive letters remain from his wife Mary, and probably others were written that have not survived. Wheelock had assured Occom that his wife "is, and 
will be, well Supplied." ${ }^{119}$ But Mary Occom, managing eleven children on her own, was having difficulty holding things together, and she reports to Wheelock that her son Aaron "behaves himself so bad that I Cannt keep him."120 She was forced to beg Wheelock for supplies, and in a 1767 letter, she writes "I am out of Corn, and have no Money to buy any with, and am afraid we Shall suffer for want, an Sr. if you will be pleased to help me in my Distress." 121

The second of only two letters that Occom wrote to Wheelock in his two and a half years in England suggests some of the turmoil he must have felt, and perhaps a sense, that despite his many successes, events were slipping away from him. Occom writes,

It has been my lot for a long time to have Sorrow of Heart, I have had Burden upon Burden, Trial upon Trial, Both without and within, far and Near, a General Concern is Riveted in my Heart, for my Poor Brethren According to the Flesh, Both for their Bodies and Souls; my Relations Causes Heavyer Sorrow; Every obstruction and Discouragement to Your School, and every Misconduct and behaviour of Your Indian scholars, Touches me to the quick; More than all these, the Consideration of my poor Family, as it ware, lets my very Hearts Blood; I am ready to Say, I am a Cruel Husband and Father, god has given me a large Family, but they have no enjoyment of me, nor I them for Some Years back, and the Whole Burden and Care of a Large Family of Children lies upon my poor Wife; What adds to my Sorrowful Heart is this, that Whilest I am a Teacher to others, I have Neglected [my] own Children, by my Perigrenations and now my Children are growing up, and are growing Wild, and the Devil has been Angry, yea he has \& is devilish Mad with me, and if he can, he will Drag all my Children into all Manner of Sins and Down to Hell . . . If I was not fully Persuaded and Asure'd that this work was of god, and I had an undoubted Call of god to Come over into this Country, I wou'd not have come over, like a fool as I did, without any Countenance from our Board, but I am Will[ing] Still to be a fool for Christ Sake. ${ }^{122}$

This letter demonstrates the syncretic mode Occom had adopted, melding the traditions of Native oratory with Christian rhetoric. He is not sad but has "sorrow of heart." He equates his personal consternation with the well-being of his people and family as a whole, but emphasizes his personal sense of a "calling" from god that has pulled him away from his people at this time. He also reveals his awareness, once again, that he is the main attraction in an untenable performance where-in his role is highly unstable and kept aloft only by the unfailing balance he brings to it. He laments he will "still be a fool for Christ sake," because this is the only option he is allowed. Which begs the question, what did Occom hope to gain from all this? How did he see it 
furthering the goals of his people? If the ties between he and Wheelock were as strained as they appear from their letters, what made Occom risk so much on the venture? It is clear from Wheelock's correspondences with the Earl of Dartmouth and others, that his intention was to build a school in the country of the six nations where he might raise up missionaries and send them out to "civilize" the wild heathen, as the tracts of land upon which they resided "are now become valuable and may soon be peopled." ${ }^{, 123}$ It is difficult to see how Occom, even with his Christian missionary sense, would regard this as a worthwhile endeavor to the extent that he was willing to leave his large family to its own devices for a number of years. But Occom was not let in on the particulars of Wheelock's design, or if he did know of them, they were discovered in a round about way. It appears from Whitaker's letters that the Mason Case was being followed closely as it came to argument in the London courts. He expresses the hope that, if the colonists were to win the case, the Mohegan, themselves, might be removed to Oneida, or some such territory, in which event "I can't see why Mr. Occom may not join . . . in this request Since it is favorable to your Gov[ernment]; tho he does not know as yet of any Such proposal." Wheelock, himself, sent an agent to London, a Mr. Jackson of Connecticut, to propose just such a solution, and was therefore, behind Occom's back, scheming to have the Mohegan forcefully removed from their lands. ${ }^{124}$ The backhanded nature of this scheme becomes even more insidious when one recalls the repeated remonstrations to Occom to steer clear of the Mason case. Occom scales back his vocal involvement in these proceedings believing that such a course of action will secure an opportunity for the Mohegan to enter into the colonial economy and secure their rights as a landholding people. But all the while Wheelock and his "agents" are lobbying the courts to rule against the Mohegan and have them relocated, thereby opening up lands for white speculation in Connecticut and Iroquoia.

Although there is little indication, in his own correspondences of the time, articulating what it is Occom hoped to gain from his time in England, another letter from Whitaker offers a 
glimpse into Occom's thinking. He writes, "Mr. Occom tells me that there is a large tract of Land on Long Island on ye north Sid[e] not far west of Southhold, which was formerly offered to the Montauk Indians for Montauk, \& which he thinks may be procured for a Small Sum which is handy for fish oysters Clams, \& so that much of the youth's living might be obtained therefrom." 25 Apparently Occom understood that the proposed school was to remain near Mohegan. He had no thoughts of venturing off into distant lands, but rather envisioned an institution that could support both branches of his own family, Mohegan and Montauk, on the traditional lands upon which both people had subsisted for centuries. No doubt he envisioned a role for himself in this institution, and it is not difficult to see how such a program, under Occom's oversight, might have been beneficial for his community. Leon Burr Richardson, the Dartmouth historian who edits the collection of letters from which this passage is extracted, observes in a footnote, without any trace of irony, that "this important asset of Long Island was evidently lost sight of when the site of the college was fixed [my italics]."126 Another case of what might be thought of as "colonial eyestrain" or unwitnessing. Whitaker finishes his letter with the assurance that, "Mr. Occom does not meddle in Masons affair." But this did not prevent Wheelock and himself from "meddling.",127

\section{"The Doctor is Turn'd Heretical": The Declaration of Independence in Occom's "A Short Narrative of My Life"}

Occom came home sometime in the spring of 1768 after spending well over two years in England. His mission raised approximately 11,000 pounds and earned Occom a reputation on both sides of the Atlantic, not necessarily as spokesman or diplomat (which he was), but as a curiosity in the evangelical community. He was in demand by both Native and colonial congregations, and throughout his life he would continue to support himself as an itinerant preacher, always invited to speak wherever he turned up. He would write to Wheelock "I have work enough. I might preach every Day I have so many calls." 128 It was not simply that he was an 
Indian preacher, but that he was the Indian preacher, despite the existence of a handful of others such as Samuel Ashpo in Mohegan and Samuel Niles, the Native preacher in nearby Narragansett. But Occom was both the representative man and the exception, curiously unrepresentative of the presumed shortcomings of his race for many who flocked to see him.

Occom had so successfully dismantled the cultural barriers placed between Indian and colonist that he seems to have alarmed his original benefactors to a degree, forcing them to employ the tools of manifest manners to reconstruct an imaginary, backsliding Occom for the archives. Where-as critics previous to his trip to England were invested in denying Occom's heathen credentials, professing that he had been born and bred to a Christian education, thus explaining his advanced refinement and learning, now Wheelock and other old benefactors saw Occom's essential Indianess as the inevitable cause of his "fall" from grace. "I fear his Tour to England and the Great respect Shewn him there will have the Sad Effect to make him aspire after Grandure \& ease, and prevent his future usefulness," Wheelock wrote to John Thornton, a benefactor in England, in the summer of $1768 .{ }^{129}$ Occom was frequently reminded by his white missionary colleagues to mind his place, to practice humility, and guard against "that Indian distemper, Pride" which was thought to be the downfall of the "tawny races."130 Wheelock further pursued this agenda, writing to another English benefactor, Robert Keen, that Occom's "sails were too high." One of Occom's former supporters and neighbors berated that "The Doctor is turn'd Heretical-abominably erroneous— Occum is become vile indeed a base fellow."131 By 1771 Wheelock had concluded in a letter to Occom that "unless ye manifestation of your Repentance has been very Public, Clear, Strong \& evident to every body your usefulness is near at an End where you are." 132 Not only was it "that Indian distemper, pride"133 that was stirring up so much trouble, but according to Wheelock, Occom had fallen repeatedly into "the Sin of Drunkenss in a public \& very aggravated Manner."134 This flurry of accusations was hurled out in order to distract the community of benefactors in England from Occom's dissatisfaction that 
the money he had raised for the Indian Charity School was now being funneled into the founding of Dartmouth College instead. As David McClure noted in a letter to Wheelock, Occom "complained, but in a friendly manner, that the Indian was converted into an English School \& that the English had crouded out the Indian Youths."135

It is easy to imagine that Occom was bitter about this development and that he rankled under Wheelock's repeated defamations of character. That Occom was able to complain "but in a friendly manner" as David McClure characterized it, demonstrates Occom's admirable composure and politic nature, his apprehension that if he openly demonstrated the extent of his hurt, it would play right into the hands of his detractors. In a much quoted letter to Wheelock, however, Occom expertly expressed his sense of betrayal, stating,

I am very jealous that instead of your Semenary Becoming alma Mater, she will be too alba mater to Suckle the Tawnees ... I verily thought once that your institution was Intended Purely for the poor Indians- - with this thought I cheerfully. Ventured my Body \& Soul, left my Country, my poor young Family all my Friends and Relations, to sail over the Boisterous Sea to England, to help forward your School, Hoping it may be a lasting Benefet to my poor Tawnee Brethren ... I am going to say something further, which is very Disagreeable. Modesty would forgive me but I am Constrain'd So to Write,-Many gentlemen in England and in this Country too, Say if you had not this Indian Buck you would not Collected a quarter of the Money you did. ${ }^{136}$

Occom was fully aware of the central role he'd played in raising funds for the college, and the bitter irony of that bounty now being directed towards the benefit of white instead of Indian students is already perfectly realized in his wordplay transforming "alma Mater" into "alba mater." Such an image confronts not only the racialized hierarchy by which the Natives have once again been cheated out of their possessions, but invokes in stark visual terms prevalent white anxieties regarding miscegenation. Even his reference to himself as "this Indian Buck" suggests the double nature of this anxiety, the sexual allure of the Indian other who has put himself on display, prostituted himself on the colonial stage, but whose progeny will not be entitled to their share of the estate. He concluded his letter by noting "this one consideration gives me great Quietness. I think I went to England with Honest Heart, I think I have done that 
which I think was my Duty to Do." ${ }^{137}$ Occom, as always, positioned his actions firmly in the context of "duty," of advocacy for his people, reminding Wheelock of the ties of ethnicity, kinship, and nationality that he served. Wheelock, by channeling the charity money elsewhere, was risking his own reputation. Occom warns him in the letter that "the opinion of many white People about here is that you have been Scheeming altogether." Nevertheless, Occom is inclined to respond to all this with a sense of "great Quietness." This was both an inward and outward quietness, as Occom's ability to speak, to contest the power structures of colonial America, and resist within the open discursive channels of the day, were, as ever, "constrained." Occom's use of this word, which we will pursue further, is interesting in that he seems to regard such constraints as both the limitation and license of speech.

What enabled Occom to confront Wheelock openly, and ward off coercive appeals for humble apologies and public confessions with "great Quietness," was the fact that, in Occom's mind, the break had already been made from his former school teacher. His benefactors in England had donated their money not only to help the Indians, but because Occom, himself, had made such a positive impression upon them. And Occom correctly guessed that any further support for his endeavors would come from England and not Wheelock. ${ }^{138}$ Upon his return from England, Occom reported directly to Robert Keen that he had traveled around visiting the Indians of the region since his return and that they were "very glad to hear the benevolent dispositions of Christians, over the mighty waters." He voiced their hopes that, by such means, "their poor children's eyes may be opened, that they may see with their own eyes." By appealing directly to Keen, instead of Wheelock, and keeping him informed of his missionary efforts, Occom was effectively cutting out the middleman in the line of funds appropriations for Indian causes. ${ }^{139}$ Occom also remarked to Keen at this time that, "I am now writing a short narrative of my life." ${ }^{140}$ This narrative, which he had begun prior to leaving for England, was likely meant to go into circulation around missionary circles in both England and the colonies. Perhaps it was also 
originally meant to be an addendum to one of Wheelock's many promotional narratives concerning the state of the Indian Charity School. What ever its original intent, the narrative was unable to find a home in the print venues of the day. If it began as an attempt by Occom to establish his heathen credentials to a skeptical community, it ended as something of a declaration of independence from Wheelock and the Connecticut Board of Correspondents with whom he had associated in the past.

I have briefly commented upon Occom's narrative in various portions of this chapter, but I would like to conclude with a consideration of the properties of the "Short Narrative" that appear to speak toward both a public and hidden transcript. Critics who have turned their focus upon this text have concentrated mostly on the opaque declaration at its end, in which Occom seems to test the limits of resistant speech for Indians in the late eighteenth century. Although the text lodges an open complaint in which Occom suggests he has been under-compensated and under appreciated as a missionary worker amongst the "poor Indians," his notice of this inequity does not strike one as necessarily subversive. There is a real danger that the text can be read as simply an appeal for higher wages and, upon initial interpretation, students in my Early American Literature classes have characterized the narrative as "whining" and ineffectual. I strongly doubt, however, that Occom finished this piece with financial considerations in mind at all. If that was all it was, the "Short Narrative" would fail to serve any larger rhetorical purpose or, as Jace Weaver claims, form a "communitist vindication of Natives in general."141 Only at the end when Occom strays from his discursive constraints by suggesting his racial identity as the cause, does this text force an irreconcilable rupture in the colonial narrative, turning a discourse of colonial beneficence into a text of racial discrimination. This rupture begins to reveal itself as Occom asserts, "I am now fully convinced, that it was not Ignorance" that lead to his being undervalued, but rather, "I must Say, 'I believe it is because I am a poor Indian.' I can't help that God has made me So; I did not make myself so." ${ }^{142}$ As with his wry comment referring to 
Dartmouth as "alba mater," Occom has singled out race as the central reason for his being misused.

This statement has given many readers pause. It's semi-contorted wording, with the central claim placed in quotation marks so that it's agency is misdirected, suggests in some manner how "colonialism inscribes itself on the colonized." ${ }^{\text {143 }}$ But it also consciously deploys the racialized paradigms of the day in order to invert them in a veiled and convoluted articulation. Dana Nelson, in her article "I Speak Like A Fool ...," notes the careful couching of Occom's words. He is repeatedly "constrain'd" into saying things he would rather not. He "must say" that if he is treated poorly, it is because he is "“sa poor Indian." In these cases, agency for Occom's speech is clouded and argues for the "structural hegemony of colonization that undercuts Occom's attempt to argue his own worth." Nelson feels that Occom, as Christian missionary, finds himself caught in the double bind of being at once colonizer and colonized and this leads to the "sense of entrapment and division" that one apprehends in his word choice. ${ }^{144}$ I don't disagree with this characterization so much as sense Occom's statements working on a number of different levels at once. David Murray has argued that Occom "actually exploit's the ambiguities of his position as civilized Indian in his writing." But still Murray cautions that it would be "a mistake to assume that in moving to a work authored . . . by an Indian we are necessarily moving further towards or away from an autonomous expression or an authentic voice." ${ }^{145}$ Both authors see Occom's narrative as stretching the boundaries of discourse, reaching "toward a different understanding of his own agency," to quote Nelson, but still confined by the hegemonic forces that allow for such texts to speak from within the archive. ${ }^{146}$

The idea that any voice can be regarded as "authentic" is, of course, problematic and brings into play concerns of what exactly informs an "authentic" speech act anyways, and how can authenticity ever really be determined in any culture. This should not distract us from the possibility, however, of a speaker's asserting agency from within a particular cultural moment, 
even if that agency has been obscured by the narrative framework through which we have habitually regarded it. What I would like to suggest is that, as long as Occom's narrative continues to be viewed from within the colonial archive, from within the narrative framework of western hegemony in which it was housed, it will continue to read as a problematic expression of identity, in which Occom argues for his place in the white missionary structure. Occom's "Short Narrative" was never more than a mute doorstop in this vestibule, however, and deserves to be read from within a narrative of Native continuity to be fully appreciated. When repositioned from colonial space and considered from another angle of vision, the text becomes one of liberation rather than vindication, one of independence rather than indenture.

One first has to imagine why Occom wrote this narrative at all, and for whom. Clearly the idea either occurred to him on his own, or was suggested to him by Wheelock, on the eve of his departure for England. As I've already stated, at that point it was important for Occom to introduce himself to the world stage he was about to enter upon, and to reinforce the important affect that he was, in fact, a former heathen who had fully crossed over to Christian refinement, therefore modeling the efficacy of Wheelock's program. When he wrote to Robert Keen that he was reworking the narrative, upon his return to Mohegan in 1768 , he must have had some other thoughts in mind. Perhaps, at this point, Occom still believed that the money he raised in England would be used to fund a true Indian School, and felt a more detailed narrative of his life would contribute to that endeavor. The narrative, however, does not seem to have found a home in print, nor can we imagine it was ever circulated, until Bernd Peyer retrieved it from the archives at Dartmouth and published it in 1982. Leon Burr Richardson seems not to have known of its existence when he compiled the letters surrounding the England Mission in 1933. He writes of Occom's declared intentions in a footnote, claiming that "apparently this project was never carried out." ${ }^{\text {147 }}$ Neither Love nor Blodgett speak of the "Short Narrative." It remains unclear how the narrative found its way to the Dartmouth archive at all. 
If we look at this document, however, with an eye towards which speech falls under the category of "constrained" and which "unconstrained," we might begin to sense something of its narrative agenda. What seems clear is that the narrative starts one way, and then finishes another. The tone is congenial enough up until the last section, entitled "From the Time I left Mr. Wheelock till I went to Europe." The focus has been on his conversion and, in some manner, the ineffectiveness of white missionary efforts in Native space, as opposed to Occom's own successes. Occom claims of the early missions to Mohegan in his youth that "there was a Sort of School kept, when I was quite young, but I believe there never was one that ever Learnt to read anything." The white missionaries would apparently have to chase down their Indian students, and Occom notes that "he used to Catch me Some times and make me Say over my letters." He describes similar conditions at Montauk, and how it wasn't until the departure of the white missionary there, a Mr. Horton, that there "was a remarkable revival of religion among these Indians." By way of contrast to the white missionary practices, Occom notes how he "took a mild way to reclaim them. I opposed them not openly but let them go on their way, and whenever I had an opportunity, I would read Such pages of the Scriptures." In this manner, he assures his audience, "the Lord was pleased to Bless my poor Endeavors, and they were reclaimed, and Brought to hear almost any of the ministers."

In relating his usefulness, Occom was almost certainly hoping to achieve some measure of agency over how the Indian Charity School would be operated. Wheelock was known to whip his Indian students when they misbehaved. His techniques were rigid, the routines of the charity school tightly regulated. ${ }^{148}$ He locked his students into patterns of dependency and subordination in which they looked to him for all assistance, both spiritual and practical, and he apportioned out only as little of each as he deemed sufficient. ${ }^{149}$ Occom, on the other hand, designed routines as a teacher that were "a Pleasure to them; and they soon learn their Letters this way." The narrative seems to stray from its purpose, however, when he begins to discuss the matter of how 
he made ends meet at Montauk. His many occupations aside from being preacher and teacher for a number of different communities, included bookbinding, farming, hunting, fishing and the making of wares such as wooden spoons, ladles, and gunstocks. He worked cedar into "Pails, Piggins and Churns." He also notes that he attended the sick, performed funeral services, acted as judge, counselor, and scribe. But what begins as an almost Franklinesque testament to his industry and frugality suddenly devolves into a discourse on the pay inequities between himself and white missionaries, until he is no longer referring back to past events, but exclaims in some frustration, "I Can't Conceive how these gentlemen would have me Live."

In a sense, Occom was a practitioner of the ethos of self-improvement and self-reliance that Benjamin Franklin would articulate in his Autobiography some twenty years later. But where-as Franklin endeavored to perform his labors beneath the public eye, thereby winning the esteem and economic support of his community, Occom labored at the peripheries of the colonial field of vision. Both were statesmen, counselors, leaders of their respective communities who devoted a considerable amount of their time and energy to civic-minded programs. The public eye that approved and rewarded Franklin's staging of industry, however, was wholly disinterested in the similar performance of a Christian Indian. ${ }^{150}$

The only possible audience for Occom's narrative, at this point, were the commissioners in England who continued to support him. And it is likely that, once the prospect of the Indian School at Montauk fizzled out, and he was granted a stipend by Keen, the reasons for constructing such an account dried up. At which point Occom's speech becomes, in his own words, "constrained." He is forced to speak in a way that he would rather not, and yet this constraint, or outside force, is what, in effect, liberates him to speak. He writes,

In my Service (I speak like a fool, but I am Constrained) I was my own Interpreter. I was both a School master and Minister to the Indians, yea I was their Ear, Eye \& Hand, as well as Mouth. I leave it with the World, as wicked as it is, to Judge, whether I ought not to have had half as much, they gave a young man Just mentioned which would have been but Ib 50 a year; and if they ought to have given me that, I am not under any obligations to them, I owe them nothing at all. 
I find Occom's deployment of the word "constraint" rather paradoxical. He has learned to perform in a world in which his speech and textual expressions are carefully modulated bits of orature, and are always, in fact, constrained. Only in the moments that he acknowledges these constraints, however, does he allow himself to gesture towards what I continue to refer to as the hidden transcript, or the carefully concealed agenda of Mohegan resistance which has informed Occom's actions from the very start. He uses the notion of constraint to actually untether the constraints of speech, and to, in fact, clear the obstructions from the "Ear, Eye \& Hand as well as Mouth," that have prevented him from speaking fully for his people. Ultimately, what I believe has been overlooked by the critical reception of this text, is Occom's blunt assertion to the missionary community of New England (and to "the World"), that "I am not under any obligations to them, I owe them nothing at all." He is not asking for more pay, but making a clean break.

He punctuates his narrative with an anecdote about a "Poor Indian Boy" who is called by his master to account for the beatings and whippings he has received at the hand of the young man to whom he has been indentured. Occom writes that the boy was asked,

what it was he did, that he was So Complained of and beat almost every Day. He Said, he did not know, but Supposed it was because he could not drive [a plow] any better, but says he, I Drive as well as I know how; and at other Times he Beats me, because he is of a mind to beat me; but says he believes he Beats me for the most of the Time 'because I am an Indian'.

I would like to venture that the nineteenth century Pequot minister, William Apess, would have appreciated this little parable, although it is doubtful he would ever have had the opportunity to have read it. The boy offers up the only explanation that has been made available to him, even though it fails to in any way address the matter at hand. He must speak as though he were in agreement with such a reality when, in fact, the two components of the verbal equation in no way connect. It is not the boy's behavior that merits his violent treatment, but the arbitrary matter of his race. Nevertheless, he must speak as though the two were the same. 
Occom ultimately equates his own circumstances with those of the Indian boy, noting that he must say he receives lesser pay than the white missionaries for the very same, seemingly arbitrary, reason. That in both cases the words "because I am an Indian" are in quotation marks points to the manner in which this utterance is forced upon the Native speaker, who is constrained to echo the justification of the colonial master. Must he use this excuse because it is the only possible justification available, or must he use it because the oppressive culture from within which he inscribes this protest allows him no other alternative discourse? Even the assimilated preacher, whose actions have gained him an international reputation, is constrained to refer to himself as a "“"poor Indian." Occom is in effect defusing this discursive containment even as he deploys it, bringing into the open the racialized underpinnings of a term that is most often invoked out of a sense of altruistic sympathy. He also uses the parable of the Indian boy who is "whipt and Beat" to unveil the paper thin layer of rhetoric that separates the Native from the African slave in colonial New England.

Occom's "Short Narrative" was never published, but languished amongst Wheelock's letters at Dartmouth until the late twentieth century. It seems quite likely, however, that Occom frequently used parables, such as the one of the Indian boy, in his sermons when he traveled about as an itinerant minister. Taken out of its colonial context and reconsidered as a parable told to other Native communities, suddenly the story becomes not only infused with irony, but registers as darkly humorous. It would have had a special resonance for those who labored under such conditions that the boy describes, and lived daily with the broken logic, the paradoxical rhetoric, of colonial oppression. We know from second hand reporting that Occom peppered his sermons with such stories, even if they did not find their way into print. Occom did note for the record that

the Sermons that are delivered every Sabbath in general, are in a very high and lofty stile, so that the common people understand but little of them. But I think they can't help understanding my talk; it is common, plain, every-day talk: Little children may understand me. And poor Negroes may plainly and fully understand my meaning; and 
it may be of service to them. Again, it may in a particular manner be serviceable to my poor kindred the Indians. ${ }^{151}$

It is not unlikely that Occom's sayings and stories were remembered amongst the Mohegan community, as well as other neighboring communities, until well after his death. 
${ }^{1}$ Melissa Jayne Fawcett., The Lasting of the Mohegans (Uncasville, CT: The Mohegan Tribe, 1995), 6.

${ }^{2}$ Craig Womack, Red on Red: Native American Literary Separatism (Minneapolis: University of Minnesota Press, 1999), 57.

${ }^{3}$ Womack, Red on Red, 87.

${ }^{4}$ Fawcett, Lasting of the Mohegans, 6.

${ }^{5}$ Ibid., 6.

${ }^{6}$ Ibid., 6.

${ }^{7}$ Robert Warrior, Tribal Secrets: Recovering American Indian Intellectual Traditions (Minneapolis:

University of Minnesota Press, 1995), 2.

8 Ibid., 3.

${ }^{9}$ Tbid., 91.

${ }^{10}$ Derrida, Jacques, Archive Fever: A Freudian Impression. Trans. Eric Prenowitz (Chicago: University of Chicago Press, 1996), 2.

${ }^{11}$ See Major John Mason's "A Brief History of the Pequot War" in which he decrees "The Pequots were then bound by Covenant, That none should inhabit their native Country, nor should any of them be called Pequots anymore, but Moheags and Narragansett forever" (40). According to Mason, God burned the Pequot "in the fire of his Wrath ... Dunging the Ground with their Flesh" (35). See also chapter two of this dissertation. John Mason, "A Brief History of the Pequot War," History of the Pequot War, ed. Charles Orr (Cleveland: Helman-Taylor Co., 1897).

12 Derrida, Archive Fever, 31.

${ }^{13}$ Sigmund Freud, The Interpretation of Dreams, trans. A. A. Brill (New York: The Modern Library, 1950), 165.

${ }^{14}$ In $1819 \mathrm{~W}$. Channing calls for a new American literature that views the figure of the Native American as the organic expression of the essentially American qualities that must be assumed. See Carol Karcher's introduction to Lydia Maria Child, Hobomok and Other Writings on Indians. ed. Carol L. Karcher (New Brunswick, NJ: Rutgers University Press, 1986), xvi.

${ }^{15}$ Larzer Ziff, Writing in the New Nation: Prose, Print, and.Politics in the Early United States (New haven, 
CT, Yale, 1991) $x$.

16 Derrida, Archive Fever, 13-14.

${ }^{17}$ Gerald Vizenor, Fugitive Poses: Native American Indian Scenes of Absence and Presence (Lincoln: University of Nebraska Press, 1998), 20.

18 James C. Scott, Domination and the Arts of Resistance: Hidden Transcripts (New Haven: Yale university Press, 1990), xii.

19 Scott, Domination, 87.

20 Scott, Domination, 90.

21 Homi Bhabha, The Location of Culture (New York: Routledge, 1994), 113-114.

22 Judith Herman, Trauma and Memory: The Aftermath of Violence-from Domestic Abuse to Political Terror (New York: Basic Books, 1992), 9.

${ }^{23}$ Thomas Wheeler, "A Thankful Remembrance of Gods Mercy To Several Persons at Quabaug or Brookfield," So Dreadful a Judgment: Puritan Responses to King Philip's War. Eds. Richard Slotkin and James K. Folsom (Hanover, NH: University Press of New England, 1978), 248-249.

24 See Neal Salisbury, "Introduction: Mary Rowlandson and Her Removes," The Sovereignty and Goodness of God by Mary Rowlandson with Related Documents. Ed. Neal Salisbury (Boston: Bedford/St. Martins, 1997), 27. Salisbury notes how it is the praying Indians in particular who receive the harshest criticism from Rowlandson and others.

${ }^{25}$ James Axtell, After Columbus: Essays in the Ethnohistory of Colonial North America (New York: Oxford University Press, 198), 54.

26 Scott, Domination, 67.

27 Ibid., 160.

28 Womack, Craig, Red on Red, 77-78.

29 W. Deloss Love, Samson Occom and the Christian Indians of New England, ed. Margaret Connell Szasz (Syracuse: Syracuse University Press, 2000,1899), 19. 
${ }^{30}$ Jean $O^{c}$ Brien, Dispossession By Degrees: Indian Land and Identity in Natick, Massachusetts, 1650-1790 ( New York: Cambridge University Press, 1997), 127.

${ }^{31}$ O'Brien, Dispossession By Degrees, 127. O'Brien describes her project as one of listening for "Indian voices in documents that had been produced for other purposes." 127.

32 Bragdon, Kathleen J. "Crime and Punishment Among the Indians of Massachusetts, 1675-1750."

EthnoHistory 28/1 (winter 1981), 23.

${ }^{33}$ Harold W. Van Lonkhuyzen, "A Reappraisal of the Praying Indian: Acculturation, Conversion and Identity at Natick, Massachusetts, 1646." New England Encounters: Indians and Euroamericans ca 16001850: Essays Drawn from New England Quarterly, ed. Alden T. Vaughan (Boston: Northeastern University Press, 1999), 217.

${ }^{34}$ Ibid., 222.

${ }^{35}$ Ibid., 224.

${ }^{36}$ Ives Goddard and Kathleen Bragdon, Native Writings in Massachusett (Philadelphia: The American Philosophical Society, 1988), 11.

${ }^{37}$ I assume the "Waban" who was town clerk throughout this period is, in fact, Thomas Waban, who was among the first cultural intermediaries to train with Eliot in the 1640's. By the 1720's he would have been in his seventies, assuming he was about ten when Eliot undertook his scholastic training. He is succeeded by yet another Thomas Waban who becomes influential in town politics in the second decade of the eighteenth century. The first Waban of colonial record probably passed away sometime in the decade following King Philip's War. See Samuel G Drake, Biography and History of the Indians of North America, From its First Discovery (Boston: Benjamin B. Mussey \& Co., 1841), 180.

${ }^{38}$ See Drake, Biography and History of the Indians, 179-180.

${ }^{39}$ Bragdon, Goddard, Native Writings, 277.

${ }^{40}$ Ibid., 301.

41 According to Perry Miller and Thomas H. Johnson there was "no questioning that men who would not serve the purposes of the society should be whipped into line" in Puritan New England. Perry Miller and Thomas H. Johnson "The Theory of the State and of Society," Essays on American Colonial History second edition, ed. Paul Goodman (New York: Holt Rhinehart and Winston, 1967), 118.

${ }^{42}$ Kathleen J. Bragdon, "Crime and Punishment Among the Indians of Massachusetts, 1675-1750." EthnoHistory 28/1 (winter 1981), 25. 
${ }^{43}$ Ibid., 27.

44 Ibid., 25.

${ }^{45}$ Bragdon, Goddard, Native Writings, 273.

${ }^{46}$ Laurel Thatcher Ulrich notes that in colonial New England the law dictated that "land and livelihood ... were normally transmitted from father to son" save under extraordinary circumstances. Laurel Thatcher Ulrich, Goodwives: Image and Reality in the Lives of Women in Northern New England, 1650-1750 (New York: Vintage Books, 1980), 36.

${ }^{47}$ Bragdon, Goddard, Native Writings, 321.

${ }^{48}$ Van Lonkhuyzen, Harold W. "The Praying Indian," 221.

${ }^{49}$ Bragdon, Goddard, Native Writings, 14.

${ }^{50}$ Ibid., 19.

${ }^{51}$ See Ford, John W. Ford, Some Correspondence Between the Governors and Treasurers of the New England Company (New York, Burt Franklin, 1970, 1896), 64.

${ }^{52}$ Bernd Peyer, The Tutor'd Mind: Indian Missionary Writers in Antebellum America (Amherst: University of Massachusetts Press, 1997), 14.

${ }^{53}$ Bragdon, Goddard, Native Writings, 14.

54 Ibid., 33.

55 Ibid., 33.

${ }^{56}$ Ibid., 373.

${ }^{57}$ This phrase is coined by Charles Edward Banks who wrote a history of Martha's Vineyard in the first decade of the twentieth century. He refers to the natives as "a people without record or civilization, but to whom it [Martha's Vineyard or Noe-pe as the indigenous inhabitants called it, meaning "middle of the water"] was a home." Charles Edward Banks, History of Martha's Vineyard Mass, vol. 1 (Edgartown: Dukes County Historical Society, 1966, 1911), 32. 
59 Ibid., 373.

${ }^{60}$ David J. Silverman, Faith and Boundaries: Colonists, Christianity, and Community Among the Wampanoag Indians of Martha's Vineyard, 1600-1871 (New York: Cambridge University Press, 2005), 50.

${ }^{61}$ Bragdon, Goddard, Native Writings, 6.

${ }^{62}$ Banks, History of Martha's Vineyard, 53.

${ }^{63}$ The authors claim that the Massachusetts language became "extinct" in the nineteenth century and they have reassembled the language from archival sources. Bragdon, Goddard, Native Writings, xix.

${ }^{64}$ Bragdon, Goddard, Native Writings, 97.

${ }^{65}$ Silverman's discussion on this occurs in Silverman, Faith and Boundaries, 141-148.

${ }^{66}$ Silverman, Faith and Boundaries, 143.

${ }^{67}$ Love, Samson Occom, 298. When Love refers to Occom as the "Indian Moses" I believe he is echoing a common sentiment that was understood amongst the evangelical communities that remembered Occom and attempted to place his acts within a Christian paradigm.

${ }^{68}$ Ibid., 152.

${ }^{69}$ Ibid., 153.

${ }^{70}$ Bernd Peyer, The Elders Wrote: An Anthology of Early Prose by North American Indians, 1768-1931 (Berlin: Dietrich Reimer Verlag, 1982) and Peyer, "Samson Occom: Mohegan Missionary and Writer of the $18^{\text {th }}$ Century," American Indian Quarterly 6.3-4 (1982), 215.

${ }^{71}$ David Murray, Forked Tongues: Speech, Writing and Representation in North American Indian Texts (Bloomington, IN: Indiana University Press, 1991), 57. Also Dana D. Nelson, "'(I Speak Like A Fool But I Am Constrained)' Samson Occom's Short Narrative and the Economies of the Racial Self," in Early American Native Writing, New Critical Essays, ed. Helen Jaskoski (Cambridge: Cambridge University Press, 1996).

${ }^{72}$ Jace Weaver, That the People Might Live: Native American Literatures and Native American Communities (New York: Oxford University Press, 1997), 49-53. 
${ }^{73}$ Love, Samson Occom, 37.

${ }^{74}$ Ibid., 21.

75 Occom, "A Short Narrative," OP at Dartmouth, 1768.

${ }^{76}$ David McClure and Elijah Parish, Memoirs of the Reverend Eleazar Wheelock, D. D. (New York: Arno Press, 1972, 1811), 16.

77 Margaret Connell Szasz, Indian Education in the American Colonies, 1607-1783 (Albuquerque: University of New Mexico Press, 1988), 196-97.

${ }^{78}$ Lisa Tanya Brooks, The Common Pot: Indigenous Writing and the reconstruction of Native Space in the Northeast, A Dissertation Presented to the Faculty of the Graduate School of Cornell University (Ann Arbor, MI: UMI and Proquest Information and Learning, 2004), 93.

79 Fawcett, Lasting of the Mohegans, 17-18.

${ }^{80}$ Occom, Samson. OP at Dartmouth College. Dec. 1743.

${ }^{81}$ Love, Samson Occom, 38.

${ }^{82}$ OP at Dartmouth College, Sept 17, 1744.

${ }^{83}$ Love, Samson Occom, 42.

84 Ibid., 39.

85 Ibid., 44.

${ }^{86}$ OP at Dartmouth College, 1768.

${ }^{87}$ Samson Occom, "An Account of the Montauk Indians, of Long Island." Collections of the Massachusetts Historical Society (CMHS) ser. 1:10 (Boston: Munroe \& Francis, 1806, 1761), 107-108.

88 Ibid., 106. 
Love, Samson Occom, 48.

${ }^{91}$ From the diary of David McClure, May 8, 1764. Quoted in Love, Samson Occom, 101. This collection of books was apparently purchased in England with the intent to create a library for the Indian School that Wheelock had proposed. The books remained in Occom's possession, however, as Wheelock never opened the school that he had proposed to Occom. See Harold Blodgett, Samson Occom (Hanover: Dartmouth College Publications, 1935), 107.

92 See The Subscribers List to the 1792 edition of The Writings of Thomas Paine in Early American

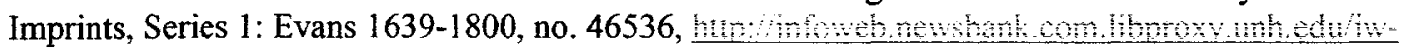
search/we/Evans?

${ }^{93}$ Love, Samson Occom, 50.

${ }^{94}$ OP at Dartmouth College, Aug 29, 1759.

${ }^{95}$ OP at Dartmouth, June 14, 1761.

${ }^{96}$ Quoted in Love, Samson Occom, 98.

${ }^{97}$ OP at Dartmouth College, June 14, 1761.

${ }^{98}$ Love, Samson Occom, 93.

99 An Indian Preacher in England, ed. Leon Burr Richardson (Hanover, NH: Dartmouth College Manuscript Series, 1933), 74.

${ }^{100}$ Occom, "An Account of the Montauk," 109.

101 Occom, Samson. "An Account of the Montauk," 110. Both descriptions of a deity and the description of heaven bear a fairly remarkable resemblance to Roger Williams' account of Narragansett spirituality in A Key to the Language of America. This either implies that Occom had read Williams and is echoing a certain brand of colonial rhetoric, or, given his intimate knowledge of Montauk custom, he is unintentionally reaffirming the veracity of Williams' observations.

102 The Letters of Eleazar Wheelock's Indians, ed. James Dow McCallum (Hanover: Dartmouth College Manuscript Series, 1932), 39.

${ }^{103}$ An Indian Preacher in England. Eleazar Wheelock to George Whitefield May 4, 1765, 30. 
${ }^{104}$ An Indian Preacher in England. Charles Smith to Eleazar Wheelock March 30 1764, 20.

${ }^{105}$ An Indian Preacher in England. Wheelock to Brainerd Jan 14, 1765. 26.

106 An Indian Preacher in England. From the minutes of the Connecticut Correspondents Mar 12, 1765, 28.

${ }^{107}$ Love writes "Samson Occom, who was morbidly sensitive, loaded this sin upon this honest soul and did humbly ask forgiveness." Love, Samson Occom, 128. The "firm hand" quote belongs to Leon Burr Richardson who edits the compilation of letters surrounding Occom's trip to England in An Indian Preacher in England. (see fn p. 29).

${ }^{108}$ Brooks, The Common Pot, 117.

109 Ibid.,117.

110 Dana D. Nelson argues that the confusion in Occom's self-presentation is a gesture "toward a selfaffirming articulation of identity that later would be evidenced more explicitly in Occom's actions toward Wheelock and the Christian missionary project." Nelson, "(I Speak Like A Fool But I Am Constrained)', 43. I agree with this assessment, but $I$ think it fails to acknowledge that Occom was consciously participating in a performance to establish his "Indian" credentials for the nay-sayers who sought to sabotage his mission to England.

111 See Indian Preacher in England, ed. Leon Burr Richardson.

112 WP, A Brief Narrative Sketch. Nov 28, 1765.

113 Indian Preacher in England. Occom to Wheelock Dec 6, 1765, 75.

114 Ibid., 75.

${ }^{115}$ OP at Darmouth College. Occom's Journal Mon Feb 10, 1766.

${ }^{116}$ OP at Dartmouth College. Journal Passage Thurs. Feb 20, 1766.

117 An Indian Preacher in England. Jillard to Wheelock Mar 2, 1767, 27.

${ }^{118}$ OP at Dartmouth July, 13, 1766. 
122 Ibid.,220.

123 Ibid.,162.

124 This is all somewhat obliquely laid out in Whitaker's lengthy Jan 20, 1767 letter to Wheelock. He refers to Mr. Jackson as Wheelock's "agent" and suggests that the solution of a removal would "be best for the Indians" regardless of the fact that the Mohegan are assuredly not advised of such an option, and it begs the question, how were they to be removed? And what would be done if they refused this invitation? The implication here is that the policy of Indian removal, already practiced in some small measure by the Puritans, has direct ties to Wheelock and the missionary endeavor. See Indian Preacher in England 203209.

${ }^{125}$ Ibid.,219.

126 Ibid.,221.

127 Occom probably did meet with Mason while he was in England, although the details of this are unclear. It appears that Mason, who had fallen into abject poverty while pleading his case in England, hoped to acquire funds from Occom to return home. The reporting on this is all second hand, however, made in imputations from Robert Keen to Nathaniel Whitaker. Occom remained silent on the issue, and Mason died from impoverished circumstances in England. See Indian Preacher in England 295-296.

Blodgett, Samson Occom, 133.

129

Indian Preacher in England, 351.

130 The "Indian distemper" quote is from a letter by Wheelock to Nathaniel Whittaker Nov 28, 1767, and can be found in An Indian Preacher in England, 321. Occom himself frequently uses the term "tawny races" to refer to indigenous peoples, as will be seen in further letters, and it is much in practice at the time.

${ }^{131}$ Blodgett, Samson Occom, 116.

132 Indian Preacher in England, 352-353.

133 Ibid.,321. 
134 Ibid.,357.

135 Ibid.,354.

136 Blodgett, Samson Occom, 122-124.

137 Ibid., 124.

138 Occom would in fact receive an annual stipend from Thornton who concluded that "Occom was the Instrument under God that was the means of collecting all the Money $\&$ had the Doctor (Nathaniel Whitaker) come without him the disgrace would have all fell to his share, whereas poor Occom proved the Scape Goat." Blodgett, Samson Occom. 127.

${ }^{139}$ Indian Preacher in England, 348.

140 Ibid.,348.

141 Weaver, That the People Might Live, 52. I do not feel as though Weaver backs up this claim with any substantial evidence, but I believe he reads it correctly nonetheless, having taken the care to regard Occom's career from a perspective that has deconstructed the colonial framework that has constrained it. I hope my reading will offer more concrete details to back up Weaver's assertion.

142 Occom Papers at Dartmouth.

143 Henry Louis Gates. Quoted in Nelson, "(I speak Like a Fool)", 42.

144 Ibid.,60.

145 Murray, Forked Tongues, 57.

146 Nelson, "(I Speak Like a Fool)", 61.

147 An Indian Preacher in England, 348.

${ }^{148}$ See David McClure and Elijah Parish, Memoirs of the Reverend Eleazar Wheelock, D. D. (New York: Arno Press, 1972, 1811).

149 Dana Nelson does a wonderful job of describing this dynamic in her article. Nelson, "(I speak Like A 
Fool)".

${ }^{150}$ In Franklin's autobiography he famously notes how "I took care not only to be in Reality Industrious and frugal, but to avoid all Appearances of the Contrary," and notes how he sometimes "brought home the Paper I purchas'd at the Stores, thro' the Streets on a Wheelbarrow" so that his neighbors would have cause to remark on his thriftiness. Ben Franklin, "The Autobiography of Ben Franklin," The Heath Anthology of American Literature, vol A, ed. Paul Lauter (Boston: Houghton Mifflin Company, 2006, 1791), 870.

${ }^{151}$ From the preface to Samson Occom, A Sermon Delivered at the Execution of Moses Paul, An Indian, Early American Imprints, Series 1, Evans Digital Display.

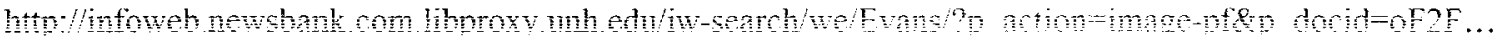




\title{
CHAPTER-5
}

\section{O' BROTHERTON WHERE ART THOU: BROTHERTON, COOPERSTOWN AND THE PERSISTENCE OF PLACE IN THE AMERICAN WILDERNESS}

\begin{abstract}
He would be a rash prophet who should assert that the expansive character of American life has now entirely ceased. Movement has been its dominant fact, and, unless this training has no effect upon a people, the American energy will continually demand a wider field for its exercise. But never again will such gifts of free land offer themselves.
\end{abstract}

Frederick Jackson Turner

Silence a people's stories and you erase a culture. To have graphic evidence of this phenomenon, all we have to do is look at a map. Mapping is, of course, an intensely political enterprise, an essential step toward appropriation and possession. Maps write the conquerors' stories over the stories of the conquered.

Louis Owens

My friends, look around and consider the goodness of the Lord. Behold this was once a wilderness wide. Now it blossoms like a rose.

Joseph Johnson

\section{A Tale of Two Settlements: Forging "A Body Politick" in the American Wilderness}

The following is a plan for the development of Brotherton, NY, as taken from the journal of one of its founding citizens, who was present at the drawing up of said plan on Monday November 7, 1785:

we proceeded to form into a Body Politick - we Named our Town by the Name of Brotherton ... J. Fowler was chosen clarke for the Town. Ralph Waupieh, David Fowler, Elijah Wympy, John Tuhy, and Abraham Simon were chosen a Committee or Trustees for the Town, for a year and for the future, the committee is to be chosen Annually. - and Andrew Accorrocomb and Thomas Putchauker were chosen to be Fence Viewers to continue a year. Concluded to have a Centre near David Fowlers House, the main Street is to run North \& South \& East and West, to cross at 
the centre. Concluded to live in Peace, and in Friendship and to go on in all their Public Concerns in Harmony both in their Religious and Temporal Concerns, and everyone to bear his part of Public Charges in the Town.

The plan-civic minded, quaint in its lack of formality and the apparent intimacy of its designers, loaded with the ideological language of a fledgling Democracy — is in many ways representative of the spontaneous and provisional formation of frontier towns in late eighteenth and early nineteenth-century America. It draws to mind Caroline Kirkland's 1839 description of the conception of Montacute, MI, when she incredulously observes how in a whirl, "my husband purchased two hundred acres of wild land ... and drew with a piece of chalk on the barroom table at Danforth's the plan of a village."1 The period directly following the Revolutionary War was infused with this sense that the American continent had been opened up, there was land for the taking, and enterprising frontiersmen and women might have a hand in drafting both the political and natural landscapes of the communities they would inhabit. One might literally delineate the contours of a projected settlement as though summoning its form fresh from the architecture of dreams.

It was a dream, however, that held fast to the enlightenment values from which it had sprung a dream of imposed order, a palimpsestic reimagining of space that privileged European style "improvements" over the traditional patterns of land use practiced by the indigenous peoples of the region. In the simple outline provided for Brotherton, with its main thoroughfares conforming to the points of the compass (its "main Street is to run North \& South, East \& West"), we may discern the beginnings of a grid mapped out to accommodate traffic and commerce. A "centre" is demarcated in this otherwise tractless domain affording a point from which future construction might spill out. In other words, the town does not simply spring up in haphazard fashion based on the immediate exigencies of the first ground breakers, but is the result of careful foresight and hopeful visions.

William Cooper, father of James Fenimore Cooper, who claimed to have "settled more 
acres than any man in America"2 first scouted out the land that would become Cooperstown in 1785. In his posthumously published tract $A$ Guide in the Wilderness, he writes, "In May, 1786, I opened the sales of 40,000 acres, which in sixteen days were all taken up by the poorest order of people."3 Always with an eye toward the larger-than-life construct of his legacy and the frontier mythology that would spring up around it, he would claim a certain primacy by asserting that the Ostego tract was "the first settlement I made, and the first attempted after the revolution." Despite the mad and opportunistic rush for land that followed, the elder Cooper had firm ideas about how his town should be structured and managed. He sold small, closely compacted lots, claiming that "every part of the land by this means is made to contribute to the common stock of labor, cooperation, and general improvement." ${ }^{\circ 5} \mathrm{He}$ felt it essential that the settlers be grouped close together and that the tracts be apportioned equally rather than held in reserve for a time when the land value would increase. He cautioned that "if fifty thousand acres be settled, so that there is but one man upon a thousand acres, there can be no one convenience of life attainable; neither roads, school, church, meeting, nor any other of those advantages, without which man's life would resemble that of a wild beast." ${ }^{\prime 6}$

One finds a rearticulation of this vision of futurity taking form in James Fenimore Cooper's The Pioneers, where the younger Cooper writes of the early settlement of Templeton, NY, a fictionalized version of Cooperstown. He remarks how the first rude buildings of the town, although "chiefly built of wood, and which, in their architecture, bore no great marks of taste," were nevertheless "grouped in a manner that aped the streets of a city, and were evidently so arranged, by the directions of one, who looked to the wants of posterity, rather than to the convenience of the present incumbents."7 Templeton/Cooperstown, from its moment of conception, is (dare I say) always already a vision of order stamped upon wilderness, a temple to the processes of civilization with Judge Temple's home at its imagined center.

Brotherton, too, had its town center placed in direct proximity to its leading family, the 
Fowlers. The town plan prioritizes the election of "fence viewers," who were likely meant to maintain and enforce the integrity of apportioned property lines. Social institutions are immediately established. Written into the town's provisional charter is the egalitarian premise that one and all are involved in the governance and maintenance of the town's interests. By effecting these designs, which are still-at least at the point where we encounter them-mere notes scribbled on a piece of paper, the town fathers imagine seeds of carefully cultivated order sprouting out into lasting democratic institutions. The founders of Brotherton, not satisfied with the mere technical development of their settlement, conclude to "live in peace, and in Friendship and to go ... in harmony both in their Religious and Temporal concerns."

In Templeton/Cooperstown we also find how the very construction of the town, with its "academies and minor edifices of learning" and particularly its churches of various denomination, might present "to the eye of a stranger . . . that variety of exterior and canonical government which flows from unfettered liberty of conscience." ${ }^{, 8}$ James Fenimore Cooper concludes his initial description of the settlement with a nod not only to the natural outpourings of its egalitarian spirit, but to the immediate sense of growth and flux inherent in the system. He writes, "In short, the whole district is hourly exhibiting how much can be done, in even a rugged country, and with a severe climate, under the dominion of mild laws, and where every man feels a direct interest in the prosperity of a commonwealth, of which he knows himself to form a part." Here was a sense, then, that democracy had taken its show on the road, and wherever its players dug in their tent stakes, there might it be performed again with its three rings of government still intact. As Benedict Anderson has formulated, the late eighteenth century harbored a notion that nations, once created, "became 'modular,' capable of being transplanted, with varying degrees of self-consciousness, to a great variety of social terrains." ${ }^{\prime 10}$

Brotherton and Cooperstown were geographical and historical neighbors, incorporated within two years of one another on the collapsing verge of what had been the domain of the Six 
Nations of the Iroquois. ${ }^{11}$ And, as I have indicated, the motivating principles behind their founding are similar in regards to the rhetoric deployed in their initial stages of planning. We might be inclined to view these two settlements side by side as historically representative examples of the ideological mobility of nationhood in the early days of our country, save for the slight omission of three words, obscured only by an ellipsis that $I$, myself, am guilty of embedding in the first sentence of the Brotherton document (which you may be pleased to refer back to at this point). Were we to repair the ellipsis we would find the words, "in Indian Eeyamquittoowauconnuck," which was how the Native American citizens of Brotherton would have pronounced the name of their newly formed village. ${ }^{12}$

The description of Brotherton's foundational schemata is taken from the diaries of Samson Occom, the Mohegan preacher and a contemporary of William Cooper. ${ }^{13}$ Occom, the ostensible leader of a group of Christianized Connecticut Natives, would become the figure most commonly associated with the Native emigration to Brotherton in the 1780's. There is, of course, very little precedent in the shaping of America's own national mythology allowing for the efforts of Native Americans emigrating westward to carve out ordered settlements in the "wild" frontier. In an era when white speculators like Cooper were buying up land in droves, most Native American communities east of the Susquehanna were, not coincidentally, experiencing a reverse phenomenon, finding their traditional, as well as legal, holdings shrinking down to virtually nothing. The settling of Cooperstown and Brotherton offers a remarkable instruction in contrast, denoting how the ideology that so invigorated the interests of one ethnic group came to be tentatively deployed by another. As we will see, the incredible risks involved become less the risks of logistics, i.e. travel, shelter, security, and land cultivation and more the politics of identity. By imagining their community into being, the Brotherton Indians were in many ways positioned into reimagining who they were as a people. However by examining the writings of the Coopers alongside those of Occom and his son in law, Joseph Johnson-by allowing these 
typically competing narratives to sound together on the mat, I hope to illustrate how the Brotherton movement was also an act of continuance, or a deliberate effort to maintain autonomy, tribal sovereignty and a link to communal traditions of the past.

Leslie Fiedler has noted that "geography in the United States is mythological."14 The narrative of how the west was won rests upon a foundation of deeply entrenched, difficult to shed, beliefs concerning the landscape and the nature of the presumably wild and savage people who inhabited it prior to white settlement. Representations of the pioneer movement popularized by Cooper, Kirkland and others, however varied and complex in relation to one another, were uniform in their portrayal of white settlers transplanting not only themselves, but their cherished notions of order, upon untamed geographies. ${ }^{15}$ This pioneering spirit was considered no less a feat of individual physical endurance than one of collective cultural stamina, and the Native communities displaced by this movement were most often regarded as little more than an obstacle, undifferentiated from the unruly landscape, to be beaten back or bent to the will of a civilizing, domesticating force. This template for western expansionism had its roots in the colonial movement of the seventeenth century, found its most precise artistic expression in the genre of the captivity narrative, and was rhetorically energized by the tensions inherent in the act of entering a liminal space and encountering the Native other. ${ }^{16}$ As Roy Harvey Pearce, Richard Slotkin, Michelle Burnham and others have noted, Americans would forge their own national identity, and consequently fulfill their presumed destiny, by bringing both the land and its indigenous people under their control. Pearce writes in Savagism and Civilization that "the Indian in his savage nature, stood everywhere as a challenge to order and reason and civilization."17 Whether the Indian was depicted as wild savage, a child of the forest, or as a culturally exhausted anachronism, reduced to drunken decrepitude in the face of a more vigorous cultural entity, the result was that the Native American, as represented, had no place in the new civic order. Lucy Maddox has posited that, by the early nineteenth century, the discourse of 
white civilization conceived of only two possibilities for Native Americans. They must either assimilate or face extinction. ${ }^{18}$ Even those who perceived themselves to be in sympathy with the plight of the Indian were inclined to attach themselves to this paradigm, as it was believed that total assimilation would effect nothing but improvements upon the lives of Natives. But assimilation came with its own snares, and any Native individual attempting it was in danger of being regarded as insincere or lacking authenticity. Philip Freneau perfectly voices the general skepticism towards Native assimilation in his 1797 poem "The Indian Convert" where he glibly asserts, "The doors are all locked against folks that are wicked:/ And you I am fearful, will never get there:- $/$ A life of REPENTANCE must purchase the ticket,/And few of you, Indians, can buy it, I fear." ${ }^{\text {"19 }}$ If assimilation or extinction were the choices, the political ramifications for Native peoples remained the steady and deliberate loss of territory. To enter into the fold of white civilization was to be physically and culturally disassociated from one's tribal inheritance, while to resist the push of European culture was to face violent reprisals that often led to forced removals from the land. To both assimilate and retain the land, as witnessed by the Cherokee, Creek, Choctaw (and many other indigenous nations) in the 1830's, was an option antithetical to the ideological aims of this discourse.

Despite this nearly untenable situation, Native peoples struggled in many ways to locate a middle ground. My claim here is that the Mohegans of Brotherton, by effectively appropriating the tool of literacy and honing their ability to wield this tool in the public transcript of the colonizers, were able to deploy the discourse of western expansionism to their own advantage. They subvert, at least for a moment in history, the paradigmatic containment that is meant to untether them from their land, using it instead to establish a new frontier settlement. The result is neither full assimilation, nor an act of cultural extinction, but rather an illuminating and, perhaps, counter-intuitive incidence of Native adaptability and continuance. This appropriation places the Brotherton movement in conversation with the kind of republican rhetoric being deployed by 
William Cooper at the time, while remaining in tacit resistance to the mythological constructions of land and Native presence long in operation on colonial soil and immortalized in the type of fiction produced by James Fenimore Cooper. Although the conversion to Christianity by Native individuals like Occom and Johnson, and their indoctrination into literacy may seem, in some ways, the ultimate capitulations to western civilization, or "Salvationist" rhetoric, these become, in fact, the means by which a certain tribal autonomy might be ensured in a political and cultural environment hostile to the very existence of the Native American. I believe the lives of Occom and Johnson, as witnessed in their written legacy, far from placing them in a kind of linguistic complicity with the colonizer, reflect a commitment to community that falls very much within the rubric of what Jace Weaver calls "communitism," or a literature that is "part of the shared quest for belonging, a search for community" within a Native American context. ${ }^{20}$ What else was the Brotherton movement but a search for Native community in an historical moment when the title to the land was in a state of violent flux?

\section{Mount Vision: Selectively Surveying the Terrain in Cooper's The Pioneers}

Following the Revolutionary War, as the Land Ordinance of 1785 demonstrates, the socalled wilderness was already being energetically parceled out by the United States government with lines being mapped out along the points of the compass and extending "throughout the whole territory; provided that nothing herein shall be construed, as fixing the western boundary. ${ }^{21}$ In fact, the American frontier movement was eerily anticipated by a predetermined parceling of the land. As John R. Stilgoe notes in Common Landscapes of America, in the late eighteenth century the section lines that continue to shape America's material and political boundaries existed only,

in surveyor's notebooks and on the rough maps carefully stored in federal land office drawers. Here and there a blazed tree or a pile of stones marked an intersection, but otherwise the lines existed only as invisible guides. Not until farmers settled the great rectangles platted by the surveyors and began shaping the land did the lines 
become more than legal abstractions of boundaries. ${ }^{22}$

This projection of frontier space, with its precise and sustained geometrical configurations blotting out all complications of prior human involvement with the land, was at once boldly ambitious and historically negligent. Nevertheless, it was an imaging that, as Stilgoe claims, "determined the spatial organization of two-thirds of the present United States." ${ }^{23}$ It seemed that the newly minted American government already assumed its proprietary authority over the as yet uncharted west, with the management and eventual assimilation (or extermination) of indigenous peoples clearly articulated into this vision. The articles of the Land Ordinance simply ignored the existence of traditional Native communities while allowing for specific townships to be set aside for the "sole use of the Christian Indians who were formerly settled there, or the remains of that society, as may, in the judgment of the geographer, be sufficient for them to cultivate."24

Larzer Ziff has noted of Jeffersonian republicanism, that it "required tracts of vacant space as the site for its actualization." 25 But to vacate this space demanded of the Native inhabitants that they either conveniently vanish, or become assimilated into white culture. Such a feat could not be accomplished quickly, conveniently, or without bloodshed. But one could lay the ideological groundwork as easily as one could imagine a vast continent already divided up into convenient checkerboard portions. Intrinsic to the ideology of western expansionism was an ingrained disavowal of the fact that Natives had previously inhabited the land in any meaningful way. As the Pequot minister William Apess would write in his impassioned 1836 oratory "Eulogy on King Philip,"

Look at the deep-rooted plans laid, when a territory becomes a state, that after so many years the laws shall be extended over the Indians that live within their boundaries. Yea, every charter that has been given was given with the view of driving the Indians out of the states, or dooming them to become chained under desperate laws, that would make them drag out a miserable life as one chained to the galley; and this is the course that has been pursued for nearly two hundred years. ${ }^{26}$

Apess was merely committing to paper what many Native communities had already taken to 
heart- the fact that there was no place for them in the dream of American expansionism.

It remains endlessly fascinating, in a grotesque sort of way, to uncover the various machinations by which this construction of Native impermanence was elaborated and tirelessly maintained in the interest of manifest destiny. On his expedition to survey the Ostego region in 1785, William Cooper wrote of being "alone three hundred miles from home . . . with nothing but melancholy wilderness all around me."27 James Fenimore Cooper re-enacts this persuasive sense of solitude in The Pioneers when he has Judge Temple, the fictional counterpart to Cooper's father, narrate his first glimpse of the region, stating how,

I rode to the summit of the mountain, that I have since called Mount Vision . . . I mounted a tree, and sat for an hour looking on the silent wilderness. Not an opening was to be seen in the boundless forest except where the lake lay like a mirror of glass .. not the vestige of man could I trace . . . no clearing, no hut, none of the winding roads that are now to be seen, were there; nothing but mountains rising behind mountains. ${ }^{28}$

Both Coopers, caught in the rapture of their transcendent communion with America's vast forest primeval, gave themselves license to elide Native occupation of the land. In surveying the prospect before them, they saw not only virgin wilderness, but the "mirror of glass," as though all this terrain might offer was a pale reflection of their own image thrown back at them. This despite the fact that, as the younger Cooper notes in his 1832 introduction to The Pioneers, "Ostego is said to be a word compounded of Ot, a place of meeting, and Sego, or Sago, the ordinary term of salutation, used by the Indians of this region." It was here, Cooper informs us, that the Natives would meet "to make their treaties, and otherwise to strengthen their alliances."29 Clearly this region was not only well traveled, but was a cultural center of sorts, however manifestly different from what white settlers might consider a "hub." The idea that the Natives left no mark on the land, or made "no improvements" as the colonists would have it, is challenged by Alan Taylor who, in his book William Cooper's Town, calls this the "myth of the second creation;" a belief that white settlers could be likened to the biblical patriarch Adam confronting a new, uninhabited, Eden. ${ }^{30}$ The act of erasure embedded in this insistent perception 
stands in sharp contrast to the version of settlement that Occom, Johnson and the New England Natives would pursue as they began their own westward push. As I will demonstrate, their arrival to the territory was realized through negotiations with their Iroquois brethren, patterns of mutual respect, and a recognition of one another's tribal autonomy. It never would have occurred to the Brotherton Natives to insist that the land they settled was previously uninhabited.

James Fenimore Cooper rendered with an elegiac eye, the gradual, and what he considered to be inevitable, domestication of frontier space, his Natty Bumppo/Leatherstocking/Hawkeye and John Mohegan/Chingachgook/Serpent representing what Richard White has described as a "middle ground" 31 where ideas of western order come to inhabit the presumably more libertine structures of Native life. Both are hybrid characters, Natty Bumppo the white man in animal skins whose habits were "so nearly assimilated to those of the savages,"32 and John Mohegan, the Indian who has at least nominally embraced Christianity. Cooper writes, "From his long association with the white-men, the habits of Mohegan, were a mixture of the civilized and savage states ... In common with all his people, who dwelt within the influence of Anglo-Americans, he had acquired new wants, and his dress was a mixture of his Native and European fashions." ${ }^{33}$ Cooper's creation of Chingachgook has been faulted, over the last half-century of criticism beginning with Pearce, as a romanticized notion of the Native as a sort of noble savage, unable or unwilling to make the transition into a modernizing world. The Pioneers, however, offers the other end of the paradigmatic extreme in which John Mohegan (as he is most typically referred to in The Pioneers) is, for the most part, a defeated figure, degraded by cultural submission and drink, only capable of summoning up his once formidable spirit in brief nostalgic flashes. He is not undone by his intractability in the face of white civilization, but rather by the accommodations he has already made to it.

There are only two moments in The Pioneers in which Mohegan is seen to forcefully reassert his Indian identity. One is in the famous tavern scene where the citizens of Templeton 
rub elbows, debating new laws and customs, in a space presumably dismissive of class boundaries and ethnicity. John Mohegan is found chanting softly to himself in a corner, lost in a trance-like state, offering his inchoate resistance to the conversation around him. Cooper writes that "his notes were gradually growing louder, and soon rose to a height that caused a general cessation in the discourse. ${ }^{34}$ The threat of a revived Native presence, a return to the law of the wild, seems to shudder through the bar, but is quickly suppressed by the Leatherstocking who speaks to Chingachgook in his own language, reminding him that the old days have gone. Both Leatherstocking and Chingachgook are saddened by the tyranny of law that is sweeping the land. Both will ultimately be driven out by this development. As Fiedler notes, Leatherstocking, too, is "a Vanishing American." ${ }^{35}$ But while the Leatherstocking retains his voice and his agency, John Mohegan is rendered ineffectual. As his features begin to glow "with an expression of wild resentment ... his hand seemed to make a fruitless effort to release his tomahawk, which was confined by its handle to his belt, while his eyes gradually became vacant." ${ }^{36}$ Unable to communicate his own version of history or strike a blow to defend his beliefs, John Mohegan is quickly pacified with drink, and the tension he generated in the room is all but forgotten.

Mohegan's wrath, if we can call it that, is stirred up one last time toward the end of the novel during the climatic forest fire scene that heralds his demise. When Elizabeth Temple, daughter of Judge Temple, stumbles upon him on a rocky ledge outside of town, he has thrown off his blanket and adorned himself with "entwined ornaments of silver, beads, and porcupine quills" and "streaks of red paint" on his face and body. He was now "an Indian warrior prepared for some event of more than usual moment.. ${ }^{, 37}$ In what has become the signature gesture of the Indian in white literature, John Mohegan has prepared himself in recognition that his time has come, decided upon his own death, and in this moment he returns to his traditional persona, in what we are given to believe is an awakening of sorts from a long delusory dream.

The location where John Mohegan and Elizabeth chance to meet is none other than 
Mount Vision, the epicenter of Cooper's imperial gaze. And it is here that Mohegan lodges his protest against the way the land was taken, asking, "where are the blankets and merchandise that bought the right ... Did they say to him, brother, sell us your land, and take this gold, this silver, these blankets, these rifles, or even this rum? No, they tore it from him, as a scalp is torn off an enemy; and they that did it looked not behind them, to see whether he lived or died." 38 Elizabeth's response is interesting, in that she protests the accusation, claiming "but you hardly understand the circumstances," and yet we are informed that she "was more embarrassed then she would own, even to herself." 39 Cooper acknowledges here, to some extent, the layers of denial that are wrapped up in the question of land ownership and the means by which it was gained. Even as these words are spoken, however, a fire is raging over the summit of the mountain, and we might ask ourselves if it was not set by Mohegan himself, as he seems to have anticipated his own death and is neither startled nor moved to action by the fact that their little ledge has become encircled by a ring of flame. This may be Mohegan's sole gesture of reclamation, yet looking out upon the very same view that provided unlimited vision for the Coopers, Mohegan finds "his eyes grow dim. He looks on the valley; he looks on the water; he looks in the hunting grounds - but he sees no Delawares. Everyone has a white skin." ${ }^{40}$ At the last Mohegan renounces his Christianity, to the utter dismay of the Minister, Mr. Grant, who has somehow wandered on the scene. Speaking in his own language, so that only Leatherstocking can understand him, Mohegan relates that his eyes "grow young" once more, and he perceives a land where there are "no white skins; there are none to be seen but just and brave Indians."41 This offering of inverted vision serves to displace, for Mohegan, the more melancholy prospect previously described. To be ultimately pacified and reconciled to his death, he must project a vision of land occupation that exists solely in his own dreams and visions. But, of course, the only ground Mohegan will claim is his grave, and, in perhaps the novel's most egregious example of ironic (dis)placement, he is interred in a cave directly beneath the overlook on the 
summit of Mount Vision.

While Leatherstocking retains some of his interest as a literary creation, the figure of John Mohegan quickly wasted into stereotype, and bore little relation to Samson Occom, Joseph Johnson, and the other "real" Mohegans who relocated to New York in the 1780's. Alan Taylor, however, notes that "according to local tradition, one wandering Mohican basket maker and hunter named Captain John served as the model for Chingachgook. ${ }^{, 42}$ If so, then it is tempting to speculate that the prototype for John Mohegan was actually of the Brotherton Natives, or perhaps a Stockbridge Indian, who had immigrated from Connecticut or Massachusetts in the previous century, as these were the Mohegan/Mohicans most likely to be residing in Iroquois country at the time. Economically marginalized by the encroachment of white communities, many Natives of the northeast were forced to manufacture homemade crafts. Occom himself eked out a living binding books, making spoons and ladles and "piggins" which were small wooden pails. ${ }^{43}$ When Natives appeared at all before the settler community in the eighteenth and nineteenth century, it was often to sell such wares.

There was some precedent, too, for Christian Indians from the Brotherton and Stockbridge families having, like Chingachgook, fought with the English in both the French and Indian Wars and the Revolutionary War. Joseph Johnson's father, a Mohegan, was known as Captain Johnson and died in the defense of Fort William Henry, the battle that stands as the centerpiece for Cooper's novel The Last of the Mohicans. ${ }^{44}$ Hendrick Aupaumut, or Captain Hendrick, was a leader of the Stockbridge Mohicans serving in the Revolutionary War. ${ }^{45}$ Although there remains some confusion over which tribe Chingachgook/John Mohegan supposedly belonged to, Cooper always associated him with a nation that had come from the eastern seacoast. In his understanding of indigenous history the Mohegans and Mohicans were one tribe, an off shoot of the Delaware or Lenape, that had broken from the main and moved east. After King Philip's War, a branch of the eastern Mohegans again "sought a refuge around the 
council fire of the mother-tribe, or the Delaware. ${ }^{.46}$.It is this branch of the Mohegan, who had presumably been driven inland so that he might claim he had "never seen the sunshine but through the trees," to which Chingachgook traces his bloodline. ${ }^{47}$ Cooper, ensnared by his own racialized aesthetics, would never have associated Chingachgook with a movement of Christian Indians who lived in framed houses and farmed the land. But it would be a mistake to think that he was completely ignorant of such developments, or turned a deliberate blind eye to Indian assimilation. As Bumppo laments toward the end of The Pioneers,

When I look about me at these hills, where I used to could count, sometimes twenty smokes, curling over the tree-tops, from the Delaware camps, it raises mournful thoughts, to think, that not a Red-skin is left of them all; unless it may be a drunken vagabound from the Oneidas, or them Yankee Indians, who, they say, be moving up from sea-shore; and who belong to none of God's critters, to my seeming; being, as it were, neither fish nor flesh; neither white-man, nor savage. ${ }^{48}$

Ironically Bumppo condemns the Brotherton immigrants for being, in many ways, exactly what he and John Mohegan are-liminal figures, caught between two worlds, "neither white man nor savage."

Cooper, however, cannot articulate this paradox. His perspective, always strategically situated from a prominent height, a "Mount Vision," that takes in and encompasses both the geographical and ideological landscapes over which he endeavors to lay narrative claim, is one that still effectively erases, or buries, Indian presence. According to Cooper, the "true" Indians, the "pure," "authentic," “noble" race of Bumppo's and John Mohegan's past, have vanished, their camp fires permanently doused so that "not a redskin is left of them all." Of the few exceptions he allows, either drunks or "them Yankee Indians," who we can understand to be the Christianized, or Brotherton Indians, Cooper makes it clear these are not legitimate specimens. They are, in fact, so degraded in form that they must not even be considered amongst God's creatures. They are not only consigned, but literally damned, to inhabit an interstitial space, being neither "fish nor flesh." What then? 
Occom's biographer W. DeLoss Love noted of the Native American that "he has been known in our literature chiefly as a savage. What may he become if he is Christianized?"49 And, at least as a rhetorical strategy, this was one of the driving questions behind the colonial endeavor and the justification for westward expansionism that followed. European powers came to these shores with the expressed idea that they would improve the lives of godless savages by spreading Christianity and imposing their own notions of agriculture and land distribution. William Cronon observes that "the struggle was over two ways of living and using the seasons of the year, and it expressed itself in how two peoples perceived of property, wealth, and boundaries on the landscape. ${ }^{.50}$ When Natives actually began engaging with Christianity and European forms of agriculture, however, beginning in the early seventeenth century in New England, the response of the settler was, more often than not, similar to that of Cooper's, confining such creatures to political and rhetorical limbo. As Neal Salisbury has noted, Mary Rowlandson, in her 1682 narrative, is particularly disdainful of the Christian Indians she encounters during her captivity in King Philip's War. ${ }^{51}$ And the Christian Indians themselves, who had been structurally reorganized into Praying Towns as a result of John Eliot's missionary interventions, confirmed this antagonism, recognizing it as coming from both ends of the cultural spectrum. In the words of one of the so-called "praying Indians," John Wampas, "because wee pray to God, other Indians abroad in the countrey hate us and oppose us, the English on the other side suspect us, and feare us to be still such as doe not pray at all. ${ }^{.52}$ From the very start then, the prospect of conversion presented a double bind for indigenous peoples. From the viewpoint of the colonist, there seemed a compromised quality to the figure of the converted Indian that stood in stark contrast to the more useful representation of a savage race headed for cultural obsolescence. The revolutionary poet Freneau would articulate this suspicion by having his "Indian Convert" reject Christianity and the notion of heaven altogether, stating "I cannot consent to be lodged in a place/Where there's nothing to eat and but little to steal." ${ }^{253}$ Anthony F. 
C. Wallace argues in his case study of the Cherokee Removal, The Long Bitter Trail, that for many whites "the threat was not so much the savage, drunken Indian as the civilized one, who if left in place to govern himself in his own territory would beat the white man at his own game ... and prevent the further acquisition of Indian land. ${ }^{54}$

From within this marginalized space of cultural identity carved out by the colonist for Christian Indians arises not only the question of whether or not "Christianized Natives" have a place in European culture, but also whether they can be seen as legitimate ideological claimants to American Indian communities and traditions. Arnold Krupat wrote that "when the Native lost his land he lost his voice as well," and he regards this loss as the genesis of the "salvationist rhetoric" that becomes synonymous with Native literacy in the eighteenth and nineteenth centuries. ${ }^{55}$ Andrew Wiget asserts that "the very education that enables [William] Apess to write his own story also displaces him from that culture of his parents and grandparents to which he seeks to testify." ${ }^{" 56}$ This of course is only true if one imagines Apess' parents and grandparents hadn't already been oppressed, fragmented and traumatized by the circumstances of colonialism. ${ }^{57}$

Krupat's above-mentioned statement has become a contentious flashpoint for some Native critics like Warrior and Weaver, despite the fact that on the surface there is some validity to his point. One need not be a trained literary scholar to note the surface differences between the writings of Occom or Apess and, say, the "as told to" autobiographies of Black Hawk or Geronimo. The contrast in tone and content is striking. These narratives surface, however, in greatly different rhetorical situations and are meant to perform different tasks. The "as told to" tales, with their subtext of a once fierce but now subdued Native resistance, have engendered claims of their being the more "authentic" or "pristine" indigenous narratives, but Occom's discursive strategies were probably better suited to help his community at a given moment in time. ${ }^{58}$ Moreover, the search by the Brotherton Natives for new land called for a new voice, a 
dialogic engagement that in many ways transcended the rhetorical positions of those who remained on traditional lands.

As long as we view the imposition of Christianity on Natives as an uncompromising coercive force that erases all other identity markers and refuses the possibility of a dual reciprocal agency, we will continue, on some level, to maintain this notion of compromised identity. Perhaps it is for just such reasons that Cooper feels most comfortable in his Leatherstocking series representing John Mohegan either as a fully credentialed savage, or a drunken relic. He is literally incapable of imagining any vital synthesis of the two. In Writing Indians, Hilary Wyss attempts to break through this binary, asserting that "by writing their own narratives of conversion, Natives were defining their place in a newly forming colonial structure, positioning themselves simultaneously as Native Americans and as colonial subjects." Apess, the Methodist Pequot preacher, faced similar choices in the following decades, but as Ron Welburn notes, "he defers to Christianity to effect his survival and empower his self-identity," learning to "negotiate the images of Christianity in order to attack white hypocrisy." I would like to reconsider the settlement of Brotherton in just such a way-not as aberration, as Cooper sees it, or simply as an unexpected ripple in the narrative of American frontier expansionism, but as a positive strategy by a community of Native Americans to define their own destiny and maintain some remnant of their cultural moorings in a hostile environment.

Creek Literary critic Craig Womack in his book Red on Red defines Native "traditionalism" as "anything that is useful to Indian people in retaining their values and worldviews, no matter how much it deviates from what people did one or two hundred years ago. ${ }^{\prime 61}$ Although he does not regard Christianity as an explicit deviation from this notion, he does confide that "when an Indian converts to Christianity, not all of him gets converted, no matter how thorough his newfound convictions." ${ }^{22}$ To dismiss Samson Occom as simply a "Christian Indian," is to misunderstand the complex dynamic within which someone like Occom 
operated in his own community and the role he played in preserving traditional practices. True enough, Occom's writings are often loaded with signifiers that suggest how a white hegemonic set of norms has invaded his discourse and forced him to view his own persona, both public and private, through a distorted, racialized template. But however sincere and, in some measure, transformative his Christian beliefs, he remained a strong vocal advocate for Mohegan community throughout his life.

\section{“Natural Rights": The Mohegans and the Mason Land Case}

The particulars of the Mason case help to illustrate the complicated tensions surrounding Native land use, and, in some ways, can be seen to break down the apparent dichotomy between Christian and traditional Native identity. It was understood, by some at least, that Mohegan land was held in trust by the Mason family of Connecticut; by treaty, these lands could not be sold. But as the colonists continued to forcefully assert their presence, these former treaties were regarded as ambiguous at best, and it became conveniently unclear who had lawful authority over the territories in question, or what the original intent of the treaty might have been. Because whites preferred to deal with individual "kings" rather than tribal structures, they maneuvered to influence the succession of sachems to insure that the Mohegan at least nominally in power, Ben Uncas III, was sympathetic to their own desires. Occom led the protest against the sale and division of Mohegan lands, and used his influence as a well-loved and respected minister to try to repeal these decisions. Although Uncas presumably had the weight of traditional tribal authority in his favor, Occom was the most vocal and effective tribal advocate for retaining communal holdings of Mohegan lands. His education allowed him to formally protest the legal proceedings and apparently his actions were disruptive enough to raise "a public and loud clamour" amongst the Connecticut Board of Correspondents. ${ }^{63}$ In other words, while the sachem, Uncas, apparently privileged the practice of individual profit through the sale of tribally held 
lands, it was Occom, the supposed non-traditionalist Christian, who led the efforts to retain landholdings in what is assumed to be the traditional manner. This ideology was carried with him to Brotherton where, as the historian William DeLoss Love notes, "he proposed from the first to prevent this disintegration of his indian colony by making such sales impossible." ${ }^{64}$

Lisa Brooks argues that we should not be so quick to understand that sachems were simply selling out their nations for personal gain in these related transactions. She observes that "considerable confusion erupted when English deed making began to enter the space of Algonquian councils and the practices of Algonquian sachems began to enter the space of colonial land transactions. ${ }^{, 65}$ Going back to the original treaty language, or the "League of Amnity" between the Mohegan and the English in 1681, she finds that the first Uncas granted only "the rights of shared inhabitation" to the English, and not an outright purchase. The treaty Uncas put his mark to states, "I do resign up to the Colony of Connecticut all my Lands and Territories, hereby, for myself, my Heirs and Successors, binding myself and them that 1 will make no other Dispose of them to any person or people whatsoever, without their Grant and Allowance first had and obtained." Brooks understands this to mean that Uncas granted to the English, as a recognized power in the region, the right to mutual inhabitation and use of resources. While Uncas retained sachem rights to occasionally open a parcel of land for English settlement, he had not, by any means, ceded the distribution of Mohegan lands over to the colonists. Brooks states that "for Uncas, the agreement laid out the terms for sharing the space of the watershed." And she observes that "writing, like wampum, solidified the 'binds' between the two groups that would enable their mutual habitation. ${ }^{966}$ Such an understanding would have been in keeping with the patterns of land distribution that occurred in other Native regions of New England, resulting in similar disputes that led to King Philip's War in 1676.

We shouldn't assume, either, that the English had only one way of interpreting such agreements. As we have seen, there were continuous disputes about what original "title" the 
Natives had to the land, and what right European powers had to simply come over and claim indigenous lands for themselves. Because such acts had legal implications beyond the realm of colonial land grabs, it became important for the English to establish precedent and negotiate retroactively land transactions that had been determined orally or by vaguely worded treaties. Roger Williams had argued that the Natives owned the land outright, and this was, in large part, the cause for his being banished in 1635. By discrediting the legitimacy of the New England settlements, Williams irritated the Puritan elite and, in fact, weakened their already tenuous position as a patented colony. ${ }^{67}$ In 1724 the Reverend John Bulkley of Colchester, Connecticut openly acknowledged the many disagreements concerning rightful ownership of land on the North American continent. In a treatise entitled "An Inquiry Into the Right of the Aboriginal Natives to the Lands of America," he argues that "this is a matter more talked about than understood," and, agreeing with Williams, he takes the stance that there is, in fact, "a Native right" (although he feels compelled to refer to this as "the vulgar phrase" for the matter at hand). ${ }^{68}$ Bulkley argues that the Native right is synonymous with John Locke's articulation of "natural rights," or the rights that adhere to those who exist in "a state of nature." Locke had argued that the law of reason "makes the deer the Indian's who had killed it, it is allowed to be his goods, who has bestowed his labor upon it." ${ }^{, 69}$ But to substantiate a claim that open, unimproved land (read: wilderness) could be properly said to belong to anyone in "a state of nature" was absurd. As to the "pretended claims" of "the Moheags," Bulkley affirms that any agreement made with them was made whilst they were in such a state of nature, and therefore was unbinding, regardless of how anyone interpreted it now. "Instead of such large territories they have been ignorantly . . . thought by some to have, they had really good right or title but to here and there a few spots of it, viz. only to so much as by the means of the abovementioned they had separated and enclosed from the rest of the country."70 That the Mohegan were, in fact, in "a state of nature" at the time of these treaties, he argued, could be affirmed by the "manners of the 
more uncivilized part of their survivors at this day, who I imagine may reasonably be thought the liveliest images of their ancestors, and most to retain their customs." $" 71$

To reiterate Bulkley's tortured syntax, the Colchester minister was trotting out the familiar "vacuum domicilum" policy argued by the Puritans that declared open, unimproved lands, to have no clear ownership as a result of natural law. But, in a new twist, he was using this idea to render invalid previous land transactions and treaties. He argued that the Mohegan in particular, had nothing that could be called "civilization" and, knowing virtually nothing of Mohegan culture beyond the fact that he disapproved of what he saw, referred to the current Mohegan residents as the best proof of this. Lacking culture, art, history, and particularly writing, Native land title instantly became "perplexed and in the dark [so] that nothing can be known."72 He wondered where the proof was to decide the many conflicting claims that various sachems made concerning the bounds of particular villages and nations, and tellingly, he asserts that any attempt to find such proofs was "like a search for the living among the dead." ${ }^{\text {"73 }}$ Mohegan land claims, for Bulkley and a number of like-minded colonists, became "a mere chimera of fiction."

For whatever reasons, the Mason family (relations of the same Major John Mason who ordered the fire of the Pequot fort in the previous century and declared that the English would "root their very name out of this country") came to side with the Mohegan in the particulars of this case. ${ }^{75}$ The Mason's took their arguments to the King of England and it was during this decision in 1743 that the above-mentioned treaty with Uncas was unveiled. But the English court rejected the view of the Mohegan that the treaty called for mutual habitation. The decision went to the colonists, arguing that the lands had been ceded outright, and that because settlers had already made improvements upon the land, it would be detrimental to scale back, robbing these settlers of their legal purchase and risking that the land fall "once again into a Wilderness.",76

By this point it was probably impressed upon the Mohegan that their claims to sovereignty and their traditional memory of treaties made in the past, would remain under 
contestation by aggressive colonial powers until they themselves could take control of the legal forms by which the colonists claimed authority. As Lisa Brooks suggests, "the best route to protecting their lands was for the Mohegans to acquire the power of literacy for themselves." 77 And so it was that, in the same year their court case failed in England and Mohegan itself split into two factions, Samson Occom "crossed over" to Eleazar Wheelock's residence in order to acquire an English education.

One can argue that, within Native tradition, sachems had always held the right to apportion tribal lands without the consent of the tribe. David Silverman makes a case that for Native New England, the concept that lands were held communally was, in fact, a result of continued exposure "to English private-property ways, missionaries, and especially threats against the Native land base," rather than any traditional conviction. ${ }^{78}$ There is a splendid irony in this claim: that it was the rather rabid imposition of private property values on the part of the English that led to Native Americans adopting an articulated ethic of communal land holding. But then, I imagine the English would have responded in precisely the same manner had the King or Queen begun selling off chunks of the motherland to foreigners for personal gain. Somebody would be bound to step up and say, hey, this land belongs to all of us (perhaps Woody Guthrie is motivated by a like impulse). Across the board, Native communities in New England stood up and tried to stop their sachems from selling off land. Whether this was in keeping with traditional responses or not, and whether or not sachems were operating on a misunderstood notion of the types of agreements into which they were entering, one thing remains clear: the people of Native New England objected to the practice, and in their writings we can determine that they at least attempted to exercise their sovereignty as a people to put a stop to it.

Lisa Brooks argues that the drafts of Occom's correspondence seeking support in the Mason Case, demonstrate how he "struggled with choices in wording and metaphor, so that the letter would follow the style of Native oratory, including appeals to political kinship and prayers 
for pity and empathy." ${ }^{, 79}$ In a petition to William Johnson he expressed that the Mohegan "children" now "make their cries in your ears." But, as Brooks also points out, Occom seems to have used his English education to bone up on the legal language and codes involved in such cases. By declaring "we have a Law and a Custom to make a Sachem without the help of any People or Nation," allowed for "aboriginals" to govern their own internal proceedings. In effect, Occom had developed a syncretic form of discourse that mixed traditional rhetoric with the legalese he had acquired from his English education. His desire to learn Latin with Wheelock was apparently motivated by the same principles that motivated him to learn the Oneida language. In his letter to Johnson he would invoke both "Custom" and "Law" understanding, at least in this context, one to belong to the domain of oral culture and the other to the domain of European legal practices that were rooted in the traditions of alphabetic literacy. Occom was fluent in both of these realms, comfortable with their norms, adaptable, effective, and committed to Mohegan unity. He would continue throughout his life to contest the white power structure, and to find ways to subvert it from both within and without the system. Therefore, when the opportunity to move to Brotherton came about, Occom was likely to see this move not so much as a religious exodus as part of a continued struggle to achieve social and political autonomy.

Occom has enjoyed the reputation of being the "the foremost man of [his] race in the colonies," "the Moses of his people" and, perhaps more significantly for modern scholars, the first Native American to publish his own writings. ${ }^{81}$ His fame, such as it was and is, had its basis in the novelty of a "heathen" preaching the Christian bible as an ordained minister of the New Light movement that was part of the overall "Great Awakening" of the mid eighteenth century. Trying to understand Occom and his contemporaries through their published writings, however, is something like trying to comprehend the diverse geographical contours of the American continent through the hyper-structured, grid-lined projections of the 1785 Land Ordinance. The 
writings offer a study in containment by which the complexity of identity is made to conform to the ordered lines of print discourse in the eighteenth century. Laura Murray (the compiler of Joseph Johnson's writings) however, offers a telling anecdote that allows us to apprehend something of the not so hidden transcript in Mohegan land conflicts. She relates that when Ben Uncas died in 1769 , his pallbearers, Occom among them, dropped his coffin to the ground in front of the Connecticut officials who had come to pay their respects, in protest of their supporting his sachemship. Such actions, given no voice, no archival articulation by the Mohegan themselves, nevertheless simmer up through the archival depths, awaiting contextualization, awaiting the emergence of new narrative strategies to articulate their resistance. They are in some sense para-archival, having been displaced from a coherent cultural framework, and serve only as placeholders in the colonial archive until the ruptures of colonialism can be repaired or reconstructed by the introduction of a regenerated human archive, an archive held in the heart and not in the external house of power.

\section{O Mohegan: Joseph Johnson and the Writing of Brotherton into Being}

If William Cooper saw himself surveying a second Eden in 1785 , it was an Eden that had many prior visitors. The Iroquois had already inhabited the lands there for thousands of years, but French Missionaries had also been visiting the area since the late 1600 's, alongside Dutch and English traders throughout the 1700 's. The region had also been visited by a number of Native American Missionaries who had graduated from Moor's Charity School, and were sent there to proselytize to their "heathen brethren" by Wheelock. Moor's Charity School was conceived following the success of Occom under Wheelock's tutelage. Wheelock, a man as fiercely devout as he was opportunistic, was able to translate Occom's international reputation into a money-making operation that would lead to the boarding of many more Indian students - one of whom was Joseph Johnson—and ultimately pave the way towards Wheelock's 
establishing of Dartmouth in $1768^{82}$

Wheelock was of the opinion that he had made Occom what he was, and therefore would easily be able to suit up an entire legion of Indian missionaries to enter out into the wilderness and perform as effectively as his first student. "The influence of their own Sons among them will likely be much greater than of any Englishman whatsoever," he wrote, in the first of many narratives advertising his newly formed charity school for Indians. He asserted that "Indian Missionaries may be supposed to better understand the Tempers and Customs of Indians, and more readily conform to them in a thousand things... They will look upon such an one as one of them, his Interest the same with theirs . . . And will be more likely to submit patiently to his Instructions and Reproofs." ${ }^{83}$ But this proved foolhardy for a number of reasons. Wheelock wrongly assumed that a Native of one tribe would naturally be able to acclimate himself to the customs of another tribe and meet with little cultural resistance. But, in fact, the young, illprepared Native missionaries that Wheelock sent off into the woods were very much like fish out of water, unable to speak the languages of those to whom they ministered, and unfamiliar with the diet and customs they encountered. Also they were a long way from home with little or no social, emotional or institutional support. Eighteen year old Hezekiah Calvin, a young Delaware sent by Wheelock to teach to the Mohawk, wrote in 1766 ,

I am ready to give out with these Indians \& with the Pains I have, I have a hard head ache certain time in the afternoon which sonetimes is so hard that I hardly know what I am about \&cc The Indians say I shall not come home these three Years they think that I am their Servant \& are obliged to keep school for Yem \& yet they wont send their Children ... These things make me faint hearted together my wanting to see my father Mother \& relations. ${ }^{84}$

Calvin, frustrated by his inability to speak the language, referred to himself as a "dumb stump that has no tongue to use" amongst the Mohawk. ${ }^{85}$ In another letter he would confess to Wheelock, "I have foolishly spent my time to no purpose I have no peace of Conscience when I come to recollect back It seems to me to be in vain to tarry here any longer, there is great many things I might relate But my Conscience forbids. ${ }^{866}$ 
Other missionaries met with similar problems and anxieties. David Fowler, Occom's brother-in-law, while staying with the Oneida would complain, "I eat like a dog here, my folks

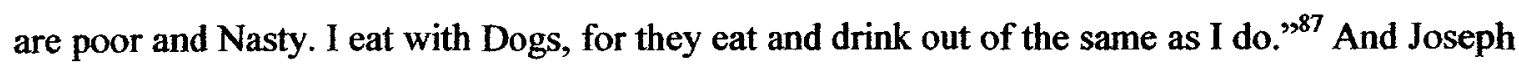
Johnson, Occom's son-in-law, would ultimately abandon his post and engage in the ritual celebrations of the Oneida. Johnson was probably not the only young Indian missionary to break ranks with the colonial endeavor, however briefly, and allow himself to participate in indigenous custom rather than stand in rigid opposition to it. But he was the only one who was willing to confess as much (Hezekiah Calvin's "conscience" forbid him to speak of such matters) and it led to his breaking off from Wheelock and being cast adrift as a sailor on whaling expeditions for the next two and a half years. The problems faced by these young missionaries, alone in a foreign culture, are most poignantly expressed in yet another letter from Calvin to Wheelock. He wrote,

there is something that makes me want to go Home, what I can't tell, Home is in my Mind all the time I want to go Home soon \& see my Relations \& it seems to me to tarry home awhile or all the Time $\&$ and let me see if that I am able to support myself. I have tarryed upon Charity long enough, when I have had no more Gratitude to my Benefactors than I have done, but all prove to the Contrary instead of being grateful, I am as ungrateful as a Beast. $^{88}$

The extremely difficult circumstances under which Calvin and his peers labored under probably contributed greatly to William Johnson's judgment of 1766 that the Indian missionaries had "become a Gloomy race \& lose their Abilities for hunting \&co spend their time in Idleness \& hang upon the Inhabit[ant]s for a Wretched subsistence hav[ing] lost those Qualities which render them usefull to us." ${ }^{.89}$ In other words, the very qualities of "savagery" that Wheelock labored to breed out of his students were the qualities found to be lacking in making them useful missionaries. In statements like these we begin to further apprehend the double bind of becoming a "civilized" Indian in the late seventeenth and eighteenth centuries. Only by distancing themselves from the colonial gaze and its contradictory paradigms meant to ground out the very existence of Native life and culture, could these Christian Indians forge out a meaningful existence for themselves without having to question their own identity as indigenous peoples. 
Wheelock had assumed that other young Natives would meet with the same success that Occom had encountered amongst the Montauk. But Occom had been friendly with the Montauk even before his appointment there, and he shared culture, language and kinship with them. Also, while Occom should not necessarily be held up as an exceptional example, he felt he had a personal calling and it was primarily his decision, alone, to follow such a path. When Occom went to the Oneida in 1761 , he seems to have understood that he was making diplomatic inroads rather than representing a foreign and superior culture. He forged alliances, exchanged wampum, and brought a representative from the Oneida home with him so that they might learn one another's languages and nurture a relationship. These practices, the patience and insight that Occom brought to his forays into Native space, facilitated future negotiations with the six nations of the Iroquois.

It was Joseph Johnson, however, who probably did more than anyone to facilitate the move to Brotherton. Johnson is an interesting and little known figure in Native American, and consequently, American history-a, perhaps not surprisingly, conflicted and tragic youth who came of age just as the United States itself was inscribing itself into being. Johnson did not necessarily go unnoticed by historians like Love and Blodgett who more or less credited Occom with the sole leadership role in establishing the Brotherton community. But the invaluable contribution that his letters provide to the study of Native American literature in colonial New England are hardly hinted at in these works. Love noted of Johnson that he wandered the seven Christian towns of the Connecticut and Massachusetts colonies "preaching the emigration as one might a crusade. ${ }^{.90}$ But Love suggests that "surely the design was a development in the mind of Samson Occom."91 Critical work on Johnson has been scarce and one must credit Laura J. Murray for her excellent commentary on his writings and for bringing him to the attention of the scholarly community. Murray notes how Johnson's rhetoric, over the course of his career, gradually shifts "from the religious to the political plane," and how "as Johnson's cause and the 
revolutionary cause came into competition, Johnson did on occasion champion what he calls 'Native liberty," which Murray interprets to mean "some kind of basic indigenous right or custom." 92

Little is known of Johnson's youth, although, as mentioned earlier, his father was a renowned captain in the French and Indian Wars who also was instructed in reading and writing. Johnson comes to Wheelock's however, after his father's death, and his time at Moors Charity School was probably as tumultuous as the rest of his life. He comes into the archive swinging, as David McClure notes in a letter to Wheelock dated September 25, 1765. McClure writes,

On Tuesday last, Sun about two hours high, Johnson, \& John Wheelock, were standing near the woodpile, great William by the gait, William and John Wheelock were chatting together calling one a nother Names. At last John challenges William to fite Johnson, calling him spekkle face white Eye \&c which Johnson repeated. William being run upon by Johnson's threats, advances up to Johnson \& offers to fite him. Whereupon they both strip their waistcoats, $\&$ prepare for an incounter, and in the mean time the most of the School Boys were gather'd around.

As the fight progressed Johnson called Big William, who was probably the son of the Superintendent for Indian Affairs of the colonies, William Johnson, a "Son of a Bitch" and an "Indian Devil," and according to McClure, they remained at blows, continuing "domineering over each other till Sun down." The fight continued when the boys went inside and they tore the shirts from one another's backs. McClure notes 'one Nation seem'd to be at variance with each other. ${ }^{, 93}$ Although Johnson went on to receive an adequate English education from Wheelock, and became a missionary on the Oneida reservation at the age of fifteen, his relationship with Wheelock remained stormy at best, and Wheelock had little hope for his student, whom he perceived to be of no account. ${ }^{94}$ Johnson was under enormous pressure at Oneida as a young man, far from home, expected to carry the torch for a system of faith he had not wholly embraced himself. Living with only the sickly white missionary Samuel Kirkland for company, the young Johnson rebelled from his situation and, as Kirkland wrote to Wheelock, "turn'd pagan for about a week-painted, sung-danc'd-drank \& whor'd it, with some of the savage Indians he cou'd 
find." 95

Kirkland's interpretation of events was unnecessarily dire. Johnson, as an energetic and charismatic youth, was drawn to the company of a people in his proximity who were probably more familiar to him, and perhaps more welcoming, than the flaccid missionary who seems to have considered Johnson something of a personal man-servant rather than an assistant in Christ. This event also establishes the possibility that Johnson, rather than "whoring" , "drinking", and "dancing," had actually made intimate connections with the Oneida himself, that transcended the often limited role one could play as a missionary outsider trying to make inroads within a resistant culture. Although Kirkland seemed to view Johnson's participation in Oneida rituals as a sudden rupture or apostasy, it was probably more in keeping with a general inclination on Johnson's part to involve himself in the daily living routines of the community. As he had written to Wheelock some seven months earlier, "I have nothing strange to Acquaint you at present. I shall go with the Indians next week to their hunt (as all my Scholars will go). ${ }^{, 96}$ Such connections, though routinely downplayed by Johnson, may have helped facilitate the eventual Mohegan exodus to Oneida. But his having crossed the line by participating in pagan ceremonies was also the event, naturally, that led to Johnson's falling out with Wheelock.

Johnson's letters to Wheelock while he is at Oneida, detail his unhappiness and his sense of rootlesness, a theme that will remain with Johnson throughout his short life. Having lost his father, and seemingly ambivalent concerning his own family attachments, Johnson would consistently portray himself as in search of a home and an identity. At one point, in one of his many gestures of remorse to Wheelock, he writes, "Methinks I feel in Some Measure the down Cast Spirits of Cain when He received his curse; but no equal to his; tho my Crimes are more than Equal. ${ }^{.97}$ Whether his remorse was real or simply calculated to keep the lines of communication open for further need, it is difficult to say. But his identification with the cursed biblical brother who bears the mark of a separate race, and is driven away from his family and 
people just this side of Eden, is telling both in regards to Johnson's view of himself and the discursive construction from which he is fleeing.

After leaving Oneida, the young Johnson broke from Wheelock "intirely" and would spend a number of years adrift, "wandering up, and down, in this Delusive World." teach for a time in Providence and see the world from a whaling boat before returning home to Mohegan and reestablishing himself with Occom and the rest of the Christian community there. That Johnson is a man very much in search of spiritual and temporal grounding throughout his life, is made clear in his letters and journals. His private writings are loaded with a poignant and melancholy questing that settles restlessly on Christianity and teaching, but finds a more perfect fit for his energies in the endeavor to gain new lands for the Mohegans and to break new ground. Throughout his young adult life he articulates a sense of fugitive self. In his journals he calls out repeatedly for a "new heart," whether through the salvation of Christ or by some other means. He asks for knowledge "of my self as I really am by Nature." 999 One senses the embattled state of Johnson's mind, and his quest for an identity that escapes the constrictive formations of Eleazar Wheelock's training and the conflicted affairs of his Mohegan elders. The homeland Johnson yearned for had, in his mind at least, been psychologically reduced, so that, as it stood, there was no Mohegan for him to go home to. As he so wistfully laments in his journal,

Mohegan is a lonsome place, oft have I sighed - but sighed in vain-desired, but desired in vain - Cast down - but no one to Comfort me - in destress - no one to relieve me - no friend to open my heart and vent my Sorrows- I opened my mouth to the open air-and told the Stones my Sorrow. Thus o Mohegan have you treated me-and thinkest thou-I can forget thee-or thy inhabitants-thinkest thou- or thine inhabiters that I am desireing to be on thee or with them - far far from me be such a thought- - but Still there is a precious few in thee, which Causes my mind often to Meditate of theo-Perhaps in due time I may once more Come on thy borders-but first I have to go, to distant Lands; and far Country - and Differant Nations I have to walk throughbefore I see thee. Thus O Mohegan I must bid you farewell, and Shut the door of my Heart against thee. ${ }^{100}$

In American Lazarus, Joanna Brooks notes how portions of Johnson's mournful rhapsody resemble Psalm 137 "substituting 'Mohegan' for 'Jerusalem.",101 But really what is at 
work here is a sort of reverse typology. For while the biblical Psalm pines for the homeland that has been lost as a result of captivity, Johnson's verse seeks a homeland of the heart and mind, rejecting the geographical Mohegan which is yet within his reach. Mohegan itself is "a lonsome place" that he has been "Cast down" from, as in his earlier letter to Wheelock when he compared himself to Cain. Who exactly has cast him out, and to what does he owe this fugitive condition of the heart? This is partly the natural lament of an energetic young man searching for his place in the world, but it is also a very real assessment of how the conditions of his life have forced him into the peripatetic wanderings that will define his remaining days. As a Christian Indian in Revolutionary America, he is "neither fish nor flesh." If he is captive, it is not in the physical sense, but rather, to a racialized identity. He has been schooled away from the traditions of his homeland, sent to far off lands to preach the works of an alien culture to yet another alien culture, and when the stress became too great, he was forced to flee from all of it and wander abroad. No wonder all he could see in front of him was further wandering "to distant lands and far countries_and Differant Nations I have to walk through." The mood and sensibility Johnson evokes in this passage is a far cry from the pseudo-nomadic "Wandering Life up and down in the Wilderness" that Occom described in his first personal narrative. ${ }^{102}$ Rather than describing the "benighted" cultural condition of an entire people, he is expressing an existential angst that has its roots in political realities. For Johnson, it seems (and perhaps for the other emigrants as well), the quest for new land is essentially a quest for spiritual reinvention or regeneration, and an opportunity to create a sense of home, a Mohegan, that the socio-political and individual circumstances of his life had all conspired to deny him. As much as being indigenous meant being of a specific place, it wasn't the first time that the Mohegan had to consider uprooting their homes and building a life elsewhere.

Laura Murray notes that "those who did move west at the end of the 18 th century, in the movement to Brotherton ... did not so in solitary flight, like Cooper's Chingachgook and Uncas, 
but with a determined community vision." ${ }^{\text {103 }}$ While this is certainly so, it is difficult to pinpoint the moment in letters when that community vision came into being. There are letters as early as 1767 detailing that Wheelock had been planning an Indian missionary community in the Oneida territory for quite some time. Such a community would be the fruition of his plan to educate a small portion of Natives and then remove them to a wilderness location where they might educate their so-called savage brethren through direct missionary work as well as by example. In one letter he writes, "I have been trying to collect a town of Christianized Indians, from ye New England Colonies, and settle them in some suitable place, in ye heart of ye Indian Country ... This would furnish an Asylum for our Missionaries, set ye Savages a pattern, and exhibit to them ye advantages of a Civilized life." ${ }^{\text {104 }}$ Wheelock also mentions in a letter, written upon Occom's return from England, that he had advised Occom "to dispose of his Family and Affairs agreeably to make himself a Settlement in the Wilderness, Where he may have an Advantage which no Englishman can have, viz, as much of their best lands as he could reasonably desire."105 Wheelock also apparently suggested that Occom start a school there, but as Occom "seemed disinclined to hear it," Wheelock lamented that, "I fear his tour to England and the great Respect Shewn him there will have the Sad Effect to make him aspire after Grandeur and ease and prevent his future usefulness." 106

Whether or not Occom or Johnson were aware of Wheelock's designs for an Indian settlement, they took the initiative upon themselves, and effectively cut Wheelock's missionary schemes out of the picture. ${ }^{107}$ In February of 1773 Johnson wrote to Occom that "When Ever I shall be losed from here, I purpose to go to Onoida." ${ }^{\text {"108 }}$ Although he does not state the reason for his proposed visit, his efforts to launch a colony in New York State take off from this moment. He begins a tireless campaign to try to raise funds, ostensibly for himself and his teaching efforts, but it becomes apparent that what Johnson really seeks is the funding to get himself to Oneida so that he can negotiate for land. He finally turns to his former mentor, Wheelock, for financial 
assistance. This could not have been a desirable turn of events for Johnson, and his letter of August 30,1773, is loaded with a number of pained rhetorical contortions that become a ready staple in Johnson's bag of discursive tricks. He writes, "If I were an Englishman, and was thus respected by you, I should be very thankful, but much more doth it now, become me being an Indian, to be humble, and very thankful in very deed."109 The forced obsequiousness here is almost blatantly ironic. In one breath he foregrounds Wheelock's inherent lack of respect for the Indian race, and, yet, signals that he will play the part demanded of him regardless. Wheelock apparently expected a certain amount of groveling in his correspondence with his students, but Johnson makes very little effort to conceal that he is merely going through the motions, and finishes his preamble to the letter with the phrase, "But to conclude my Indian Introduction," before moving onto business. ${ }^{110} \mathrm{He}$ seems to signal here, to us and to Wheelock, that the "introduction" in question is an unattractive but necessary phase of the transaction. The business, as Johnson states it is "that $I$, and the rest of the Chosen men, Should go into the Wilderness, to vizit our Savage Brethren, and to Converse with them Concerning our Proposals.” He also adds that, "I find I am Obliged to Solicit your favor this once more, for which I am very Sorry.",11

It is doubtful that Johnson was able to squeeze funds out of Wheelock, who preferred his Indians to go "a begging" elsewhere for resources. But by October of that year Johnson had put up a public notice on Mohegan lands addressed from the "Farmington Indians to 'All our Indian Brethren," calling for the Natives of Mohegan, Niantick, Pequot, Stonington, Narragansett, and Montauk to each send a man so that "they may go with us, and Seek a Country for our Brethren." Among the undersigners of this document are Elijah Wimpey and Andrew CorComp, both of whom were named in the Brotherton charter from Occom's journal.

In the series of letters that follow Johnson will write to Occom, the Oneida, Wheelock, The Connecticut Assembly, Connecticut Governor Jonathan Trumble, and other Missionary societies, attempting to raise the funds needed for a mass removal to Oneida. In these letters he 
repeatedly represents himself as a "poor ignorant lad," "a despised Indian" or "fatherless, motherless and almost friendless." ${ }^{.113}$ But he was equally capable, when necessity demanded, of adopting the high tones of American liberation discourse, writing in one letter to the citizens of New Haven: "Gentlemen, let me with humility tell you, that I have exerted myself, used my uttermost endeavors to help my poor Indian Brethren in New England; to bring them out of Bondage, as it were: and to lead them into a land of Liberty, where they, and their Children might Live in peace." 114 The multiplicity of voices, of self-presentations, that Johnson inscribes become almost dizzying. He moves from being a self-described object of pity, to an example of America's burgeoning republican spirit, to the respectful "younger brother" of the Oneida, whom he addresses in January of 1774 , intoning "we pray you to consider seriously of our Words, ye old men who are wise, also ye warriors, and stout hearted young men. Listen unto us, yea let Children hearken, that what we say may not soon be forgotten."115 Johnson, a quick study by anyone's standards, has not only mastered the form of what he calls his "Indian Epistle,"116 but he evidently mastered the diplomatic rituals of the covenant chain, ${ }^{117}$ standing shoulder to shoulder with the leaders of the Six Nations of the Iroquois, exchanging calamuts, tobacco and wampum. It should be noted, however, that Johnson, in his personal writings and letters to other Natives, never resorts to the obsequious tones adopted in his letters to whites. Clearly this is a controlled discourse that he is capable of stepping in and out of, and, as he writes to Occom, "I have been constantly improving my talents that God hath graciously bestowed upon me, chiefly among the English." ${ }^{\prime 18}$ Or, in other words, he was beginning to recognize his own powers of using literacy coupled with rhetorical genius to effect political action.

The Oneida lands were deeded over to the New England Indians on October 4, 1774. Occom and David Fowler had been to the region in July of that year and surveyed the lands to their approval. Johnson now had until the spring of the following year to try to round up willing recruits. He gloats to Wheelock that he expects "upwards of Sixty young Indian men from the 
Seven Tribes that will . . . be distinguished as noble Spirited Indians, who will do their uttermost to get good and do good." 119 It is doubtful whether Wheelock had ever heard any of his students refer to their own people as "noble" and "spirited" before, and in this letter Johnson conveys the spark of optimism and national pride that was engendered by the coming emigration.

\section{"The Best Land I Ever Did See": The Brotherton Exodus}

Which brings us round once again to the unusual event of a group of Native Americans ordering their own westward migration at the dawn of both rampant American expansionism and Indian removal. In the spring of 1775 a small constituency of New England Natives who went up to Oneida were able to build some crude huts, to break ground, and "got some cornfields planted and gardens made. ${ }^{\prime 120}$ That may have been the happiest time of Johnson's adult life. He had inscribed a new home into being for himself and his people, and seen the first fruits of his dream ripened into a reality. But the settlement was begun on the eve of the American Revolution, and Johnson, whose negotiating skills had apparently earned him recognition, was enlisted to seek a truce of neutrality between the Iroquois and the colonial rebels. Somewhere en route between Mohegan and Oneida, while carrying a message from General George Washington to the Six Nations, Johnson disappeared from view, a casualty of war, race hatred, or simply of being caught in that liminal space between contested worlds. He was twenty-four years old. Shortly after that the Brotherton settlement was broken up and would not reconstitute itself for yet another decade, after the war had finally ended. ${ }^{121}$

Plans for the establishment of the Brotherton community were put into motion once more by the end of the war, led by David Fowler, Occom's brother-in-law. Occom would travel back and forth in the ensuing years from his house in Mohegan to the newly established village in upstate New York. On the first of these trips in 1785, he wrote in his journal of the welcome he received as he rode up to the fringes of the settlement after weeks of travel. Coming upon 
Fowler's house in the rain, he relates how "I heard a Melodious Singing, a number were together Singing Psalms hymns and Spiritual Songs. We went in amongst them and they all took hold of my Hand one by one with Joy and Gladness from the greatest to the least, and we sot down awhile, and then they began to sing again."122 In the following weeks he would recount the drawing up of the town plan. He would also spend a number of days surveying the territory, much as William Cooper would in that same fateful year. As Occom relates joyfully in his journal, "Thirsday Fryday and Saturday, look about a little to see the land and it is the best land I ever did see in all my Travils."

Occom became the preacher for both the Brotherton and Stockbridge communities in Oneida in the years that followed, becoming close associates with Captain Hendrick, or Hendrick Aupaumut, who was, himself an influential figure amongst the Mohican, and who left a trove of letters and narratives that also deserve notice in this space if there were only time to accord it. Aupaumut would attend service with Occom and, as Occom records in his journal "after I had done speaking Capt. Hendrick rehearsed what he could remember in his own tongue." ${ }^{\text {124 }}$ Despite the fact that Occom left behind textual notes and transcripts for a good many of his sermons, he also was in the habit of speaking extemporaneously. According to Love, "especially in his later years, he made use of more similes and stories, interrupting his discourse by such illustrations." 125 Occom himself, in his "Short Narrative" remarked of his preaching style amongst the Montauk that he would "read from Suitable portion of Scripture, and so Just give the plain Sense of it in Familiar Discourse." And a Dr. Buell of East Hampton observed that Occom "when he preaches to the Indians, is vastly more natural, free, clear and eloquent, quick and powerful, than when he preaches to others. ${ }^{9126}$ In short, when amongst his own people, Occom's delivery was unconstrained.

In 1853 a reverend Daniel Waldo, who had attended a sermon by Occom when just a boy of fourteen, was asked to recall some of the particulars, though some sixty years later. He writes, 
His voice was pleasant, but not very loud . . . but I recollect that his subject led him to speak somewhat at length of what he called a traditionary religion; and he told an anecdote by way of illustration. An old Indian, he said, had a knife which he kept till he wore the blade out; and then his son took it and put a new blade to the handle, and kept it till he had worn the handle out; and this process went on till the knife had had half a dozen blades, and as many handles; but still it was all the time the same knife. ${ }^{127}$

The Reverend Waldo goes on to say that "I cannot be very particular as to the application he made of it, but the story I remember very well, and it seemed to me, at the time to be very pertinent to the object for which it was told" (217). But, if Waldo could not remember nor comprehend the context, we might be able to read into this parable a striking tale of Native transformation, syncretism, and continuance. Nothing of the sort ever appeared in Occom's published works, nor could it. And yet, Occom's Indian knife is, perhaps, something passed down to him by a line of writers, singers, story-tellers who also put the knife to use, found ways to repair it and keep it sharp, using whatever materials were at hand.

And it continues to pass from hand to hand. Perhaps intellectual sovereignty, then, is the acknowledgement that there is no one, supreme archive. Derrida's notion of the house of the archons, with its ability to sweep everything into its purview, ultimately performs the function of the colonial gaze. In a gesture of assumed passivity, inevitability even, it possesses all mode of thought and inscription and places it in the service of colonized thought, under the containment of colonized space. This totalizing archive may behold the Indian knife that passes from hand to hand, but the narrative value of that knife belongs to a different house of power, we'll call it a longhouse of power, or a Native space where narrative occurrences have a separate weight, a separate valence that is not fully apprehended by any one discursive hegemon. Even when the stricken inscription defies complete suppression, as Derrida supposes, and resurfaces in the realm of dream, that dream Indian, that Chingachgook, that Hobomak, that Injun' Joe or Hiawatha, remains a pure product of the colonist's imagination, a fever dream. It will never bear any direct relation to the communities of flesh and blood that maintain themselves beyond the pale of the colonial dreamer. 
Figures like Samson Occom and Joseph Johnson have as much of an historical presence for me as does Benjamin Franklin, George Washington, Thomas Paine or James Fenimore Cooper. I spent a great deal of my life, however, steeped in a tradition that understood how to value the self-presentations of a Franklin, for instance, and did not, even after prolonged scrutiny, appreciate precisely how to regard the presentation that someone like Occom put forward. The historical Natives who appear in the colonial archive, either through their own transcription or through the textual representations of others, were no less flesh and blood creatures than their colonial counterparts. They lived, struggled, loved, gave birth, gave chase, gave themselves up to systems of thought and belief that consecrated their individual lives to something larger and more complex, and we should not make the mistake of dismissing such entities as mere shadows, traces, misrepresentations (for they are no more these things than their colonial counterparts) just because we gain only partial insight into their respective existences through the efforts of colonial preservation. We lend both Franklin and Occom substance by imagining them from beyond the discursive structures of colonialism. History is like the child's refractor which bears one image, but then an entirely different image when shifted under the light. Likewise, a performance regarded in one setting, takes on entirely new meaning when presented in a different setting. That setting, that stage, is being constructed through the effort of listening to Native voices, Native scholars, Native historians, who have labored to reestablish Native contexts for interpreting history and literature. Other voices contribute to the ever shifting ground upon which these fields of knowledge are comprehended. It is not so much that one must draw from the colonial archive to achieve such knowledge, but rather one must figure out how to get out from under it, how to get out from under the wave. Too often we confound the dream with the real and confound historical lives with the dream. Archive fever, with its language of disease and pathology, infects a large body of thought in a fairly predictable fashion given the overall tide of western discourse. It functions as both poison and remedy. It establishes a regime in which it is 
both sovereign and subject. But it fails to imagine a patient other than itself. It fails to imagine how healing can occur from beyond its own corpus. The cure in this case is a singing cure. A narrative that passes from voice to voice, just as the knife passes from hand to hand. No story is complete under a single roof, a single archive. Every narrative must mend itself through a communion of voices.

Brotherton and Cooperstown appear on the map within a year of one another. Both settlements represented, in some way, the exportation of American ideals into Native territories, although, if there is anything in a name, then "Brotherton" signaled the hope of a truly egalitarian society, whereas "Cooperstown" held something of the patrician ideology of pre-revolutionary times. You might say that Joseph Johnson wrote Brotherton into being on the expanding map of the American frontier, just as, in some ways Cooper wrote Templeton/Cooperstown into the American imaginary. Johnson's letter writing campaign to open the way for migration and settlement was astonishing in terms of the multiplicity of voices he was capable of adopting, and, if nothing else, Johnson's efforts afforded the Natives of southern New England some control over their own destinies, an option that was increasingly rare with the era of forced removal just on the horizon.

But when I look at the map, I see no Brotherton next to Cooperstown. Where the one still has its place on the shores of the lake that Cooper affectionately referred to as "Glimmerglass," the other has been elided, it is a cartographer's ellipsis. By the 1830 's, the same kind of pressures that had prompted the Connecticut Natives to emigrate in the first place had reasserted themselves on what had, only a few years prior, been the western frontier. The Brotherton Indians eventually pulled up their tent stakes again, acquiring land in Green Bay, Wisconsin amongst the Munsee Indians where many still reside today. They remained in control of their own destinies, but by 1839 , facing new pressures from white settlers and the United States government, many exchanged their tribal status for individually owned forty acre lots rather than 
be removed once again from their lands. ${ }^{128}$ In the final analysis, Brotherton's falling off the map is an event that serves the American hegemonic dream as fully as Cooperstown. But as we have seen, even as Cooper was consigning his ideal Mohegans to a dwindling twilit corner of the nation's psyche, Johnson and Occom's flesh and blood Mohegans were finding strategies to struggle, adapt, persevere and create their own narratives in the town next door, on the most remote edge of Cooper's field of vision. 
1 Abbreviations:

$\mathrm{OP}=$ Occom Papers at Dartmouth College.

WP $=$ Wheelock papers at Dartmouth College

CHS $=$ Occom Papers at the Connecticut Historical Society

${ }^{1}$ Montacute is Kirkland's fictionalized name for the actual town of Pinckney, MI. Caroline M. Kirkland, $A$ New Home Who'll Follow?, ed. William S. Osborne (1839; Schenectady, NY: The New College and University Press, 1965), 34.

2 William Cooper, A Guide in the Wilderness or the History of the Settlements in the Western Counties of New York with Useful Instructions for Future Settlers (Dublin: Gilbert \& Hodges, 1810), 8.

3 Ibid, 9.

4 Ibid, 11. Although William Cooper may have boasted that his settlement was the first, there were, in fact, previous settlements of both indigenous and European origin. Cooper's hastiness in surveying and marking off these lands as his own would lead to legal disputes down the road, and the politics of land ownership would become a dominant theme in the works of his son, James Fenimore Cooper. For an excellent discussion on this see Alan Taylor, William Cooper's Town: Power and Persuasion on the Frontier of the Early American Republic (New York: Vintage, 1995).

5 Ibid, 13.

6 Ibid, 14

7 James Fenimore Cooper, The Pioneers (New York: Oxford University Press, 1823 [1980]), 41.

8 Ibid, 15.

9 Ibid, 15-16.

${ }^{10}$ Benedict Anderson, Imagined Communities: Reflections on the Origins and Spread of Nationalism (London: Verson, 1991), 4.

11 The Six Nations of the Iroquois remained one of the most powerful indigenous confederations in North America throughout the period of colonization, playing an important role in the fur trade and successfully balancing their interests between the constantly warring European factions that threw up around them. Following the Revolutionary War, however, they saw their power base weakened as the United States became the sole European force to contend with in the region. Beginning with the Treaty of Fort Stanwix in 1784, the US claimed military sovereignty over Iroquois lands, and then "gifted" back greatly diminished parcels to the Six Nations, thereby opening up large tracts of land for white settlement. Although the Six Nations ultimately denied the legitimacy of this treaty they lacked the military muscle to refute it. In other words, the United States simply declared sovereignty over Iroquois lands and defied the Six Nations to do anything about it. While the Brotherton Indians acquired their lands through negotiations with the Oneida, William Cooper was among those who were able to take advantage of the sudden opening of Native lands 
to be purchased from the state. See Anthony F.C. Wallace The Death and Rebirth of the Seneca (New York: Alfred A Knopf, 1970), 149-183. See also Dean R. Snow, The Iroquois_(Cambridge: Blackwell Publishers, 1994), 141-157.

12 The passage in question (the schemata of the town) is to be found in Samson Occom's journals amongst the Occom Papers at Dartmouth College. OP, Samson Occom's diary, Nov 7, 1785.

13 Brotherton is settled in 1784 , although initially the land was cleared and the first huts established ten years earlier. This settlement was disrupted by the onset of the Revolutionary War and abandoned until the date given above. Cooperstown was established by Cooper's father, William Cooper in 1786, although Cooper asserts that the community was well populated by time Ostego became an official county of New York "shortly after the peace of 1783." J. F. Cooper, Pioneers, 6.

14 Fiedler, Leslie A. The Return of the Vanishing American_(New York: Stein and Day Publishers, 1968), 16.

15 The historical novel as a means of easing European anxieties concerning colonization became a popular form following Cooper's success with The Pioneers_in 1823. Lydia Maria Child, Catherine Maria Sedgewick, Robert Montgomery Bird and others wrote tales that looked nostalgically back upon earlier periods of colonization and settlement, and to varying degrees, found means of justifying the displacement of Native Americans with European civilization. These themes became standardized throughout the nineteenth century in dime store novels and through later works like Owen Wister's The Virginian and A. B. Guthrie's The Way West. Naturally the Hollywood western takes its cues from this genre of fiction as well as has had enormous influence in disseminating highly ethnocentric representations of the frontier movement.

16 In his work Regeneration Through Violence_Richard Slotkin identifies Rowlandson's captivity narrative as the "myth artifact" to which we might retrace an understanding of the mythology of the west. The structure of the myth involves a white adventurer entering the wilds of native space and internalizing "savage" survival skills. The adventurer, best typified by Daniel Boone, and mythologized in the literature of Cooper, used these skills attained in the wild to subdue the land and paradoxically clear it for European settlement and domestication. See Richard Slotkin, Regeneration Through Violence: The Mythology of the American Frontier 1600-1860 (Norman, OK: University of Oklahoma Press, 1973).

${ }^{17}$ Roy Harvey Pearce, The Savages of America: A Study of the Indian and the Idea of Civilization (Baltimore: John Hopkins Press, 1953), 6.

${ }^{18}$ Lucy Maddox, Removals: Nineteenth-Century American Literature and the Politics of Indian Affairs (New York: Oxford University Press, 1991), 8.

19 Philip Freneau, "The Indian Convert," in Poems of Freneau ed. Harry Hayden Clark (New York: Hafner Publishing Company, 1960), 401.

${ }^{20}$ Jace Weaver, That the People Might Live: Native American Literature and Native American Community (New York: Oxford University Press, 1997), 45. 
22. John R. Stilgoe, Common Landscapes of America, 1580 to 1845 (New Haven: Yale University Press, 1982), 87.

23 Ibid, 99. According to Stilgoe the idea of "the grid" was introduced to the English colonies by William Penn in 1681, when he implemented his plan for the lay out of what would become Philadelphia. Previous to this, towns arose organically, and most tracts were determined by factors like soil types, elevation, and natural boundaries like waterways, swamps, and forests (99-101). William Cooper, who was a Pennsylvania Quaker himself, was well acquainted with the Philadelphia model and organized Cooperstown around similar guiding principles.

24 C. White, Survey, 3.

${ }^{25}$ Larzer Ziff, Writing in the New Nation: Prose, Print, and Politics in the Early United States (New Haven: Yale University Press, 1991), 130.

${ }^{26}$ William Apess, "Eulogy on King Philip," in On Our Own Ground: The Complete Writings of William Apess, Pequot, ed. Barry O'Connell (Amherst, MA: University of Massachusetts Press, 1992), 306.

${ }^{27}$ W. Cooper, Guide, 32.

28 J. F. Cooper, Pioneers, 236. I also wish to note that this connection of quotes between father and son is first presented in Alan Taylor's book. Taylor makes it abundantly clear that there were not only pre-existing Native communities within Cooper's field of vision, but that European land claims had been staked all about the Ostego region. Taylor notes that Cooper's society "rewarded those who effaced the signs of Indian occupation, but its courts penalized those who ignored the new marks of ownership sold by governors and blazed, mapped, sketched, and described by surveyors." Taylor, William Cooper's Town, 45.

29 Ibid, 7.

${ }^{30}$ Taylor, William Cooper's Town, 33.

31 See Richard White, The Middle Ground: Indians, Empires, and Republics in the Great Lakes Region, 1650-1850 (Cambridge: Cambridge University Press, 1991). White demonstrates how cultural accommodations were made on both sides when Europeans and Natives came into contact with one another. These cultural accommodations were generally forged and tested on both an ideological and geographical middle ground where the rules of contact were constantly being improvised. This middle ground begins to collapse, however, in the early nineteenth century, as America gains confidence in its autonomy, expands its borders, and begins to more forcefully assert its hegemonic control over the continent.

32 J.F. Cooper, Pioneers, 85. 
33 Ibid, 85-86.

34 Ibid, 165.

${ }^{35}$ Fiedler, Return of the Vanishing American, 121.

${ }^{36}$ J.F. Cooper, Pioneers, 166.

37 J. F. Cooper, Pioneers, 400.

38 Ibid, 401.

39 Ibid, 401.

40 Ibid, 416.

41 Ibid, , 421.

42 Taylor, William Cooper's Town, 40.

${ }^{43}$ Samson Occom, "A Short Narrative of My Life," Heath Anthology of American Literature, ed. Paul Lauter, $5^{\text {th }}$ edition, vol A (Boston: Houghton Mifflin Company, 2006, 1768), 1120.

44 See Laura J. Murray, To Do Good to My Indian Brethren: The Writings of Joseph Johnson, 1751-1776 ed. Laura J. Murray (Amherst: University of Massachusetts Press, 1998), 25-26.

45 For details on Hendrick Aupaumut see Hilary E. Wyss, Writing Indians: Literacy, Christianity, and Native Community in Early America_(Amherst: University of Massachusetts Press, 2000), 106-122. See also Electa F. Jones, Stockbridge, Past and Present or, Records of an Old Mission Station (Springfield, MA: Samuel Bowles \& Co. 1854).

46 J. F. Cooper, Pioneers, 84. In The Last of Mohicans Chingachgook recounts for Hawkeye the origins of his people. J. F. Cooper, The Last of the Mohicans (New York: Oxford University Press, 1980), 23-26. He claims that they held all the lands from the Hudson River to the ocean. But when the Dutch came and sold them liquor, then "foot by foot they were driven back from the shores" (25). His family found refuge with the Delaware but still identified themselves as Mohicans. It is this specific clan line that Chingachgook ultimately terminates when he dies in The Pioneers, and not the entire tribe of Mohicans that is presumed to have died off. While some have scoffed at Cooper's version of history or simply assumed his ignorance on the subject, much of what he relates as history here is in agreement with Mohegan Tribal Historian Melissa Jayne Fawcett's recounting of Mohegan origins. Melissa Jayne Fawcett, The Lasting of the Mohegans, Part 1: The Story of the Wolf People_(Uncasville, CT: The Mohegan Tribe, 1995), 7-22. 
${ }^{47}$ Cooper, Last of the Mohegans, 25.

48 J. F. Cooper, Pioneers, 452-53.

49 W. Deloss Love, Samson Occom and the Christian Indians of New England_(1899; Syracuse: Syracuse University Press, 2000), 1.

${ }^{50}$ William Cronon, Changes in the Land: Indians, Colonists, and the Ecology of New England (New York: Hill and Wang, 1983), 53.

${ }^{51}$ Neal Salisbury, "Introduction: Mary Rowlandson and Her Removes." The Sovereignty and Goodness of God by Mary Rowlandson with Related Documents. (Boston: Bedford/St. Martins, 1997), 41. Salisbury argues that Rowlandson "reserves her greatest contempt for native converts to Christianity." This seems to have been a backlash to the fact that some of these Christian Natives whom she met in captivity were exonerated and roaming about freely following the war.

52 Quoted in "The Cleare Sunshine of the Gospell Breaking Forth Upon the Indians in New-England." The Eliot Tracts. Ed. Michael P. Clark (Westport, CT: Praeger, 2003, 1648), 136.

${ }^{53}$ Freneau, Poems of Freneau, 401.

${ }^{54}$ Anthony F. C. Wallace, The Long Bitter Trail: Andrew Jackson and the Indians (New York: Hill and Wang, 1993), 62 .

${ }^{55}$ Arnold Krupat, The Voice in the Margins: Native American Literature and Canon (Berkeley: University of California Press, 1989), 144-147.

${ }^{56}$ Andrew Wiget, Native American Literature, (Boston: Twayne Publishers, 1985), 52.

${ }^{57}$ As Barry O'Connell notes in his indispensable introduction to the life and works of the Pequot minister, Apess' mother had been held in bondage as a slave, and his grandparents were alcoholics who beat him severely as a child. Barry O'Connell, On Our Own Ground: The Complete Writings of William Apess, A Pequot. Ed. Barry O'Connell (Amherst: University of Massachusetts Press, 1992), xxvii-xxviii.

58 David Brumble in particular makes a case for the distinctive narrative differences between autobiographical forms in native tradition, and those in western tradition. He argues that the native tradition of autobiography is non-linear, unconcerned with childhood development and parentage. They are often modeled after coup-tales. David Brumble, American Indian Autobiography (Berkeley: University of California Press, 1988), 49-55.

${ }^{59}$ Hilary E. Wyss, Writing Indians: Literacy, Christianity, and Native Community in Early America 
(Amherst: University of Massachusetts Press, 2000), 5.

${ }^{60}$ Ron Welburn, Roanoke and Wampum: Topics in Native American Heritage and Literatures (New York: Peter Lang, 2001), 88.

${ }^{61}$ Craig Womack, Red on Red: Native American Literary Separatism (Minneapolis: University of Minnesota Press, 1999), 42.

${ }^{62}$ Womack, Red on Red, 183. For some Native American perspectives on Christianity two helpful books are Vine Deloria Jr., God is Red: A Native View of Religion (Golden, CO: Fulcrum Publishing, 1992). and Weaver, That the People Might Live. While Deloria Jr. tends to view Native religious beliefs as inherently incompatible with Christianity, Weaver recognizes a Native engagement with Christianity that is more syncretic, capable of maintaining cultural integrity even if adopting certain practices within the Christian tradition.

${ }^{63}$ An Indian Preacher in England, "Minutes of the Connecticut Correspondents, Mar, 12, 1765," ed. Leon Burr Richardson (Hanover, NH: Dartmouth College Manuscript Series, 1933), 28.

${ }^{64}$ Love, Occom, 208. Unfortunately the policy of banning the sale of land and keeping all holdings under tribal possession was abandoned after Occom's death, and just as occurred with the Dawes Act a century later, the ability to lease and sell Indian lands to whites initiated the ultimate erosion of Native holdings.

${ }^{65}$ Lisa Tanya Brooks, The Common Pot: Indigenous Writing and the Reconstruction of Native Space in the Northeast, A Dissertation Presented to the Faculty of the Graduate School of Cornell University (Ann Arbor, MI: UMI and Proquest Information and Learning, 2004),79.

${ }^{66}$ Ibid, 79.

${ }^{67}$ Williams' 1633 tract on Indian land rights was ordered burned by John Winthrop in 1634. But his opinion that the land properly belonged to the natives and could only be gained through fair purchase was expressed often in his publications and letters. See Roger Williams, The Complete Writings of Roger Williams, vol. 1(New York: Russell \& Russell Inc, 1963), 324-325. See also Edwin S. Gaustad, Roger Williams: Lives and Legacies (New York: Oxford University Press, 2005), 9-10.

${ }^{68}$ John Bulkley, "An Inquiry Into the Right of the Aboriginal Natives to the Lands in America, and the Titles Derived From Them." 1724, CMHS vol 4, 159.

${ }^{69}$ Ibid, 163.

${ }^{70}$ Ibid, 165.

${ }^{71}$ Ibid, 166. 
72 Tbid, 174.

${ }^{73}$ Ibid, 166.

${ }^{74}$ Ibid, 181 .

${ }^{75}$ For the Mason quote see Mason, "A Brief History of the Pequot War," The History of the Pequot War, ed. Charles Orr (Cleveland: Helman-Taylor Co., 1897), 35. The Masons probably saw their title to the land bound up with that of the Mohegan in a state of protectorship. Therefore it was in their interest to argue against the idea that the Mohegan had actually ceded their land rights over to the state. See Laura Murray's arguments in To Do Good to My Indian Brethren, 34-36. See also chapter two of this dissertation.

${ }^{76}$ See Murray, Laura, To Do Good, 35.

${ }^{77}$ Brooks, Lisa. The Common Pot, 98.

78 David J. Silverman, Faith and Boundaries: Colonists, Christianity, and Community Among the Wampanoag Indians of Martha's Vineyard, 1600-1871 (New York: Cambridge University Press, 2005), 183.

${ }^{79}$ Lisa Brooks, The Common Pot, 110.

80 See Lisa Brooks, The Common Pot, 112 for a fuller explication.

${ }^{81}$ Love, Occom, 152 and 298.

82 Occom played the major role in raising the needed funds for Dartmouth College. He toured around England for just over two years, from late 1765 to early 1768 , preaching and placing his own "civilized" skills on display. This dog and pony show was profitable enough to supply the seed money for the college which was intended to be an Indian School. Wheelock never lived up to his promise, however, of creating a viable institution of higher learning for Natives, and this was the cause of a falling out between Occom and Wheelock. Though Dartmouth was founded on money intended for the education of Indians and such a mission was written into its charter, only three Natives would graduate in the 18 th century and only eight in the entire 19th.

${ }^{83}$ Wheelock, Eleazar. "A plain and faithful narrative of the original design, rise, progress and present State of the Indian Charity-School at Lebanon, in Connecticut." (1763) Early American Imprints, Series 1, 17 http://infoweb.newsbank.com.libproxy.unh.edu/iw-search/we/Evans?p_action=doc\&f_r. . .

${ }^{84}$ The Letters of Eleazar Wheelock's Indians. Ed. James Dow McCallum (Hanover: Dartmouth College Publications, 1932), 51. 
${ }^{85}$ Ibid, 58.

${ }^{86}$ Ibid, 54-55.

${ }^{87}$ Ibid, 91.

${ }^{88}$ Ibid, 63.

${ }^{89}$ Ibid, 21.

${ }^{90}$ Love, Samson Occom, 223.

${ }^{91}$ Ibid., 207.

${ }^{92}$ Laura J. Murray, To Do Good to My Indian Brethren, 23.

${ }^{93}$ Letters of Eleazar Wheelock's Indians, 76-77.

94 In truth, as Laura Murray notes, "every one of Wheelock's Indian students who lived long enough or studied long enough to take up a post in the field did break with Wheelock" "'Pray Sir, consider a little' : Rituals of Subordination and Strategies of Resistance in the Letters of Hezekiah Calvin and David Fowler to Eleazor Wheelock" Early Native American Writing, New Critical Essays, ed. Helen Jaskoski (Cambridge: Cambridge University Press, 1996), 19. Wheelock underpaid his Indian missionaries or left them entirely to their own devices, and they often labored under great financial and physical want in endeavoring to meet Wheelock's objectives. Generally their letters to him, requesting either funds, clothing, or simply acknowledgment of their work, went unanswered.

95 Johnson, Do Good, 78.

${ }^{96}$ Ibid, 71 .

97 Ibid, 74.

${ }^{98}$ WP 773480. Letter from Joseph Johnson to Enquiring Friends and Strangers. August 30, 1773.

${ }^{99}$ CHS, Diary of Joseph Johnson, January 2, 1772.

${ }^{100}$ CHS, Diary of Joseph Johnson, December 17, 1772. 
101 Joanna Brooks, American Lazarus: Religion and the Rise of African-American and Native American Literatures (New York: Oxford University Press, 2003), 69.

102 WP

${ }^{103}$ Laura J. Murray, "Introduction," in To Do Good to My Indian Brethren, 5.

104 Richardson, Indian Preacher, 315.

105 Ibid, 352.

${ }^{106}$ Ibid, 352.

${ }^{107}$ Although it must be confessed that once Brotherton is established Wheelock manages to send two white missionaries to the settlement, who then become the source of a great deal of friction in the religious community there. See Wyss, Writing Indians, 123-53.

108 Johnson, Do Good, 181.

${ }^{109}$ Ibid, 190.

110 Ibid, 190. In Laura Murray's article "Pray Sir Consider A Little" and Dana D. Nelson's "(I Speak Like A Fool But I Am Constrained)' Samson Occom's Short Narrative and the Economies of the Racial Self," in Early American Native Writing, New Critical Essays, ed. Helen Jaskoski (Cambridge: Cambridge University Press, 1996). we see the obsequious manner that Wheelock seems to have cultivated in his Indian students.

111 Johnson, Do Good, 190-91.

112 Ibid, 198.

113 Ibid, 194-195. I should note that "removal" is a word that Johnson himself often uses to refer to the emigration to Brotherton. Johnson, Do Good, 235.

${ }^{114}$ Ibid, 225.

${ }^{115}$ Ibid, 206.

116 Ibid, 194. 
117 The Covenant Chain was a term for the alliance between the Five Nations and the English, first established by Governor Andros and the Iroquois in the late seventeenth century, and ending a long period of conflict between the two. The rituals of this alliance were established in accordance with the rites of the Condolence Ceremony and the Great League of Peace, and these rituals were sealed with the exchange of wampum. See Daniel K. Richter, The Ordeal of The Long House: The Peoples of the Iroquois League in the Era of European Colonization (Chapel Hill, NC: The University of North Carolina Press, 1992), 133161.

118 Johnson, Do Good, 232.

119 Ibid, 252.

120

Ibid, 265

121 Love suggests that the settlement was hastily abandoned during the attack on Fort Schuyler by the British armies. Having nowhere to go, many of the first settlers of Brotherton joined with the Colonial forces. Others ended up in Stockbridge with the Housatonic tribe, their fates becoming tied from that point on, as the Mohegans would convince their Stockbridge brethren to migrate west with them after the war. Eighteen of the Brotherton Mohegans would die in the Revolutionary War. Love, Occom, 231-232.

122 OP. Diary of Samson Occom, August 26, 1787.

${ }^{123}$ OP. Diary of Samson Occom, November 9, 1785.

${ }^{124}$ OP. Diary of Smason Occom, July 141787.

${ }^{125}$ Love, Samson Occom, 175.

${ }^{126}$ William Buell Sprague Annals of the American of the American Presbyterian Pulpit: or Commemorative Notices of Distinguished Clergymen of the Presbyterian Church in the United States, vol. 3 (New York: Robert Carter and Bros., 1860), 195.

${ }^{127}$ Sprague, Annals, 195.

${ }^{128}$ See James W. Oberly, A Nation of Statesmen" The Political Culture of the Stockbridge-Munsee Mohicans, 1815-1972 (Norman, OK: University of Oklahoma Press, 2005). 


\title{
CONCLUSION
}

\section{CONDOLING METAMORA: "RESTORING TO LIGHT" TWO NINETEENTH CENTURY THEATRICAL STAGINGS OF KING PHILIP'S WAR}

\author{
Once we were a people who left no tracks. Now we are different. We \\ print ourselves deeply on the earth.
}

\author{
Louise Erdrich
}

This is my book, and I own this forever

Annotation by Nannahdinnoo written beneath the Book of Revelations on one of the original Eliot bibles.

And this is a wound/to be healed/in the spin of winter, / the spiral of beginning.

$$
\text { Wendy Rose }
$$

Following King Philip's War the head of the defeated Wampanoag leader, Philip or Metacom, was said to have been impaled by the colonists upon the gates of Plymouth for twenty years, serving as gruesome reminder to any indigenous visitor in need of reminding, of the futility of resisting colonial power, and by extension, the power of the Christian God. Cotton Mather, expounding on this topic in his Magnalia Christi Americana, presents us with an anecdote in which he claims to have personally confronted this visage, or perhaps specter, of Philip. He boasts that "the Hand which now Writes, upon a certain occasion took off the Jaw from the Blasphemous exposed Skull of that Leviathan." Mather, in a sense, likens himself to the biblical Samson who, with the jawbone of an ass, single handedly laid to waste the Philistines. It is through different means, however, that Mather schemes to silence a nation. He seems to imply that by stealing Philip's jaw, he might rob the indigenous figure of the ability to speak on the 
same historical page upon which he inscribes his own thought.

Not content to engage with history at an abstract remove, Mather, if we are to take his story at face value, must lay his hands upon the very object of his musings, to more viscerally connote his subjectivity. He must heap violence upon violence and expunge, from the already voiceless remains, even the implied threat of continued speech. The implication of Mather's act, beyond the raw insult it levies, is surely that, to the victors goes the privilege of writing history. Mather is found in the act of inscribing and silencing at the precise same moment, in effect demonstrating the machinations by which power constructs archival memory.

In an insightful and counter-intuitive reading of this performance, however, Laura $\mathrm{J}$. Murray posits that Mather's “attack on Philip's jaw suggests a specific and deep fear of the power of Indian words, a power so great that even death did not silence their capacity to signify." We perceive that Mather's act is at once symbolic and literal. Mather is silencing Philip in history. He is stealing the last word. He is engaged in an act of historical soliloquy in which Philip gets to play the role of "poor Yorick," or Babo, the insurrectionist slave in Melville's Benito Cereno-that "voiceless" skull and "hive of subtlety" that can only be represented and can never self-represent. Only through a trickster rhetoric might Philip reemerge as a man of infinite jest. But Mather's act, which must be read as a moment of uncontained excess, also suggests the persistent anxiety that no amount of rhetorical silencing, no amount of colonial containment, can put to rest. To crib a line of stage direction from the 1829 play Metamora, which restages the events of King Philip's War, "The door of the tomb opens, and Metamora appears."

What I hope to suggest in this work is that the silencing taking place within such rhetorical gestures is never complete. Nor are its effects, by any means, operative upon the colonized alone. In order to repair the disturbing, even traumatic, memories that entangle themselves in events like King Philip's War, the transcript of power must either fail to record it, 
or, having already recorded it, avert its gaze from the most troubling aspects of these events. More precisely put, it is not so much the victor who gets to write history so much as it is the victor who is compelled to forget it. The public transcript of power labors to render its moments of violent rupture whole once more in a manner that distorts the historical record, crosses out that which it cannot bear to witness, and bridges the ruptures with fabricated narratives of nationalistic wish fulfillment. These wishes, not surprisingly, often manifest themselves in the literary productions of a given period. In this paper I will look at the way that John Augustus' Stone's Metamora, and William Apess' Eulogy on King Philip offer counter narratives of the historical staging of King Philip's death. I suggest that while Stone's play is invested in a project of cultural forgetting, Apess purposefully draws upon the native tradition of the condolence ritual to bring the elided elements of Philip's life back to narrative light, and, in the language of the condolence ritual, clear the collective grief that has served to blind the senses by obstructing the eyes, ears and throat.

Judith Herman, whose work on Trauma and Recovery has been influential to my thinking upon the functions of history, writes

in order to escape accountability for his crimes, the perpetrator does everything in his power to promote forgetting. Secrecy and silence are the perpetrator's first line of defense ... To this end, he marshals an impressive array of arguments, from the most blatant denial to the most sophisticated and elegant rationalization. After every atrocity one can expect to hear the same predictable apologies: it never happened; the victim lies; the victim exaggerates; the victim brought it upon herself; and in any case, it is time to forget the past and move on.

It may be apparent to some here that Herman is speaking of the trauma of rape, but she is also speaking of the more transcendent cultural trauma that labors to silence such violence, so that her analysis reaches beyond isolated individual acts and moves into the realm of what we call history. She observes that "the more powerful the perpetrator, the greater is his prerogative to name and define reality, and the more completely his arguments prevail. ${ }^{, 3}$ Herman's language here asks us to view history in terms of perpetrators and victims, and while this may not always 
be the most useful paradigm to apply to the situation of colonization, the rhetorical framework she perceives underlying this operation remains compelling and useful. Nothing is more agreeable to a secure society than to remain a passive witness to the constructions of a selfserving historical narrative. Herman reminds us that "it is very tempting to take the side of the perpetrator. All the perpetrator asks is that the bystander do nothing. ${ }^{.4}$ For those who do not feel comforted or included within the dominant narrative, there are powerful reasons not to openly contest it.

Cotton Mather is often times a too-clever manipulator of history and narrative. Still, many of his manipulations have withstood the test of time. The coloring he applies to the events surrounding his lifetime will sink deeply into the colonial canvas and become part of a long, deliberate mural, a panorama, that in so many ways forms the backdrop of perception for the lives of Americans today. We do not simply regard this panorama from a remove, but feel ourselves moving through it, become intimate with its shapes and contours, comforted by its sunsplashed pastorals, pleased by scenes of domesticity in harmonious coexistence with displays of martial agility. We are made uneasy by the darkly shaded perimeters drawn there in remembrance of a less secure past when savages were thought to wait in ambush from such removes. Often the naked forms of these previous sovereigns can be seen through the brush, crouched, waiting, in war paint and feathers. These images become part of a pastiche that informs our knowledge of the world and makes iconic colonial assignations of race and gender (insert photo of the Durham Post Office Mural).

King Philip will play many roles in the staging of colonial history. John Eliot, in his Indian Dialogues, portrayed him as yet one more agreeable candidate in a line of successful Indian converts. Mather's generation cast Philip in the role of blood-thirsty hell-fiend, bent on driving the English back into the sea. And nineteenth-century playwright, John Augustus Stone, following the literary tastes of his era, saw Philip, or Metamora as he calls him, as the noble 
savage and child of the forest, acting out a narrative of native disappearance. In each case Philip serves the discursive agendas of colonial power, in each case his stolen speech is what allows the colonist to speak his words for him on a stage of their own design. The first articulate words we hear from the theatrical Philip in Stone's production occur as he defeats a ravenous wolf in hand to hand combat, and then hurls the wolf over the edge of a cliff, crying, "Ha, ha, ha! Turned on me- brave beast; he died like a red man."

Stone's Metamora, The Last of the Wampanoags becomes the ultimate wish fulfillment fiction whereby the colonial audience is permitted to valorize that which it has actively tried to destroy, and displaces its own agency in this destruction by wiping out the historical record of war, murder and slavery in one fell rhetorical gesture. This extraordinarily popular play opened with an introductory statement penned by one Prosper $M$. Wetmore (a pseudonym for the playwright himself?) that seemed to fully comprehend the act of literary interment/exhumation taking place. He forewarns that the play will "read strange lessons from a nation's tomb," and that the very halls of the performance space "usurp a monarch's resting-place." Invoking Shakespeare, Wetmore, marvels at how the English bard "conjured up the mighty dead from earth" and he wonders, rhetorically, if "native [by which we should read, colonial] pens in vain the field essay." What he is wondering, of course, is if "colonial" pens can hope to contend with the artistic productions of the motherland (a preoccupation of his era). But perhaps the doubleedged use of the word "native" is intended, the claim to indigeneity purposefully made, as Wetmore concludes by asserting "tonight we test the strength of native powers." (italics all mine). What is discursively at stake in this production, and a hundred other literary productions just like it from America's early national period, is the question of which power will have the right to claim the mantle of "native," on this American soil. The answer, of course, has already been decided and the play is meant only to rhetorically reinforce these conclusions.

Stone's play was wildly successful, remaining in production for the next two decades, 
with America's favorite thespian, Edward Forrest, coming to inhabit the title role. ${ }^{6}$ There were some, however, who regarded the play as a whitewash of Indian atrocities, altogether too sympathetic to its title figure, and dangerously provocative in what was, after all, the era of forced Indian removal from their lands. One reviewer looked scathingly upon the spectacle of white audiences "applauding with strange enthusiasm the reckless cruelties of a bloody barbarian, who stabs his subjects like pigs, and delights the white men of the present day, by burning the villages of their forefathers, and involving women and children in one indiscriminate massacre" ${ }^{\text {"7 }}$ But as Jill Lepore notes in The Name of War, the play ultimately spotlighted Philip's death, "a tragic death, yes, but a necessary one." Lepore writes, "Metamora mourned the passing of Philip and the disappearance of New England's Indians but it mourned these losses as inevitable and right."

Metamora, in significant ways, shored up the paradoxical sentiments white Americans brought to what came to be known as "the Indian question." Whether audiences loved the play or were angered by its efforts to sympathize with a hated enemy, they were acquiescing to a set of dramatic assertions that had little or no relevance to the complex relationships between Native and Euro-Americans in the nineteenth, or any other, century. The play condenses King Philip's War, which has been characterized by some as the bloodiest war in American history, into a skirmish of an evening in which roughly four or five people are killed on stage. ${ }^{9}$ Philip's actions in the play are capricious and most often performed in isolation, without political deliberation, as opposed to the concerted, pan-tribal nature of the actual historical event. Perhaps not surprisingly, we see Metamora plunge his knife into the breasts of more Indians than white men in the course of the play. And although the preface of my 1996 edition assures me that "Stone's source for the play was historical . . his vision remarkable and his research thorough," one is hard pressed to find more than one or two facts that even loosely conform to the various historical reports of this war. Nevertheless, the play seems to have articulated a fairly accurate 
sense of how citizens of a young United States understood their role in appropriating American soil. The play at once allows them to grieve for the passing of its former claimants, and assuages their fears concerning the violence by which that land was taken. (We should keep in mind, here, Lucy Maddox's thesis that, regardless of how sympathetic certain literary productions of the nineteenth century might appear, the paradigmatic contours of such works allow only two choices for Native Americans: total assimilation or extinction, and that, from a cultural standpoint, these are really one and the same thing).

If productions like Metamora appeared sympathetic to native causes from a certain angle of vision, the underlying violence of its message does not go unnoticed by the native communities still making their living on New England's civic and economic margins in the

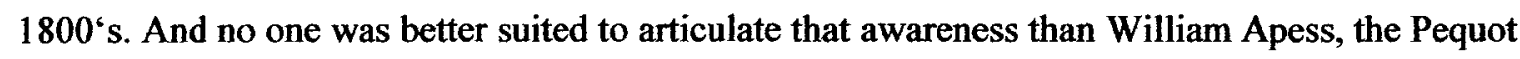
writer, activist and minister who claimed to be a descendant of Philip's. As noted by Barry O'Connell, who has compiled Apess' writings and offered a superb introduction to his life and works, Apess was born in the area of Colrain, Connecticut in 1798, to a father who was "of mixed blood" having parents of both Native and European descent, and a mother who was probably a slave at the time of Apess' birth. Raised by his grandparents in his early years, he was, by his own report, horribly beaten and abused and eventually indentured to white families at the age of four or five, where he lived, labored, and learned to read and write a little. At fifteen he ran away to New York City and enlisted in the army, serving through a number of major campaigns during the war of 1812. Following the war he reconnected with the native communities of his youth and eventually became an ordained itinerant minister who preached amongst the scattered native communities of New England and New York. ${ }^{10}$ He had seen enough of American life to comprehend its complexity, and had the faith, intelligence and wit to pierce through its discursive containments in his writings. In his 1836 Eulogy on King Philip, Apess summed up the self-serving sentiments of nineteenth-century attitudes toward natives, observing 
that "although in words they deny it, yet in [their] works they approve of the inequities of their fathers." Apess' text sought to insinuate itself within the framework of the extinction/assimilation paradigm for natives, exposing its operations and suggesting a different kind of space for native continuance.

While there is no way of knowing if Apess ever saw Stone's play, his Eulogy on King Philip stands as counter-testimonial, consciously operating against the kinds of discursive conditions that allowed for works like Metamora to be viewed as sympathetic to native concerns. Metamora, of course, played to hundreds of different audiences over a twenty year period, traveling all along the established interior of the new nation, reaching thousands of Americans. Apess' Eulogy, on the other hand, was performed on two nights only, both in January of 1836, at the Odeon Theater in Boston. The two productions will not accrue an equal discursive relevance in their own time. Nevertheless, Apess proceeds to recuperate Philip's career, not only by drawing from an indigenous memory bank of regard for the vanquished leader, but by entering into the archival house of power and reinterpreting the postings of historical witnesses on the colonial scene. He notes the ubiquity of accounts in which European explorers such as Thomas Hunt rounded up curious natives on their ships and brought them back to Europe to be sold into slavery. By placing such actions in direct relation to the repeated claims of Europeans that they were engaged in a project of civilizing brute savages, Apess begins to circle the many sites of rupture in the colonial narrative (Mention Mass Bay Company Seal).

He deliberately deploys the rhetoric of nationalism and Christian evangelism, but reverses its hierarchical movement, demonstrating how it was the natives, in each instance, who behaved according to a civilized ideal. It was the Wampanoags at Plymouth who, "without shedding of blood or imprisoning of anyone, bore" the incursions upon their lands. It was Massasoit and his young chiefs who enacted a policy of "showing the Pilgrims how to live in their country and find support for their wives and little ones; and for all this, they were receiving 
the applause of being savages."12

Most, if not all, period accounts of King Philip's War either labor to render its events the acts of a capricious heathen nature, or the design of an angry God who felt a need to rebuke his covenanted children for backsliding. Mather claims that "several of those nations which thus refused the gospel quickly afterwards were so devil-driven as to begin an unjust and bloody war upon the English, which issued in their speedy and utter expirtation from the face of God's good earth." ${ }^{13}$ Apess makes a rather lucid case, howver, for the proposition that King Philip's War, far from being a savage and unprovoked confrontation, was the result of a deliberate series of actions and abuses on the part of the settlers. He cites the manipulation of land deals, blatant violations of native sovereignty, and the mysterious death of Philip's brother Alexander while in colonial custody, as just a few of the causes leading to war. He writes, "it must be recollected that this war was legally declared by Philip, so that the colonies had a fair warning. It was no savage war of surprise, as some suppose, but one sorely provoked by the Pilgrims themselves."14 Apess is, in effect, not just airing out old grievances, but framing a legal argument that, given the power structure of the early nineteenth century, will never find its way into a court room. The courts of his time were preoccupied with deciding whether or not the so-called "civilized tribes" of the south could be forcefully removed from their lands. It was in the interest of the nation, therefore, to maintain the notion that New England's Indians had already vanished, thereby admitting no precedent of native continuance or successful assimilation. Andrew Jackson, himself, told Congress in 1829, that 'the fate of the Mohegan, the Narragansett, and the Delaware is fast overtaking the Choctaws, the Cherokee, and the Creek, "15 as though these New England nations had simply ceased to exist.

Nineteenth-century perceptions of native identity were inexorably caught in a doublebind, in which assimilation was mandatory, but to assimilate meant to become a degraded thing, retaining none of the essential value of a prior, authentic heritage. All that was considered worth 
valuing of native traditions had been dissipated and lost to the past. This notion is, perhaps, best expressed in a dialogue between the white hero and heroine of Metamora. When the righteous friend to the Indian, Oceana, cries out on behalf of Metamora, "Teach him Walter; make him like to us," her hero and husband to be replies, "twould cost him half his native virtues."16

By placing both Metamora and Eulogy on King Philip, together on the mat, we allow ourselves the opportunity to hear the accounts of either side and to weigh their worth in a manner that was not available in previous decades. The value of both sides being heard, of offering a ritualized clearing in which, perhaps, competing cultural narratives might be in some manner reconciled, is not that it offers a necessarily correct way of regarding history. But in the language of Iroquois diplomacy, it helps clear the smoke from the eyes, the dirt from the ears, and the obstructions from the throat. It is the means of achieving clear vision, or what is known in Iroquois tradition as Gaiwiio, the good mind. Such are "the rules of life and laws of good government, $" 17$ according to Seneca historian Arthur Parker. These might also be considered acceptable parameters for a field of literary criticism that deals with intercultural relationships.

When we bring Stone's Metamora and Apess' Eulogy into this process, their perhaps unanticipated agendas, the foci of grievance and anxiety, emerge more clearly. Both texts are intended as a kind of theatrical production in which events in the life of Philip, or Metamora, are acted out. Both purport to be mourning some aspect of this life. But both are invested in forwarding something as well. In Metamora it is the colonists who extend the olive branch, holding out their "civilization," their legal system as the proper way to settle disputes. The Wampanoag leader is advised "be thou not rash, but with thy tongue of manly truth dispel all charge that wrongs thy noble nature. Throw not the brand that kindles bloody war lest thou thyself should be victim." Metamora agrees to appear in the settler's court, but before leaving he speaks to his wife concerning the fate of their only son. "Nahmeokee," he says, "by the blood of 
his warlike race, he shall not be the white man's slave."18

Metamora, gets his day in Puritan court, and is shown to be guilty, in fact, of the crime of murdering the Harvard Educated Indian preacher, John Sassamon, but his refusal to accept the verdict results in the outbreak of the minor skirmish in the play that stands in place of King Philip's War. The political complexities of colonialism are utterly elided, and the audience is left to begrudgingly admire Metamora's ardent, if impetuous, "warlike" nature. But it is not only the political exigencies leading up to war that are elided in Stone's play. The after-effects of the war must be forgotten as well, and this is apprehended in Metamora's seemingly groundless warning that his son "shall not be the white man's slave." Indeed, the threat of slavery only emerges when an incidental character in the play captures Metamora's son and observes "the brat is saleable." But Oceana intrudes, calling the man a "measureless brute" and forcing him to return the child. Here it is the daughter of the white Puritan power structure that protects Metamora's son from an inconceivable fate. ${ }^{19}$

By the end of the play, however, the infant son is tragically killed as Nahmeokee flees the pursuit of Benjamin Church's army. In the climax, Metamora witnesses the end of his line, in the form of his dead child, and gently concedes, "Well, is he not happy? Better to die by the stranger's hand than live his slave. ${ }^{\prime 20}$ In this final moment, the play speaks directly to its ultimate concerns. Nahmeokee asks of her husband "is our nation dead? Are we alone in the land of our Fathers?" to which Metamora responds, "the palefaces are all around us, and they tread in blood. The blaze of our burning wigwams flashes awfully in the darkness of their path. We are destroyed-not vanquished; we are no more, yet we are forever." ${ }^{\text {"1 }}$ These comforting words seem to imply that Metamora's race is not being systematically extirpated, to use Mather's elegant phrase, so much as sent off to a better, more convenient place, away from the domain of colonial expansionism, where they might convalesce and live forever according to their ancient manner. These are the "happy hunting grounds," we often hear of, a place where, by implication, natives 
would have little to complain about. And in the penultimate gesture of the play, Metamora personally sends Nahmeokee to this destination, telling her that the white man "may seize thee, and bear thee off to the far country, bind these arms that have so often clasped me in the dear embrace of love, scourge thy soft flesh in the hour of his wrath, and force thee to carry burdens like the beasts of the field."22 To spare her this fate, Metamora plunges his ever thirsty knife into her bosom, assuring her that "the home of the happy is made ready for thee." And he quickly reassures himself as well, stating, "she felt no white man's bondage-free as the air she lived-pure as the snow she died. In smiles she died! Let me taste it, ere her lips are cold as the ice. $^{, 23}$

The rest we can anticipate. As with the wolf at the start of the play, Metamora dies fighting "like a redman," but also slowly enough to allow time for him to issue his final curse on the white man, and to alert Nahmeokee that he is on his way to join her in that better, happy, place. The curtain draws, and another white interlocutor, not Prosper M. Wetmore, appears to deliver an epilogue in stately iambic pentameter, in which the questions of the introduction are decisively answered. "What fault find you, sir? Eh! Or you, sir? None!/Then if the critic's mute, my cause is won." 24

This presumption that the audience would be so speechless with appreciation that none might venture a critique is, of course, a confection, and yet speaks truer than it presumes to know. Cotton Mather had pried the very jaw off the skull that might posit the most productive challenge to the events as told. But Native American writers were beginning to write back in the nineteenth century, finding that the tools of alphabetic literacy were essential in the process of pro-actively engaging with the dominant culture. If productions like Metamora were invested in the view of a static Native American identity best consigned to the past, Apess faced the problem of Native American survival in the present, and understood that such survival was predicated as much upon a fluid identity as it was the maintenance of traditional beliefs and cohesive 
communities.

In the end of the play, Metamora's family is spared the inconceivable fate of slavery by the seemingly more positive alternative of violent death. In reality, however, slavery was precisely the fate that befell Philip's wife and children, along with countless other native survivors of King Philip's War. And Apess, shedding the role of mute critic, makes this recognition the centerpiece of his Eulogy. He writes, "The most horrid act was in taking Philip's son, about ten years of age, and selling him to be a slave away from his father and mother. While I am writing, I can hardly restrain my feelings, to think a people calling themselves Christians should conduct so scandalous, so outrageous [an act], making themselves appear so despicable in the eyes of the Indians;" And in case his audience might be content to view this a matter of the past, he reminds that, "even now, in this audience, I doubt but there is men honorable enough to despise the conduct of these pretended Christians ... Gentleman and ladies, I blush at these tales, if you do not, especially when they professed to be a free and humane people . . They took a part of my tribe and sold them to the Spaniards in Bermuda, and many others. ${ }^{, 25}$ While white northerners are eager to absolve themselves of the taint of southern slavery, Apess places slavery as an issue at the center of a discourse on Native American continuance. He asserts "there is no manner of doubt but that all my countrymen would have been enslaved if they had tamely submitted" to colonial force. ${ }^{26}$

Apess' Eulogy takes on a ritualized function near its close by delivering the Lord's Prayer in the Algonquian language. He draws from John Eliot's one hundred and fifty year old translation of the prayer, indicating how this has become, in some measure, enfolded into native tradition, and a practice now held in common between the two peoples. But his concluding gesture is also in keeping with the ancient practices of native diplomacy, drawing the so called clash of civilizations into a single struggle that might be healed through dialogue, engagement, and a recognition of interdependency. Apess, having now offered the historical facts, of "our 
common fathers in their struggle together," finds that " it was indeed nothing more than the spirit of avarice and usurpation of power that has brought people in all ages to hate and devour each other." Apess critiques the practices of "pretended Christians" and calls upon the better spirits of both cultures to forge a spirituality that answers to the cause of hospitality and charity between races, whereby "all men must operate under one general law." In a sense Apess, with his recognition of a "common past" and his calls for togetherness and "one law," appears to be consciously stepping into the role of Hiawatha from the Deganawidah Epic (who, himself, was a cannibal that hated and devoured people). He is sounding the words that might result in Gaiwiio, or Good Mind. This is the way of the condolence ritual which, as noted by anthropologist Frank Speck, called for a return of light after a period of grief, a rekindling of the mind that had fallen into chaos and disorder as a result of being blinded by emotional responses to tragic events. ${ }^{28}$ When employed in diplomatic relationships, the object was to ritually clear the grief so that two parties might listen to each other and respond to one another without the obstructions to the senses brought on by rage and sorrow. This was how Hiawatha had brought the warring nations together and instituted the long house religion of the Haudenosaunee. ${ }^{29}$ Apess ends the Eulogy with the words: "you and I have to rejoice that we have not to answer for our fathers' crimes; neither shall we do right to charge them to one another. We can only regret it, and flee from it; and from henceforth, let peace and righteousness be written upon our hearts and hands forever, is the wish of a poor Indian." ${ }^{30}$ Apess' text ultimately absolves colonial grievances just as Metamora did. But it exonerates such grievances by acknowledging them rather than eliding them, by bringing them into the light rather than allowing them to reside in continued darkness. If I still, at times, have difficulty convincing my students that Metamora is a play that is not, at heart, sympathetic to Native Americans, I have to remember Judith Herman's assertion that “it is very tempting to take the side of the perpetrator." We seem to do it without quite noticing. But where I often fail to illicit the responses I desire from an in-class reading of Metamora, William 
Apess often succeeds with his Eulogy. Or rather, I would suggest, that it is the reading of the two together, in the proper order that brings about a sharpened comprehension of the historical complexity of the human narrative, which is, in the end, according to Cherokee/Greek writer Thomas King, nothing more than the stories we tell ourselves.

And this has been one of those stories. 
Laura J. Murray, "Joining Signs with Words: Missionaries, Metaphors, and the Massachusett Language," The New England Quarterly, Vol. 74, No. 1 (Mar., 2001), 66.

${ }^{2}$ John Augustus Stone, Metamora, or The Last of the Wampanoags (New York: Feedback Theater Books and Prospero Press, 1996, 1829), 32.

${ }^{3}$ Judith Herman, Trauma and Recovery: The Aftermath of Violence from Domestic Abuse to Political Terror (New York: Basic Books, 1992), 8.

${ }^{4}$ Herman, Trauma and Recovery, 7.

${ }^{5}$ Stone, Metamora, 5.

${ }^{6}$ Lepore notes how Forrest absorbed a great deal of literature about King Philip's War, took to speaking in what he considered to be an Indian accent, and called his real life mistress by the name of Philip's wife in the play, Nahmeokee. Apparently he also lived for a time with a Choctaw man, of whom he made an intimate study. See Jill Lepore, The Name of War: King Philip 's War and the Origins of American Identity (New York: Vintage Books, 1998), 200-202.

${ }^{7}$ This quote originally appearing in an 1830 issue of the American Quarterly Review, is drawn from Lepore, The Name of War, 201. Lepore offers an excellent explication of Metamora and the discursive productions of its time.

${ }^{8}$ Lepore, The Name of War, 210.

9 This assertion is commonly made in accounts of the war and references the percentage of the overall population that was killed in combat. I use Jill Leopre as a source. Lepore, The Name of War, xi.

${ }^{10}$ For biographical details on Apess see Barry O'Connell, "Introduction." On Our Own Ground: The Complete Writings of William Apess, a Pequot, ed. Barry O'Connell (Amherst: The University of Massachusetts Press, 1992). See also William Apess, "A Son of the Forest," On Our Own Ground: The Complete Writings of William Apess, a Pequot. Ed. Barry O'Connell (Amherst: The University of Massachusetts Press, 1992).

"William Apess, "Eulogy on King Philip" On Our Own Ground: The Complete Writings of William Apess, A Pequot., ed. Barry O'Connell (Amherst: The University of Massachusetts Press, 1992), 287.

${ }^{12}$ Ibid., 280-281.

${ }^{13}$ Cotton Mather, Magnalia, Christi Americana, 512.

${ }^{14}$ Apess, Eulogy, 296. 
15 Quoted in Maureen Konkle, Writing Indian Nations: Native Intellectuals and the Politics of Historiography, 1827-1863 (Chapel Hill, NC: University of North Carolina Press, 2004), 73.

${ }^{16}$ Stone, Metamora, 7.

${ }^{17}$ Arthur Parker, Seneca Myths and Folktales (Buffalo, Buffalo Historical Society, 1923) 404.

${ }^{18}$ Stone, Metamora, 12.

${ }^{19}$ Ibid., 26.

${ }^{20}$ Ibid., 38.

${ }^{21}$ Ibid., 39.

22 Ibid., 39.

${ }^{23}$ Ibid., 39-40.

24 Ibid., 41.

25 Apess, Eulogy, 301.

${ }^{26}$ Ibid., 301.

${ }^{27}$ Ibid., 310.

${ }^{28}$ Frank Speck with Alexander General (Deskaheh), Midwinter Rites of the Cayuga Long House (Lincoln, NE: Bison Books, 1995), 161-160.

29 See Anthony F. C. Wallace, Death and Rebirth of the Seneca, (New York: Alfred A. Knopf, 1970), 9798. It might be considered inappropriate to link Apess with the mythological traditions of the Iroquois. It also might be considered a stretch or simply erroneous. But I feel as though there is a conscious working of the elements of the Haudenosaunee belief system in Apess' address. Apess traveled, lived, and labored amongst the Iroquois following his service in the war of 1812. He lived for a time in Kingston, Ontario where he had what Lisa Brooks referred to as his "Native conversion experience." He witnessed "on the top of a very high mountain ... A large pond of water, to which there was no visible outlet-this pond was unfathomable." He also sees a rock "that had the appearance of being hollowed out by a very skilful artificer; through this rock wound a narrow stream of water: it had a most beautiful and romantic 
appearance, and I could not but admire the wisdom of God in the order, regularity, and beauty of creation; I then turned my eyes to the forest, and it seemed alive with its sons and daughters. There appeared to be the utmost order and regularity in their encampment." (Apess, "Son of the Forest," 32-33). This equating of native order with God's order occurs in the very place where the figure of Deganawidah was said to have originated and first attained his vision "on the north shore of Lake Ontario not far from the site of modern Kingston, Ontario." according to Paul Wallace (33). On his departure Deganawidah is said to have told his mother "should you wish to know if all is well with me, go to hilltop yonder where stands a single tree. Cut at the tree with your hatchets, and, if blood flows from the wound, you will know that I have perished and my work has failed. But if no blood flows, all is well, my mission is successful." See Paul A. W. Wallace, The Iroquois Book of Life: White Roots of Peace, Santa Fe: Clear Light Publishers, 1994, 1946), 34.

${ }^{30}$ Apess, Eulogy, 310. 


\section{BIBLIOGRAPHY}

\section{Archives and Serials:}

$\mathrm{OP}=$ Occom Papers at Dartmouth College.

WP $=$ Wheelock Papers at Dartmouth College

CHS $=$ Occom Papers at the Connecticut Historical Society

CMHS = Collections of the Massachusetts Historical Society

$J R=$ The Jesuit Relations and Allied Documents

$J M=$ The Jesuit Relations and Allied Documents: Travels and Explorations of the Jesuit Missionaries in North America (1610-1791).

\section{Works Cited:}

Allen, Chadwick. Blood Narrative: Indigenous Identity in American Indian and Maori Literary and Activist Texts. Durham, NC : Duke University Press, 2002.

Allen, Paula Gunn. The Sacred Hoop: Recovering the Feminine in American Indian Traditions. Boston: Beacon Press, 1986.

Amory, Hugh. Bibliography and the Book Trades: Studies in the Print Culture of Early New England,. Edited by David D. Hall. Philadelphia: University of Pennsylvania Press, 2005 .

Anderson, Benedict. Imagined Communities: Reflections on the Origins and Spread of Nationalism. London: Verson, 1991.

Angel, Michael. Preserving the Sacred: Historical Perspectives on the Ojibwa Midewiwin. Winnipeg: University of Manitoba Press, 2002. 
Apess, William. On Our Own Ground: The Complete Writings of William Apess, A Pequot. Edited by Barry O'Connell. Amherst: The University of Massachusetts Press, 1992 (1831).

Ascher, Maria, and Robert Ascher. The Code of the Quipu: A Study in Media, Mathematics, and Culture. Ann Arbor: The University of Michigan Press, 1981.

Axtell, James. After Columbus: Essays in the Ethnohistory of Colonial North America. New York: Oxford University Press, 1988.

Banks, Charles Edwards. History of Martha's Vineyard Mass, Vol. 1. Edgartown: Dukes County Historical Society, 1966 (1911).

Barton, Benjamin Smith. "Some Remains of Antiquity," Transcriptions of the American Philosophical Society O. S. iv (1799).

Bercovitch, The American Puritan Imagination: Essays in Revaluation. New York: Cambridge University Press, 1974.

Bhabha, Homi. The Location of Culture. New York: Routledge, 1994.

Blodgett, Harold. Samson Occom. Hanover: Dartmouth College Publications, 1935.

Boone, Elizabeth Hill. "Introduction: Writing and Recorded Knowledge," in Writing Without Words: Alternative Literacies in Mesoamerica and the Andes, Edited by Elizabeth Hill Boone and Walter D. Mingolo. Durham NC: Duke University Press, 1994.

Bradford, William. Of Plymouth Plantation: The Pilgrims in America. Edited by Harvey Wish New York: Capricorn Books, 1962.

Bragdon, Kathleen J. Native People of Southern New England 1500-1650. Norman OK: University of Oklahoma Press, 1996.

"Crime and Punishment Among the Indians of Massachusetts, 1675-1750." EthnoHistory 28, no.1 (1981): 23-32. 
Brooks, Lisa Tanya. The Common Pot: Indigenous Writing and the reconstruction of Native Space in the Northeast, A Dissertation Presented to the Faculty of the Graduate School of Cornell University. Ann Arbor, MI: UMI and Proquest Information and Learning, 2004.

Brumble, H. David. American Indian Autobiography. Berkeley: University of California Press, 1988.

Bulkley, John. "An Inquiry Into the Right of the Aboriginal Natives to the Lands in America, and the Titles Derived From Them." 1724, CMHS, Vol. 4. Boston: Charles C. Little and James Brown, 1848.

Burnham, Michelle. Captivity and Sentiment: Cultural Exchange in American Literature, 1682-1861. Dartmouth College: University Press of New England, 1997.

Cabeza de Vaca, Alvar Nunez. Castaways, The Narrative of Alvar Nunez Cabeza de Vaca. Edited by Enrique Pupo-Walker, Translated by Frances M. Lopez-Morillas. Berkeley: University of California Press, 1993 (1555).

Caruth, Cathy. Unclaimed Experience: Trauma, Narrative, and History. Baltimore: The Johns Hopkins University Press, 1996.

Cave, Alfred. The Pequot War. Amherst: University of Massachusetts Press, 1996.

Champlain, Samuel de. Voyages of Samuel De Champlain, 1604-1618. Edited by W. L. Grant New York: Charles Scribner and Sons, 1907.

Clifford, James. The Predicament of Culture: Twentieth Century Ethnography, Literature, and Art. Cambridge, MA: Harvard University Press, 1988.

Cogley, Richard. John Eliot's Mission to the Indians before King Philip's War. Cambridge: Harvard University Press, 1999.

Colden, Caldwallader. The History of the Five Indian Nations Depending on the Province of New-York in America. New York: Cornell University Press, 1958.

Columbus, Christopher. The Four Voyages. Edited and Translated by J. M. Cohen. New York: Penguin Books, 1969. 
Cook-Lynn, Elizabeth. Anti-Indiansim in Modern America: A Voice from Tatekeya's Earth. Chicago: University of Illinois Press, 2001.

Cooper, James Fenimore, The Last of the Mohicans. New York: Bantam Books, 1981 (1826).

The Pioneers. New York: Oxford University Press, 1980.

Cooper, William. A Guide in the Wilderness or the History of the Settlements in the Western Counties of New York with Useful Instructions for Future Settlers. Dublin: Gilbert \& Hodges, 1810.

Copway, George. Life, Letters, and Speeches. Edited by A LaVonne Brown Ruoff and Donald B. Smith. Lincoln, NE: University of Nebraska Press, 1997.

The Traditional History and Characteristic Sketches of the Ojibwe Nation. London: Charles Gilpin, 1850.

Cronon, William. Changes in the Land: Indians, Colonists, and the Ecology of New England New York: Hill and Wang, 1983.

Delabarre, Edmund Burke. Dighton Rock: A Study of the Written Rocks of New England. New York: Walter Neale, 1928.

Deloria, Philip J. "American Indians, American Studies, and the ASA." American Quarterly, vol. 55 , no. 4 (2003): 669-680.

Deloria, Vine Jr. God Is Red: A Native View of Religion. Golden, CO: Fulcrum Publishing, 1992.

Deloria, Vine Jr. and Wildcat, Daniel R. Power and Place: Indian Education in America Golden, CO: Fulcrum Resources, 2001.

Derrida, Jaques. Archive Fever: A Freudian Impression, trans. Eric Prenowitz Chicago: University of Chicago Press, 1996.

Dissemination. Translated by Barbara Johnson. Chicago: The University of Chicago 
Press, 1981.

Dewdney, Selwyn. The Sacred Scrolls of the Southern Ojibway. Toronto: University of Toronto Press, 1975.

Diaz, Bernal. The Conquest of New Spain. Translated by J. M. Cohen. New York: Penguin, 1963.

Drake, Samuel. Biography and History of the Indians of North America, From its First Discovery. Boston: Benjamin B. Mussey \& Co., 1841.

Du Bois, W. E. B. The Souls of Black Folk. New York: The Modern Library, 2003.

Duran, Diego. The History of the Indies of New Spain. Translated by Doris Heyden. Norman, OK: University of Oklahoma Press, 1994.

Eliot Tracts. Edited by Michael P. Clark (Westport, CT: Praeger, 2003).

Eliot, John. John Eliot's Indian Dialogues: A Study in Cultural Interaction. Edited by Henry W. Bowden and James P. Ronda. Westport, CT: Greenwood Press, 1980, 1671.

Erdrich, Louise. Books and Islands in Ojibwe Country. Washington D.C.: National Geographic Society, 2003.

Fawcett, Melissa Jayne. The Lasting of the Mohegans. Uncasville, CT: The Mohegan Tribe, 1995.

The Federal and State Constitutions, Colonial Charters and Other Organic Laws of the United States Vol. II. Compiled by Ben Perley Poore. Washington: Government Printing Office, 1878.

Fiedler, Leslie A. The Return of the Vanishing Native. New York: Stein and Day, 1968.

Ford, John W. Some Correspondence Between the Governors and Treasurers of the New England Company in London and the Commissioners of the united Colonies in America The Missionaries of the Company and Others Between the Years 1657 and 1712. Edited by John W. Ford. New York: Burt Franklin, 1970. 
Franklin, Benjamin. "Remarks Concerning the Savages of North America." In Heath Anthology of American Literature Vol. A. Edited by Paul Lauter. Boston: Houghton Mifflin Company, 2006.

Freneau, Philip. Poems of Freneau. Edited by Harry Hayden Clark. New York: Hafner Publishing Company, 1960.

Freud, Sigmund. Beyond the Pleasure Principle. New York: W. W. Norton and Co., 1961.

The Interpretation of Dreams. Translated by A. A. Brill. New York: The Modern Library, 1950.

Gardener, Lion Leift. "Gardener's Narrative," in The History of the Pequot War. Edited by Charles Orr. Cleveland: Helman-Taylor Co., 1897.

Gaustad, Edwin S. Roger Williams, Lives and Legacies. New York: Oxford University Press, 2005.

Goddard, Ives and Kathleen J. Bragdon. Native Writings in Massachusett. Philadelphia: The American Philosophical Society, 1988.

Gookin, Daniel. "Historical Collections of the Indians of New England," Collections of the Massachusetts Historical Society (CMHS) Vol. 1. Boston: Munroe \& Francis, 1806, 1674.

Gookin, Daniel. An Historical Account of the Doings and Sufferings of the Christian Indians in New England in the Years 1675, 1676, 1677. New York: Arno Press, 1972-1836.

Gray, Robert. A Good Speed to Virginia. New York: Da Capo Press, 1970, 1609.

Greenblatt, Stephen. Marvelous Possessions: The Wonder of the New World. Chicago: The University of Chicago Press, 1991.

Grumet, Robert S. ed. Northeastern Indian Lives 1632-1816. Amherst: University of Massachusetts Press, 1996.

Hale Horatio, ed. The Iroquois Book of Rites. Toronto: University of Toronto Press, 1963. 
Hall, David, ed. The Antinomian Controversy, 1636-1638: A Documentary History. Durham: NC, Duke University Press, 1990.

Hariot, Thomas. "A Briefe and True Report of the New Found Land of Virginia." The English Literatures of America, 1500-1800. Edited by Myra Jehlen and Michael Warner. New York: Routledge, 1987, 1588.

Havelock, Eric. Origins of Western Literacy. Toronto: The Ontario Institute for Studies in Education, 1976.

Heckewelder, John. History, Manners, and Customs of the Indian Nations Who Once Inhabited Pennsylvania and the Neighboring States. Philadelphia: Publication Fund of the Historical Society of Pennsylvania, 1876.

Herman, Judith. Trauma and Recovery: The Aftermath of Violence-from Domestic Abuse to Political Terror. New York: Basic Books, 1992.

Hudson, Nicholas. Writing and European Thought 1600-1830. Cambridge, UK: Cambridge University Press, 1994.

Hultkrantz, Ake. The North American Indian Orpheus Tradition: A Contribution to Comparative Religion. Stockholm: The Ethnographical Museum of Sweden, 1957.

Jaenen, Cornelieus J. "Ameriindian Views of French Culture in the Seventeenth Century." American Encounters: Natives and Newcomers From European Contact to Indian Removal, 1500-1850. Edited by Peter C. Mancall and James H. Merrell. New York: Routledge, 2000.

The Jesuit Relations and Allied Documents (JR) vols. 1-8. New York: Pageant Book Co. 1959.

Jaskoski, Helen, ed. Early Native American Writing, New Critical Essays. New York: Cambridge University Press, 1996.

Jennings, Francis. The Invasion of America: Indians, Colonialism, and the Cant of Conquest. Chapel Hill, NC: University of North Carolina Press. 
The Jesuit Relations and Allied Documents: Travels and Explorations of the Jesuit Missionaries in North America (1610-1791) Edited by Edna Kenton. New York: Albert \& Charles Boni, 1925.

Josselyn, John. “An Account of the Two Voyages to New England.” CMHS Vol. 3, Series 3.

Karcher, Carol L. "Introduction" Lydia Maria Child. Hobomok and Other Writings on Indians. Edited by Carol L. Karcher. New Brunswick, NJ: Rutgers University Press, 1986.

Kellaway, William. The New England Company, 1649-1776. Missionary Society to the American Indians. Westport, CT: Greenwood Press, 1961.

Kidwell, Clara Sue. "Native American Systems of Knowledge." A Companion to American Indian History. Edited by Philip J. Deloria and Neal Salisbury. Malden, MA: Blackwell Publishers, 2002.

King, Thomas The Truth About Stories: A Native Narrative. Minneapolis: University of Minnesota Press, 2003.

Kirkland, Caroline M. A New Home Who'll Follow? Edited by William S. Osborne. Schenectady, NY: The New College and University Press, 1965, 1839.

Konkle, Maureen. Writing Indian Nations: Native Intellectuals and the Politics of Historiography, 1827-1863. Chapel Hill, NC: University of North Carolina Press, 2004.

Kroeber, Karl, ed. Traditional Literatures of the American Indian: Texts and Interpretations (Lincoln: University of Nebraska Press, 1981).

Krupat, Arnold. The Voice in the Margin: Native American Literature and Canon. Berkeley: University of California Press, 1989.

Las Casas, Bartolome de. In Defense of the Indians. Translated by Stafford Poole. DeKalb Northern Illinois University Press, 1992.

Lenik, Edward J. Picture Rocks: American Indian Rock Art in the Northeast Woodlands. Hanover, NH: University Press of New England, 2002.

Leon, Portilla, Miguel. The Broken Spears: The Aztec Account of the Conquest of Mexico. Edited 
by Miguel Leon-Portilla. Boston: Beacon Press, 1962.

Lepore, Jill. The Name of War: King Philip's War: King Philip's War and the Origins of American Identity. New York: Vintage Books, 1998.

Littlefield, George Emory. The Early Massachusetts Press 1638-1711. New York: Burt Franklin, 1907.

Longfellow, Henry Wadsworth. Poems and Other Writings. New York: Library of America, 2000.

Love, William Deloss. Samson Occom and the Christian Indians of New England. Syracuse: Syracuse University Press, 2000, 1899.

Maddox, Lucy. Removals: Nineteenth-Century American Literature and the Politics of Indian Affairs. New York: Oxford University Press, 1991.

Mason, Major John. "A Brief history of the Pequot War," in The History of the Pequot War. Edited by Charles Orr. Cleveland: Helman-Taylor Co., 1897.

Mather, Cotton. Magnalia Christi Americana or the Ecclesiatical History of New England. Vol. 1. Hartford, CT: Silas Andrus, 1820, 1702.

"The Wonderful Works of God Commemorated," Early American Imprints, series 1: Evans Digital Display (2006): 4, hin mom the

Mayhew, Experience. Indian Converts: or Some Account of the Lives and Dying Speeches of a Considerable Number of the Christianized Indians of Martha's Vineyard in New England. Ann Arbor, MI: University Microfilms International, 1992.

Mayhew, Thomas. A Further Discovery of the Present State of the Indians. Compiled by Henry Whitfield. New York: Sabin's Reprints, 1865, 1650.

McCallum, James Dow, ed. The Letters of Eleazar Wheelock's Indians. Hanover: Dartmouth College Manuscript Series, 1932.

McClure, David and Elijah Parish. Memoirs of the Reverend Eleazar Wheelock, D. D. New 
York: Arno Press, 1972, 1811.

McCutchen, David. The Red Record, The Wallam Olum: The Oldest Native North American History. Garden City Park, NY: Avery Publishing Group, 1993.

Meserve, Walter T. "English Works of Seventeenth-Century Indians," American Quarterly, 8.3 (Autumn, 1956): 264-276.

Mignolo, Walter D. "Signs and Their Transmission: The Question of the Book in the New World." Writing Without Words: Alternative Literacies in Mesoamerica and the Andes. Edited by Elizabeth Hill Boone and Walter D. Mingolo. Durham NC: Duke University Press, 1994.

Miller, Perry. The New England Mind: From Colony to Province. Cambridge MA: Harvard University Press, 1953.

Roger Williams: His Contribution to the American Tradition. New York: The Bob Merrill Company, Inc., 1953.

Miller, Perry and Thomas H. Johnson. "The Theory of the State and of Society." In Essays on American Colonial History, $2^{\text {nd }}$ ed. Edited by Paul Goodman. New York: Holt Rinehart and Winston, Inc. 1972.

Milton, John. "Paradise Lost." In The Norton Anthology of English Literature, 7th edition, Vol. i. Edited by M. H. Abrams. New York: W. W. Norton \& Company, 2000.

Misra, Neelesh and Sanyal Rupak. "In Rare Meeting; tribesmen tell officials of survival." The Boston Globe. 7 Jan. 2005: A 18.

Morison, Samuel Eliot. Harvard College in the Seventeenth Century. Cambridge, MA: Harvard University Press, 1936.

Builders of the Bay Colony. Boston: Houghton Mifflin Co., 1930.

Morison, The Founding of Harvard College. Cambridge, MA: Harvard University Press, 1935. 
Morton, Thomas. New English Canaan. New York: De Capo Press, 1969 (1637).

Motolinia, Toribio. Motolinia's History of the Indians of New Spain. Translated by Elizabeth Andross Foster. Westport, CT: Greenwood Press, 1950.

Mukerjee, Madhusree. The Land of Naked People: Encounters with Stone Age Islanders. New York: Houghton Mifflin Co., 2003.

Murray, David. Forked Tongues: Speech, Writing and Representation in North American Indian Texts. Bloomington, IN: Indiana University Press, 1991.

Murray, Laura J. "Joining Signs with Words: Missionaries, Metaphors, and the Massachusett Language,” The New England Quarterly, 74. 1 (Mar., 2001): 62-93.

To Do Good to My Indian Brethren: The Writings of Joseph Johnson, 1751-1776. Edited by Laura J. Murray. Amherst: University of Massachusetts Press, 1998.

Nabokov Peter. A Forest of Time: American Indian Ways of History. Cambridge, UK: Cambridge University Press, 2002.

Nelson, Dana D. “'(I Speak Like A Fool But I Am Constrained)' Samson Occom's Short Narrative and the Economies of the Racial Self." In Early American Native Writing, New Critical Essays. Edited by Helen Jaskoski. Cambridge: Cambridge University Press, 1996.

Oberly, James W. A Nation of Statesmen" The Political Culture of the Stockbridge-Munsee Mohicans, 1815-1972. Norman, OK: University of Oklahoma Press, 2005.

O'Brien, Jean. Dispossession By Degrees: Indian Land and Identity in Natick, Massachusetts, 1650-1790. New York: Cambridge University Press, 1997.

Occom, Samson. "An Account of the Montauk Indians, of Long Island.” CMHS ser. 1:10. Boston: Munroe \& Francis, 1806 (1761).

Occom, Samson. "A Short Narrative of My Life." In Heath Anthology of American Literature, Edited by Paul Lauter, $5^{\text {th }}$ edition, Vol A. Boston: Houghton Mifflin Company, 2006, 1768. 
Occom, Samson. A Sermon Delivered at the Execution of Moses Paul, An Indian, in Early American Imprints, Series 1: Evans: doc. No. 9537.

in Then.

O'Connell, Barry. On Our Own Ground: The Complete Writings of William Apess, A Pequot. Edited by Barry O'Connell. Amherst: University of Massachusetts Press, 1992.

Oestricher, David. "Unraveling the Walam Olum" Natural History, 105. 10 (Oct., 1996): 13-29.

Ong, Walter. Orality and Literacy: The Technologizing of the Word. London: Routledge, 1982.

Parker, Arthur. Seneca Myths and Folk Tales. Buffalo: Buffalo Historical Society, 1923.

Parkman, Francis. The Jesuits in North America in the Seventeenth Century. Lincoln, NE: University of Nebraska Press, 1997 (1867).

Pearce, Roy Harvey. Savagism and Civilization: A Study of the Indian and the American Mind. Berkley: University of California Press, 1988 (1953).

Peat, David. Blackfoot Physics, A Journey into the Native American Worldview. Grand Rapids MI: Phanes Press, 2002.

Peyer, Bernd. The Elders Wrote: An Anthology of Early Prose by North American Indians, 1768 1931. Berlin: Dietrich Reimer Verlag, 1982.

"Samson Occom: Mohegan Missionary and Writer of the $18^{\text {th }}$ Century." American Indian Quarterly 6.3-4 (Autumn - Winter 1982): 208-217.

The Tutor'd Mind: Indian Missionary Writers in Antebellum America. Amherst: University of Massachusetts Press, 1997.

Plato, The Works of Plato. Edited by Irwin Edman. New York: Random House, 1956.

Popul Vuh: The Mayan Book of the Dawn of Life. Translated by Dennis Tedlock. New York: 
Simon and Schuster, 1985.

Pratt, Mary Louise. Imperial Eyes: Travel Writing and Transculturation. New York: Rutledge Press, 1992.

Pulitano, Elvira. Toward a Native American Critical Theory. Lincoln: University of Nebraska Press, 2003.

Reid, Jennifer. "Roger Williams's Key: Ethnography or Mythology." Rhode Island History 56:3 (1999): 77-87.

Richardson, Leon Burr, ed. An Indian Preacher in England. Hanover, NH: Dartmouth College Manuscript Series, 1933.

Richter, Daniel. Facing East From Indian Country: A Native History of Early America. Cambridge: Harvard University Press, 2001.

Ross, Kurt. Codex Mendoza: Aztec Manuscript. Barcelona: industria grafica, 1978.

Rowlandson, Mary. The Sovereignty and Goodness of God. Edited by Neal Salisbury. Boston: Bedford St. Martins, 1997.

Rubertone, Patricia. Grave Undertakings: An Archaeology of Roger Williams and the Narragansett Indians. Washington: Smithsonian Institution Press, 2001.

Ruoff, A. LaVonne Brown. American Indian Literatures: An Introduction, Bibliographic Review, and Selected Biography. New York, The Modern Language Association of America, 1990.

Sahagun, Bernardino De. Florentine Codex: General History of the Things of New Spain, Introductory Volume. Edited by Arthur J. O. Anderson and Charles Dibble. Salt Lake City: The School of American Research and the University of Utah, 1982.

Said, Edward W. Orientalism. New York: Vintage Books, 1978.

Salisbury, Neal. Manitou and Providence: Indians, Europeans, and the Making of New England, 1500-1643. New York: Oxford University Press, 1982. 
"Introduction: Mary Rowlandson and Her Removes," The Sovereignty and Goodness of God by Mary Rowlandson with Related Documents. Edited by Neal Salisbury. Boston: Bedford/St. Martins, 1997.

"Red Puritans: The 'Praying Indians' of Massachusetts Bay and John Eliot," The William and Mary Quarterly, $3^{\text {rd }}$ Ser. 31.1 (Jan.,1974): 27-54.

Savage, Charlie. "Supreme Court splits rulings in Commandments: Display allowed in Texas not in KY." Boston Globe, June 28, 2005, sec A1.

Schmidt, David L. and Murdena Marshall, eds. Mi 'kmaq Hieroglyphic Prayers: Reading in North America's First Indigenous Script. Halifax, NS: Nimbus Publications, 1995.

Schoolcraft, Henry Rowe. Indian Legends. Edited by Mentor L. Williams. (East Lansing: Michigan State University Press, 1991.

Scott, James C. Domination and the Arts of Resistance: Hidden Transcripts. New Haven: Yale University Press, 1990.

Seaver, James E. A Narrative of the Life of Mrs. Mary Jemison. Edited by June Namias. Norman, OK: University of Oklahoma Press, 1992 (1824).

Seawall, Samuel. The Diary of Samuel Sewall Vol. 1, 1674-1708. Edited by M. Halsey Thomas. New York: Farrar, Straus, and Giroux, 1973.

Sedgwick, Catherine Maria. Hope Leslie. Edited by Mary Kelley. New Brunswick, NJ: Rutgers University Press, 1987 (1827).

Shay, Jonathan. Achilles In Vietnam: Combat Trauma and the Undoing of Character. New York: Maxwell Macmillan, 1994.

Silverman, David J. Faith and Boundaries: Colonists, Christianity, and Community Among the Wampanoag Indians of Martha's Vineyard, 1600-1871. New York: Cambridge University Press, 2005.

Simmons, William S. Spirit of the New England Tribes: Indian History and Folklore, 1620-1984. Hanover, NH: University Press Of New England, 1986. 
Slotkin, Richard. Regeneration Through Violence: the Mythology of the Frontier 1600-1860. Norman, OK: University of Oklahoma Press, 1973.

Smith, John. The Travels and Works of Captain John Smith, President of Virginia and Admiral of New England, 1580-1631. Edinburgh: John Grant, 1910.

Snow, Dean R. The Iroquois. Cambridge: Blackwell Publishers, 1994.

Speck, Frank with Alexander General (Deskaheh), Midwinter Rites of the Cayuga Long House. Lincoln, NE: Bison Books, 1995.

Sprague, William Buell. Annals of the American of the American Presbyterian Pulpit: or Commemorative Notices of Distinguished Clergymen of the Presbyterian Church in the United States, Vol. 3. New York: Robert Carter and Bros., 1860.

Standing Bear, Luther. Land of the Spotted Eagle. Lincoln, NE: University of Nebraska Press, $1978,1933$.

Stevens, Laura M. The Poor Indians: British Missionaries, Native Americans, and Colonial Sensibility. Philadelphia: University of Pennsylvania Press, 2004.

Stilgoe, John R. Common Landscapes of America, 1580 to 1845. New Haven: Yale University Press, 1982.

Stone, John Augustus. Metamora, or The Last of the Wampanoags. New York: Feedback Theater Books and Prospero Press, 1996 (1829).

Szasz, Margaret Connell. Indian Education in the American Colonies, 1607-1783. Albuquerque: University of New Mexico Press, 1988.

Taylor, Alan. William Cooper's Town: Power and Persuasion on the Frontier of the Early American Republic. New York: Vintage, 1995.

Tinker, George E. Spirit and Resistance: Political Theology and American Indian Liberation. Minneapolis: Fortress Press, 2004. 
Todorov, Tzvetan. The Conquest Of America: The Question of the Other. Translated by Richard Howard. New York: Harper \& Row, Publishers, 1982.

Tooker, William Wallace. Cockenoe de Long Island: John Eliot's First Indian Teacher and the story of his career from the early records. New York: Francis Harper, 1896.

Ulrich, Laurel Thatcher. Goodwives: Image and Reality in the Lives of Women in Northern New England, 1650-1750. New York: Vintage Books, 1980.

Underhill, John. Newes From America. New York: Da Capo Press, 1971.

van der Loo, Peter L. "Voicing the Painted Image: A Suggestion for Reading the Reverse of the Codex Cospi." in Writing Without Words: Alternative Literacies in Mesoamerica and the Andes. Edited by Elizabeth Hill Boone and Walter D. Mignolo. Durham, NC: Duke University Press, 1994.

Van Lonkhuyzen, Harold W. "A Reappraisal of the Praying Indian: Acculturation, Conversion and Identity at Natick, Massachusetts, 1646." New England Encounters: Indians and Euroamericans ca 1600-1850: Essays Drawn from New England Quarterly. Edited by Alden T. Vaughan. Boston: Northeastern University Press, 1999.

Vespucci, Amerigo. "Letter to Pier Soerini, Confalonier of the Republic of Florence." The English Literatures of America 1500-1800. Edited by Myra Jehlen and Michael Warner. New York: Routledge, 1997.

Vincent, Philip. "A true relation of the late battle fought in New England, between the English and the Salvages, with the present state of things there," in The History of the Pequot War. Edited by Charles Orr. Cleveland: Helman-Taylor Co., 1897.

Vizenor, Gerald. Fugitive Poses: Native American Indian Scenes of Absence and Presence. Lincoln: University of Nebraska Press, 1998.

Manifest Manners: Postindian Warriors of Survivance. Hanover, NH: University Press of New England, 1994.

Wallace, Anthony F. C. The Death and Rebirth of the Seneca. New York: Knopf, 1970. The Long Bitter Trail: Andrew Jackson and the Indians. New York: Hill and 
Wang, 1993.

Wallace, Paul A. W. White Roots of Peace: The Iroquois Book of Life. Sante Fe: Clear Light Publishers, 1994.

Walam Olum or Red Score, The Migration Record of the Lenni Lenape or Delaware Indians. Indianapolis: Indiana Historical Society, 1954.

Warrior, Robert Allen. Tribal Secrets: Recovering American Indian Intellectual Traditions. Minneapolis: University of Minnesota Press, 1995.

Weaver, Jace. That The People Might Live: Native Literatures and Native American Community. New York: Oxford University Press, 1997.

Welburn, Ron. Roanoke and Wampum: Topics in Native American Heritage and Literatures. New York: Peter Lang, 2001.

Wheelock, Eleazor. An Indian Preacher in England: Being Letters and Diaries Relating to the Mission of the Reverend Samson Occom and the Reverend Nathaniel Whitaker to Collect Funds in England for the Benefit of Eleazor Wheelock's Indian Charity School, From Which Grew Dartmouth College. Edited by Leon Burr Richardson. Hanover, NH: Dartmouth College Manuscript Series Number Two, 1933.

White, C. Albert. A History of the Rectangular Survey System. US Department of the Interior, 1983.

White, Richard. The Middle Ground: Indians, Empires, and Republics in the Great Lakes Region, 1650-1815. New York: Cambridge University Press, 1991.

Wiget, Andrew. Native American Literature. Boston: Twayne Publishers, 1985.

Williams, Roger. The Complete Writings of Roger Williams. Vol. i. New York: Russell \& Russell Inc., 1963.

"The Letters of Roger Williams." The Complete Writings. Vol. vi. New York: Russell \& Russell Inc., 1963. 
The Complete Writings of Roger Williams. Vol. vii. New York: Russell \& Russell Inc., 1963.

Winship, George Parker. The Cambridge Press, 1638-1692. Freeport, NY: Books for Libraries Press, 1946.

Winslow, Edward. "Good News from New England." CMHS. Vol. ix, series 2. Boston: Charles C. Little and James Brown, 1815.

Winslow, Edward. A Relation or Journall of the Beginning and Proceeding of the English Plantation Setled at Plimoth. London: John Bellamie, 1622.

Winslow, Ola. Master Roger Williams, A Biography. New York: The Macmillan Company, 1957.

Winthrop, John. The History of New England from 1630-1649. Vol. 1. Edited by James Savage. Baltimore: Clearfield, 2003 (1853).

“"A Modell of Christian Charity." In The Heath Anthology of American Literature. $5^{\text {th }}$ ed. Vol. A. Edited by Paul Lauter. New York: Houghton Mifflin Company, 2006.

Wiseman, Frederick Matthew. Voice of the Dawn: An Autohistory of the Abenaki Nation. Hanover, NH: University Press of New England, 2001.

Womack, Craig S. Red on Red: Native American Literary Separatism. Minneapolis: University of Minnesota Press, 1999.

Wood, William. New England's Prospect. Edited by Alden T. Vaughan. Amherst, MA: University of Massachusetts Press, 1977, 1634.

Wyss, Hilary. Writing Indians: Literacy, Christianity, and Native Community in Early America. Amherst: University of Massachusetts Press, 2000.

Ziff, Larzer. Writing in the New Nation: Prose, Print, and Politics in the Early United States. New Haven, CT: Yale University Press, 1991.

Zinn, Howard. On History. New York: Seven Stories Press, 2001. 


\section{Works Referenced:}

Burnham, Dorothy. To Please the Caribou: Painted Caribou-Skin Coats Worn by the Naskapi, Montagnais, and Cree Hunters of the Quebec-Labrador Peninsula. Seattle: University of Washington Press, 1992.

Michelle Burnham. Captivity and Sentiment: Cultural Exchange in American Literature, 16821861. Hanover, NH: University Press of New England, 1997.

Callahan, Alice S. Wynema: A Child of the Forest, Edited by A LaVonne Brown Ruoff. Lincoln: University of Nebraska Press, 1997.

Demos, John. The Unredeemed Captive: A Family Story From Early America. New York: Vintage Books, 1994.

Eastman, Charles. From the Deep Woods to Civilization. Boston: Little Brown, 1916.

Namias, June. White captives: Gender and Ethnicity on the American Frontier. Chapel Hill: University of North Carolina Press, 1993.

Pearce, Roy Harvey. "The Significance of the Captivity Narrative," American Literature 19:1 (1947): 1-20.

Richter, Daniel K. The Ordeal of The Long House: The Peoples of the Iroquois League in the Era of European Colonization. Chapel Hill, NC: The University of North Carolina Press, 1992.

Salisbury, Neal. "Introduction: Mary Rowlandson and Her Removes." The Sovereignty and Goodness of God. Edited by Neal Salisbury. Boston: Bedford/St. Martins, 1997.

Standing Bear, Luther. My People the Sioux. Lincoln: University of Nebraska Press, 1928.

Zitkala-Sa, American Indian Stories. Lincoln: University of Nebraska Press, 1985. 